\title{
EXPLORING THE WORKING RELATIONSHIP BETWEEN PROFESSIONAL CONTRACTORS AND PERMANENT EMPLOYEES THROUGH ORGANISATIONAL SOCIALISATION AND THE PSYCHOLOGICAL CONTRACT
}

\author{
BY \\ ELLEN PATRICIA YARROW
}

A thesis

submitted to the Victoria University of Wellington in fulfilment of the requirements for the degree of Doctor of Philosophy

Victoria University of Wellington

2020 


\section{Acknowledgements}

I would first like to thank my primary supervisor who has been with me for the duration of this undertaking. Dr. Jane Bryson was always available with feedback, advice and challenging questions about my research and writing. She steadily steered me in the right the direction. Thank you to Dr. Christian Yao, my secondary supervisor, whose perspective was always fresh, valuable and thought provoking.

I would also like to sincerely thank the 51 interviewees who were involved in the study. Without their time, honesty and input this thesis could not have been successfully completed. My sincere appreciation also goes to all participating organisations for making teams of professional contractors, permanent employees and their manager available. I enjoyed meeting every individual and found the interviews so very interesting and informative.

Finally, I would like to express my very profound gratitude to my husband, Dean, and to my darling daughters, Laura and Claire, for providing me with unfailing support and continuous encouragement throughout my many years of study. This accomplishment would not have been possible without your patience, tolerance and love. Thank you. 


\begin{abstract}
This study explores the relationship between professional contractors and the permanent employees they work with at organisations in New Zealand. This thesis uses two concepts, organisational socialisation and the psychological contract, as lenses through which the working relationship is explored. The 20th century notion of standard employment has largely been eroded, giving way to different forms of non-standard work. Professional contractors are now found performing a variety of roles in many organisations across this country. Many are doing the work of permanent employees, but they are neither employees nor permanent. Professional contractors are a type of non-standard, transient worker. As part of a blended workforce, professional contractors work alongside permanent employees, but little is known about how they work together.
\end{abstract}

This qualitative study involves 49 face-to-face interviews with professional contractors, permanent employees and managers working in the Information Technology (IT) divisions of 10 organisations in three major cities in New Zealand. This research design results in a rich data set. The data collected was subject to analysis using the software NVIVO. This data was analysed in relation to the literature on organisational socialisation and the psychological contract to further explain the working relationship between professional contractors and permanent employees.

The findings reveal professional contractors' experience of Van Maanen's (1979) socialisation tactics were: collective, informal, variable, random and serial. It was found that an organisation's policy sets the tone for the treatment (induction, inclusion and management) of professional contractors. According to the professional contractors interviewed, the Chao, O'Leary-Kelly, Wolf, Klein, and Gardner (1994) socialisation content dimensions that are important are structure, culture and values and language but history was not considered important. According to the managers interviewed, contractors need to know about the processes and procedures of the client organisation, have strong technical skills and industry, sector or domain knowledge. It was found that the indicator of adjustment 'acceptance by insiders' (Bauer \& Erdogan, 2012) may be a sign that the contractor is adjusting to their new role but it is not essential. A new indicator of adjustment for professional contractors - output - clearly emerged from the data. The notion of 'time to productivity' is highly relevant to professional contractors and three factors affecting it are identified (contractor capability, role complexity and organisation readiness). Another important finding is that permanent employees play a key role as socialisation agents (Feldman, 1994; Jones, 1983; Van Maanen, 1978) in the socialisation of professional contractors. Surprisingly, it was found that other professional contractors also act as socialisation agents assisting the newcomer to adjust. 
It was found that proactive socialisation is particularly important for professional contractors. Together these findings establish the need to reconceptualise organisational socialisation for professional contractors specifically.

The second part of this thesis explores the psychological contract by asking interviewees about their mutual expectations. The expectations of each of the three parties (managers, professional contractors, and permanent employees) are subtly different, potentially influencing the psychological contract they develop. Permanent employees expect great things, professionalism and independence from professional contractors. Managers expect speed, professionalism and value for money from contractors. On the other hand, professional contractors simply expect to be treated with respect by their colleagues. Professional contractors expect to be given autonomy by their managers and support or guidance, should they require it. This study was not able to ascertain what type of psychological contract a professional contractor may develop. It is possible that a professional contractor develops a hybrid psychological contract. Alternatively, it is possible that a professional contractor's psychological contract moves between the types developed by Rousseau (1995) over the course of their term with the client organisation. The insights gained by exploring the expectations of professional contractors, permanent employees and their managers are two-fold. Firstly, these expectations provide a valuable insight into the working relationship. Secondly, the exploration of a breach or violation of the psychological contract indicates that a malleable psychological contract (one that will shift or adjust) is less likely to manifest a breach or violation. Therefore, it is better for a professional contractor to develop and maintain a malleable rather than rigid psychological contract.

This study's findings highlight the interrelationship between organisational socialisation and the psychological contract. This thesis asserts that the working relationship between professional contractors and permanent employees is specifically influenced by the socialisation of contractors as newcomers and in the mutual expectations, which form the psychological contract. As a result, it contributes to theorising and understanding of the working relationship between professional contractors and permanent employees. It identifies several tensions in the co-dependent working relationship, which are: time, team, treatment and training. This study has implications for Human Resource practitioners and managers because there is a need for corporate or HR policy relating to the treatment professional contractors. The use of organisational socialisation and the psychological contract as lenses with which the working relationship is explored is both original and meaningful. 
Table of Contents

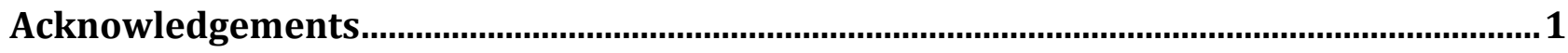

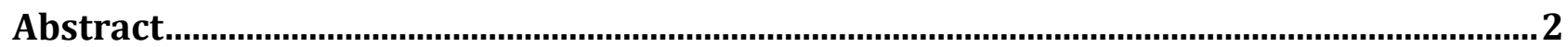

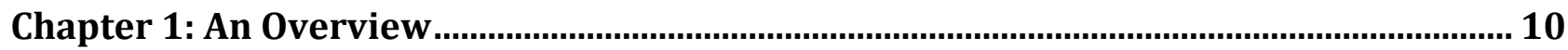

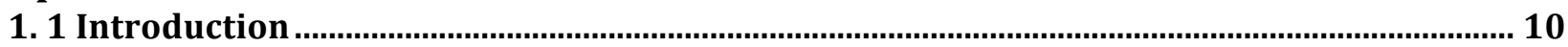

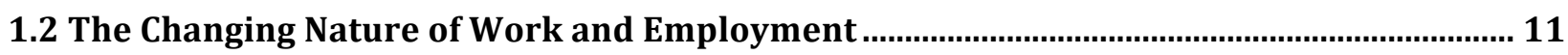

1.2.1 Standard and Non-standard Work …………................................................................................... 11

1.2.2 The Rise of Non-standard Work ……............................................................................................. 13

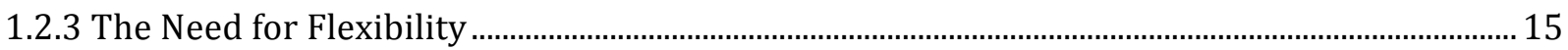

An Organisational Perspective: Organisations' Needs ……………………………......................................... 15

An Individual Perspective: Professional Contractors' Needs .............................................................................. 18

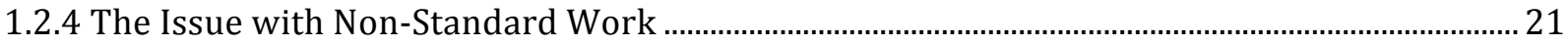

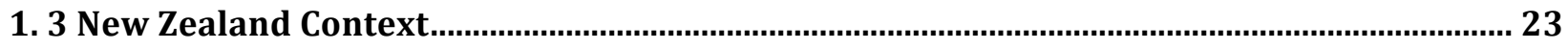

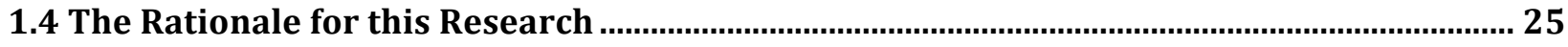

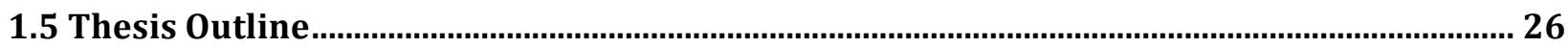

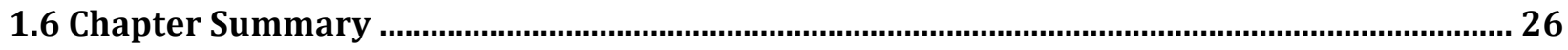

Chapter 2: Literature Review - The Professional Contractor .......................................... 28

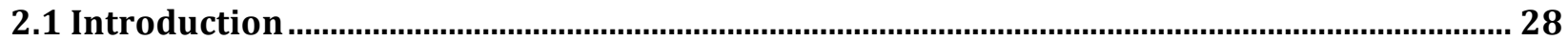

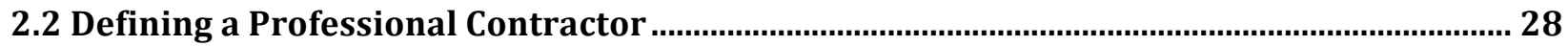

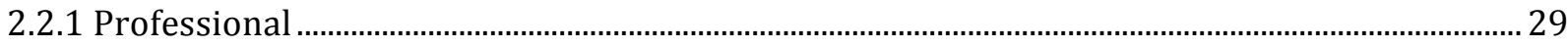

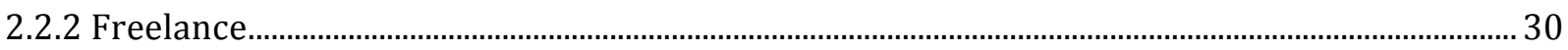

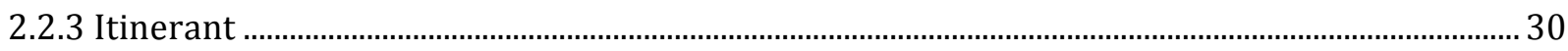

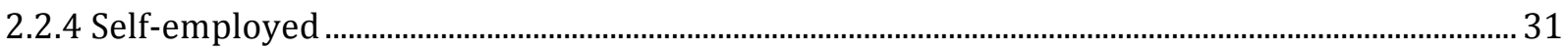

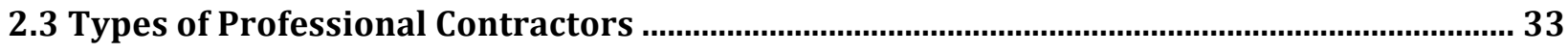

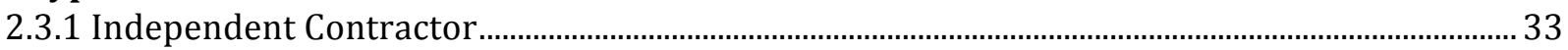

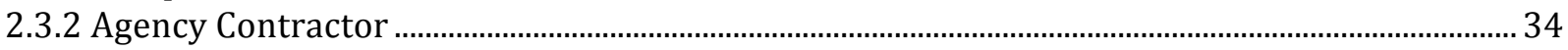

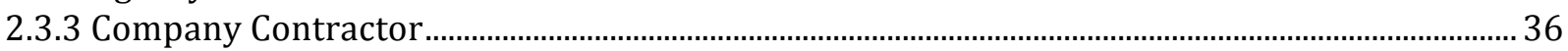

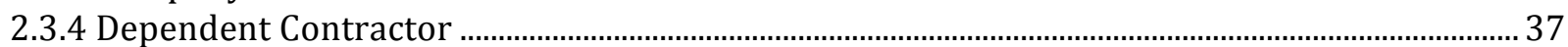

2.3.5 Comparing Professional Contracting to Permanent Employment ................................................. 39

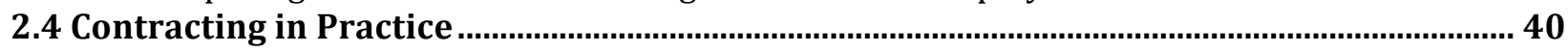

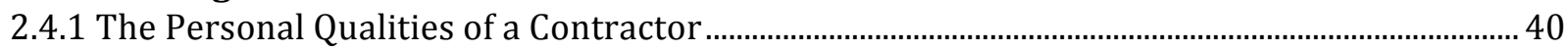

2.4.2 Occupational Identity is Important ................................................................................................... 40

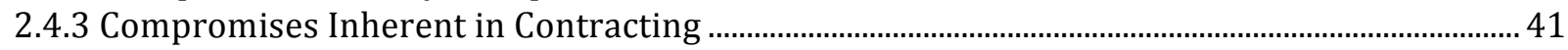

2.5 Focusing on Information and Communications Technology Sector ...................................... 41

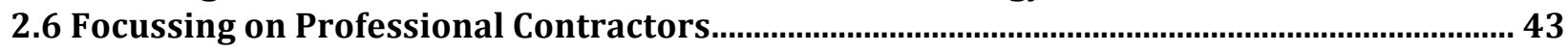

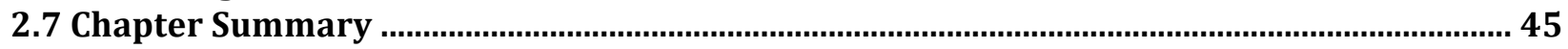

Chapter 3: Literature Review - The Conceptual Framework ................................................. 46

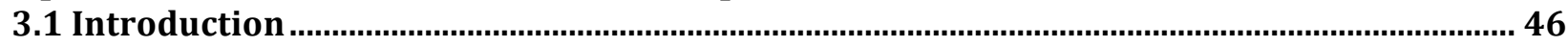

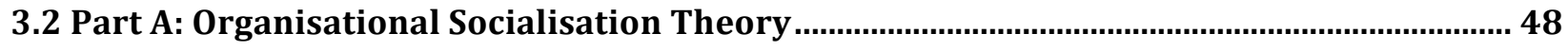

3.2.1 The Socialisation Process ............................................................................................................... 49

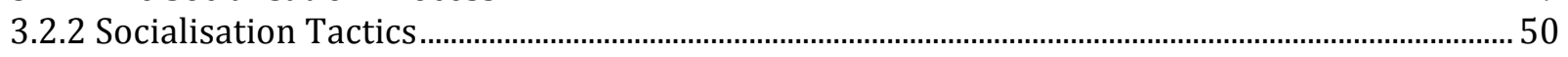

3.2.3 The Content of Socialisation ........................................................................................................ 51

3.2.4 Indicators of Adjustment ............................................................................................................ 53

'Time to Productivity' ............................................................................................................................................ 54

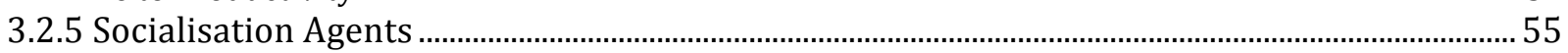

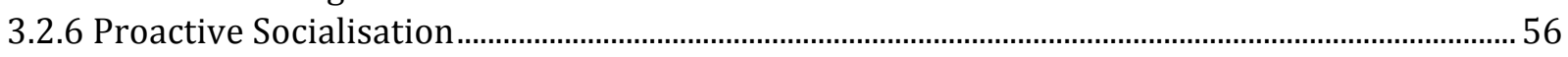

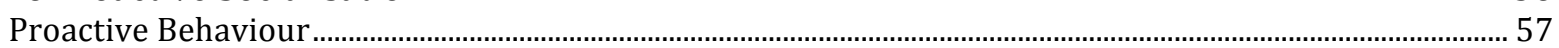

3.2.7 Phases in Organisational Socialisation Research ........................................................................... 58

3.2.8 Relating Organisation Socialisation and Professional Contractors ................................................ 59

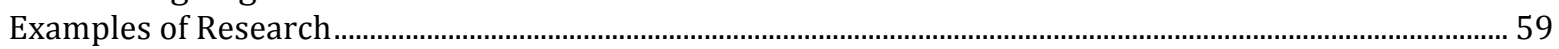




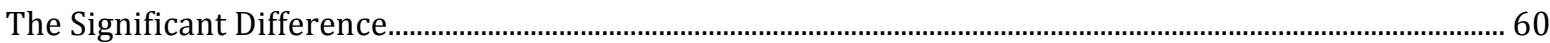

3.3 Part B: The Psychological Contract

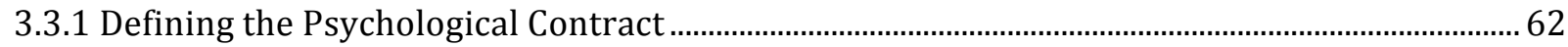

3.3.2 Conceptualising the Psychological Contract........................................................................................6 63

3.3.3 Formation of the Psychological Contract....................................................................................... 63

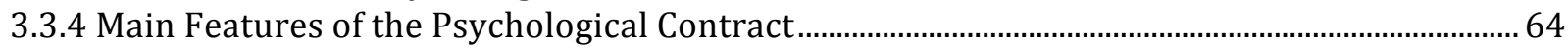

3.3.5 A Violation or Breach of the Psychological Contract .........................................................................66

3.3.6 Relating the Psychological Contract to Professional Contractors....................................................67

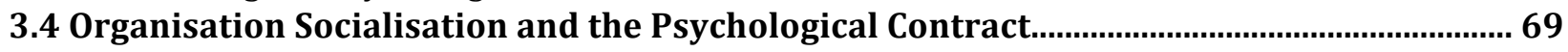

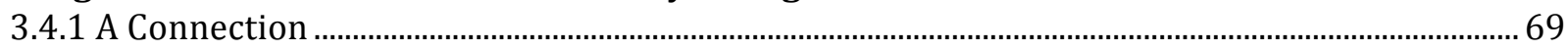

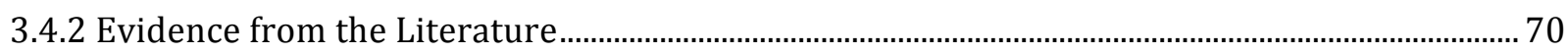

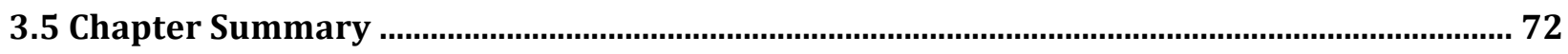

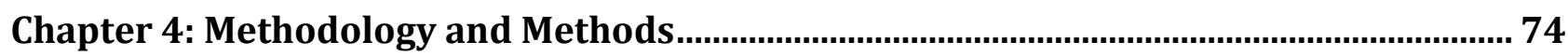

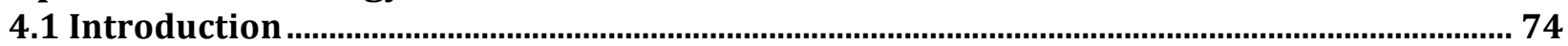

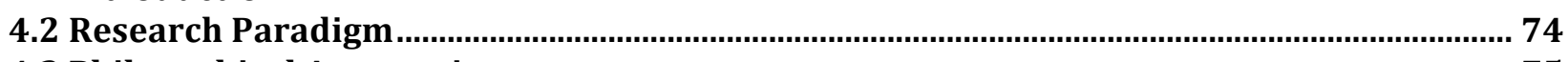

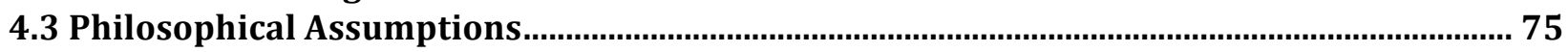

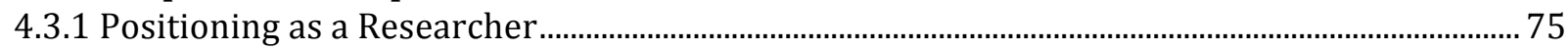

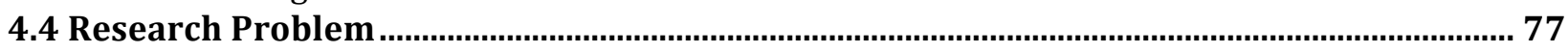

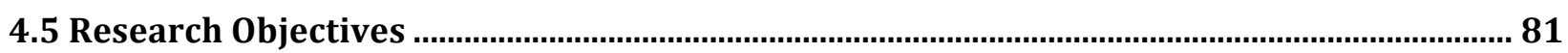

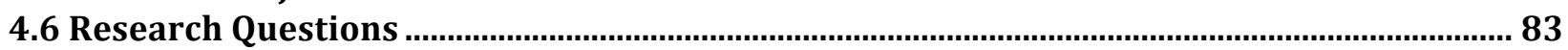

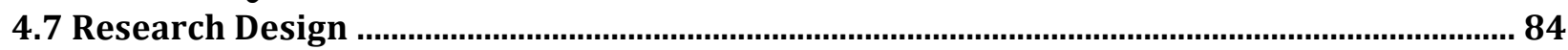

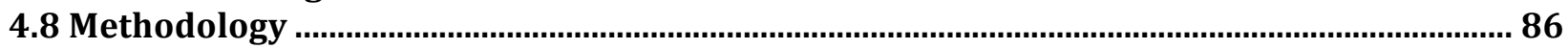

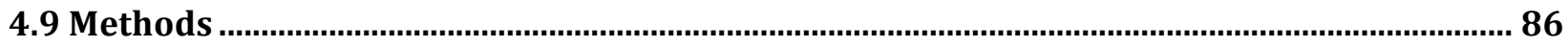

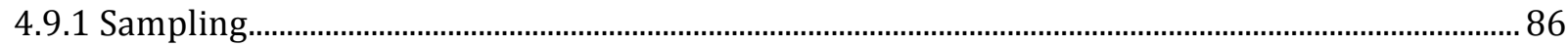

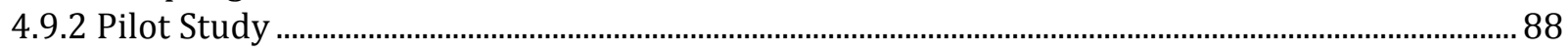

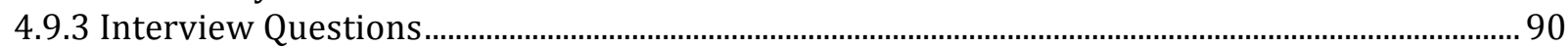

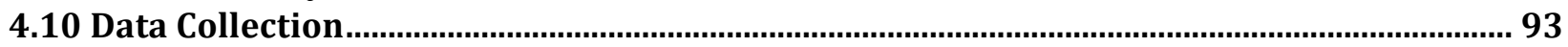

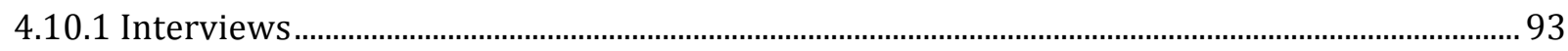

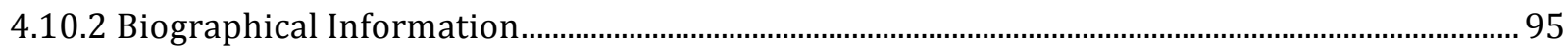

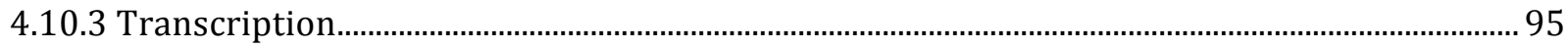

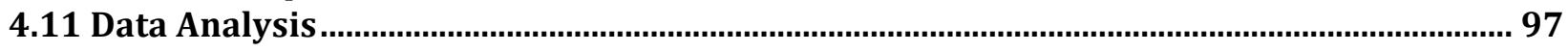

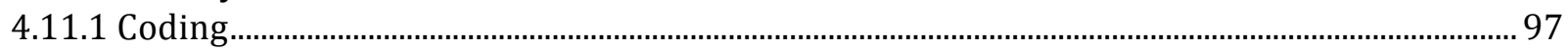

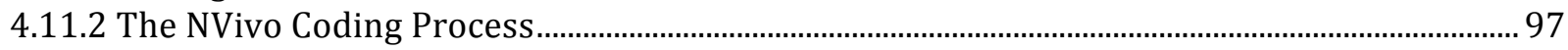

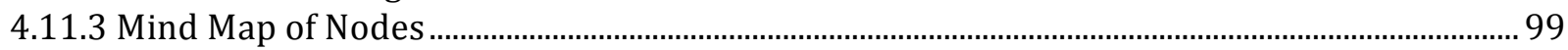

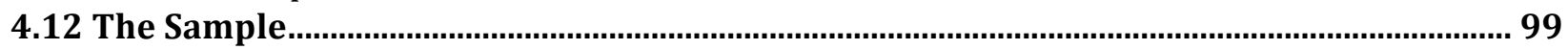

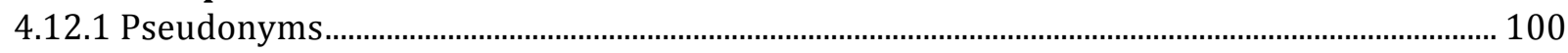

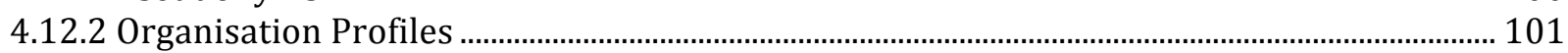

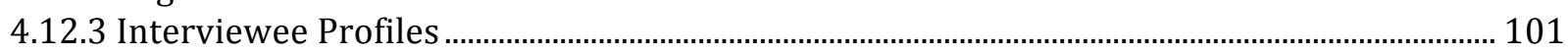

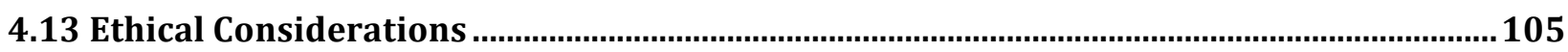

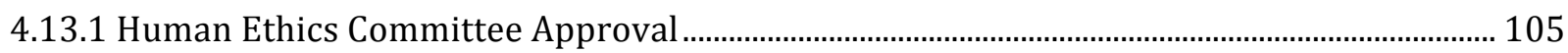

4.13.2 Data Management ......................................................................................................................... 106

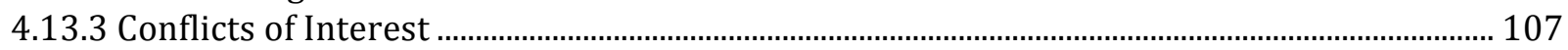

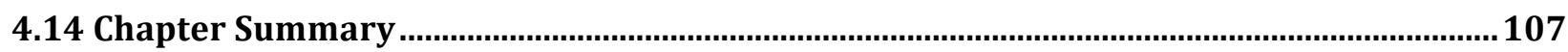

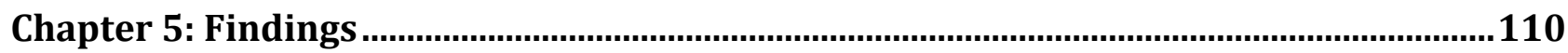

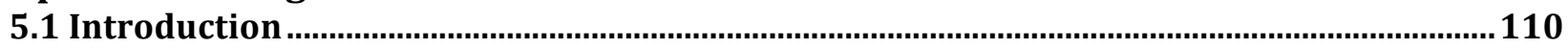

5.2 Part A: How are Professional Contractors Organisationally Socialised? ..............................110

5.2.1 Organisational Policy regarding Professional Contractors......................................................... 110

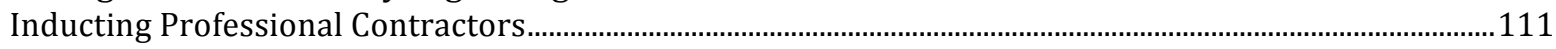

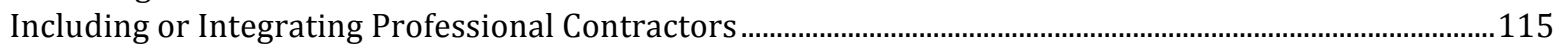

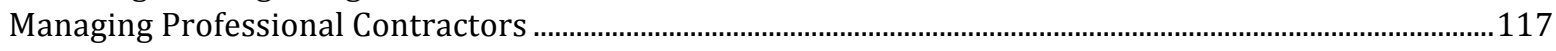

5.2.2 The Content of Socialisation Messages ........................................................................................... 118

Contractors need to know about the client organisation's culture \& values, structure and language.....119

Contractors need to know about processes \& procedures and have strong technical skills. .......................123 
5.2.3 Professional Contractors' Indicators of Adjustment.............................................................. 124

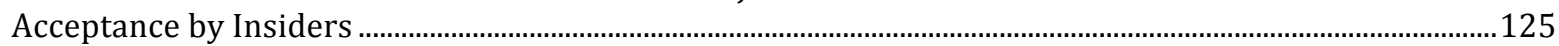

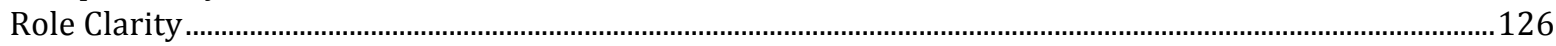

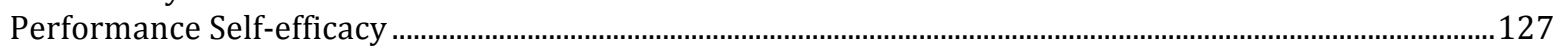

An Additional Indicator of Adjustment of a Professional Contractor: Output................................................128

5.2.4 A Professional Contractor's 'Time to Productivity' ....................................................................... 129

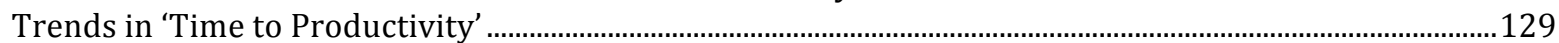

Three Factors Affecting Contractors' 'Time to Productivity'...............................................................................131

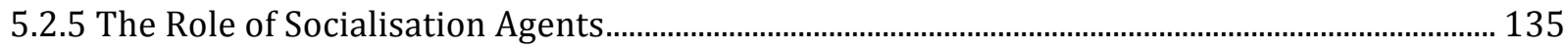

An Essential Ingredient................................................................................................................................135

Socialisation Agents are both permanent employees and professional contractors.......................................136

5.2.6 Proactive Socialisation and the Professional Contractor.............................................................. 137

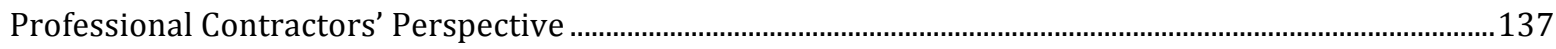

Permanent Employees' Perspective....................................................................................................................138

5.3 Part B: Findings about the Psychological Contracts of Professional Contractors,

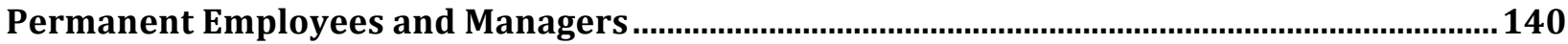

5.3.1 The Type of Psychological Contract.............................................................................................. 140

5.3.2 What do Employees, Managers and Contractors Expect? .......................................................... 141

Employees expect great things, independence and professionalism from professional contractors .......141

Managers expect speed, professionalism and value for money from professional contractors..................143

Professional contractors expect respect from permanent employees ................................................................145

Professional contractors expect autonomy, support and guidance from their manager ...............................145

5.3.3 A Breach or Violation of the Psychological Contract ................................................................... 146

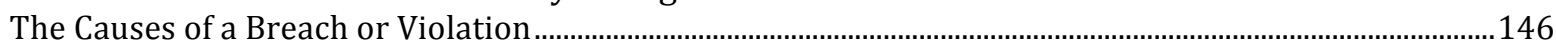

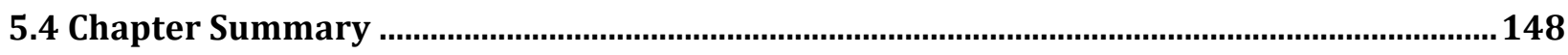

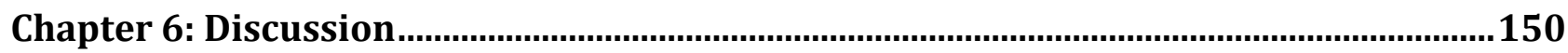

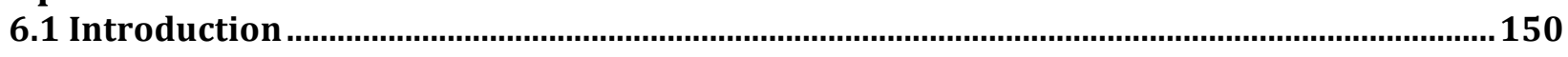

6.2 The Interrelationship between Organisational Socialisation and the Psychological

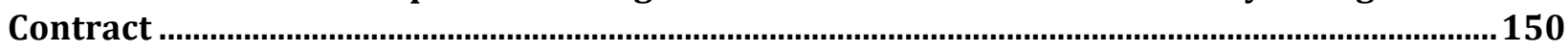

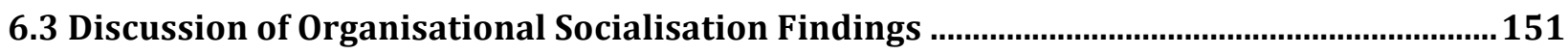

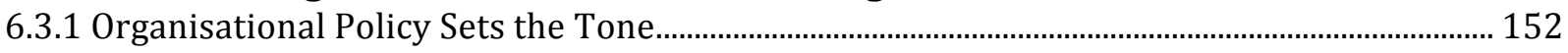

6.3.2 Socialisation Content Needs to be Customised ........................................................................... 156

6.3.3 Four Indicators of Adjustment for Professional Contractors ................................................... 157

6.3.4 'Time to Productivity' can be influenced ........................................................................................ 159

6.3.5 Socialisation Agents Play a Key Role …………........................................................................ 161

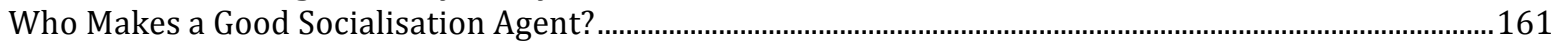

The Benefits for the Socialisation Agent …………………............................................................................162

The Issues with Being a Socialisation Agent .............................................................................................164

6.3.6 Proactive Socialisation is Important.......................................................................................... 165

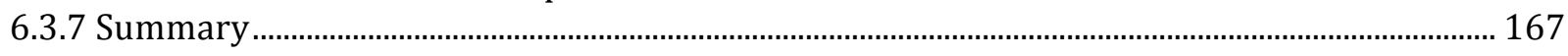

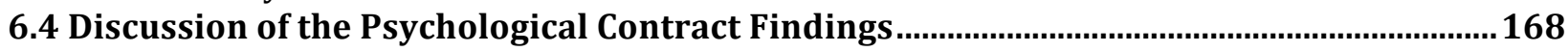

6.4.1 A Different Type of Psychological Contract ………………………………............................... 168

6.4.2 Permanent Employees and Managers have great expectations ................................................ 170

6.4.3 Professional contractors expect to be given respect and autonomy......................................... 172

6.4.4 A Malleable or Dynamic Psychological Contract for Professional Contractors......................... 173

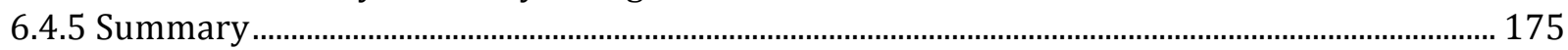

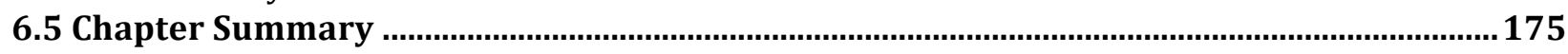

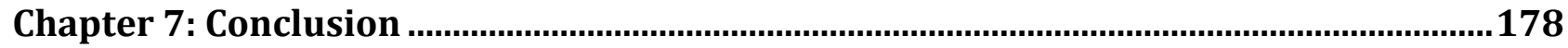

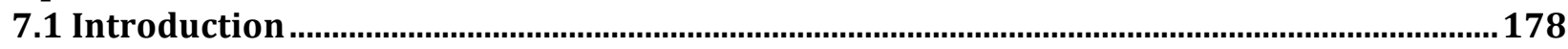

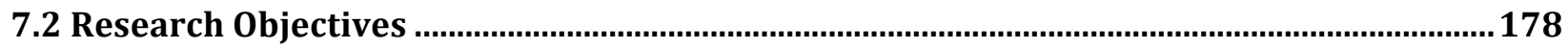

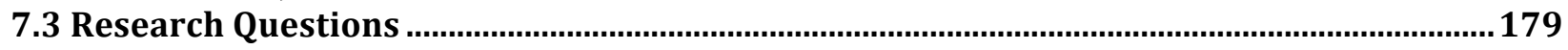

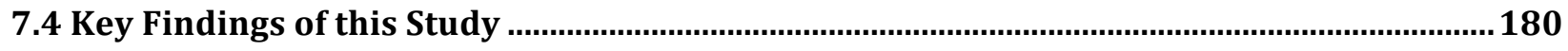

7.5 Conclusions related to the Organisational Socialisation of Professional Contractors ..... 181

7.6 Conclusions related to the Psychological Contracts of Professional Contractors ............... 182 
7.7 Conclusions related to the working relationship between Professional Contractors and Permanent Employees

7.7.1 Professional Contractors as Socialisation Agents..... 183

7.7.2 Proactive Socialisation is vital for Professional Contractors ....................................................... 183

7.7.3 Tensions in the Working Relationship.......................................................................................... 184

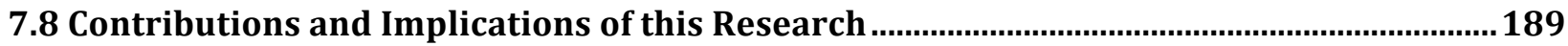

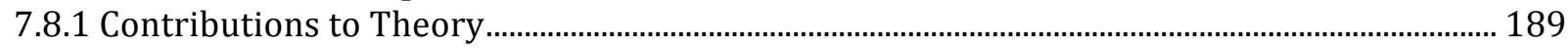

7.8.2 Human Resource Practitioner Contribution ................................................................................. 191

7.8.3 Practical Implications for Managers .............................................................................................. 193

7.8.4 Practical Implications for Professional Contractors and Permanent Employees ................... 193

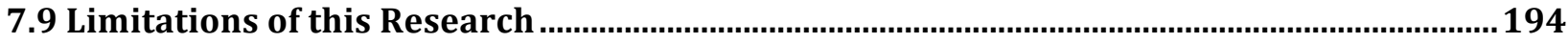

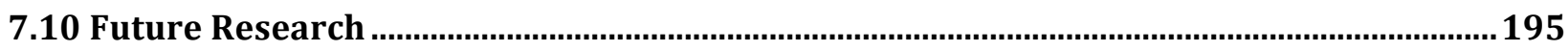

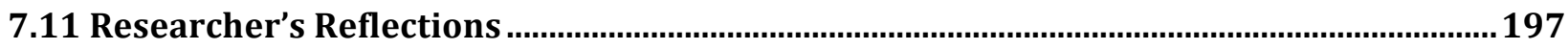

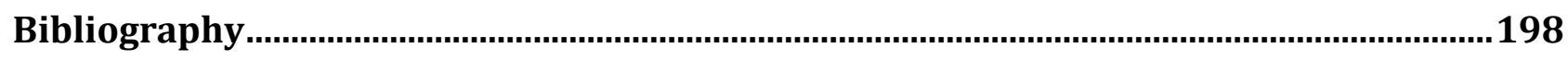

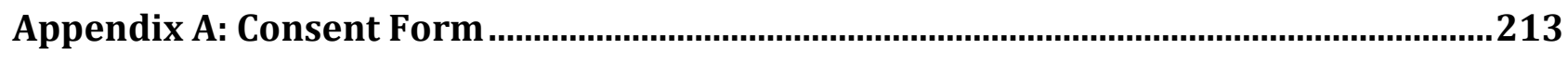

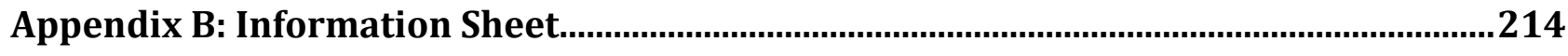

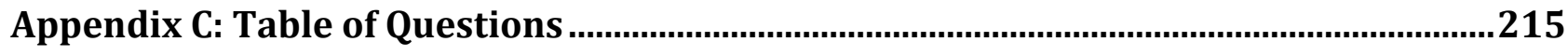

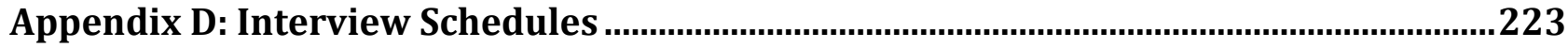

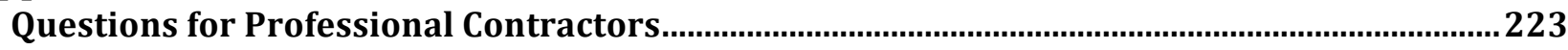

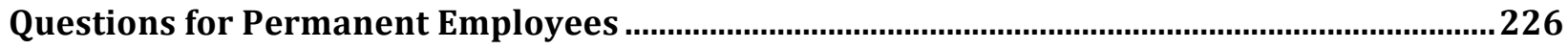

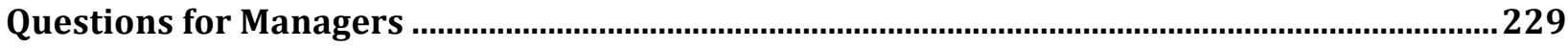

Appendix E: Human Ethics Committee Approval............................................................232 


\section{List of Figures}

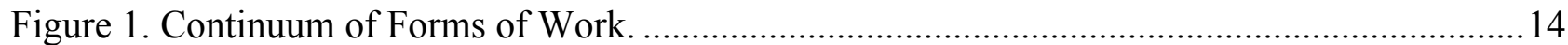

Figure 2. Employment Status in Main Job (Statistics New Zealand, 2016). ..................................24

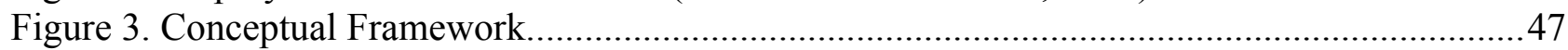

Figure 4. Socialisation Tactics (Jones, 1986 based on Van Maanen and Schein, 1979).................51

Figure 5. Socialisation Over Time (Bauer and Erdogan, 2012)................................................53

Figure 6. Types of Psychological Contract (Rousseau, 1995) ....................................................64

Figure 7. NVivo Nodes mapped to Research Question (and underpinning concepts). ...................99

Figure 8. Factors affecting a contractor's Time to Productivity................................................. 135

Figure 9. Organisational Socialisation Findings and the Conceptual Framework.........................152

Figure 10. Professional Contractor Socialisation Over Time (based on Bauer and Erdogan, 2012)

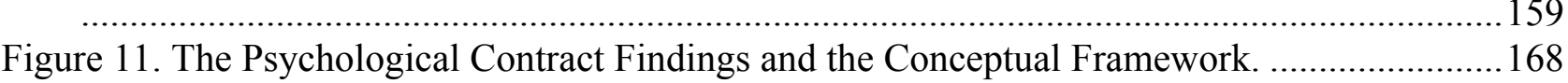

Figure 12. Key Findings and the Conceptual Framework. ....................................................... 180

\section{List of Tables}

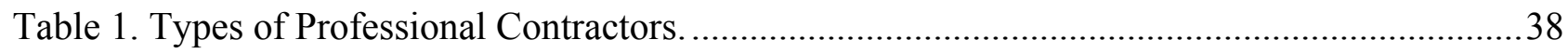

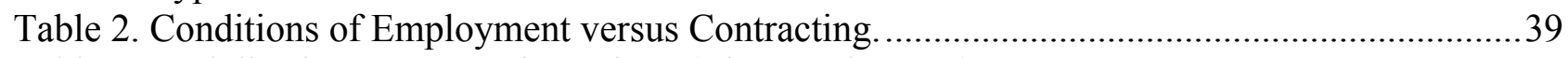

Table 3. Socialisation Content Dimensions (Chao et al., 1994)..................................................52

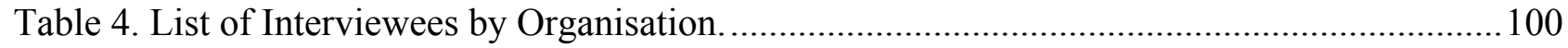

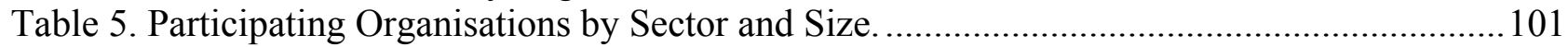

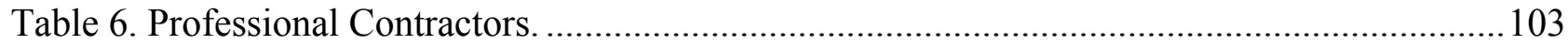

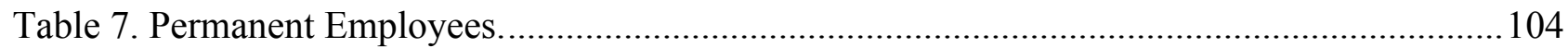

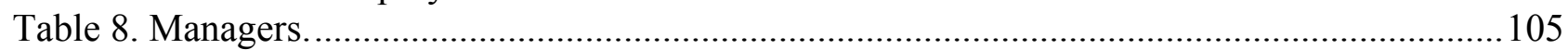

Table 9. Socialisation Content: What a Contractor Needs to Know.............................................119

Table 10. Managers' Perspective on What a Contractor Needs to Know. .................................... 123

Table 11. Professional Contractors' Age and Experience.......................................................... 133

Table 12. Expectations of Permanent Employees, Managers and Professional Contractors........... 141

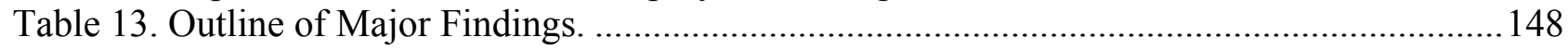




\section{Chapter 1: An Overview}

\section{1 Introduction}

Professional contractors are becoming an increasingly common and important feature of the blended workforce (McKeown \& Cochrane, 2017). Professional contractors are often integral, albeit impermanent, members of the teams they join and play significant roles in the functioning of many organisations. Many large-scale pieces of work such as transformational change projects are highly dependant on professional contractors (Davis-Blake \& Uzzi, 1993; Kalleberg, Reynolds, \& Marsden, 2003). The focus of this thesis is one type of non-standard worker: the professional contractor. In this thesis a professional contractor is defined as those who are contracted to provide services to an organisation but do not have the legal status of an employee. Professional contractors are engaged under a contract for services, which is a commercial contract (Rudman, 2019). In contrast, employees are engaged under an individual or collective employment contract either (IRD, 2019).

There is a distinct human resource management (HRM) perspective to this research. This is because it relates to work, workers and their management within organisations. HRM relates to managing work and people towards certain goals or ends (Boxall, Purcell, \& Wright, 2008). However, professional contractors often fall outside the remit of HR. There have been calls for human resource (HR) professionals to better cater for a blended workforce rather than adhering to and valuing of traditional arrangements of work (McKeown \& Cochrane, 2017; Pichault, McKeown, \& 2019). This study goes beyond the standard HRM discipline and literature of employment relations and industrial relations to draw on other disciplines such as organisational behaviour, organisational psychology and sociology as well as management literature. The conceptual framework of this thesis avails of two concepts - organisational socialisation and the psychological contract - both of which have roots in different disciplines. Organisational socialisation is related to the broader concept of socialisation, which is borrowed from psychology (Chao, 2012). More specifically, organisational socialisation is an organisational psychology concept. The psychological contract, credited to Denise Rousseau who is an organisation scholar, is an organisational behaviour (OB) concept (Rousseau, 1989).

This thesis is concerned with the working relationship between professional contractors and the permanent employees they work alongside. In this thesis the working relationship refers to those who are connected because they are members of the same team. Belbin (1981)'s definition of team 
is used in sampling: a team is described as a group of people working toward a collective purpose. Therefore, the working relationship or workplace relationship is the connection between people working toward a collective purpose. Flinchbaugh, Zare, Chadwick, Li, and Essman (2019) acknowledge that other studies have outlined the importance of supportive workplace relationships in general. They cite Joiner and Bakalis (2006) who report that the presence of supportive relationships (e.g. colleagues or clients) and social networks offset any negative role perceptions that contractors developed. Similarly, Gavino, Martinez and Malos (2010) and Van den Born and Van Witteloostuijn (2013) found that the existence of supportive working relationship improved contractors' perceptions of satisfaction, commitment and career success. The suggestion is that increased connection to the role, client organisation and to other team members or colleagues resulted from professional contractor's perception of a supportive organisation and/or relationships within the organisation (Flinchbaugh et al., 2019). Other researchers have called for a more thorough understanding of what permanent employee's experience of working with contractors is and how contractors are perceived by staff (Bryant \& McKeown, 2016). Therefore, this thesis considers the multiple perspectives of those that comprise the working relationship. This chapter provides the contextual background for this research by explaining the changing nature of work and employment.

\subsection{The Changing Nature of Work and Employment}

The changing nature of work and employment has been significant in the last 20-30 years. The assumption that a single employer, permanent, indefinite model of employment predominates the workplace is now out-dated (Spoonley, De Bruin, \& Firkin, 2002). Not only has the notion of an organisational career or a linear career path faded away but also full-time, permanent employment is no longer as common as it once was. As standard work erodes, non-standard work has developed in both degree and importance (Mangan, 2000; Spoonley et al., 2002; Wooden, 2001; Zeytinoglu \& Muteshi, 1999). With increasing incidence of non-standard work, even the conceptualisations of 'employment' are being challenged (Connelly \& Gallagher, 2012).

\subsubsection{Standard and Non-standard Work}

The concept of non-standard work is really only meaningful if there is an understanding of what standard work is. Traditionally in New Zealand, standard work is regarded as paid, waged or salaried (Carroll, 1999), permanent, full-time or more than 30 hours per week employment that 
takes place on-site (Brosnan \& Walsh, 1996). Brosnan and Walsh (1996) also include standard working hours of 8 am to $5 \mathrm{pm}$, Monday to Friday, in their definition of standard work. In other words, standardised or standard work is generally considered full-time work at a single employer's premises in return for wages or salary with an expectation that this employment is for an indefinite period (Spoonley, Dupuis, \& De Bruin, 2004).

The concept of standard work underpins the notions of employment throughout the mid to late 20th century. This period was characterised by mass production and consumption that leveraged economies of scale and the division of labour, which provided stable, sustained standardised employment, particularly in urban areas of New Zealand (Spoonley et al., 2004). Even in the rural areas of New Zealand where primary production was predominant, the principles of mass production applied to industries such as milk production, meat processing and forestry (Spoonley et al., 2004). Standard work, which became the 'norm', is really only a new concept since it has its origins in the mid to late 20th century (Bridge, 2016; Spoonley et al., 2004). It is actually nonstandard work that has existed as long as the history of work has (Zeytinoglu \& Muteshi, 1999).

There are increasing numbers of workers who fall outside the traditional notion of standard work as a full-time, stable job of an indefinite duration (Connelly \& Gallagher, 2004; McKeown \& Hanley, 2009). Any work outside this norm is considered non-standard so such work encompasses a gamut of paid work such as part-time, casual, seasonal, temporary, contract and self-employed (Spoonley et al., 2004). There are also several new forms of work, namely on-call labour, zero-hours contracts, own-account working, platform work and gig work (OECD, 2018b). The breadth of non-standard work is captured in Eurofound's broad definition of non-standard employment as is:

Non-standard employment is an umbrella term for different employment arrangements that deviate from standard employment. They include temporary employment; part-time and oncall work; temporary agency work and other multiparty employment relationships; as well as disguised employment and dependent self-employment. The most relevant of possible future developments, whatever their contractual form, are related to digitisation (Eurofound, 2020).

The concept of non-standard work is considered a contentious one. Firstly, there are obvious issues with defining a concept by what it is inherently not rather than what it is. However, the debates are not merely linguistic but theoretical, too. There are questions about how 'standard' standard work really is (Bridge, 2016; Mangan, 2000). Over 15 years ago, Spoonley (2004) reported that only 40\% of those in employment in New Zealand were in standard work. If less than half of those in 
employment are actually in standard work, then how standard is that work? Is the notion of standard or traditional work erroneous? Such debates continue to swirl, fuelled by the growth of new types of non-standard work (Eurofound, 2018; OECD, 2018b).

Secondly, as the Eurofound (2020) quote above clearly demonstrates, another issue with the concept of non-standard employment is that it refers to such a wide range of alternatives to traditional employment. Non-standard work includes a plethora of work such as casual work, seasonal work, part-time, temporary work, fixed-term work, self-employment and contracting (Spoonley et al., 2004). In addition to these types of work, the term non-standard work also includes new forms of work, most of which are experiencing significant growth globally. Gig-work and platform work are all examples of new forms of work that are categorised as non-standard work (OECD, 2018b).

Finally, there is the issue of 'work' versus 'employment.' In the literature, these words are regularly used synonymously but they are not entirely equivalent. Eurofound's (2020) definition of nonstandard employment is an example of the confusing use of the term 'employment'. Non-standard work is often not technically employment. Therefore, for the purposes of this thesis, the term nonstandard work is preferred. The definition of non-standard work is: a variety of arrangements by which individuals are engaged by organisations to perform work. The increasing incidence of nonstandard work will be addressed in the next section.

\subsubsection{The Rise of Non-standard Work}

The incidence of non-standard work has been rising steadily, to the extent that there are claims that “impermanence is becoming permanent" (Connell \& Burgess, 2006; Rubin, 1995). Recently it was acknowledged that most OECD countries have experienced increases in at least one of several new forms of work in the last few years (OECD, 2018b). There is evidence of growth in many forms of non-standard work (Fudge, 2017). Across OECD countries, non-standard work arrangements comprise $33 \%$ of total employment (OECD, 2014). It is common to refer to non-standard work as anything other than standard work. While grouping all non-standard work together may be convenient, it is far too simplistic. It is worthwhile for the different forms of non-standard work to be separated out and examined independently. Professional contractors should be distinguished from other types of non-standard such as temporary staff (temps) or fixed-term employees (Connelly \& Gallagher, 2012). 
A common example of non-standard work in the modern economy is temporary work. These socalled temps have been studied quite a bit over the years (Alach \& Inkson, 2003; Biggs, Burchell, \& Millmore, 2006; Burgess \& Connell, 2006; Casey \& Alach, 2004). Casey and Alach (2004) found that temps were motivated to engage in this type of work for three different reasons. These are 1) to cover a transitional period such as returning from travel, losing a previous job due to business failure or redundancy; 2) to meet a need for flexibility to accommodate other interests such as hobbies, activism, sport, voluntary work, education; and 3) due to dissatisfaction with conventional hours of work or employment patterns. Another form of non-standard work is called own-account working, which is synonymous with self-employment (Burke, 2015). In a basic sense, selfemployment involves working as an independent consultant, contractor, or service provider (Feldman \& Bolino, 2000). Zero-hours contracts are also an example of non-standard work. Zerohours contracts are a kind of casual work so do not guarantee hours of work or have them specified in the agreement between the employee and the employer (Herriot \& Pemberton, 1996). Such ambiguity creates uncertainty so it is considered unfair particularly for the employee. In New Zealand in 2016 changes were made to legislation to limit this unfair practice ("Addressing zerohours contracts," 2018). Another example is gig-work, which is also becoming increasingly common as digital technology advances. Gig-work allows the worker to “...work as a freelancer taking on different short-term 'gigs' or jobs for a variety of clients" (Gowan, 2018). Digital work often falls out of traditional statistical categories so it is not really clear just how much gig-work is occurring or how much it is growing (Kässi, 2018). An example of gig-work is an Uber driver who accepts fares when it suits rather than during regular hours (Barley, 2017).

The descriptions provided above illustrate considerable differences between the types of nonstandard work, so much so that they can be thought to sit on a continuum with casual work at one end and professional contracting at the other (McKeown, 2005; McKeown \& Hanley, 2009). Other types of non-standard work can be seen to fit in between depending on certain variables that comprise their job such as the term, hours, engagement, and security (Tucker, 2002).

\section{Permanent}

$$
\text { Contractor }
$$

Seasonal

Temporary

Gig-work

Casual

Figure 1. Continuum of Forms of Work. 
Figure 1 takes the idea of a continuum a little further by graphically representing the different forms of work that comprise the modern workforce with traditional permanent employment (standard employment) on the left and casual work the right. All other forms of work are seen to fit in along the continuum from those with more security (left) to those with more flexibility (right). Why is the incidence of non-standard work increasing? The next section addresses an important driver for the steady increase in non-standard work: flexibility. It is this need that has contributed to the steady increase in non-standard work as described below.

\subsubsection{The Need for Flexibility}

Flexibility is often claimed as one of the main reasons for non-standard work. The need for flexibility can be considered from different perspectives. The rise of non-standard work has been traditionally attributed to organisations' need for flexibility (Dastmalchian \& Blyton, 2001). However, individual workers also increasingly prefer flexibility, which also drives the rise of nonstandard work and employment (Houseman, 2001; Kalleberg et al., 2003; Wooden, 2001). These drivers will be further explained in this section, beginning with the organisational perspective.

\section{An Organisational Perspective: Organisations' Needs}

Non-standard work arrangements suit employers who want numerical flexibility. Numerical flexibility is said to permit employers to make adjustments to the hours worked or the number of workers to accommodate fluctuations in demand (Truss, Mankin, \& Kelliher, 2012). In general, all non-standard work is an example of numerical flexibility. Organisations hire non-standard workers largely for flexibility.

The structure of the organisation is one approach to creating flexibility. Possibly one of the bestknown models of organisational structure is Atkinson's 1984 Model of a Flexible Firm. Atkinson (1984) describes two layers of peripheral workers around a core of full-time, permanent career employees. This core and peripheral notion is central to the model of a flexible firm as it is the peripheral workers who provide the (externally derived) numerical flexibility that allows an organisation to meet their market's/customers' demands. Employers desire and make use of labour market flexibility strategies in order to meet the current and future needs of the business and subsequently their customers (Dastmalchian \& Blyton, 2001). A professional contractor is an important component of Atkinson's model. Contracting is at the second layer of peripheral workers, who can provide both functional (availability of necessary skills) and numerical (availability of the 
number of people a firm needs) flexibility (Atkinson, 1984). When the need arises, an organisation may have to increase headcount but not necessarily for the long-term. It is in this instance that the organisation may have to retain a non-standard worker for reduced hours or for a limited time.

Another significant model is that proposed by Charles Handy (1989). Handy uses the Irish emblem of a Shamrock - a three-leafed clover - to describe the organisation of the future. As he claims, "Essentially, it is a form of organisation based around a core of essential executives and workers supported by outside contractors and part-time help" (Handy, 1989, p. 25). Central to this notion is the fact that each of the three leaves that comprise the shamrock is a group of very different workers (Handy, 1989). The first leaf is the "professional core" (Handy, 1989, p. 72). This group is essential and expensive so therefore is small in number. The second leaf is the "contractual fringe", which is made up of both self-employed individuals and organisations that provide results in return for fees (Handy, 1989, p. 73). Flexible workers - part-time and temporary workers - make up the third leaf of the shamrock (Handy, 1989). The contractual fringe referred to comprises the type of professional contractors this research is interested in.

These models may be a useful way of conceptualising peripheral or non-standard work. Fundamental to them is the idea that non-core activities that require transferable, generalisable skills are those that can be contracted out. However, it is apparent that these models are not an accurate reflection of practice. The reality is that many professional contractors are actually in a variety of roles. Lautsch (2002), Gramm and Schnell (2001) and Smith (2001) conducted studies that found that contracted workers are not differentiated from regular workers but were integrated and performed core activities (Olsen, 2006, p. 94). Similarly, Thompson and McHugh (2009) argue that the core-periphery model does not do justice to part-time work, which is considerably more central in a modern economy than it is peripheral. Discussions with professional contractors in preparation for this research reveal an interesting point: many of these contractors are working in roles that are essentially core roles.

There are multiple drivers for an organisation's need for numerical flexibility. The literature reveals several other important reasons for organisations using non-standard forms of workers such as contractors: as a form of inspection screening, specialised expertise and experience, headcount restrictions and cost reduction (Barley \& Kunda, 2004; Bidwell, 2009; Houseman, 2001; Olsen, 2006; Osnowitz, 2010). It is sometimes said that the use of non-standard workers is in order to screen potential workers for regular full-time positions (Houseman, 2001; Olsen, 2006). It appears 
that screening is really only relevant for temps rather than other types of non-standard work and even then only rarely (Houseman, 2001). Colloquially termed 'try before you buy', it is really only seen among the temp workforce, who may be offered a permanent role after a stint as a temp (Connell \& Burgess, 2006). The literature on professional contractors does not show any indication of this practice being common among highly skilled professionals, possibly because many such individuals are not seeking full-time, permanent roles. It has been found that relatively few workers in this type of non-standard arrangement express a preference for a standard job (Connelly \& Gallagher, 2004; Kalleberg, Reskin, \& Hudson, 2000; McKeown \& Cochrane, 2017).

Through their discussions with managers and permanent employees in client organisations, Barley and Kunda (2004) found three relevant reasons for firms hiring professional contractors. The first is in reference to specific skills: expertise and experience that permanent employees do not possess. According to Barley and Kunda (2004), professional contractors are either a hired gun, a guru or a warm body. In some cases, the professional contractor's highly specialised expertise is required for a short time in order to complete a critical task or assignment. That services such as engineering cannot be produced economically in-house is a reason that firms may use contractors (Davis-Blake \& Uzzi, 1993; Kalleberg et al., 2003). Here, the professional contractor is considered a hired gun: an expert hired to do a specific job. In other situations the professional contractor, like a guru who has a lot of experience in or knowledge about a particular subject, is required to transfer his or her superior technical skill and knowledge to permanent staff members. A guru is akin to a teacher or wise, trusted adviser. A warm body refers to somebody - anybody - to fill a role or sit in a seat in order to do a particular role. It is implicit that no particular skill is necessary so in such cases it may be that there is a need for a quantity of contractors rather than quality.

Headcount restrictions are another important reason for hiring a professional contractor (Barley \& Kunda, 2004; Bidwell, 2009; Osnowitz, 2010). During periods of headcount freezes, managers may elect to engage a professional contractor because they are unable to hire a permanent employee. However, a professional contractor is not part of the traditional headcount so is not a payroll expense (Houseman, 2001; Tucker, 2002). The organisation bears no superannuation, income taxation or insurance costs in association with a professional contractor because the individual is responsible for these (Rudman, 2019). Appelbaum (1992) suggests that it is the magnitude of the latter, non-wage costs of permanent employees that is significant enough for organisations to resort to using professional contractors (Gallagher, 2008). This is referred to "management by headcount" and it is explained that "keeping the company head count down and fixed costs low can thus bolster 
the price of the company stock, and because contractors do not figure in its head count, their presence can obscure actual labour costs" (Osnowitz, 2010, p. 26).

According to the literature, there are several cost associated reasons for engaging professional contractors (Barley \& Kunda, 2004; Bidwell, 2009; Osnowitz, 2010). Barley and Kunda (2004) provide a description about how firms use non-standard workers to appear more productive. This can be summarised as a numbers game. By having fewer actual employees, calculations of various ratios, rates and percentages are positively skewed. Therefore measures of productivity particularly per employee - seem healthier than they would be if the costs of professional contractors were included. Due to the fact that contractors are not employees, they remain outside full-time equivalent (FTE) counts. It has been said that one way to inflate an organisation's stock price is to hire contractors (Barley \& Kunda, 2004).

Furthermore Bidwell (2009) highlights a "lack of separation costs" and "morale costs" as reasons for engaging professional contractors (p. 203). According to those Bidwell (2009) studied, if employees are made redundant the organisation tries to find other positions within the organisation for those employees. However, if that is not possible then the individual is paid severance pay, which can be a significant amount of money. Contractors, however, are not entitled to any compensation, severance pay or benefits of any kind. It is widely understood by those involved in contracting that "...contractors could be let go at any time, for any reason, without any entitlement to compensation" (Bidwell, 2009, p. 203). The organisational trauma of laying off employees, particularly mass redundancies, is referred to as "morale costs" (Bidwell, 2009, p. 203). The use of contractors is a way around this trauma or impact on morale. Generally, letting go of a contractor is considerably easier than terminating a permanent employee. For example, in New Zealand the process for dismissing a permanent employee is both administratively complicated and lengthy. However, contractors can be let go with little procedure or protocol. Also, contractors' tenures are usually short term so the actual cost is a short-term cost (David, 2008).

\section{An Individual Perspective: Professional Contractors' Needs}

Non-standard work suits many individuals who have to arrange other responsibilities in addition to work. A report on the Survey of Working Life (2012) suggests that non-standard work is a feature of the labour market due to the participation of women in the workforce, the need for part-time or temporary work to support tertiary level study and the numbers of older persons transitioning into 
retirement (Statistics New Zealand, 2014a). The need for flexibility is certainly not limited to New Zealand but is seen in other countries such as Spain and Italy, where there is evidence of this quest for flexibility in what are two traditional labour markets (Cebrian, Moreno, Smek, Semenza, \& Toharia, 2003). Workers wish for more flexible working schedules to accommodate or balance the demands on their time (Houseman, 2001; Kalleberg et al., 2003). In fact, in several jurisdictions such as New Zealand, the right to request flexible work is enshrined in employment regulations (Rudman, 2019). Examples of other countries with similar legislation are the United Kingdom and the Netherlands (OECD, 2016). Autonomy, flexibility, the desire to create personal wealth and to escape organisational bureaucracies are reasons offered in favour of self-employment (Feldman \& Bolino, 2000).

Kunda, Barley, and Evans (2002) report three common reasons for individuals leaving full-time employment or standard work: politics, incompetence (of others) and inequity. Firstly, office or organisational politics, is explained as the "machinations and manipulations of self-interested others" (Kunda et al., 2002, p. 241). This includes the personal (hidden) agendas of both managers and team members. Barley and Kunda (2004) refer to freedom from corporate politics as one of the reasons cited by individuals for seeking to become professional contractors. Other authors have found similar trends regarding politics (Borg \& Soderlund, 2014; Peel \& Inkson, 2004; Spoonley, 2004), for instance, "attachment to a single employing organisation can swallow up an employee's time and energy, including the expectation of unpaid overtime and a preoccupation with the organisation's culture, social activities and company politics which many seek to avoid" (Spoonley et al., 2004, p. 135). Borg and Soderlund (2014) found that those in their study "referred to a certain freedom - the positive effects of having a valid reason not to get involved in some issues or activities" (pp. 189-190). It is said that contracting frees individuals from "cloying constraints" such as organisational politics (Peel \& Inkson, 2004, p. 554).

The second reason reported is that incompetence of other specific individuals also leads many individuals into contracting Kunda et al. (2002). This claim of incompetence is levelled at both senior management and middle management. The third and final reason Kunda et al. (2002) identified for entering contracting is inequity, particularly in the employment relationship. For instance, nowadays permanent employees are expected to work long hours, sometimes without commensurate pay. They are expected also to be loyal but without the security that was historically guaranteed. Additionally, there is sometimes competition and tension between permanent employees who perceive they are compensated differently (Kunda et al., 2002). These types of 
inequities lead permanent employees to opt for contracting careers. Interpersonal conflicts and jealousies between employees and contractors are exacerbated by the differences in terms and conditions of employment or contracts respectively (Peel \& Inkson, 2004, p. 553).

The reasons proposed by Kunda et al. (2002) described in the previous paragraph are examples of pushes into contracting. Each of these reasons for becoming a contractor provides individuals with the impetus to get out of traditional employment and into an alternative arrangement. Indeed, a useful way of conceptualising an individual's motivations is by considering whether the move into contracting was a push or a pull (McKeown, 2001). For instance, a push into contracting is precipitated by loss of "prior employment through redundancy or lack of career opportunity" (McKeown, 2005, p. 277). Osnowitz (2010) found that contractors often experience a push into contracting, which she terms an "external factor" (p. 53). This is often redundancy, layoffs, downsizing or general organisation instability that prompts a move into contracting (Osnowitz, 2010). On the other hand, there are factors that attract or pull individuals into professional contracting. "More money and career autonomy" are factors that would pull an individual into contracting (McKeown, 2005, p. 277). Pulled into contracting implies that the move is voluntary. A significant factor influencing individuals' choice between employment or contracting is the increased earning potential of the latter (Barley \& Kunda, 2004; Peel \& Inkson, 2004).

While a push or pull matrix is a useful way to conceptualise the impetus of a move into contracting, it is argued that the move is far too complex to reduce to push or pull (Barley \& Kunda, 2004). They claim that there are many more factors and influences in play. Kunda et al. (2002) state, "The complexity of pushes and pulls that led informants into contracting make it difficult to distinguish contingent workers who entered temporary labour markets voluntarily from those who did so involuntarily" (p. 247). However, the distinction between push and pull is volition, which is the desire or preference for non-standard or permanent employment (Connelly \& Gallagher, 2004; Kalleberg et al., 2003; McKeown \& Cochrane, 2017). Those who choose professional contracting and their work assignments are likely to experience greater degrees of engagement and commitment to their work (McKeown \& Cochrane, 2017). While contracting may bring individuals flexibility, there are trade-offs for that flexibility such as security for variety, deep involvement for broad involvement, upward progression for broad experience, or stable income for high income (Peel \& Boxall, 2005, p. 1690). 


\subsubsection{The Issue with Non-Standard Work}

Non-standard work is often associated with the notion of it being precarious (Hannif \& Lamm, 2005; McKeown, 2005; Spoonley et al., 2004; Tucker, 2002). Even permanent work, in certain circumstances, may be experienced as precarious (Centre for Research on Work Education and Research, 2004). Precarious work is employment that is "low in quality and which puts workers at risk of injury, illness, and/or poverty (from low pay and little opportunity for training and career progression)" (Tucker, 2002, p. 2). There is international evidence that firms which use nonstandard workers are inclined to underinvest in training, technology and innovation that could have positive effects on productivity (ILO, 2018). In fact, it is said that the literature on non-standard work is full of claims of "marginalisation and disadvantage" (McKeown, 2005, p. 276). In a review of existing literature it was found that non-standard work is not necessarily precarious but more likely to be precarious than permanent employment (Hannif \& Lamm, 2005). Standing (2014) notes in his book The Precariat that there is a developing group of underclass workers. This group of people is characterised not just by precariousness but by "systematic insecurity" (Standing, 2014, p.?). However, non-standard work is not always analogous with a bad job because non-standard jobs are not necessarily sub-standard (Kalleberg et al., 2000; Wooden, 2001).

It is the nature of the job and the preferences of the worker that ultimately make a non-standard job precarious or not (McKeown, 2005; Spoonley et al., 2004; Tucker, 2002). There is a significant disparity between the types of non-standard work. Workers with poor educational qualifications and who perform low-skilled work are in a very different situation to workers who have scarce skills such as those in information technology (Connell \& Burgess, 2006). Workers who have a lack of choice enter into working arrangements that are more precarious, while knowledge workers such as new technology workers have more flexibility and choice so it is less precarious (Spoonley et al., 2004). Whether or not the non-standard job was entered into voluntarily (a pull) or as a result of redundancy (a push) is key to how precarious it is (McKeown, 2005). It is volition that makes a job precarious or not (Hannif \& Lamm, 2005; McKeown, 2005; Spoonley et al., 2004; Tucker, 2002). It is clear in the literature on non-standard employment that some workers may be compelled to choose "suboptimal arrangements" because they have no choice (McKeown, 2005, p. 279). It is implicit here how easy it would be to enter permanent employment if an individual's circumstances changed; that is, the employability of the individual. Many professional contractors have a strong preference for contracting and would only return to permanent work under certain conditions (Osnowitz \& Henson, 2016). 
The level of precariousness between the types of non-standard work such as professional contracting or temporary work differs considerably, though both are examples of non-standard work. Even within contracting there are likely to be opportunities that are less precarious than others. McKeown (2005) suggests that, "There are clear differences between secure and insecure forms of professional contracting that are not easily captured by the traditional indicators of occupation or even by notions of polarisation of underclass and an elite" (p. 292). The precariat overlaps with both independent and dependant contractors but due to contractors' strong occupational identity most contractors have security (Standing, 2014). For a growing number of workers, entering non-standard work is an increasing likelihood (Eurofound, 2018; OECD, 2018a). For some workers non-standard work is voluntary but for others it will not be (Standing, 2014). In New Zealand, like many other nations, there is evidence that non-standard work is also on the rise. The next section provides some context for non-standard work and professional contracting in this country. 


\section{3 New Zealand Context}

This research is anchored in the New Zealand context. The number of people who work as professional contractors is rising. One out of every twenty New Zealanders in the workforce is a contractor, which equates to approximately 5\% of the population (Statistics New Zealand, 2019). Scott Ussher, Labour Market Statistics Manager at Statistics New Zealand, makes this point in a recent press release. Mr Ussher also reports, “There is considerable interest in contracting, given the perceived trend towards a 'gig economy' where people increasingly work on short-term contracts or freelance jobs." (Statistics New Zealand, 2019). In 2017 an annual salary survey reported that there is a preference for contractors in the Wellington market (Robert Walters Salary Survey, 2018). Shay Peters, New Zealand Director of a large international recruitment firm, acknowledges the trend towards non-standard employment, saying that there is a "...global trend of increasing reliance on transient and contingent labour" (Peters, 2018). This global trend is part of a worldwide development often referred to as the changing nature of work and employment, which recognises a multitude of changes that are happening in the world of work. The rise in non-standard work is an example of one of these changes. Professional contractors are one example of non-standard work.

In fact, there is evidence of increasing use of contract workers in some occupational groups. For example, the public sector in New Zealand spent more than half a billion dollars on contractors and consultants in the 2016-2017 financial year (Pennington, 2018). This is more than double the amount spent eight years earlier. An explanation for this number is the cap placed on the number of permanent public servants, which restricts the hiring of new permanent staff to do the work that needs to be done. In order to circumvent the cap, government agencies have had to engage contractors or consultants to undertake the work. At the time of writing, the cap placed on the number of permanent public servants was removed, which may reduce the government's spend on contractors and consultants.

The rise of non-standard work is largely driven by the need for flexibility. Over 10 years ago Spoonley (2004) raised the question of whether “...non-standard work is becoming standard?" in New Zealand (p. 3). In particular, he referred to the increasing prevalence of temporary work and the significant growth in the numbers of self-employed. According to a report released by Statistics New Zealand on Flexibility and Security in Employment, "a third of New Zealanders could be described as non-standard workers in that they were either self-employed, temporary or part-time workers" (Statistics New Zealand, 2014, p. 5). 
In Figure 2 the dashed line shows the obvious increase in the number of 'self-employed not employing others' in the workforce. This line is indicated with a \# in Figure 2. The number of 'selfemployed not employing others' grew significantly in the early part of this century, with selfemployment reaching a peak in 2011, after which there has been some decline attributable to the global financial crisis of 2007 (Statistics New Zealand, 2016). Since 2013 this number has continued to climb (Statistics New Zealand, 2016). Figure 2 highlights the strong increase in two categories of 'employers' (up 62,500) and the 'self-employed not employing others' (up 32,000) over the June 2016 quarter. These figures were partly offset by a drop of 45,400 in the number of 'paid employees' (Statistics New Zealand, 2016). In Figure 2, this declining trend is indicated with an*.

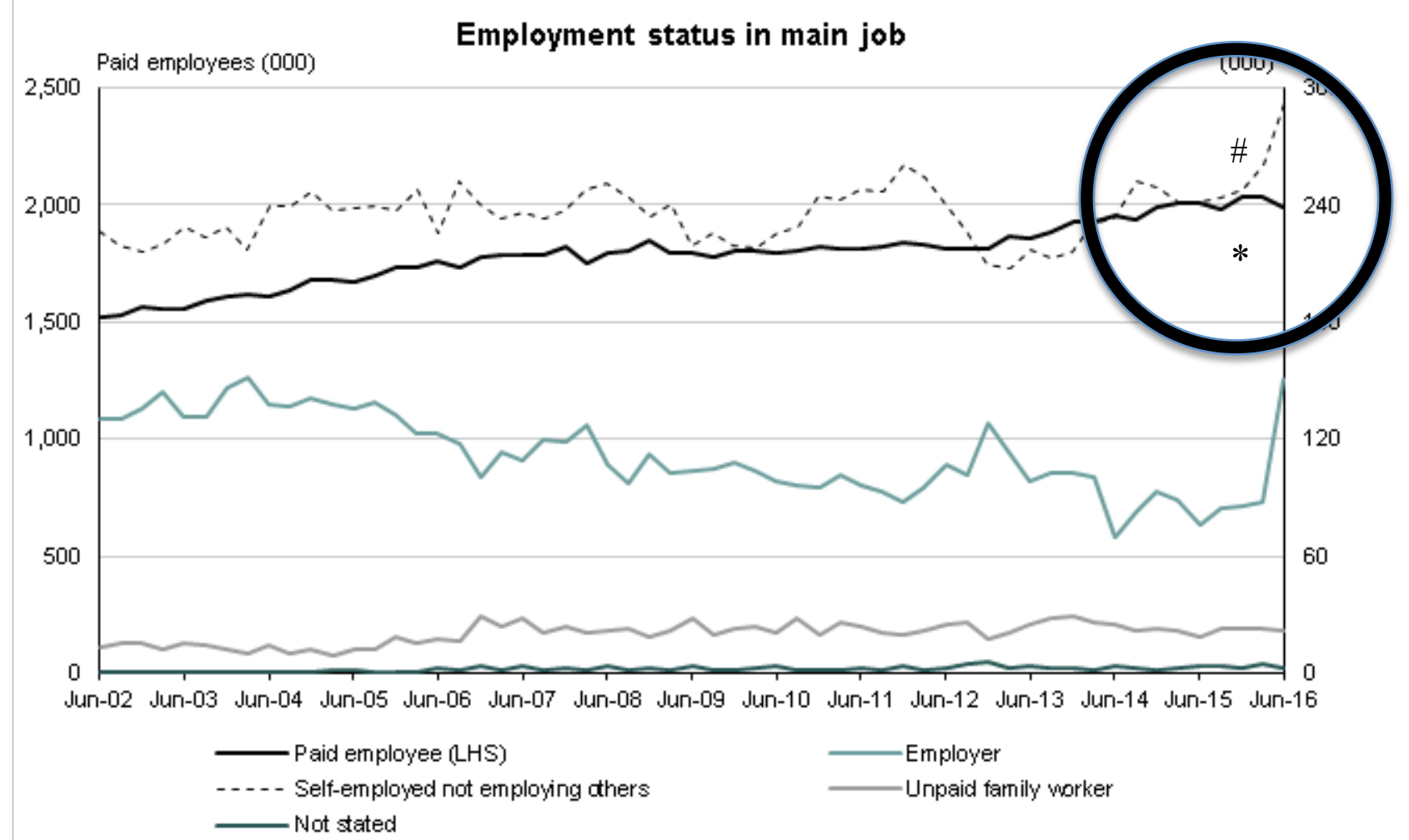

Source: Statistics New Zealand

Figure 2. Employment Status in Main Job (Statistics New Zealand, 2016).

In 2016, following suspected over-counting of workers in paid employment, Statistics New Zealand changed the questions on their Household Labour Force Survey (HLFS) questionnaire. It was recognised that "some self-employed people, such as contractors, may not think of themselves as owning their own business, and were likely to answer that they worked in a paid job" (Statistics New Zealand, 2016, p. 2). This is particularly relevant in the case of contractors operating through a staffing or recruitment agency. 
Therefore, in October 2018 the Survey of Working Life (SWOL) was conducted for the first time. This was the first time people were asked about their employment conditions, work arrangements and satisfaction with their job and their work-life balance. Statistics New Zealand also asked contractors about their work. In New Zealand just over 144,000 people work as self-employed contractors (Statistics New Zealand, 2019). Men (7\%) are more commonly found to be contractors compared to women (4\%) (Statistics New Zealand, 2019). There is evidence that contracting is prevalent in some sectors. For example, the Statistics New Zealand (2019) found that contractors make up as much as $14 \%$ of the professional, scientific, technical, administrative and support services workforce. Possibly one of the most telling statistics is that 9 out of 10 of the contractors surveyed were satisfied or very satisfied with their jobs (Statistics New Zealand, 2019). Similarly, 9 out of 10 contractors reported a preference for self-employment rather than working for someone else (Statistics New Zealand, 2019). Despite being a unique, rich data source of people's working habits in New Zealand, neither this survey (SWOL) nor its predecessor (HLFS) offer further information or details about the nature of the employment these individuals are involved with. The lack of detail notwithstanding, it is clear that the category 'self-employed not employing others' is increasing.

\subsection{The Rationale for this Research}

Several authors call for greater insight or investigation into different groups of workers (Ashford \& Nurmohamed, 2012; Bryant \& McKeown, 2016). Bryant and McKeown (2016) make a case for “...developing a more thorough understanding of how staff in client organisations perceive highly skilled contractors and what their experience of working with contractors..." is (Bryant \& McKeown, 2016, p. 400). Similarly, Ashford and Nurmohamed (2012) suggest an investigation of leaders, co-workers and teams. The assumption that all workers are permanent employees is inaccurate because non-standard workers are a feature of a blended workforce. Permanent employees are no longer working with other permanent employees but are increasingly likely to work alongside professional contractors. Therefore, the rationale for this study is that professional contractors are now a common feature of a blended workforce but little is known about how they work with permanent employees at client organisations. A greater understanding of how professional contractors and permanent employees work together would provide valuable insight into how to manage a blended workforce. In turn, this would inform the development of policy, procedure and practice (of both HR and management) at organisations in New Zealand. Traditional models and philosophies of management and HR are no longer adequate. 


\subsection{Thesis Outline}

This thesis comprises seven distinct chapters. In Chapter 1, the changing the nature of work and employment has brought about an increase in non-standard work, of which professional contracting is an example. The context is New Zealand specific but important connections are made to the relevant international literature as well. In Chapter 2: Literature Review: Professional Contractors, relevant literature relating to professional contractors and professional contracting is reviewed to provide the focus of this study. In this chapter professional contractors are defined and the characteristics of their jobs are discussed in the context of a contemporary workforce. Some of the practical realities that are characteristic of contracting are also presented. In Chapter 3: Literature Review: Conceptual Framework the relevant literature relating to the organisational socialisation process is the first part of this review. In the second part of this chapter, the literature related to the psychological contract is examined. At the end of this chapter the two theories or 'lenses' are related to each other. Chapter 4: Method and Methodology contains descriptions of the way this research was carried out and the philosophical approaches of this study. The design of this research is described in detail. This includes descriptions of the pilot study, the development of the interview schedules, recruitment of participants, data collection and data analysis. Chapter 4 also includes profiles of the 10 organisations and 49 interviewees who participated in this research. The results of data analysis are contained in Chapter 5: Findings. It is in this chapter that the actual voices of the professional contractors, permanent employees and managers interviewed are heard. It is where the variety of the different perspectives comes to the fore. Patterns emerge as the data is related to the literature reviewed. These form the findings of this study and are discussed further in Chapter 6: Discussion. This thesis draws to a close in Chapter 7: Conclusion, with the contributions, implications, and limitations of the study as well as reflections for further research before the conclusions of this research are made.

\subsection{Chapter Summary}

This chapter provided the background or context for this study. There is a distinct human resource management (HRM) perspective to this research in response to calls for better understanding of a blended workforce (McKeown \& Cochrane, 2017; Pichault et al., 2019). This study goes beyond standard HRM literature by exploring employment relations, industrial relations, organisational behaviour, organisational psychology and management literature. The conceptual framework of this thesis avails of two concepts - organisational socialisation and the psychological contract - which have roots in different disciplines. Reflecting an international trend of the changing nature of work 
and employment, this chapter positions professional contracting as one form of non-standard work. Better understanding of non-standard work is clearly warranted because of the evidence of its increase (OECD, 2018b).

The breadth and range of non-standard work was described to depict its significance in the modern economy. The issue with non-standard work has also been discussed. In this chapter both the individual and organisational perspectives of the need for non-standard work were described. The reasons individuals opt for non-standard work such as professional contracting includes the need for flexibility to balance work-life demands. There are those who make the move to professional contracting because of politics, incompetence and inequity (Barley \& Kunda, 2004). For some professional contracting is attractive because of the greater earning potential and autonomy it provides (McKeown, 2005; Peel \& Inkson, 2004). Organisations' needs are complex but engaging professional contractors is often attributed to a need for more numerical flexibility. Underlying this are several other reasons such as screening, specialised expertise and experience, headcount restrictions and cost reduction (Barley \& Kunda, 2004; Bidwell, 2009; Houseman, 2001; Osnowitz, 2010).

Some New Zealand-specific context is provided with regard to the increasing instance of nonstandard work. In fact, a third of the New Zealand workforce is in non-standard work (Statistics New Zealand, 2014). The increase in the numbers of 'self-employed not employing others' category in the workforce clearly quantifies the change that is happening. One type of non-standard worker - the professional contractor - is central to this research. There is evidence that they comprise 5\% of the workforce in New Zealand but are more highly represented in certain sectors or industries (Statistics New Zealand, 2019). The rationale of this study is briefly outlined at the end of the chapter highlighting several reasons for embarking research that focuses on professional contractors. This chapter ended with a brief outline of this thesis. 


\section{Chapter 2: Literature Review - The Professional Contractor}

\subsection{Introduction}

The focus of this chapter is the professional contractor. This supplements the information provided earlier on non-standard or contingent work because a professional contractor is a type of nonstandard worker. The 20th century notion of standard employment has largely been eroded, giving way to different forms of non-standard work. In fact, non-standard work arrangements comprise as much as $33 \%$ of total employment across OECD countries (OECD, 2014). Professional contractors are now found performing a variety of roles in many organisations. Professional contractors are perpetual newcomers, who manage steep learning curves and synthesise large amounts of information while developing and maintaining relationships. They balance these conflicting demands but still sustain their focus and apply their high skills, expertise and experience in order to deliver within a limited timeframe. This chapter starts with a comprehensive review of the literature on professional contractors. It covers definitions, types and other characteristics of a professional contractor.

\subsection{Defining a Professional Contractor}

There is no internationally accepted definition of an 'independent contractor.' This is because each national jurisdiction must develop their own according to their regulations (IOE, 2019). The definition of professional contractor captured below is the definition that is embraced in this thesis.

A professional contractor is defined as an individual (self-employed, sole trader or independent contractor) who provides short-term services to a client organisation (either directly or via a third party) but is not considered a permanent employee of that organisation. Therefore, that individual has no expectation of continuing employment, is not entitled to the rights or benefits of permanent employees and is not paid a salary but invoices the client (either directly or via a third party) for services provided.

This is a working definition developed for the purposes of this thesis because no existing definition entirely captures the nuances of a professional contractor's role. The term contractor is deliberately qualified with the word professional in order to clearly distinguish the type of contractor in this study from both temps and fixed-term employees as well as to indicate a focus on knowledge work. Due to the IT sector focus of this study, the majority of those interviewed are indeed professionals with high skills, superior knowledge and proven abilities. They are also experienced. 
It is acknowledged that professional contractors are important for innovation and workforce flexibility (McKeown \& Cochrane, 2017). According to an official at the Ministry of Business, Innovation and Employment (MBIE) the following describes a contractor:

A contractor is an individual who is either hired directly or via a third party to perform duties that would normally be provided by an existing staff member. The contractor is under the direct supervision of the client and the client is responsible for managing any risks associated with the contractor's work. (Mackay, 2016)

This alternative to standard employment was once common for tradespeople but recently it has "increasingly become the employment arrangement for high-level executives, accountants, information technology specialists, educators, translators, scientists and attorneys" (McKeown \& Hanley, 2009, p. 298). Professional contractors provide contract for service. Rudman (2019) describes contractors as "self-employed people, sole traders and independent contractors do not enter into contracts of service: instead they (or, where they have them, their companies) contract to provide services to their clients" (p. 37). Contracting work now encompasses the "best and the brightest" (McKeown \& Hanley, 2009, p. 298). What is already known about professional contractors? There are several terms that are commonly applied to describe a contractor such as: professional, freelance, itinerant and self-employed.

\subsubsection{Professional}

Traditionally jobs that were performed by a person who was a member of a particular profession (such as doctor, lawyer) were considered professions and incumbents were considered professionals. Today, jobs that involve specialised education or high skill are often considered professional. Therefore, highly skilled contractors in the knowledge economy are often considered professional and their profession is contracting. Contractors are described as “... well educated and professionally trained with skills that are either in short supply or for which the organisation has an immediate but not long-term need" (Gallagher, 2008, p. 473). The idea that professional contractors are generally well educated is a common one in the literature on contractors. Osnowitz (2010) reports that, "Professionals possess expert knowledge, usually gained through formal education, an investment in human capital expected to pay off in relatively high incomes and positions of authority" (p.14). Professional contractors essentially sell their knowledge and expertise so being well educated and qualified is part of the package (Gallagher, 2002; McKeown \& Cochrane, 2011). There is a recent trend to refer to these itinerant professionals as independent professionals or IPros 
(Burke, 2015; Leighton \& McKeown, 2015; McKeown \& Cochrane, 2017; Pichault et al., 2019) "IPros are distinctive within the engaged workforce because of their professional occupations, knowledge worker characteristics (high uniqueness, high strategic value) and commercial rather than employment contract with organisations" (McKeown \& Cochrane, 2017, p. 1415).

\subsubsection{Freelance}

Freelance is a useful way to describe a professional contractor because it is defined as someone with no fixed employer who works in an activity that requires specialist skills such as selfemployed journalists, technicians, actors and musicians (Heery \& Noon, 2008). Since early this century, contracting has been lauded as a way to cast off organisational constraints and take control as a form of free agency (Pink, 2001). Gallagher (2008) writes, "Within most countries, independent contractors or freelance workers are legally defined as self-employed persons who contract or sell their services to a client organisation on a fixed-term or project basis" (p. 473). Similarly, fields that are conducive to the professional or independent contractor form of employment are "freelance editors, engineering or computer programming" (McKeown, 2005, p. 276). Osnowitz (2010) book entitled Freelance professionals: Contract professionals in the new economy also clearly describes contractors as freelance, drawing parallels between it and free agency. Several of Osnowitz's (2010) informants objected to the use of the word freelance because of the connotations of the word free, which undervalues the work they do. More recently, Burke's (2015) The handbook of research on freelancing and self-employment also features the term freelance. According to Burke (2015) freelancers can reject certain assignments that they are not comfortable working on because they have less loyalty to a particular organisation (Burke, 2015). Freelancers tend to buffer themselves in times of less business by overbooking their schedule (Burke, 2015). The term e-lancer is a newly coined term that refers to those who freelance using the support of digital or electronic platforms (Cascio \& Boudreau, 2017).

\subsubsection{Itinerant}

Barley and Kunda (2004) use the term itinerant to describe professional contractors in the title of their book on the experiences of professional contractors in the Silicon Valley to clearly signal the impermanence of such contractors. It is also suggested that there is a new occupational identity: itinerant professional (Barley \& Kunda, 2006; Bryant \& McKeown, 2016). The short-term nature of contractors' role is possibly the most important feature of this type of work. This limited tenure has several implications and creates certain imperatives because contractors do not have the option of 
protracted learning curves. It is this feature that consigns contractors to being perpetual newcomers who are constantly moving in and out of organisations (Borg \& Soderlund, 2014). Contractors have skills that may be in short supply or skills that clients have immediate but short-term needs for (Gallagher, 2002).

For an itinerant professional such as a professional contractor, the positive of short-term assignments is that this provides some much-appreciated variety. It exposes them to many different organisations, organisational cultures and technologies. All of these experiences provide opportunities for contractors to be challenged and extended, ensuring their technical skills are kept highly relevant and up to date (Barley \& Kunda, 2004). A professional contractor's current contract essentially prepares them for their next contract and so forth. The disadvantages of being a perpetual newcomer are steep learning curves, transactional relationships, being an expert/outsider/stranger, access to only incomplete information and the pressure of urgency (Bryant \& McKeown, 2016; Kunda et al., 2002).

For permanent employees the job market is likened to a "soon-to-be-forgotten liminal space between periods of work" (Barley \& Kunda, 2004, p. 170). This is in stark contrast to professional contractors who regularly inhabit that liminal space. Professional contractors are never far removed from the job market and must be constantly aware of market trends and have good networks (Barley \& Kunda, 2004). It is said that coping with liminality is very important for successful self-employed contractors (Borg \& Soderlund, 2014). There is a concern that increased liminality will result in detached professional contractors who are alienated or estranged from the organisation and its goals (Bryant \& McKeown, 2016).

\subsubsection{Self-employed}

Over 30 years ago it was suggested that self-employed individuals are often older workers, who have had extensive experience (Bururu, 1998). Today many professional contractors are selfemployed, although many do not describe themselves as such. Self-employment simply entails working as either a service provider, an independent consultant or a contractor (Feldman \& Bolino, 2000). Peel and Inkson (2004) report that, “...downsizing, delayering, and reduction of organizational cores of permanent full-time employees in favour of larger peripheries of part-time and temporary workers reduce opportunities for ongoing employment. At the same time trends to outsourcing and contracting increase opportunities for self-employment” (p. 543). They report that, 
given the lack of security in permanent employment, contracting is no less secure (Peel \& Inkson, 2004). Self-employment appeals to some workers because of increased autonomy, earning maximisation and security, personal development, change and involvement (Peel \& Inkson, 2004).

The fact that many contractors choose to be in this type of work is an important characteristic (McKeown, 2005; Peel \& Boxall, 2005; Peel \& Inkson, 2004). The issue of volition is an important consideration when it comes to professional contracting (Connelly \& Gallagher, 2004; Kalleberg et al., 2003; McKeown \& Cochrane, 2017). Connelly and Gallagher (2004) have found that the attitudes and behaviour of non-standard or contingent workers are affected by whether or not that form of work was voluntary. There is a common misconception that many contractors enter into this type of work because they have no other options but this is not necessarily true. Contracting is a career choice for many, particularly in certain industries such as information technology (Barley \& Kunda, 2004; Connelly \& Gallagher, 2004; McKeown \& Hanley, 2009; Osnowitz, 2010). Being self-employed is an aspirational goal for many such professionals (Greene, 2000). Self-employed workers without employees may have several options to earn an income depending on their industry, skills, experience and objectives. There are several observable trends in the labour market such as increases in part-time work, contract work, temporary work, portfolio working, homelocated work and self-employment (Spoonley et al., 2004).

Related to self-employment are a boundaryless career or a portfolio career. The idea is of increasing relevance as individuals move from job to job, from organisation to organisation and take on different modes of employment to suit their needs and the demands of their lifestyle. Boundaryless careers are based on the accumulation of career-relevant competencies through multiple new jobs (Arthur \& Rousseau, 1996; Peel \& Inkson, 2004). It is fundamentally about moving away from the notion of a career in one organisation, to a series of related jobs that span organisations, industries and borders (Arthur \& Rousseau, 1996). However, as Osnowitz (2010) points out, a boundaryless career is based on permanent employment but an extra-organisational career is an alternative to describe careers that "allow for variable trajectories, without the organisational contexts that define achievement for employees" (p. 146). Those who leave an organisational career and go on to develop work independently have a portfolio of clients or portfolio careers, which are characterised by diversity of industry and role rather than the more traditional focus on function or organisation and may involve part-time or temp work (Mallon, 1998). They, too, are a way to achieve more sustainable balance between work and life. 


\subsection{Types of Professional Contractors}

For this study four subtly different types of professional contractors or contracting arrangements will be explained: 1) independent contractor, 2) agency contractor, 3) company contractor, and 4) dependent contractor. Each of these is described below.

\subsubsection{Independent Contractor}

Truly independent, self-employed professional contractors provide a service for a client organisation during a specified timeframe at a negotiated cost (often at an standard rate). Key to this mode of employment is the fact that the individual is not an employee of the organisation so is not on the payroll (Rudman, 2019). Therefore the individual is not subject to the standard terms and conditions of employment (Greene, 2000). This type of contractor is truly independent from the firm so the issue of autonomy is critical to this type of contractor. Independent contractors have fewer legal protections than employees (Connelly \& Gallagher, 2012). For example, in New Zealand the right to pursue a personal grievance (PG) is not available to the worker if he or she is indeed an independent contractor rather than an employee. As Greene (2000) states:

Independent contractors are not afforded employment protection such as that provided by the Minimum Code. In theory, arrangements between an independent contractor and an organisation or another individual are between two parties on an equal footing; independent contractors are independent, and do not need protection. (p. 194)

Genuine independent contractors are those who are not wholly dependent on only one client as their source of income but have several clients over a period of time (Greene, 2000). Alternatively, an independent contractor may work simultaneously with multiple clients (Connelly \& Gallagher, 2012). By virtue of being self-employed, independent contractors are entitled to claim tax deductions of their employment-related expenses (IRD, 2019). Typically, independent contractors charge for their work in the form of an invoice with Goods and Services Tax (GST) included (Rudman, 2019).

Independent contractors have been around for many years. There are accounts that organisations regularly engage former employees, who have been laid off or encouraged to leave, as independent contractors (Brosnan \& Walsh, 1996). There is some evidence that this occurred in the mid to late 1990s but Brosnan and Walsh (1996) found that it was not actually as common as it was claimed to be. Similarly, references are made to the conversion of employees to independent contractors either by redundancy or by explicit arrangement (Greene, 2000, pp. 193-194). There are observations that 
"many utilities companies have contracted out much work that was previously done in-house, often converting employees into self-employed contractors, or discarding employees in favour of outside contracting companies" (Peel \& Inkson, 2004, p. 546).

Internationally, the question of whether a worker is truly an independent contractor or an employee is one that still vexes the legal fraternity. In the US, a famous case of this involves IBM and found that a large number of IBM staff were in fact employees rather than independent contractors. This entitled those individuals to years of back pay for unpaid benefits and compensation for not being remunerated as employees (Barley \& Kunda, 2004). The crux of the issue was that the terms and conditions of work for the contractors were the same as permanent employees but they were not entitled to the same pay and benefits by virtue of being in-name-only contractors. Since then the US Inland Revenue Department (IRS) developed a checklist of 20-point questions to help ascertain whether or not a worker is actually a contractor or an employee (Barley \& Kunda, 2004).

\subsubsection{Agency Contractor}

Many professional contractors are not genuinely independent but are beholden to an intermediary: a recruitment, staffing or employment agency (Barley \& Kunda, 2004). An agency contractor is placed at a client organisation through such an agency. These individuals are essentially independent contractors engaged by an agency, which contracts them out to fill a specific job, role or task (often a project) at a client organisation. In such cases, the professional contractor is paid by the agency. It is the agency that invoices the client organisation. The agency acts as a broker in the relationship between the hiring organisation or client and the professional contractor for a fee or a percentage of the contractor's hourly rate. An agency contractor is an example of a multi-party employment relationship that is a common to non-standard employment (ILO, 2018).

A discussion with a staffing agency representative has indicated that in some businesses or industries large portions of the workforce are contractors. For example, of the 150,000 IT workers in New Zealand approximately $30-40 \%$ are professional contractors and the majority of those are agency contractors (A. Allan, personal communication, 8 August, 2014). For example, informal, personal communication with several staffing agencies reveal that the majority of the professional contractors in the Wellington region are agency contractors rather than truly independent contractors. 
In this situation, a professional contractor's de jure or legal employer is the agency for the duration of that contract (Kalleberg et al., 2000). A professional contractor's client is known as the de facto or functional/effective employer, creating a triangular employment relationship between agency, professional contractor and client organisation (Kalleberg et al., 2000). The triangular or triadic relationship between each of these stakeholders adds more complexity to the relationships (Barley $\&$ Kunda, 2004). In their study Morf, Arnold, and Staffelbach (2014) found that, "in such exchange relationships with three parties, the individual's evaluation of the relationship with one interaction partner is not independent from the evaluation of the relationship with the other partner" (p. 710).

Hiring organisations are reluctant to engage contractors directly due to the risks involved but these risks are not explained by those organisations. There are several known advantages to using an agency to fill a contractor role. An agency is likely to provide a larger pool of qualified candidates than the organisation might receive through directly engaging them. The organisation has recourse: if a contractor does not work out, the agency will quickly find a replacement. Many organisations value the fact that a contractor's references are checked by a third party (the agency) because of the logistics and time involved in doing a thorough job. Many hiring managers do not have the time to do so for professional contractors because their tenure is short. Furthermore, billing is simplified by a single invoice from an agency.

The major disadvantage associated with an agency contractor is that most agencies charge the organisation a higher rate for the contractor. Therefore, an agency contractor is likely to cost the organisation more than an independent contractor. Agencies restrict contractors from engaging directly with the client organisation through non-compete clauses in their agreements. This perpetuates the reliance the contractor has on that agency for their next and subsequent contracts.

Independent contractors are generally advised to seek their next contracts through their networks as well as through recruitment or staffing agencies (Business.govt.nz, 2019). The Business.govt.nz web page offers 10 steps to help an independent contractor find work and build a good reputation. An extract from the website showing the advice is as follows:

Recruitment, staffing or employment agencies, which specialise in the contractor's industry will be able to assist with finding a client, provide advice and negotiation as well as give more generic contracting advice such e.g. professional indemnity insurance. (Business.govt.nz, 2019) 


\subsubsection{Company Contractor}

There is another type of contractor in the labour market: a company contractor. This kind of worker is essentially a permanent employee who functions as a contractor but does not feature in literature relating to non-standard employment because they are in standard employment. A company contractor is a permanent employee of an organisation but their role involves being contracted out to other organisations on short-term assignments. Many large IT, financial services and advisory companies in New Zealand hire permanent employees who only work at and for client organisations. As permanent employees of an organisation they are entitled to all the benefits of being an employee including the security of ongoing employment (Rudman, 2019). For example, company contractors are entitled to sick leave and holiday pay as well as professional development provided by their employer. All other contractors have to fund sick leave, holiday pay and professional development themselves. The most significant difference between this type of contractor and permanent employees is they have no permanent place of work but generally work at the client site. The descriptions of de jure and de facto employers included above are particularly relevant in the case of company contractors (Kalleberg et al., 2000).

Company contractors are not true professional contractors but they are discussed here because several of this type of contractor are included in the sample of those interviewed for this study. These individuals do the work of and function like contractors but are not contractors in all senses of the term. Admittedly, from the perspective of the client organisation, he or she is a contractor. The worker is referred to as a contractor but the reality is that he or she is a permanent employee who is contracted out to the client organisation. Like an agency contractor, this type of professional contractor is an example of a multi-party employment relationship (ILO, 2018).

A company contractor is not responsible for finding their next contract but may work in conjunction with their employer to identify opportunities. A company contractor would not be involved in rate negotiations or invoicing the client organisation. The actual employer handles all administrative issues and duties. They are casually described as having "all the trappings of contracting but with all the benefits of permanent employment" (J. Johnston, personal communication, 6 May, 2018). The implication of this statement is that, although there is significantly more job security, the remuneration is not as good as it would be for a truly independent, self-employed professional contractor. Furthermore, all typical downsides of traditional, permanent employment also apply. 


\subsubsection{Dependent Contractor}

A dependent contractor is reliant upon one client for the majority of his or her income (Connelly \& Gallagher, 2006; Greene, 2000). This type of contractor is a contractor in name only (McKeown, 2005). The client organisation often treats such contractors as though they are employees. Therefore, dependent contractors blur the line between employee and independent contractor. The idea of an independent contractor is attributed to Arthurs (1965) and has been around for longer than the notion of a dependent contractor (Greene, 2000).

In New Zealand, the essential difference between an employee and contractor is about control, as employees are “...subject to direction and control of their employer and are obliged to carry out employer instruction" (Greene, 2000, p. 188). This suggests that if a contractor is subject to this control then the individual is actually a dependent contractor and more akin to an employee. However, in some cases a worker's skill is so unique and individual that the employer has no real control over the person's work even though he or she is an employee. There are two other 'tests' to determine if a worker is in fact an employee: integration and fundamental. It is clearly pointed out that, "If the worker is integral to and integrated with the organisation, that person is likely to be an employee with a contract of service" (Rudman, 2019, p. 45). However, the question of whether or not a contractor is integrated is becoming harder and harder to ascertain so the fundamental test involves questioning if the worker is in 'business for his or her own account'. If so, then that person is most likely to be an independent contractor rather than a dependent one.

In summary, it is not possible to quantify the proportion of professional contractors in each of the categories outlined above due to the lack of detail in the statistical data on professional contractors themselves. This is further complicated by the fact that independent and agency contractors move between the two categories regularly. It is apparent that the once "...clear distinction between employee and contractor is blurring, and there are now statutory entitlements and protections for non-employees that were once reserved for employees" (Rudman, 2019, p. 39). At the time of writing, the possible legislative protection of dependent contractors is a topic that is being discussed at a central government level (Rowe, 2018). A professional contractor may be truly independent, an agency contractor, a company or dependent contractor. The distinctions between these types of professional contractor relate to their independence from an organisation. Table 1 summarises this information. 
Table 1. Types of Professional Contractors.

\begin{tabular}{|c|c|c|c|c|}
\hline & $\begin{array}{l}\text { Independent } \\
\text { Contractor }\end{array}$ & $\begin{array}{l}\text { Agency } \\
\text { Contractor }\end{array}$ & $\begin{array}{l}\text { Company } \\
\text { Contractor }\end{array}$ & $\begin{array}{l}\text { Dependent } \\
\text { Contractor }\end{array}$ \\
\hline Description & $\begin{array}{l}\text { Truly independent } \\
\text { of an organisation } \\
\text { so has multiple } \\
\text { clients either } \\
\text { consecutively or } \\
\text { concurrently. }\end{array}$ & $\begin{array}{l}\text { An agency brokers } \\
\text { the relationship } \\
\text { between } \\
\text { organisations and } \\
\text { contractors. }\end{array}$ & $\begin{array}{l}\text { Permanently } \\
\text { employed by a } \\
\text { company but } \\
\text { placed at client } \\
\text { organisations as a } \\
\text { contractor. }\end{array}$ & $\begin{array}{l}\text { Reliant on one } \\
\text { client, a de facto } \\
\text { employer. }\end{array}$ \\
\hline $\begin{array}{l}\text { Legal } \\
\text { implications }\end{array}$ & $\begin{array}{l}\text { Civil Law } \\
\text { determines most } \\
\text { of their rights and } \\
\text { responsibilities. }\end{array}$ & $\begin{array}{l}\text { A multi-party } \\
\text { relationship. }\end{array}$ & $\begin{array}{l}\text { The company } \\
\text { remains the legal } \\
\text { or de jure } \\
\text { employer. }\end{array}$ & $\begin{array}{l}\text { Possibly a } \\
\text { disguised } \\
\text { employee. }\end{array}$ \\
\hline $\begin{array}{l}\text { Commercial } \\
\text { issues }\end{array}$ & $\begin{array}{l}\text { A truly } \\
\text { commercial } \\
\text { relationship: one } \\
\text { business to } \\
\text { another business. }\end{array}$ & $\begin{array}{l}\text { The agency is the } \\
\text { middleman for } \\
\text { which it receives a } \\
\text { fee but may add } \\
\text { little value other } \\
\text { than the placement } \\
\text { or introduction. }\end{array}$ & $\begin{array}{l}\text { A multi-party } \\
\text { commercial } \\
\text { arrangement. }\end{array}$ & $\begin{array}{l}\text { Likely to be } \\
\text { prevented from } \\
\text { working for } \\
\text { another client. }\end{array}$ \\
\hline
\end{tabular}

There are several legal parameters that distinguish a contractor from an employee. First, a contractor has no expectation of on-going or continued employment. Their tenure is for the duration of the contract, which may be extended or rolled over but the client organisation does not offer job security. Secondly, as a contractor, the worker is not entitled to many of the legal rights granted to an employee e.g. sick leave and holiday pay (Employment New Zealand, 2020). They do not have the right to lodge a personal grievance (PG) against the client-organisation for any reason (Employment New Zealand, 2020). Thirdly, a contractor issues an invoice and is paid in arrears by accounts payable (or the equivalent) rather than by payroll. A contractor is not on an organisation's payroll so cannot be considered a full time employee (FTE) (Rudman, 2019).

In reality, however, it is not always easy to distinguish a contractor from an employee, which is where the issue of a disguised employee arises. Dependent contractors may actually be disguised 
employees. They present as self-employed but this is actually a sham and in reality they are an employee in all senses except on paper (Leighton \& McKeown, 2015). A recent example of this occurred in the case of Leota vs Parcel Express Limited, where the judge found Mr Leota to be an employee of Parcel Express Limited despite paperwork claiming he was an independent contractor. For example, Mr Leota had little control or autonomy over his work, had no GST registration nor did he have the opportunity to serve his own business interests. In her ruling the judge stated that the way the relationship operated in practice was more revealing than the documentation (Inglis, 2020). An increasing variety of intermediaries between a client organisation and a contractor further increases the complexity of the issue for enforcement authorities (McKeown, 2016).

\subsubsection{Comparing Professional Contracting to Permanent Employment}

Table 2 summarises conditions of employment for permanent employees and professional contractors. The essential feature of contracting is the agreement between the client (the organisation that requires work done) and an individual outlining the particular details of the arrangement. For professional contractors, key to this agreement is the lack of expectation of ongoing employment: there is no future job security. An individual is contracted to provide a service or complete a piece of work for a client organisation within a limited timeframe at a negotiated cost (often at an standard rate) (Rudman, 2019). Not only have the traditional notion of job security and employment protection gone but there are several other consequences for an individual (Greene, 2000). For instance, taxation, pension plan and health insurance are the responsibility of the professional contractor. Similarly, training and personal development costs must be borne by the profession contractor themselves.

Table 2. Conditions of Employment versus Contracting.

\begin{tabular}{|c|c|c|}
\hline Description & Permanent Employee & Professional Contractor \\
\hline Income tax/PAYE & $\begin{array}{l}\text { Paid by organisation (on } \\
\text { employee's behalf) }\end{array}$ & Contractor's responsibility \\
\hline Pension payments & Covered by organisation $^{1}$ & Self-funded \\
\hline Holiday pay & Covered by organisation & Self-funded \\
\hline Sick pay & Covered by organisation & Self-funded \\
\hline Professional development & Provided by organisation & Self-funded \\
\hline Training & Provided by organisation & Self-funded \\
\hline Other benefits & Health insurance & N/A \\
\hline $\begin{array}{l}\text { Ongoing } \\
\text { employment/security }\end{array}$ & Presumed & None \\
\hline
\end{tabular}

\footnotetext{
${ }^{1}$ In New Zealand, employers do not make pension contribution but do make KiwiSaver contributions.
} 
On the other hand, professional contractors command high hourly rates ostensibly to cover the costs of the above and to mitigate the short-term nature of the employment. It is said that contractors cost 20-30\% more than employees (Bidwell, 2009). The typically high cost of hiring professional contractors is often used as a reason to argue against the use of such non-standard workers (McKeown, 2001). In the literature the high cost of professional contractors is countered with the caveat that it is only a short-term cost (David, 2008). This is the price of numerical flexibility for the employer and the compensation for insecurity for the contractor.

\subsection{Contracting in Practice}

There are several recurring themes that emerge from the literature on professional contracting. These are framed here as practical issues as they are issues that are associated with the day-to-day functioning of a contractor. These are broadly summarised as the personal qualities of a contractor, the importance of occupational identity, compromises inherent in contracting and managing a contractor.

\subsubsection{The Personal Qualities of a Contractor}

It is no surprise that personality surfaces in the literature on professional contractors (Connelly \& Gallagher, 2012; Feldman \& Bolino, 2000; Peel \& Inkson, 2004). It is likely that some contractor behaviours, such as proactive behaviour, can be attributed to a contractor's personality, particularly self-confidence (Crant, 2000). Other aspects of personality that are associated with professional contractors are comfort with risk, tolerance of ambiguity (Connelly \& Gallagher, 2004), independence and self-motivation (Osnowitz, 2010). There are some personality types that are more comfortable with the risks associated with professional contracting than others (Peel \& Boxall, 2005). Being entrepreneurial is also associated with professional contracting but it is argued that self-employment is not the same as entrepreneurship (Peel \& Inkson, 2004). Characteristics of entrepreneurs include high need for achievement, control and a tolerance of ambiguity, which overlap with the traits associated with self-employed contractors. The objectives of the two are different (Feldman \& Bolino, 2000).

\subsubsection{Occupational Identity is Important}

For professional contractors, occupational identity becomes even more important as they make the transition into professional contracting. Several authors, particularly those who were involved in lengthy, in-depth studies, mention this (Barley \& Kunda, 2004; Kunda et al., 2002; Osnowitz, 
2010). The technical contractors interviewed placed an emphasis on their occupational identity, linking occupational identity to the occupational communities and communities of practice that arose among similar professionals in the contingent labour market (Kunda et al., 2002). It is the occupation rather than the organisation that becomes central to an individual's career (Barley \& Kunda, 2004, 2006; Osnowitz, 2010). Permanent employees often define themselves by their organisation but professional contractors look to their occupation for their identity (Osnowitz, 2010). A possible trend toward occupational forms of organising is recognised as being associated with this development (Barley \& Kunda, 2004).

\subsubsection{Compromises Inherent in Contracting}

This review of the literature has revealed that there are several compromises that are a necessary part of contracting. Some of these compromises are described as "independence versus being an outsider, security versus uncertainty, enhanced income versus hidden costs, and skills as expertise versus skills as a commodity" (Kunda et al., 2002, p. 248). Similar issues are framed elsewhere as trade-offs. For example, security is traded-off for variety, and deep involvement in an organisation is traded-off for wide exposure to new organisations, cultures and technologies (Peel \& Boxall, 2005). Furthermore, upward or linear career progression is replaced by broad experience and a stable income is traded-off for a potentially high income (Peel \& Boxall, 2005). Also described as contradictions, which have to be managed by a professional contractor, balancing autonomy and constraint are referred to, although the claim is that these are not limited to professional contractors but to all professionals (Osnowitz, 2010). Regardless of the term applied, it is apparent that professional contractors must navigate their way though many complexities, making compromises as they go. Professional contracting requires skilful balancing of competing demands.

\subsection{Focusing on Information and Communications Technology Sector}

This research has an explicit focus on those in the information and communications technology sector for several reasons. Firstly, professional contracting is well established in the IT sector so much so that it is considered both an "occupational norm" and a "sustainable career" (McKeown, 2005, p. 283). McKeown (2005) notes that "very clear occupation and industry differences emerged, particularly in relation to the IT and engineering professions where there were clear norms of contracting as being an acceptable, and even standard, form of employment" (p. 291). Connelly and Gallagher (2012) state that because contracting is so common among contingent workers, there is less job insecurity or anxiety. Contracting is a viable alternative to permanent employment or a 
"rite of passage" (Connelly \& Gallagher, 2012, p. 272). Contracting is prevalent in IT because many organisations rely on professional contractors for transformational change projects (DavisBlake \& Uzzi, 1993; Kalleberg et al., 2003). Rudman (2019) also acknowledges that project-based engagements, which are prevalent in the IT sector, are on the increase in the gig economy. A local example of this is provided in a survey published by an international staffing agency, which reports that particularly in the public sector in New Zealand substantial business transformation projects are underway (such as RealMe ${ }^{2}$, which is a collaboration between the Department of Internal Affairs and Inland Revenue). It is expected that this will result in increased competition over the finite number of IT professionals in the New Zealand market (2018, p. 101). A key characteristic of IT contractors is that they have high skills, which are in high demand but in short supply (McKeown, 2016). For such projects, workers are needed until a specific project is completed but there is no continuing need for those skills.

The second reason for focusing on the IT sector is simply the availability of and access to a blended workforce. For the reasons described above, it is well known that the IT sector operates in teams, particularly project teams. Pichault et al. (2019) describes this as work becoming "projects" and contractors coming and going as needed (p. 61). Such teams include representatives of the organisation (e.g. subject matter experts or SMEs) as well as externally sourced resources (e.g. technical expertise). Therefore, these teams comprise a blend of different workers because the SMEs are generally permanent employees and the technical experts are often professional contractors.

The third and final reason for the IT focus of this research is that there is a significant body of knowledge about the IT sector. Seminal works such as Barley and Kunda (2004) and Osnowitz (2010) both have an IT focus to their research in the US. More recently, there have been other studies that focus specifically on the IT sector (King, Xia, Campbell, \& Sethi, 2004). The existence of other studies would allow more relevant comparisons and contrasting of the data collected in this study and extant knowledge on professional contracting in the IT sector. Together all these reasons provide a strong foundation or rationale for focussing the research on the IT sector in New Zealand.

\footnotetext{
2 RealMe ${ }^{\circledR}$ is a secure login service that lets customers access online services across agencies and businesses with a single username and password. The verified identity service allows customers to easily and securely prove their identity online. Government agencies are required to use RealMe services rather than developing new authentication and identity verification systems (New Zealand Government, 2019).
} 
Personal communication from recruiters specialising in the IT sector reveals some very interesting trends peculiar to that sector specifically. A substantial proportion of most IT divisions or departments are often contracted workers. One recruiter claims that of people in IT in New Zealand about $35-40 \%$ of these are contractors (A. Allan, personal communication, 1 August, 2014). The average contract is for a period of six months but these may be extended or renewed sometimes several times over. Another recruiter reports that all young, inexperienced workers are advised to gain substantial experience before they consider going contracting (S. Willoughby, personal communication, 27 June, 2014). No permanent employee would be encouraged to leave permanent employment for a contract that was less than six months in duration (S. Willoughby, personal communication, 27 June, 2014) Yet another recruiter shares that, in her experience, all roles can be filled by a contractor: business as usual roles, specialist roles and change roles/business transformation roles (G. Makarios, personal communication, 30 June, 2014).

\subsection{Focussing on Professional Contractors}

A contractor role is typically characterised by the generally short duration of contractor tenure, the expectation of immediate productivity and the project or task focus of such contractors. There are several reasons for focusing on professional contractors. Firstly, professional contracting is becoming more common particularly in some sectors like IT (Barley \& Kunda, 2004; McKeown, 2005, 2016; Osnowitz, 2010). The modern workplace is characterised by a blended workforce comprising different types of workers: casual, temporary, part-time, contracted and permanent. Secondly, there is evidence that professional contractors are in jobs that permanent employees could hold so they are doing the work of permanent employees. Contractors are no longer filling peripheral jobs but are also found in core roles (Redpath, Hurst, \& Devine, 2009). Therefore, professional contractors will work with other types of workers especially permanent employees.

The third reason for focussing on professional contractors is because relationship between professional contractors and permanent employees has not been extensively explored. There are some studies that have approached the topic (Connelly \& Gallagher, 2012; Redpath et al., 2009). Connelly and Gallagher (2012) acknowledge that, though not widely recognised, interaction between those at a client organisation and contractors are an important part of the "employment landscape" (p. 267). Redpath et al. (2009) found that contingent workers were engaged in essential work and were integrated with other workers. We know very little about how professional contractors and permanent employees work together. Finally, professional contractors remain 
outside the traditional HR remit because they are neither permanent nor employees (McKeown \& Cochrane, 2017; McKeown \& Hanley, 2009). The relationship between a contractor and the clientorganisation is a commercial one rather than an employee-organisation relationship (EOR) (Connelly \& Gallagher, 2012). Therefore, from legal, commercial, managerial and practical perspectives the two types of workers are different.

This research is not about building contractors, tradespersons, manual labourers, port workers or forestry workers. This research is not about temps because this has been conducted extensively both in New Zealand (Alach \& Inkson, 2003; Casey \& Alach, 2004) and in the United States (Rogers, 1995; Henson, 1996). This research is not about fixed-term contract workers. Preliminary examination of fixed-term contracts reveals that they are subtly different to professional contracting in that such workers are entitled to all the benefits of permanent employment such as sick leave and holidays but only for the defined period of employment. Fixed-term contracts are similar to permanent employment but for a fixed duration. According to the following website, fixed-term employment is described as:

A fixed-term (temporary) employee's employment will end on a specified date or when a particular event occurs. A fixed-term employee might be someone who is brought in to replace another employee on parental leave, to cover a seasonal peak or to complete a project. (Employment New Zealand, 2018)

Those on fixed-term contracts receive the benefits of permanent employment but only for the duration of their contract. The Employment Relations Act 2000 allows employers to offer fixedterm agreements to employees under certain circumstances. There is no expectation of on-going employment. Fixed-term contracts are often used to backfill a position for a specified period such as during parental leave (MBIE, 2014).

This research is not about consultants, although these terms are often used interchangeably with contractors both in New Zealand and internationally. The difference between contractors and consultants is not always clear. Consultants have been found to have greater "latitude and authority" but contractors take "direction and more closely resembled employees with standard jobs" (Osnowitz, 2010, p. 20). A consultant generally provides professional advice in return for a fee. The organisation has the discretion to apply or implement the advice received. According to an MBIE official, a consultant is described as follows: 
A consultancy service is where a client is paying for a consulting company for the delivery of an outcome. A consultant is an expert in a particular field, who can demonstrate relevant skills and experience not readily available from within (the organisation). In this case, the consulting company is responsible for all the risk as well as the outcome. (Mackay, 2016)

\subsection{Chapter Summary}

Drawing on literature related to professional contractors, this chapter has discussed the definitions and types of contractors and compared professional contracting to permanent employment in New Zealand. A working definition of professional contractor is also supplied because no one existing definition entirely captures the subtleties of the professional contractors this thesis explores. Descriptions of a professional contractor often include the terms professional, freelance, itinerant and self-employed. There are four broad types of professional contractors that are relevant to this research. These are 1) Independent Contractor, 2) Agency Contractor, 3) Company Contractor, and 4) Dependent Contractor. Several themes that repeatedly emerge from the literature have been highlighted to paint a better picture of the realities of contracting. The personal qualities of professional contractors are touched upon. Occupational identity emerges as an important feature of professional contracting. Professional contracting in IT specifically is highlighted because its maturity and prevalence in that sector in New Zealand. The IT focus is also due to the availability of teams that represent a blended workforce. Other international studies also focus on the IT sector, which is another driver for this study to share a similar focus.

Professional contractors are the focus of this study for several reasons. The review of the literature has shown that contractors are becoming a common feature of a blended workforce, so how they work together with their permanent employee colleagues needs to be explored. It is essential that professional contractors are well managed or the benefits of engaging them are not realised (McKeown \& Lindorff, 2011). The information presented here demonstrates recognition of professional contractors as a feature of the modern workforce. As McKeown and Cochrane (2017) acknowledge, “....workforces are becoming complex in twenty-first century organizations, blending those traditionally employed with increasing numbers employed on a contingent, atypical or nonstandard basis and those engaged via intermediated or contracted arrangements" (p. 1414). In the next chapter the literature about two concepts, which form this study's conceptual framework, will be described. 


\section{Chapter 3: Literature Review - The Conceptual Framework}

\subsection{Introduction}

The conceptual framework is presented in this chapter. This chapter covers the concepts of organisational socialisation and the psychological contract, which are described in detail because they are the lenses that are used to explore the working relationship between professional contractors and permanent employees. Specifically, aspects of this literature relevant to the relationship between professional contractors and permanent employees are reviewed. This chapter concludes with an important section on the literature that relates to both organisational socialisation and the psychological contract.

The concept of organisational socialisation resonated as a lens with which to examine the relationship between professional contractors and the permanent employees with whom they work because it is fundamentally about integration. Organisational socialisation, like any socialisation, is a process that occurs over time (Bauer \& Erdogan, 2012). This concept is multi-faceted and involves several inputs, from different sources, making it highly relevant to professional contractors. The psychological contract offers a different, though related, way of looking at the mutual expectations that professional contractors, permanent employees and their managers develop of each other. These expectations form the basis of a contractor's psychological contract. Therefore, the use of this concept as a key construct was considered appropriate.

An additional reason for selecting these two concepts is that they are connected. Several authors suggests socialisation and the psychological contract are interrelated though it is just not clear exactly how they are connected (De Vos \& Freese, 2011; Woodrow \& Guest, 2017). Woodrow and Guest (2017) ask if the psychological contract is an outcome of the socialisation process? Is it is an intervening or moderating variable? Do these two key concepts have equal influence on the working relationship? Do these concepts work uni-directionally or multi-directionally? In this study, it is the working relationship between professional contractors and permanent employees that was identified for further exploration because it is this dynamic is a characteristic of a blended workforce. Blended workforces are becoming more common in organisations both domestically and internationally (Burke, 2015; McKeown \& Cochrane, 2017; Pichault et al., 2019). During preliminary examination of the working relationship, it became apparent that little is known about certain aspects of professional contracting, which led to the use of two interrelated as lenses with which to examine it. 
Career Theory was considered as key concept for this study but this would lead this research in a different direction. It was not the researcher's goal to pursue, test for, or establish careercompetencies that identify contractors. Nor did the researcher wish to investigate the personalities that make an individual suitable for professional contracting. It should be acknowledged that there is much relevance and applicability of career literature to professional contractors but not to the working relationship that is being examined. For example, boundary less careers, seem to be the type of career a professional contractor is representative of (Arthur \& Rousseau, 1996; Peel \& Inkson, 2004). There is certainly scope for developing studies that look at and further develop the career theory aspect of professional contracting. Alternatively, theories such as free-agency theory (Pink, 2001) and institutionalism (Kalleberg et al., 2003) discussed by (Barley \& Kunda, 2004) are inextricably linked to this topic. These theories offer opposing macro views of the labour market in particular. They are both macro-economic theories favoured by economists and sociologists or futurists. In comparison, organisational socialisation and the psychological contract perspectives offer room for personal or individual insights into the working relationship of professional contractors and the permanent employees they work alongside. Such options were considered but ultimately a decision was made to use the key concepts of organisational socialisation and the psychological contract as lenses with which to examine the working relationship between professional contractors and permanent employees. In Figure 3 the two key constructs are depicted in the figure to form this study's conceptual framework.

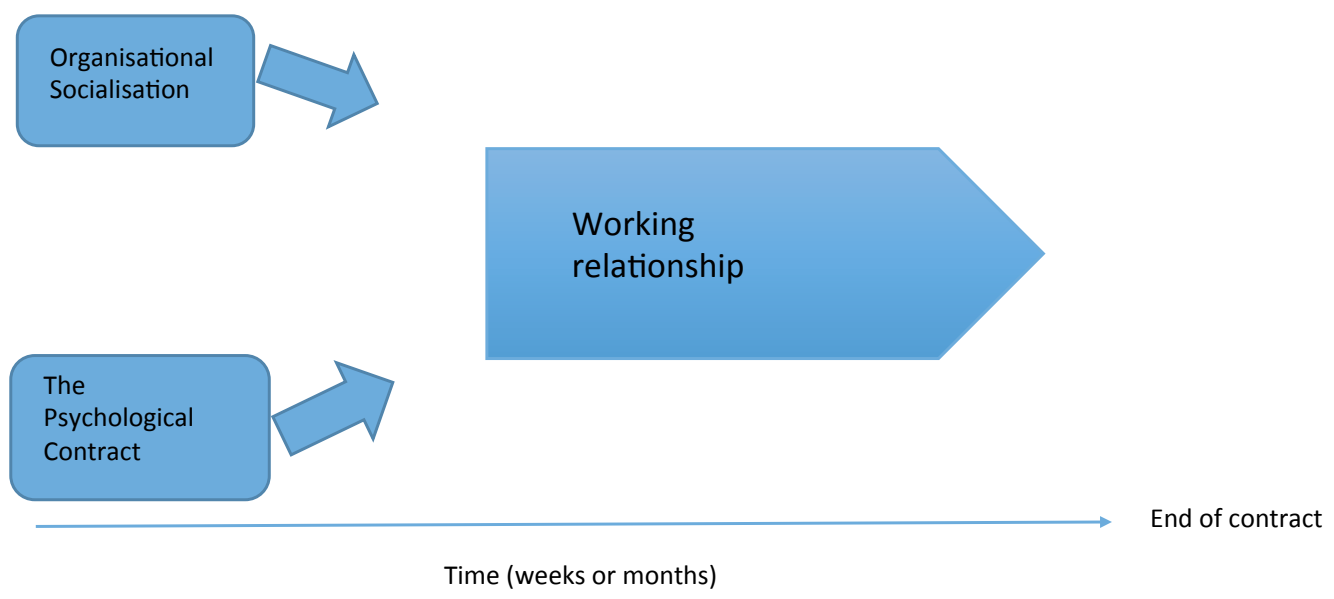

Figure 3. Conceptual Framework. 


\subsection{Part A: Organisational Socialisation Theory}

Socialisation theory began in social science (Goslin, 1969). It sprang from a desire to understand how newcomers are integrated into a group or community. Socialisation is commonly theorised as a process involving main players, several stages, time and key outcomes. Socialisation is about values, norms and behaviour patterns of a particular group or organisation (Schein, 1968). Organisational socialisation is particularly focussed on the orienting norms that are common in the workplace and those norms that are characteristics of certain occupational categories (Moore, 1969). Organisational socialisation is also described as the "process by which an individual acquires the social knowledge and skills necessary to assume an organisational role" (Van Maanen \& Schein, 1979, p. 211). The following extract contains some of the key phrases that are commonly associated with the process:

Socialisation refers to the process of teaching the new recruit how to get along in the organisation, what the key norms and rules of conduct are, and how to behave with respect to others in the organisation - what is often referred to as "learning the ropes." The new recruit must learn where to be at specified times, what to wear, what to call the boss, whom to consult if he or she has a question, how carefully to do a job, and endless other things which insiders have learned over time. (Schein, 1988)

It is the manner by which employees become transformed from organisation outsiders to participating and effective members of an organisation (Feldman, 1981). Organisation socialisation is the "primary process by which people adapt to new jobs and organisational roles" (Chao et al., 1994, p. 730). It is generally agreed that organisational socialisation is fundamentally a learning activity (Bauer \& Greene, 1994; Chao et al., 1994; Ostroff \& Kozlowski, 1993; Saks \& Ashforth, 1997). Key to each of these definitions is the fact that socialisation is a process that happens over time. There are debates as to when socialisation actually starts and the duration of it but there is general agreement that it is a process (Ashford \& Nurmohamed, 2012). These authors recommend creating some boundaries to organisational socialisation in order to distinguish it from the wider learning that occurs in the workplace over time or it becomes meaningless. Therefore, organisational socialisation is often restricted to the learning that takes place between expecting a specific transition to a fixed period following that transition (Ashford \& Nurmohamed, 2012). In the case of permanent employees that is usually one year. For professional contractors, however, that period will be considerably shorter. 
Organisational socialisation is recognised as an important HRM practice that leads to both successful individual and organizational outcomes (Cooper-Thomas \& Anderson, 2006; Field \& Coetzer, 2008). In the literature much attention has been given to the socialisation tactics but not to the specific practices that organisations use (Bauer, 2010). Over the years large organisations have developed and introduced socialisation programmes for the newcomers joining their organisations. These can be highly sophisticated, elaborate and carefully designed to achieve specific targets or outcomes (Bauer \& Erdogan, 2012). Sometimes called orientation, onboarding or induction, such interventions usually comprise a set or combination of orientation programmes, training programmes, socialisation tactics, job characteristics and socialisation agents (Saks \& Gruman, 2012). Onboarding is a modern, chiefly American term, to describe organisational socialisation and is used synonymously (Bauer, 2010; Bauer, Erdogan, Truxillo, \& Tucker, 2007). In this thesis all three terms - orientation, onboarding and induction - are used interchangeably to refer to the early part of the organisational socialisation process, which is a particular interest of this study. Given that organisational socialisation is fundamentally about learning, all orientation, onboarding or induction programmes are intuitive facets of that process.

There are several concepts or models within the organisational socialisation literature that are especially relevant to this study because they specifically involve the interaction between workers. This is not an exhaustive review but highlights the literature that is particularly pertinent to exploring the working relationship between professional contractors and permanent employees. These are organisational socialisation tactics (Jones, 1986; Van Maanen \& Schein, 1979), organisational socialisation content (Chao et al., 1994; Taormina, 1994), indicators of adjustment (Bauer \& Erdogan, 2012), ‘time to productivity' (Bauer, 2010; Tarquinio, 2006), socialisation agents (Feldman, 1994; Van Maanen, 1978) and proactive socialisation (also called newcomer proactivity) (Crant, 2000). At the end of this section, organisational socialisation is explicitly related to professional contractors.

\subsubsection{The Socialisation Process}

It is widely accepted by scholars of organisational socialisation, particularly in light of the amount of information about organisations available today, that socialisation starts even before an individual's first day of work; that is, as soon as an individual considers applying for a job with an organisation in anticipation of securing the role (Bauer, 2010). The organisational socialisation process continues with the recruitment and interview procedures, as it is during this period that the 
individual first encounters the organisation and its representatives (Bauer, 2010). It is postulated that it is around entry to the organisation that the individual is most receptive to organisational socialisation (Jones, 1983). Therefore, organisational socialisation is at its strongest just after new members join the group (Van Maanen \& Schein, 1979). There has been criticism of these three phases because of the implication that socialisation is a linear process and the passive role of the individual (Bauer et al., 2007; Morrison, 1993b). The socialisation process is not necessarily linear but is comprised of several phases, stages or interventions.

\subsubsection{Socialisation Tactics}

Van Maanen and Schein (1979) describe polarised pairs of socialisation tactics that an organisation could utilise. Newcomers may be socialised collectively or individually. An example of the latter is a tailor-made socialisation programme. Formal or informal socialisation techniques can be used including separating newcomers from veteran members and socialising them in separate groups (Van Maanen \& Schein, 1979). For example, communication of rules and procedures may be carried out through workshops, classes and other formal learning settings (Van Maanen \& Schein, 1979). Conversely, informal socialisation does not require the segregation of newcomers. An example of this form of socialisation is on-the-job training (OJT). Socialisation may be sequential or random (Moore, 1969). Random socialisation involves an emergent set of socialisation procedures. Sequential socialisation involves a fixed set of steps leading to the assumption of a role. Van Maanen and Schein (1979) also discuss fixed or variable socialisation tactics. A fixed tactic is the appointment of a successor who begins work before the incumbent leaves the role. The handover period is a period of socialisation and has a finite duration. Variable socialisation, on the other hand, has no particular timeframe. Socialisation may be serial or disjunctive (Van Maanen \& Schein, 1979). A serial tactic is being used when current members are involved in socialising the newcomer to the role. A disjunctive tactic means new employees are required to learn for themselves because senior employees do not actively participate.

These socialisation tactics have been further refined by Jones (1986) with investiture and divestiture, referring to the nature of the social support provided by organisational insiders to the newcomer. Reflecting social or interpersonal aspects of the socialisation process, investiture or divestiture concerns the extent to which newcomers receive positive or negative social support. The first two sets of tactics are grouped as those that pertain to the context in which information is provided to newcomers, while the second two sets of tactics relate to the content of the messages provided during the socialisation process (Jones, 1986). The final two sets are about the social 
interactions with organisational insiders (Jones, 1986). Figure 4 depicts the adjustments Jones (1986) made.

Tactics concerned

mainly with:

\begin{tabular}{|c|c|c|}
\cline { 2 - 3 } CONTEXT & Collective & Individual \\
Formal & Informal \\
\cline { 2 - 3 } CONTENT & Sequential & Random \\
SOCIAL ASPECTS & Variable \\
\cline { 2 - 3 } & Serial & Divestiture \\
& Investiture & Disjunctive \\
\hline
\end{tabular}

Figure 4. Socialisation Tactics (Jones, 1986 based on Van Maanen and Schein, 1979).

In his study of MBA graduates prior to starting a new job and then five months into starting that job Jones (1986) found that institutionalised socialisation tactics were negatively associated with an innovative role orientation. It was also found that individualised socialisation tactics were positively linked to innovative role orientations along with high role conflict and ambiguity. A possible explanation for the latter is that incumbents may attempt to resist the newcomers' attempts to do things differently. It seems that social (rather than context or content) socialisation tactics will have more effect on the transition of newcomers. Socialisation tactics in relation to IT contractors have received special attention from King et al. (2004), who caution about using one-size-fits-all socialisation tactics on this group of workers. Their study, the first to examine the socialisation of IT professionals, discovered that the socialisation tactics which had the significant effects on employees' role adjustment and attachment to the organisation were tactics that recognise employees' values and skills (investiture tactics) and focussed on interpersonal and mentoring aspects (serial tactics) (King et al., 2004).

\subsubsection{The Content of Socialisation}

While much of the organisational socialisation research has been about the process of socialisation, the content of the organisational socialisation messages that newcomers experience has also been an area of interest (Ashford \& Nurmohamed, 2012). Such research has explored what kind information 
or knowledge newcomers should acquire. Some researchers have developed and tested various hypotheses relating to socialisation to advance theories on the topic. For example, Chao et al. (1994) conceptualise six socialisation dimensions of what is to be acquired during the organisational socialisation process. These are performance proficiency, people, politics, language, organisation's goals and values, and history. Each of these dimensions is described in detail in Table 3. The so-called Chao et al. Socialisation Scale is used investigate and relate socialisation to organisation outcomes. Knowledge about an organisation's politics, goals and values, and language have been linked to higher commitment and satisfaction (Chao et al., 1994). The same content dimensions were linked to lower turnover (Chao et al., 1994). This begs the obvious question: Which of these content dimensions is relevant to professional contractors? Better understanding of the relevance of each of these dimensions to professional contractors is essential for better understanding of the organisational socialisation of professional contractors.

Table 3. Socialisation Content Dimensions (Chao et al., 1994).

\begin{tabular}{|l|l|}
\hline Content Dimension & Description \\
\hline Performance proficiency & $\begin{array}{l}\text { Identifying what needs to be learned and mastery of knowledge, } \\
\text { skills and abilities. }\end{array}$ \\
\hline People & $\begin{array}{l}\text { Involves establishing successful and satisfying work relationships } \\
\text { with members of the organisation. }\end{array}$ \\
\hline Politics & $\begin{array}{l}\text { Acquiring information about the organisation's formal and informal } \\
\text { work relationships and power structures. }\end{array}$ \\
\hline Language & $\begin{array}{l}\text { Knowledge of technical terminology as well as jargon, acronyms } \\
\text { and slang that are specific to that organisation. }\end{array}$ \\
\hline Organisation's goals and values & $\begin{array}{l}\text { This is the link to the larger organisation and includes the unwritten } \\
\text { goals and values that are espoused by influential members as well as } \\
\text { an understanding of rules and principles of the organisation. }\end{array}$ \\
\hline History & $\begin{array}{l}\text { Knowledge of the background, traditions, customs, myths and rituals } \\
\text { of an organisation. }\end{array}$ \\
\hline
\end{tabular}

Several other researchers have developed similar scales, such as Taormina (1994, 2004), Haueter, Macan, and Winter (2003) and Klein and Heuser (2008). There are several obvious differences between each of the scales. For example, the Taormina's Organisational Socialisation Index (OSI) considers future prospects, but 'language' and 'history' feature in the Chao et al. Socialisation Scale (Chao et al., 1994; Taormina, 1994). The subtle differences are an indication that there is no one accepted measure of socialisation in the workplace. It is also clear that each of these scales or measures is related to permanent employees of an organisation. It is not yet clear how these content dimensions would relate to a professional contractor. 


\subsubsection{Indicators of Adjustment}

The tactics described earlier have been widely studied in socialisation research and form the basis of subsequent models of socialisation (for example (Ashford \& Nurmohamed, 2012; Jones, 1986)). One such model, Bauer and Erdogan's (2012) model of Socialisation Over Time is a popular conceptualisation of the socialisation process for employees. At this juncture, there is no model for the socialisation of contractors. In lieu of one, this model is used to provide a basis for conceptualising the organisational socialisation process that occurs over a period of time in an organisation. Bauer and Erdogan's (2012) model incorporates the outcomes that have been the focus of much research, particularly the indicators of adjustment. These tactics and practices described above are a part of the organisation's socialisation process, which are intended to produce socialisation outcomes. Certain socialisation outcomes are essential for the effective performance of the newcomer. The two types of outcomes are proximal outcomes and distal outcomes (Bauer \& Erdogan, 2012).

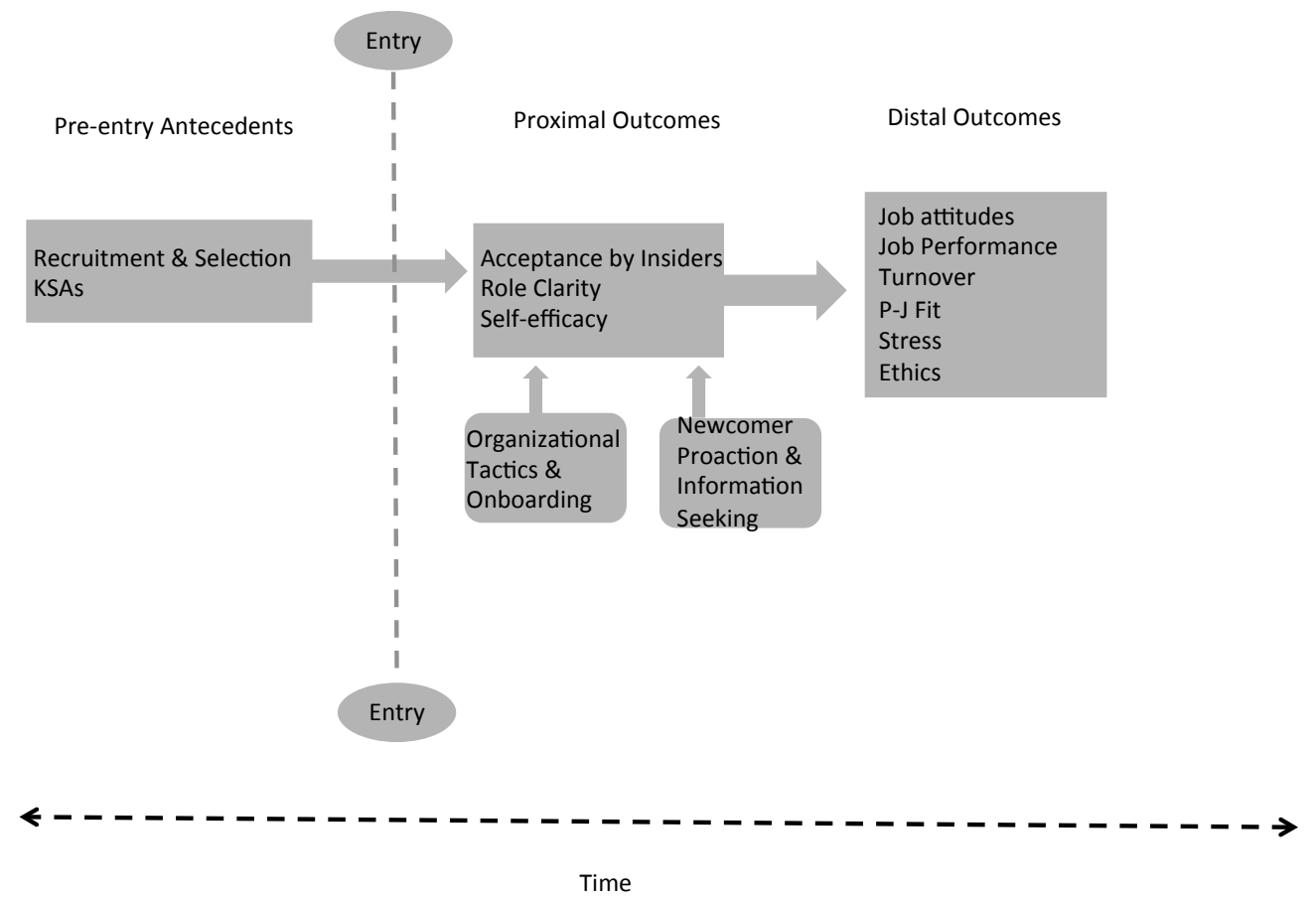

Figure 5. Socialisation Over Time (Bauer and Erdogan, 2012).

Proximal outcomes are the early (within the first few months to a year) indicators of adjustment to the new organisation (Bauer et al., 2007). These include 'acceptance by insiders', 'role clarity', and 'performance self-efficacy' (Bauer \& Erdogan, 2012). These are depicted in the centre of Figure 5, above. Acceptance by insiders is key to adjustment, particularly because without integration into the organisation failure to succeed is far more likely (Bauer \& Erdogan, 2012). The extent to which a 
newcomer is integrated into an organisation can be measured by the Fey (1995) scale, which shows a connection between self-acceptance and the acceptance of others. It is sometimes called social acceptance (Bauer et al., 2007; Bauer, Morrison, \& Callister, 1998; Feldman, 1981). Role clarity is considered highly important as there is evidence that confusion and ambiguity about one's role are costly, stressful and associated with poor performance, low job satisfaction and commitment (Bauer \& Erdogan, 2012, p. 100). It is claimed that there are both individual as well as organisational consequences that result from role conflict and role ambiguity in complex organisations (Rizzo, House, \& Lirtzman, 1970). Finally, performance self-efficacy is essentially about confidence in being able to do the job. The idea is based on Bandura's (1986) work, which "predicts that increased confidence in one's ability to do one's job should relate to positive organisational outcomes such as performance" (Bauer \& Erdogan, 2012, p. 101). In a new situation, an individual's expectations about being able to perform successfully are influenced by their selfefficacy (Jones, 1986). Self-efficacy moderates this learning process, resulting in a strong custodial role orientation when newcomers possess low levels of self-efficacy. The way a newcomer adjusts to task requirements and performs their role is referred to as role orientation (Jones, 1986).

Distal outcomes are those realised in the longer term and relate to the ultimate goal of all tactics of socialisation, which is effective socialisation of employees. Effective socialisation is recognised to improve 'time to productivity', retention rates and customer satisfaction (Bauer, 2010; Tarquinio, 2006). Other outcomes such as job attitudes, job performance, turnover, person-job fit, stress and ethics are considered distal outcomes (Bauer \& Erdogan, 2012). Figure 5, above, depicts these distal outcomes on the far right of the figure.

\section{'Time to Productivity'}

'Time to productivity' is an idea that is relevant to professional contractors whose tenure at an organisation is limited. 'Time to productivity' is linked to 'time to proficiency' studied by Pinder and Schroeder (1987). These authors found that though the data was not "readily generalised from one transfer to another", the "levels of support an individual receives from peers and supervisors at a new setting are also important" (p. 349). Tarquinio (2006) connects 'time to productivity' with both recruitment efforts and the use of technology in the onboarding process, although she warns that it is not a panacea. An example of the latter is a new hire portal (Tarquinio, 2006). The indicators of adjustment are signs that a newcomer is being effectively socialised. Also particularly relevant is the role of the organisational insiders who aid the adjustment of newcomers. They too have an important, though often unnoticed, role to play in the socialisation process. 


\subsubsection{Socialisation Agents}

The literature on organisational socialisation introduces the concept of socialisation agents. Socialisation agents are "the insiders responsible for socialising new hires" (Feldman, 1994, p. 213). These socialisation agents play a pivotal role in the adjustment of newcomers (Bauer et al., 1998). It is apparent in the literature that relationships and interactions with experienced insiders, particularly colleagues, is an important for the learning and assimilation of newcomers (Morrison, 2002). Socialisation agents are really helpful in supplementing formal orientation and/or training by providing information, resources and social support (Saks \& Gruman, 2012). The best sources of information for newcomers were peers, colleagues or co-workers and then supervisors (Louis, Posner, \& Powell, 1983; Saks \& Gruman, 2012; Thomas \& Anderson, 1998). Socialisation agents do not replace orientation programmes but operate in tandem with such practices by filling in any residual gaps (Saks \& Gruman, 2012). However, Saks and Gruman (2012) cite several studies that found that strong relational ties to organisational insiders or socialisation agents were even more important to adjustment and coping than formal training (Feldman \& Brett, 1983; Nelson \& Quick, 1991; Lundberg \& Young, 1997). It is suggested that socialisation rates can be increased through interventions that require interaction between newcomers and insiders such as buddy systems and informal social activities (Reichers, 1987). There are different types of relationships: informational relationships and friendship relationships (Morrison, 2002). Morrison (2002) found that broad, organisation-spanning informational networks were correlated with greater organisational knowledge. Deep and strong informational networks were correlated with better task mastery and greater role clarity (Morrison, 2002).

Being a socialisation agent is often an informal role that veteran employees step into to facilitate the adjustment of a newcomer. Socialisation agent is not a designation or title that will be found in the workplace. In some organisations, however, this role can be formalised and the socialising agent becomes an official buddy or a mentor for a newcomer. A mentor is a senior, more experienced insider who helps a newcomer develop their political, social and technical skill (Ostroff \& Kozlowski, 1993). It was found that newcomers with mentors had a positive correlation with job satisfaction but not with other measures such as commitment or intention to leave (Louis et al., 1983). Since then, particularly in the last 15 years, mentoring has been studied in terms of organisational adjustment (in addition to career advancement). In fact, employees with mentors acquired more knowledge about their new organisations than other newcomers (Bauer, 2010; Ostroff \& Kozlowski, 1993; Saks \& Gruman, 2012). Chao (2007) links mentors to the serial or disjunctive pair of organisational socialisation tactics, as it is this set of tactics is most likely to 
involve mentors. She states that, "peer mentors can act as powerful role models to help newcomers adjust to their new positions" (p. 181). Haueter, Macan, and Winter (2003) found that across three dimensions of socialisation (organisation, group and task) having a mentor within the organisation resulted in significantly higher levels of socialisation than not having a mentor. On the other hand, the socialisation agent could be a buddy. A buddy is an existing member of the team to whom the newcomer can informally comfortably ask trivial, sensitive or difficult questions (Rollag, Parise, \& Cross, 2005). Rollag et al. (2005) observe that the presence of a 'buddy' is a key factor in "rapid onboarding" (p. 35). These researchers developed their notion of rapid onboarding from newcomers capable of building information relationships with co-workers more quickly than others who joined at the same time (Rollag et al., 2005). Similarly, the idea of 'swift socialisation' has been advocated by Ashforth (2012) and Bauer et al. (1998). Neither of these ideas have been related to professional contractors as yet.

Socialisation is a two-way process but little is done to examine the socialisation agent side of the relationship (Feldman, 1994). The role of socialisation agent has positive and negative aspects to it. Feldman (1994) proposes that “... by mentoring and coaching younger new hires, older insiders can gain a feeling that they have knowledge and expertise worth passing on to others" (p. 216). Feldman (1994) also lists other positive effects, including being motivated or energised by the newcomer. Similarly, the veteran may learn more about his or her current organisation, other organisations, the market and the industry from the newcomer through the socialisation process (Feldman, 1994). The extra time and energy it takes to show a newcomer 'the ropes' may take a toll on the insider in terms of work overload and stress (Feldman, 1994). There is a general call for more investigation of those doing the socialisation: the colleagues or co-workers and managers or supervisors of the newcomers (Ashford \& Nurmohamed, 2012). Their claim is that much of the socialisation that takes place in organisations is very local so more must be learnt about how those insiders facilitate the socialisation of newcomers (Ashford \& Nurmohamed, 2012). Further development of the organisational socialisation field has arisen from the application of theories from outside the field. One such example is proactive socialisation (Saks \& Ashforth, 1996).

\subsubsection{Proactive Socialisation}

In the past, organisational socialisation was discussed in terms of something that happened to a newcomer. There was an assumption that newcomers were naïve and responsive to the organisation (Jones, 1983). It was about what organisations could do to foster the outcomes they required of 
newcomers. However, the responsibility for the socialisation of a newcomer does not rest entirely with the organisation or its representatives. It is now widely acknowledged that the newcomer also plays an active role in his or her own organisational socialisation (Bauer \& Erdogan, 2012; Crant, 2000; Feldman, 1994; Wanberg \& Kammeyer-Mueller, 2000). Proactive socialisation borrows from the literature on proactive behaviour and a proactive personality (Crant, 2000). It is also referred to as newcomer proactive behaviour (Cooper-Thomas \& Burke, 2012), proactivity in the socialisation process (Wanberg \& Kammeyer-Mueller, 2000) and newcomer proaction (Bauer \& Erdogan, 2012). By bridging the socialisation and feedback-seeking literatures, new insights have been gained about newcomers' proactive efforts to collect relevant information (Crant, 2000). A key to proactive socialisation is the fact that socialisation is not passive but can be initiated by that newcomer.

The most critical time for learning about a role is at organisational entry (Miller \& Jablin, 1991). It is theorised that when both newcomers and insiders are highly proactive the highest rate of socialisation will occur (Crant, 2000; Reichers, 1987). Therefore, when managers, employees and newcomers are proactive, organisational socialisation will occur at a quicker pace. Given that socialisation is fundamentally about getting new employees up to speed as quickly as possible proactive socialisation is highly relevant (Cooper-Thomas \& Burke, 2012). This claim has potential implications for reducing a contractor's 'time to productivity', so is particularly useful. The idea of proactive socialisation is based on proactive behaviours (Crant, 2000).

\section{Proactive Behaviour}

Organisational socialisation has been linked to certain proactive behaviours, about which the idea of proactive socialisation is formed. Morrison's studies (1993a, 1993b) suggest that proactive behaviours by newcomers have valuable outcomes from an organisational perspective. The socialisation tactics an organisation chooses to utilise may also have an impact on the newcomer in that role. Rather than collective and formal tactics, it has been found that individualised, informal socialisation tactics lead to proactive and innovative role orientations (Crant, 2000, p. 445; Jones, 1986). It is intuitive that proactive socialisation is related to more general proactive behaviour and personal initiative. Proactive behaviours include information-seeking, building social networks and negotiating job changes (Crant, 2000, p. 447). For professional contractors, information seeking and building social networks are likely to be particularly relevant but negotiating job changes is less so because of the short-term nature of contracting. Proactive behaviour is considered an "extra-role 
behaviour" for permanent employees (Crant, 2000, p. 451). According to Saks, Gruman, and Cooper-Thomas (2011), by engaging in proactive behaviours newcomers learn about their abilities, better understand the work environment and tasks and also adjust their behaviour to improve their socialisation as well as career success (Morrison, 1993a, 1993b; Ostroff \& Kozlowski, 1993; Saks et al., 2011; Wanberg \& Kammeyer-Mueller, 2000).

The literature contains an interesting warning, however. Crant (2000) quotes, "Bateman and Crant (1999) who cautioned that too much, or misguided, proactive behaviour can be dysfunctional and counterproductive. A bias for initiative, action, and change cannot come at the expense of necessary core activities" (p. 455). The warning here is that there is a limit to just how proactive an employee should be. Constant questioning of the status quo is not always viewed positively by others (Crant, 2000). Cooper-Thomas and Burke (2012) also consider whether or not there is a risk in newcomer proactive behaviour for organisations and individuals. They ask if too much newcomer proactive behaviour is actually maladaptive (Cooper-Thomas \& Burke, 2012). In their comprehensive review of the literature related to newcomer proactive behaviour, these authors present findings related to newcomer proactive behaviours studied by several scholars and researchers. Bolino, Valcea and Harvey (2010) found that there were several risks to newcomer proactive behaviours (CooperThomas \& Burke, 2012). For example, newcomer proactive behaviour may cause more work for colleagues or disruption of accepted productivity levels (Cooper-Thomas \& Burke, 2012). Organisations may rely on the newcomers to be proactive about their organisational socialisation, thereby forgoing an opportunity to invest in the learning and development of those employees. This would potentially inhibit some of the longer-term outcomes of organisational socialisation such as job satisfaction or reduced turnover (Cooper-Thomas \& Burke, 2012). There are some dissenting arguments about some of the information presented above. There are claims that proactive socialisation is about a personal disposition or personality but other authors maintain that proactivity is a response to certain situational cues (Morrison \& Phelps, 1999).

\subsubsection{Phases in Organisational Socialisation Research}

Close examination of the literature relating to organisational socialisation reveals three general phases in the research (Ashford \& Nurmohamed, 2012). The first was all about the socialisation tactics the organisation could initiate (the institution's role). The next phase recognised that a newcomer is not passive in the organisational socialisation process but has an active role to play in their own socialisation (the individual's role). A third phase in the study of socialisation is about 
bringing together organisational tactics and proactive socialisation. This phase is a fusion of the two roles acknowledging the role of organisational socialisation is both the responsibility of the organisation as well as that of the newcomer (Ashford \& Nurmohamed, 2012). It is at this juncture that the research into organisational socialisation has arrived. It is apparent, however, that while organisational socialisation tactics and proactive socialisation of employees have been discussed, studied and developed extensively, there is scope for more research on how institutionalised and individualised forms of organisational socialisation can work together. For example, CooperThomas and Burke (2012) discuss evidence that some proactive socialisation can replace the more institutionalised socialisation process that organisations can develop. There is also evidence from Griffin, Colella and Goparaju (2000) that organisational socialisation tactics moderate the relationship between proactive socialisation or newcomer proactive behaviours and socialisation outcomes, either increasing or limiting the effect of that proactive behaviour (Cooper-Thomas \& Burke, 2012; Griffin, Colella, \& Goparaju, 2000).

\subsubsection{Relating Organisation Socialisation and Professional Contractors}

\section{Examples of Research}

There is little doubt that organisational socialisation is important to all newcomers but the literature on organisational socialisation is focussed on permanent employees. Most studies investigate the socialisation of employees or "salaried workers" (Bauer, 2010, p. 15). Few studies have touched on the organisational socialisation of non-standard workers, in general, or professional contractors, more specifically. One of the very few examples of research on the organisational socialisation of non-standard workers is Krauss (2010), who conducted a qualitative study investigating the onboarding of the hourly workforce (Bauer, 2010). In Krauss' study it was found the hourly workers claimed to be productive or fully functional in three and a half weeks but their supervisors' opinions differed: three months. While this study is not about contractors specifically, such a difference highlights the need for further investigation into the socialisation of non-standard workers, as further understanding this sector of the workforce can only benefit the parties involved. Recently, another study has been discovered that claims to be the only study about the socialisation of contingent workers (Benzinger, 2016). Benzinger (2016) asserts that the socialisation of contingent workers has been overlooked but could be create a win-win for both firms and contingent workers. This study found that institutionalised tactics promote information-seeking behaviours among contingent workers. 


\section{The Significant Difference}

Today professional contractors often fill roles or positions that could be or have been held by permanent employees (Redpath et al., 2009). However, there are several key differences between permanent employees and professional contractors. These differences are short-term tenure and desired socialisation outcomes.

Short-term tenure. Professional contractors are transient so are generally engaged for a short time at a client organisation. This time generally varies widely but initial contracts are often between three to six months and are generally less than a year. Admittedly, these contracts are can be rolled over, extended or reviewed. Adjustment indicators or proximal outcomes are realised in a very similar timeframe so these remain relevant to contractors as well. In fact, due to a contractor's limited tenure at an organisation, proactive socialisation, in particular, holds more relevance and importance.

Proactive socialisation continues to be important for all newcomers, particularly in light of the changing nature of work and employment. Proactive socialisation is highly relevant but does not absolve organisations from their responsibilities to ensure they do their best to help all newcomers get up to speed as quickly as possible. Orientation, onboarding and induction programmes still have a place. As Ashford and Nurmohamed (2012) state, the phases of socialisation research have reached a juncture where it is neither about what the institution can do nor is it about what the individual can do, but both. It is the form that these take that will be relevant to professional contractors who are only around for a short time and will have different socialisation outcomes to a permanent employee.

Socialisation Outcomes. Getting new employees up to speed as quickly as possible is the concern of socialisation (Cooper-Thomas \& Burke, 2012). For permanent employees, effective socialisation is attributed to outcomes such as reducing turnover and increasing engagement, loyalty and commitment in addition to job performance (Bauer, 2010). However, client organisations neither expect nor require those same outcomes when it comes to professional contractors. With the exception of job performance, the traditional outcomes of socialisation such as reduced turnover, loyalty and commitment (Bauer \& Erdogan, 2012) are not relevant for professional contractors because of their short-term tenure. It is possible that proactive behaviour of professional contractors may be particularly important to their socialisation because it has to be quick. 
The previous work experience of a newcomer is likely to influence how that individual reacts to the new organisational context including existing organisational members' expectations of them (Jones, 1983). Feldman (1989) notes that much of the research on socialisation has implicitly treated newcomers as tabula rasa, ${ }^{3}$ when in fact newcomers often bring very distinctive, and sometimes very powerful, sets of expectations with them from previous jobs (Feldman, 1994). Both these authors reject the idea that newcomers are blank slates in favour of acknowledging that they are the sum of their knowledge, skills and abilities as well as their experience. This is particularly relevant to professional contractors who are often specifically hired because of their technical skills, broad experience and knowledge.

\subsection{Part B: The Psychological Contract}

The working relationship between professional contractors and permanent employees is further explored using the psychological contract as a lens. The psychological contract has become a "popular platform for understanding how workers make sense of their relationship with the firm" (Peel \& Boxall, 2005, p. 1678). In this section the psychological contract is defined, the evolution and formation of the concept is described. Several main features of the psychological contract are described before its violation or breach is discussed. This section concludes by explicitly relating the psychological contract to professional contractors through several relevant studies that have been conducted to date.

Social exchange theory is central to our understanding of the employee-organisation relationship (EOR) in general (Connelly \& Gallagher, 2012). These authors point out that the EOR is the basis of so many of the fundamental theories that explain worker behaviour such as the psychological contract, organisational commitment, perceived organisational support and leader-member exchange. Fundamentally, psychological contract theory is based upon social exchange theory (De Vos, Buyens, \& Schalk, 2003). The notion of exchange is at the heart of a traditional employment relationship (Druker \& Standworth, 2004). Shore and Tetrick (1994) write that the psychological contract is based on an interactive process whereby the employee looks to the organisation to fulfill their obligations in terms of the contract and takes steps to fulfill their part of the contract. As Osnowitz (2010) puts it, "The psychological contract of the mid-twentieth century exchanged job security for demonstrated commitment" (p.51). However, the relationship between a professional contractor and the client-organisation is not an EOR so it is different.

\footnotetext{
${ }^{3}$ Latin: The mind in its hypothetical primary blank or empty state before receiving outside impressions (Merriam-Webster).
} 


\subsubsection{Defining the Psychological Contract}

The psychological contract is not a legal contract nor is it a written contract but a set of expectations often not even articulated (Rousseau, 1989). Although the psychological contract is often credited to Denise Rousseau, it was actually originally proposed by Argyris (1960), who referred to it as psychological work contract. Farnsworth (1982) touches on the psychological contract by referring to it as a link between an employing organisation and the individual workers through mutual expectations. Since Rousseau (1989) published this seminal work, the concept has been considerably extended and developed from the implied and psychological contracts discussed then (Rousseau, 1989, 1995, 2001; Rousseau \& Schalk, 2000). Rousseau (1995) writes, "The psychological contract is the individual beliefs, shaped by the organization, regarding terms of an exchange agreement between individuals and their organization"

There are numerous subtly different definitions of the psychological contracts presented (Guest, 1998). Guest (1998) quotes definitions from Kotter (1973), Schein (1978), Herriot and Pemberton (1995) and Rousseau (1989) to illustrate these differences. For example, Kotter's (1973) definition emphasises the implicit nature of the psychological contract. Schein's (1978) definition is about reciprocal expectations. Herriot and Pemberton (1995) refer to perceptions and implied obligations, while Rousseau (1989) mentions individuals' beliefs and promises, which create future obligations. Roehling (2008) acknowledges that there are three parallel definitions: 1) expectations, 2) obligations, and 3) promises perceived by the employee (Svensson \& Wolven, 2009, p. 186). Fundamentally, the notion of the psychological contract is an unscientific way of describing the implicit in relationship between an employee and the organisation that employs them (Millward \& Brewerton, 1999). For purposes of this study, Schein's definition of the psychological contract will be used. Schein (1988) describes it as an unwritten set of expectations operating at all times between every member of an organisation and the various managers and others in that organisation. It involves consideration of promises made and expectations of the parties to the employment relationship (Druker \& Standworth, 2004). This definition also considers managers as proxies for the organisation, which is practical given an organisation does not make promises but people do.

Guest (1998) is somewhat critical of the concept because it is "hypothetical" and drawn (perhaps) “inappropriately from a legal metaphor" (p. 650). Several other authors such as Arnold (1996), Cullinane and Dundon (2006) and Anderson and Schalk (2006) have questioned the unclear nature 
of the psychological contract (Svensson \& Wolven, 2009). Nevertheless, Guest (1998) does concede that the psychological contract has some value because it "...provides a potentially fruitful construct with which to make sense of and explore this new employment relationship" (p. 659). It is apparent that the parallel definitions of the psychological contract exist because there is an incomplete understanding of the concept. Each of the differing definitions has merits and limits because they each focus on certain aspects that comprise the psychological contract. There has been extensive research into the psychological contract, which has helped the concept evolve.

\subsubsection{Conceptualising the Psychological Contract}

The conceptualisation of the psychological contract has evolved to be regarded as more complex than it was initially suggested. The psychological contract may be about beliefs, expectations, obligations, perceptions and/or promises (Guest, 1998). Each of these words has slightly different interpretations as well as implications. For example, Conway (1996) suggests that obligations that are unfulfilled are worse that unmet expectations (Guest, 1998). Understanding the psychological contract helps to better understand the mutual expectations of each of the parties involved in the working relationship because it "has significant implications on employee attitudes and behaviour" (Peel \& Boxall, 2005, p. 1678). It seems that there is so much interchangeable use of the words 'obligations' and 'expectations' that in time the two have become synonymous in the context of psychological contracts (Thomas \& Anderson, 1998).

\subsubsection{Formation of the Psychological Contract}

It is acknowledged by many researchers that the formation of the psychological contract is not yet clearly understood because our understanding of it continues to change (Guest, 1998; Rousseau, 2001; Svensson \& Wolven, 2009). Louis (1980) suggests that the psychological contract is formed as a result of sense-making, which is an idea that is further pursued by other researchers (De Vos et al., 2003; De Vos \& Freese, 2011; Morrison, 1993a, 1993b). When a newcomer joins an organisation the psychological contract is described as pretty rudimentary (De Vos \& Freese, 2011; Rousseau, 1989; Shore \& Tetrick, 1994; Thomas \& Anderson, 1998). De Vos and Freese (2011) suggest, "psychological contracts develop through an interactive process that begins during recruitment" (p. 291). There are claims that the formation of the psychological contract is strongly influenced by an individual's first impression of an organisation (Rousseau, 1995; Svensson \& Wolven, 2009; Thomas \& Anderson, 1998). It is during that formative time of entering a new 
organisation that the psychological contract develops substantially. Fisher (1990) and Miller and Jablin (1991) found that the newcomer's co-workers provided important information during the socialisation process (Shore \& Tetrick, 1994).

The psychological contract is dynamic so influenced by both internal and external factors (Rousseau, 1995). External factors include the messages sent by the organisation or social cues that are provided by those who are currently working in the organisation (Rousseau, 1995). Internal factors refer to the individual's inner interpretations, predispositions and constructions (Rousseau, 1995). Shore and Tetrick (1994) refer to the formal employment contract as providing a foundation for the psychological contract and vice versa. In other words, the formal employment contract informs the psychological contract. In their study Thomas and Anderson (1998) found some support for the hypothesis that as newcomers were integrated, certain dimensions of their psychological contract changed or converged toward that of insiders, in this case experienced British Army soldiers. Therefore, it is no surprise that interaction with colleagues or permanent employees, supervisors or managers, and other organisational representatives will influence the formation and development of the psychological contract (De Vos \& Freese, 2011).

\subsubsection{Main Features of the Psychological Contract}

The psychological contract is commonly talked of in terms of transactional and relational contracts (Macneil, 1985; Rousseau, 1989, 1995). Short-term economic exchanges are usually transactional contracts and are typical of those in temporary positions (Rousseau, 1995). A relational contract is one that resembles a social relationship - like a marriage or a partnership - in terms of being long term, open ended and characterised by a degree of mutual trust and commitment (Rousseau, 1995). Having a shared or similar psychological contract leads to similar resulting behaviour or norms. An example of this is the use of sick leave as an entitlement rather than only when necessary (Rousseau, 1995). These two features of contemporary contracts act as the two ends of a "contractual continuum" (Rousseau, 1995, p. 91). Figure 6 is taken from Rousseau (1995) and shows a matrix in terms of duration and performance terms. There, 'duration' refers to the employment duration: either short or long term. 'Performance terms' refers to how specific performance requirements are. From this matrix four types of psychological contracts emerge: transactional, transitional, balanced or relational. 
DURATION

\begin{tabular}{|c|c|c|}
\hline & мресулеи & \\
\hline Short-term & $\begin{array}{l}\text { Transactional } \\
\text { (e.g. shop assistant hired during } \\
\text { Christmas season) } \\
\text { - Low ambiguity } \\
\text { - Easy exit/high turnover } \\
\text { - Low member commitment } \\
\text { - } \quad \text { Freedom to enter new } \\
\text { - contracts } \\
\text { - Little learning } \\
\quad \text { integration/identification }\end{array}$ & $\begin{array}{l}\text { Transitional } \\
\text { (e.g. employee experiences during } \\
\text { organizational retrenchment or } \\
\text { following merger or acquisition) } \\
\text { - Ambiguity/uncertainty } \\
\text { - High turnover/termination } \\
\text { - Instability }\end{array}$ \\
\hline Long-term & $\begin{array}{l}\text { Balanced } \\
\text { (e.g. high-involvement team) } \\
\text { - High member commitment } \\
\text { - High } \\
\text { - } \quad \text { Ontegration/identification } \\
\text { - Mutual support } \\
\text { - Dynamic }\end{array}$ & $\begin{array}{l}\text { Relational } \\
\text { (e.g. family business members) } \\
\text { - High member commitment } \\
\text { - High affective commitment } \\
\text { - High } \\
\quad \text { integration/identification } \\
\text { - Stability }\end{array}$ \\
\hline
\end{tabular}

Figure 6. Types of Psychological Contract (Rousseau, 1995).

Based on the information provided above, the psychological contract of a professional contractor is likely to sit in the transactional quadrant because a contractor is short-term and the performance terms are specified. However, it has been found that contractors do experience high levels of commitment to their work (Millward \& Brewerton, 1999). It is possible that because performance terms are not merely specified but high, contractors fall into a different type of psychological contract or possibly more than one type. A possible explanation is that a contractor's psychological contract only becomes relational when the transactional aspects have been fulfilled (Herriot, Manning, \& Kidd, 1997; Millward \& Brewerton, 1999; Svensson \& Wolven, 2009). In other words, for a contractor the psychological contract shifts or moves over the time of their contract.

Behavioural norms are also fundamentally associated with the psychological contract. As mentioned earlier, similar psychological contracts can lead to having similar behaviours or norms (Rousseau, 1995). Osnowitz (2010), who conducted a lengthy, in-depth study of professional contracting, raises the concept of the psychological contract in relation to the contractors she studied. Osnowitz (2010) writes, "Although rarely a formal agreement, a psychological contract implies an exchange between employer and employee that binds both parties to reciprocal norms ( $p$. $51)$. 
An organisation does not form or develop the psychological contract but the individuals who represent it do. These individuals are referred to as human contract makers (Rousseau, 1995). Each human contract maker plays a unique role in influencing the psychological contract of the newcomer (Rousseau, 1995). For example, it is suggested that interaction between supervisor and employee is key to building a relationship (De Vos \& Freese, 2011). However, representatives of the same organisations do not always have the same perspectives or opinions so they will influence the psychological contract quite differently (Herriot \& Pemberton, 1996). These human contract makers are viewed as agents of the organisation (De Vos \& Freese, 2011).

\subsubsection{A Violation or Breach of the Psychological Contract}

The idea of a breach or violation of the psychological contract is a feature of the literature on the psychological contract. It is an inherently subjective phenomenon (Robinson \& Morrison, 2000). What constitutes a breach of the psychological contract? A breach or violation is likely to be the breaking of a promise but it could also be unmet expectations or unfulfilled obligations; however, there is little clarity on this. An example of a perceived breach or violation of the psychological contract between employer and employee is redundancy, downsizing or restructuring. Interestingly, employees were found to be more likely to perceive that their psychological contract had been breached when they had not experienced a formal socialisation process (Robinson \& Morrison, 2000). A breach or violation is not only perceived by those who experience it but also by those who remain with the organisation (Herriot \& Pemberton, 1996). Breach and violation are slightly different notions. The violation of obligations will severely damage the psychological contract by undermining the essential element of trust in contrast to the violation of expectations, which leads to less emotional disappointment (Rousseau, 1989, 1990; Thomas \& Anderson, 1998). Simply put, a breach in the psychological contract is "an awareness that some element of the psychological contract has not been fulfilled" (O'Leary-Kelly, Henderson, Anand, \& Ashforth, 2014).

The idea of violations of the psychological contract has emerged in various studies (David, 2008; Robinson, 1996; Robinson \& Morrison, 2000). For example, it was suggested that the psychological contracts of permanent employees could be in danger of being violated by the use of independent contractors but this was not borne out by David (2008)'s research. Even in the literature relating to professional contractors specifically, a breach of the psychological contract and the more serious violation of the psychological contract is discussed (McKeown \& Cochrane, 2017; Osnowitz, 2010). A violation of the psychological contract is usually associated with employers 
reneging on the expectations of employees (Osnowitz, 2010). The consequences of a breach or violation are wide and varied. Increased turnover but decreased job satisfaction and commitment may result from a perceived breach or violation of the psychological contract (McKeown \& Cochrane, 2017). However, McKeown and Cochrane (2017) postulate that a self-confident professional contractor or IPro is likely to address a potential breach or violation prior to it actually affecting their work attitudes.

This review of the literature highlights the view that the psychological contract must be viewed as a set of expectations that is dynamic or shifting, particularly during the weeks or months following entry into an organisation (De Vos et al., 2003; Thomas \& Anderson, 1998). A malleable psychological contract will bend before it breaks but a stable one is more likely to break before bending. Following this logic, a stable psychological contract is more likely to be perceived to be violated or breached than a malleable psychological contract, which is likely to adapt to changes in the relationship. Redpath et al. (2009) suggests that, "Since psychological contracts are subjective individual perceptions, each employee's beliefs are unique, as are each manager's beliefs. In an ideal situation these two sets of beliefs are congruent, but given their idiosyncratic nature, this scenario is difficult to obtain" (p. 75).

\subsubsection{Relating the Psychological Contract to Professional Contractors}

Like many such concepts, the psychological contract is predicated on the traditional view of an employee but the workplace now is characterised by different types of workers such as professional contractors and temporary staff. The goal of the contracting relationship is to produce specific results in a defined time frame often by using specialised expertise rather than to foster a long-term employment relationship. What is known about the psychological contract of non-standard workers is highly relevant to this research. There are several studies connecting the psychological contract to non-standard workers such as temps (Druker \& Standworth, 2004; Morf et al., 2014; Svensson \& Wolven, 2009) or professional contractors (Millward \& Brewerton, 1999) or contingent workers (McLean Parks, Kidder, \& Gallagher, 1998). Connelly and Gallagher (2012) include a section on independent contractors and the employee-organisation relationship underscoring the need to consider professional contractors as part of a blended workforce in the 21st century. It is acknowledged that the psychological contract may vary with different types of employment relationship (Rousseau, 1995). A study on the multiple psychological constituencies of management and co-workers claimed a need to draw further attention to the "role of the co-workers in the 
integration of agency staff in client companies" (Morf et al., 2014, p. 184). Druker and Stanworth (2004) and McDonald and Makin (2000) confirm that non-standard workers will have psychological contracts with their client organisations, although, as McLean Parks et al. (1998) point out, these psychological contracts will almost certainly be different to those employees have with the same organisation (David, 2008, p. 65). Connelly and Gallagher (2012) suggest that it is possible that the psychological contract an independent contractor has with his or her supervisor or manager may broaden in time as the contractor seeks to retain that client.

There has been recent research into the psychological contract of temps (Druker \& Standworth, 2004; Morf et al., 2014; Svensson \& Wolven, 2009). These researchers examined the psychological contracts of temps in relation to their staffing or recruitment agency (agency) and client companies. (Druker \& Standworth, 2004) examined the "mutual expectations of employment agencies, the temporary workers who are placed by them and the client or host companies" (p. 58). They found that the temps in the study were positive about their agencies but critical of their client organisations (Druker \& Standworth, 2004). Even more significantly, a mismatch in expectations was identified between the client organisation and the temp (Druker \& Standworth, 2004). Client organisations were often poorly organised and insufficiently prepared for the temp. Druker and Standworth (2004) point out that this kind of finding is not apparent in the quantitative studies in the US. Svensson and Wolven (2009) showed that temporary workers simultaneously maintain a psychological contract with their manager as well as with co-workers or colleagues at the client organisation. Furthermore, they suggest that organisational culture may be a mediating variable in the formation of the psychological contract because it was found that the psychological contracts the temps held with managers and colleagues were virtually identical (Svensson \& Wolven, 2009). "The results indicate a need to draw further attention to the role of the co-workers in the integration of agency staff in client companies" (Svensson \& Wolven, 2009, p. 184). Morf et al. (2014) explored the double psychological contract temporary workers have with the client and an agency finding that, "in such exchange relationships with three parties, the individual's evaluation of the relationship with one interaction partner is not independent from the evaluation of the relationship with the other partner" (p. 710). In other words, fulfilment of the psychological contract with the client organisation has a positive influence on the temps' commitment to the agency.

In recent years research into the psychological contract of contracted workers has established the importance of the team (Millward \& Brewerton, 1999; Redpath et al., 2009). This is in line with 
reports of normative pressure for contractors to be good team members, resulting in them engaging in extra-role behaviours (Pearce, 1993). Millward and Brewerton (1999) discovered that, "a sense of being part of a team in a local sense may be more important for the contractor (whether permanently or temporarily employed by their agency) than the direct employee purely because it is within the team that their job derives meaning and location within the corporate whole" (p. 264). The significance of the importance of the team is that it is actually a characteristic of a relational psychological contract rather than a transactional one. Redpath et al. (2009) found that team-based and results-oriented organisations or work units were better suited to contingent staff.

Generally, the concern about contract work is that it would create a self-absorbed worker who is either not engaged or, worse still, disengaged in the work and the organisation. The psychological contract of a contractor was found to be more transactional in several ways but this does not preclude or prevent the development of a more relational contract over time (Herriot et al., 1997). The organisation and contractor form a "strategic partnership" (Millward \& Brewerton, 1999, p. 253). In Millward and Brewerton's (1999) study it was also found that contractors were not condemned to be emotionally detached but were found to invest as much in their work as permanent employees do. More specifically the authors found that contractors "... were highly committed to, and involved in, their work although there was some reluctance to work beyond the specifications of the contract" (Millward \& Brewerton, 1999, p. 258). There are suggestions that, similar to Maslow's Hierarchy of Needs, transactional considerations may be met first before the psychological contract can become relational (Herriot et al., 1997; Millward \& Brewerton, 1999; Svensson \& Wolven, 2009). In contrast, (O'Leary-Kelly et al., 2014) found that the psychological contracts of their sample actually became more transactional over time (to the point where the workers expected nothing but their pay). This study involved a set of IT H-1B Visa holders in the US, so the sample was not only unique but also non-traditional (O'Leary-Kelly et al., 2014). Given that O'Leary-Kelly et al. (2014) sample is significantly different to those in this thesis, the connections are not obvious but their findings do highlight the contradictory nature of some of theses studies.

\subsection{Organisation Socialisation and the Psychological Contract}

\subsubsection{A Connection}

This review of the literature shows that there is a distinct connection between organisational socialisation and the psychological contract but the exact relationship between the two is subject to 
continued debate. De Vos et al. (2003) claim that the psychological contract is often treated as an outcome of the socialisation process. Woodrow and Guest (2017) also query whether it is an outcome of the socialisation process or an intervening variable. Ultimately, they claim the "knowledge required during socialisation drives the psychological contract" (Woodrow \& Guest, 2017, p. 593). In fact, a crucial phase in the development of a mutually beneficial psychological contract is considered to be the socialisation period (De Vos \& Freese, 2011; Rousseau, 2001). Therefore, it can be claimed that the organisational socialisation process informs the development of the psychological contract of a newcomer.

\subsubsection{Evidence from the Literature}

Several studies have explicitly associated the psychological contract with the organisational socialisation process. Robinson, Kraatz, and Rousseau (1994) were among the first to do so, finding that newcomers expected more from their employers over time (a two-year period) but perceived they owed less to that employer. In a study of British Army recruits and how their psychological contracts changed during the socialisation process, it was found that the psychological contracts are dynamic, which means they change over time caused by both internal and external influences (Thomas \& Anderson, 1998). There was support for the assertion that “...newcomers' psychological contracts are likely to change towards those experienced insiders as they become accepted as an integral part of the company" (Thomas \& Anderson, 1998, p. 751). During the socialisation process, psychological contracts are formed as way of making sense of the new experiences the individuals involved experience (Thomas \& Anderson, 1998). The results of their study emphasise the importance of conceptualising the psychological contract as a "dynamic set of expectations" influenced by the experience of newcomers and the reality they encounter, particularly during the socialisation period (De Vos et al., 2003). The connection between organisational socialisation and the psychological contract is neatly encapsulated by the following:

Three types of knowledge are necessary for effective integration, concerning the role, team, and organization (Ashforth, Sluss, \& Harrison, 2007). Acquiring this knowledge enables newcomers to better understand the behaviours that are expected and inducements that are offered by the organization. This understanding takes the form of a cognitive schema, or psychological contract (Rousseau, 2001). (Woodrow \& Guest, 2017, p. 588)

The literature reviewed shows that the early stages of organisational socialisation (induction) coincide with the formation and development of the psychological contract (De Vos et al., 2003; 
Robinson et al., 1994; Thomas \& Anderson, 1998). The main difference between permanent employees and professional contractors are time frame and desired socialisation outcomes. For professional contractors who have a short-term tenure at a client organisation both their organisational socialisation and the development of the psychological contract must occur quickly because a contractor's 'time to productivity' is vitally important.

At times organisational socialisation is implicitly referred to in the context of the psychological contract. For example, Redpath et al. (2009) acknowledge that, "[o]ther managers realised that to be productive, contingent staff needed to establish relationships and become acclimatized to the nuances of an organisation's culture and work performance expectations" (p. 81). As Ashforth et al. (2007) point out, supervisors and co-workers are the ones who bring organisational values to life through their actions. Several authors acknowledge the need to study the socialisers (or socialisation agents) rather than just the socialised (Ashford \& Nurmohamed, 2012; Feldman, 1994). In particular, there is a call for further investigation of leaders, co-workers or colleagues and teams (Svensson \& Wolven, 2009, pp. 16-17). Therefore, it is acknowledged that the intersection between organisational socialisation and the psychological contracts is the role of socialisation agents and human contract makers, respectively. If permanent employees are assuming the key roles of socialisation agents and/or human contract makers as the literature reviewed has suggested, then their role in both organisational socialisation and informing the psychological contract of newcomers must be further understood. These individuals play an essential role in both the socialisation of newcomers and in informing the development of the psychological contract as human contract makers (De Vos \& Freese, 2011). According to the literature socialisation agents are organisational insiders who help a newcomer adjust (Feldman, 1981, 1994). Human contract makers are those who influence and shape the psychological contract (Rousseau, 1995). It seems that important human contract makers are the supervisors who are held responsible for certain organisational promises or inducements (Rousseau, 2001). Though not always officially designated, colleagues or co-workers are often the most important information source for a newcomer during the first year of employment and become increasingly important over that time (De Vos \& Freese, 2011). Given the pivotal role these individuals have, it would be valuable to further consider the perspective of those who have such an influence on professional contractors at the client organisation. 


\subsection{Chapter Summary}

This chapter is about the two key concepts that make up the conceptual framework for this research. The use of these concepts as key constructs is clearly justified because they both have relevance to professional contractors and develop during a similar timeframe and are clearly connected even though the nature of that connection is not yet well understood. Other theories such as career theory, free-agency theory and institutionalism were also considered but these were rejected primarily in favour of these two interrelated theories. This review of the organisational socialisation literature highlighted socialisation tactics (Jones, 1986; Van Maanen \& Schein, 1979), the content of socialisation (Chao et al., 1994), indicators of adjustment and time to productivity (Bauer \& Erdogan, 2012), socialisation agents (Bauer et al., 1998; Feldman, 1994; Morrison, 2002; Saks \& Gruman, 2012) and proactive socialisation (Bauer \& Erdogan, 2012; Crant, 2000; Feldman, 1994; Wanberg \& Kammeyer-Mueller, 2000). Each of these aspects of organisational socialisation are relevant to any newcomer. There have been three phases in the development of theory about organisational socialisation (Ashford \& Nurmohamed, 2012). Though overlapping somewhat, these phases have generally investigated organisational socialisation tactics (the institution's role), proactive socialisation (the individual's role) and arrived at accepting that organisational socialisation is a fusion of institutional and individuals' roles (Ashford \& Nurmohamed, 2012).

The literature on socialisation theory assumes a standard work arrangement so the socialisation of professional contractors is almost never addressed (Bauer \& Erdogan, 2012). There are numerous prescriptive and descriptive articles about orientation, onboarding or induction practices and programmes for employees. There have been longitudinal studies as well as meta-analysis on the subject (such as Ashford \& Nurmohamed, 2012; Chao et al., 1994; Major, Kozlowski, Chao, \& Gardner, 1995; Morrison, 1993a; Thomas \& Anderson, 1998). For professional contractors to perform, socialisation must occur so a better understanding of that process, its content and how it affects their working relationships is essential.

Traditionally, the psychological contract was loyalty (from an employee) in return for security (from the employer) but this is no longer as simple as it once was (Osnowitz, 2010). The changing nature of work and employment relations is a reason to further explore the meaning and operation of the psychological contract (Rousseau, 1989). Though the concept of the psychological contract has been around a long time, it is not yet fully understood (Guest, 1998; Rousseau, 2001; Svensson $\&$ Wolven, 2009). There have been several studies that have explored the psychological contract of 
temporary staff and contracted workers (Millward \& Brewerton, 1999; Morf et al., 2014; O'LearyKelly et al., 2014; Svensson \& Wolven, 2009). In a blended workforce, it is highly likely that workers have several different psychological contacts (David, 2008; Druker \& Standworth, 2004). Though the psychological contract of a contractor was found to be more transactional, it may develop to be more relational over time (Millward \& Brewerton, 1999). Emerging from research this on the psychological contracts is the importance of the team, which is usually indicative of a relational psychological contract (Millward \& Brewerton, 1999; Pearce, 1993; Redpath et al., 2009).

It can be said the formation of the psychological contract is likely to coincide with the early stages of the organisational socialisation process. Woodrow and Guest (2017) claim that the "knowledge required during socialisation drives the psychological contract” (p. 593). During the organisational socialisation process the psychological contract is formed and developed (De Vos et al., 2003; Robinson et al., 1994; Thomas \& Anderson, 1998). It is said that the psychological contract is rudimentary at the beginning but is informed, influenced and changed over time by interactions between professional contractors and permanent employees (Thomas \& Anderson, 1998). The newcomer's psychological contract was found to converge towards that of a veteran (Thomas \& Anderson, 1998). In this chapter the idea of a violation or breach of the psychological contract was introduced. It is suggested that a stable psychological contract is more likely to be violated or breached than a malleable one because the latter is more accommodating of change (De Vos et al., 2003; Thomas \& Anderson, 1998). The content of the psychological contracts of professional contractors, permanent employees and managers is not known, however. What are the mutual expectations of professional contractors, permanent employees and their managers? What do the three parties in the working relationship expect from those they work with?

This review of the literature shows that while both organisational socialisation and the psychological contract have been extensively researched in regard to permanent employees, there are missing elements. How these concepts relate to professional contractors needs further investigation, which will further illuminate the working relationship. Therefore, using organisational socialisation and the psychological contract as lenses this research explores the working relationship between professional contractors and their permanent employee colleagues. The next chapter details the Methodology and Methods that are applied in this study. 


\section{Chapter 4: Methodology and Methods}

\subsection{Introduction}

This chapter discusses the research paradigm and philosophical assumptions that are made. The section on the researcher's positioning in this research is a personal, subjective reflection on the researcher's role in this study. The research problem, objectives and questions are discussed because they are the focal point of this research. The key choices that have been made regarding the design of the study are described. This chapter covers both the methodology and methods of this study. The methodology of a study is concerned with the logic involved in a particular piece of research (Grix, 2010). Methodology is also about the procedures of qualitative research or how this research was undertaken and the type of approach used (Creswell, 2013). These include sampling, the pilot study and the development of the interview schedule. The actual method used to conduct this research (interviews) is also explained detail. Later in the chapter there is a detailed description of how data was collected and analysed. The section on analysing the data also describes the software NVIVO, which was used for coding, the coding process and presents the coding framework. The deductive and inductive emergence of themes from the data is explained. Towards the end of this chapter information about the organisations and interviewees that comprise the sample of this study are presented. Finally, this study's ethical considerations are acknowledged.

\subsection{Research Paradigm}

This research aims to better understand how professional contractors and permanent employees work together at organisations. Given that this research is fundamentally about perceptions, meanings and understanding (Grix, 2010), it is firmly interpretivist in nature. Grix (2010) describes interpretivism as, "The emphasis is on the understanding of the social world through examination of the interpretation of that world by its participants" (pp. 26-27). Characteristics of interpretivist research include a focus on social actors in a natural setting (Walshaw, 2012). Creswell (2013) refers to this established academic approach as social constructivism. Fundamental to an constructivist ontology is an assumption that there are multiple realities underling the interpretive research journey (Denzin \& Lincoln, 2011). 


\subsection{Philosophical Assumptions}

This section provides a description of the philosophical grounding underpinning this research and the interpretive framework. Researchers are advised to explicitly address how ontology, epistemology, and axiology assumptions are exemplified in a study (Creswell, 2013). According to Grix (2010) ontology and epistemology are the footings or foundations of the research. Fundamental to this research is the idea that the experience of each of the participants is unique though possibly similar to others in that situation. Participants have different perspectives of their reality, which is both informative and valuable. No two perceptions will be entirely identical but similarities will be able to be identified and connections made. This research clearly considers the different perspectives of those who comprise a team: permanent employees, professional contractors and their managers. It is acknowledged that each of these three parties will have diverse viewpoints.

Findings are presented in the actual words of the individual participants or interviewees, which is an indication of the ontological characteristics of this research (Creswell, 2013; Denzin \& Lincoln, 2011). The majority of interviews took place at participants' places of work. However, access to the workplace was usually limited to a private meeting room. In several instances, the researcher was given a tour of the workplace as a courtesy rather than an opportunity for fieldwork. The researcher did not conduct observations of participants in their place of work. The use of semi-structured interviews as the primary data-gathering tool will also mean that the researcher is not strictly separated from the interviewee but interacts with them in the course of the interview. The axiological assumptions address the researcher's 'positioning' and is discussed as a way to acknowledge biases inherent in this type of study (Creswell, 2013, p. 73).

\subsubsection{Positioning as a Researcher}

The importance of acknowledging one's subjectivity has repeatedly been emphasised in the literature (Bryman, 2016; Creswell, 2013; Denzin \& Lincoln, 2011). At its simplest, reflexivity is recognition of the role of the researcher, their background and any biases (Gibbs, 2007). Denzin and Lincoln (2011) describes this as “... a conscious experiencing of the self as both inquirer and respondent, as teacher and learner, as the one coming to know the self within the processes of research itself' (p.124). Reflexivity in qualitative research is increasingly a concern among researchers. The issue of bias in qualitative research is a particularly important one. My approach to address bias is through transparency and trustworthiness (Pratt, Kaplan, \& Whittington, 2020). In 
this thesis I outline the steps, procedures and processes that were involved at each stage of the research process. I describe, in much detail, the methods with which sampling, piloting, interview schedule development and data collection occurred. I also describe the data analysis process using the tool NVIVO as a way to add transparency to this endeavour. For data analysis purposes, I developed a clear process, system or method with which to analyse the interview data. That process was adhered to and meticulously followed in order to achieve the rich quality of data necessary. In other words, I clearly describe what I did and the choices I have made (Pratt et al., 2020).

As both the interviewer and data analyst it is not possible to separate me from the research I conducted. It is fundamentally my research. I have work experience in recruitment, human resources and organisation development, which means a professional familiarity and comfort with conducting interviews. Although I have never been a professional contractor, I have been a permanent employee of several organisations and I have been a part-time project team member. In each of those capacities I have worked with both professional contractors and permanent employees. Therefore, I have been able to observe their working relationships from the periphery. In some instances the working relationship is ideal, productive and synergetic. Sometimes, this working relationship is characterised by uncertainty, ambiguity and mistrust. It is not always easy to form a productive working relationship.

During the interview process my role was two-fold. Firstly, my job was to ask each interviewee the questions listed in the semi-structured interview schedule. However, where appropriate, I varied the order of the questions in response to the interviewee. This brings me to my second job during each interview, which was to actively listen. In the course of every single interview I asked additional, follow up or probing questions in order to gain clarity and a better understanding of the interviewee's perspective. Therefore, no interview followed a rigid structure because no two interviews were the same. Each interview was different because no two interviewees were the same. I encouraged interviewees to share anecdotes about their experiences as professional contractors, permanent employees or managers with both open questions or simply "Please tell me more..." I was particularly interested in their accounts about working with professional contractors or permanent employees respectively. 
I have no personal preference for professional contracting (or other non-standard employment) or permanent employment. I am not advocating for one over the other. I believe that choice must be a personal decision based on careful consideration of an individual's knowledge, skills and abilities (KSAs), experience, circumstances, career goals, tolerance of risk and resilience. There are advantages and disadvantages for each option, so I believe individuals making the move to professional contracting from permanent employment (or vice versa) must be well informed before making a change. Professional contracting is not for everyone. Neither is permanent employment. It is not my intention to compare and contrast one against the other but to acknowledge the reality of a modern workforce in order to further explore and understand that reality.

\subsection{Research Problem}

Given the increasing incidence of professional contractors in the workforce, permanent employees are more than ever likely to be working alongside professional contractors. A lot is known about the permanent employees' experiences because they have been the key part of the workforce for a long time (Connelly \& Gallagher, 2012). However, in the last 10 years, professional contractors and contracting has started to be the subject of more research. Several in-depth studies have revealed some further knowledge about professional contractors and contracting, particularly in IT (Barley \& Kunda, 2004; Osnowitz, 2010). This research adds a great deal to the growing picture of professional contracting as an alternative to permanent employment. It is now apparent that for many individuals professional contracting is a career choice; it is voluntary.

Personal interest and motives are important in selecting the subject of a study so researchers are advised to share what has prompted their interest in the topic being explored and what he or she will gain from that study (Wolcott, 2010). My interest in the relationship between professional contractors and permanent employees is both a personal and a professional one. It has its genesis in an experience at work, which is described in the following vignette. 


\begin{abstract}
My Story
Several years ago, I was a part-time, temporary project team member at a government department in Wellington, New Zealand. There were several things about that experience that were thought provoking. The team was made up of three types of workers: permanent employees, professional contractors and temporary workers. The project manager, several specialists and data analysts were professional contractors, some of whom were engaged directly. Other professional contractors were contracted through third parties (recruitment or staffing agencies). The permanent employee team members were all seconded from other departments such as finance and IT. Several of the employees were with the project full-time but others were part-time. In fact, one of the permanent employees was spread across three different roles. The relationship between the technically skilled professional contractors and the knowledgeable permanent employees was a curious one. It was pretty clear that the permanent employees knew and understood how things worked at the organisation. They had the information that was essential to the project. The professional contractors had superior technical skills and expertise, however. There were many, many intense discussions about the business, business processes, procedures and operations. The professional contractors were reliant on the permanent employees to 'do their bit' before the contractors could do their job. There were more discussions about the data where the specialists interpreted the numbers and the implications of those numbers for verification by the permanent employees. There seemed to be a lack of a shared understanding between the permanent employees and professional contractors. It was not clear what the professional contractors required from the permanent employees and vice versa. Ultimately, these issues were resolved through lengthy discussions and the outcome was successful for the team. This experience raised several questions about how professional contractors and permanent employees work together in organisations.
\end{abstract}

The story above typifies one of the realities faced by office-based workers in organisations in New Zealand everyday. The modern workforce is a blended one comprised of permanent employees, fixed term employees, part-time workers, contractors and temporary workers (McKeown \& Cochrane, 2017). Not only are there different forms of workers but also there are different kinds of employment contracts, different hours or days of work and some even work remotely or off-site. Most of these forms of work are known as non-standard work because they do not conform to the typical parameters of standard work. Non-standard work is also referred to as contingent, peripheral, atypical or alternative work (Barley \& Kunda, 2004; Bidwell, 2009; Burke, 2015; Gallagher, 2002, 2008; Osnowitz, 2010) but there are strong arguments that this kind of work is no longer peripheral, atypical or marginal (McKeown \& Hanley, 2009). Within the broad category of non-standard workers is the focus of this study: professional contractors. 
Organisations across the country have professional contractors among their ranks. In fact, some departments or divisions such as information and communications technology or project teams are likely to be staffed by large numbers of contractors. Despite being substantial in number, contractors are often overlooked in the human resource management literature because, in most countries, independent contractors are outside the legal definition of an employee (Connelly \& Gallagher, 2012). Contractors are disregarded because they are not on an organisation's payroll or included in full-time equivalent (FTE) counts (Houseman, 2001; Tucker, 2002). Therefore, contractors fall outside the remit of traditional HR policy and employment legislation (McKeown \& Cochrane, 2017; McKeown \& Hanley, 2009). It is apparent that many contractors are performing in roles that are essentially core jobs. This is a departure from the futurists of last century who predicted a core-periphery model of organisation structure in the future (Atkinson, 1984; Handy, 1989).

A typical permanent employee life cycle starts with recruitment and selection before moving on to orientation, onboarding or induction. Macky and Johnson (2003) refer to this as the staffing process. However, for a professional contractor both sets of processes are likely to be different because the worker is not an employee. The recruitment and selection of a contractor is simplified because there is no expectation of on-going employment. Often a recruitment or staffing agency takes on some of the traditional HR functions such as the recruitment and selection of a contractor (Burgess \& Connell, 2006). It is the agency which short-lists potential candidates for the client to consider. Where the contractor is engaged directly, personal networks are often used, which also streamlines the process. Once recruited and selected, the professional contractor contracts to provide services to their client-organisation (Rudman, 2019). Similarly, the orientation, onboarding or induction of the professional contractors is also different because the contractor is not an employee.

The rationale for this study is that professional contractors are now a common feature of a blended workforce and their performance is important to the organisation. Given their increasing prevalence/the increasing incidence of professional contractors, they are likely to have to work with permanent employees in order to deliver. This means the assumption that all workers are permanent employees is erroneous. Permanent employees are no longer working with other permanent employees but are increasingly likely to work alongside non-standard workers such as professional contractors. Bryant and McKeown (2016) call for greater insight into managing different groups of workers. These authors make a case for “...developing a more thorough understanding of how staff in client organisations perceive highly skilled contractors and what their experience of working with 
contractors...” is (Bryant \& McKeown, 2016, p. 400). Similarly, Ashford and Nurmohamed (2012) suggest an investigation of leaders, co-workers and teams. Different types of workers have to work together in order to perform their jobs, so how do they go about that? The working relationship between professional contractors and the permanent employees they work alongside at clientorganisations has not been widely explored. This gives rise to a number of questions about how professional contractors and permanent employees work together. How do permanent employees and professional contractors work effectively together? How are professional contractors integrated into the organisation? How do contractors learn the ropes? Who shows a contractor how things are done? How are contractors brought up to speed? What do professional contractors expect from their colleagues? What do managers expect of professional contractors? What do permanent employees expect of professional contractors?

Close examination of the questions listed above shows a clear pattern; some of these questions relate to the way the organisation integrates newcomers. Organisational socialisation involves getting a newcomer up to speed, showing them the ropes or helping them adjust to the new organisation (Bauer \& Erdogan, 2012; Feldman, 1981; Schein, 1968; Van Maanen \& Schein, 1979). An organisation's onboarding, orientation or induction programmes are examples of organisational socialisation. It is argued that organisational socialisation actually starts with recruitment and selection because that is the first contact the newcomer has with the organisation (Bauer, 2010). Therefore, recruitment and selection as well as orientation or onboarding of a newcomer all relate to the organisational socialisation process. However, little is known about how professional contractors are socialised at client organisations. This is anomalous, given that organisations want contractors to quickly perform at a high level. Therefore, this thesis organisational socialisation is used as a lens to explore the working relationship between professional contractors and the permanent employees they work with. This will provide insight into the working relationship because researchers have observed that a significant part of socialisation is the interaction between newcomers and incumbents such as co-workers and leaders (Ashford \& Nurmohamed, 2012; Reichers, 1987).

It is apparent that the other questions relate to the mutual expectations that professional contractors, permanent employees and their manager have. Expectations, obligations and beliefs are often attributed to the psychological contract (Roehling, 2008; Svensson \& Wolven, 2009). The psychological contract is a set of unwritten expectations, beliefs and obligations that form the basis of the informal employee-employer relationship (Rousseau, 1989, 1995). The fact that these 
expectations, beliefs and obligations are unwritten and usually unarticulated is key to the psychological contract because it is fundamentally a mental model (Rousseau, 1989). The psychological contract is particularly relevant in two ways. First, there are indications that there is a psychological contract with the client organisation but there is also a psychological contract with the temp agency, colleagues or co-workers (Svensson \& Wolven, 2009). Second, the fulfilment of the psychological contract has been found to positively affect the work attitudes of temporary workers (Morf et al., 2014). Both Morf et al. (2014) and Svensson and Wolven's (2009) studies were based on temporary workers rather than professional contractors so further exploration of the psychological contract of contractors would be illuminating. Therefore, this thesis uses the psychological contract as another lens to explore the working relationship between professional contractors and the permanent employees they work with.

\subsection{Research Objectives}

The primary research objective of this study is to gain a deeper understanding of the working relationship between professional contractors and their permanent employee colleagues. This study seeks experiences and perspective of professional contractors, the permanent contractors who work beside them and the managers who engage them. This objective will be achieved by using the two lenses of organisational socialisation and the psychological contract to further explore the working relationship. The first step will be to establish how the professional contractors in this study are socialised at client organisations and what implications this has on the working relationship. The second step will be to explore the expectations of professional contractors, permanent employees and their managers. These expectations contribute to the psychological contract that each of the parties in the relationship develops. It is also anticipated that more about the relationship between the two key concepts will also be exposed.

The theoretical contributions this study makes will be varied. This study contributes through the use of two well-known concepts - organisational socialisation and the psychological contract - as lenses to explore the working relationship between professional contractors and permanent employees. Applying organisation socialisation and the psychological contract to the working relationship between professional contractors and permanent employees is also original. An understanding of the organisational socialisation that professional contractors actually experience will be informative. It will provide some necessary detail about the organisational socialisation process and practice of professional contractors at organisations in New Zealand, with a view to 
forming a model of organisational socialisation for professional contractors. Similarly, the application of the psychological contract as a lens will be revealing. Better understanding of the type of psychological contract that professional contractors have will be informative. This study will also provide an opportunity to investigate the mutual expectations between professional contractors, permanent employees and their managers. Better understanding of these expectations will not only be informative but also help better manage those expectations.

There is also an additional methodological contribution that this study makes by including a variety of perspectives rather than those of merely one homogenous group. This research is deliberately designed to consider multiple perspectives to explore the working relationship between professional contractors and permanent employees. Interviews were conducted with individuals who comprise a team: professional contractors, permanent employees and their managers. Several authors call for studies that investigate different groups of workers (Ashford \& Nurmohamed, 2012; Bryant \& McKeown, 2016).

This research has practical implications for HR practitioners and managers. It is in the interest of both HR professionals as well as people managers to better understand the intricacies of a blended workforce, a characteristic of the modern organisation. As McKeown and Cochrane (2017) suggests, "While the reality is that work is increasingly comprised of an array of blended workforce arrangements, HR largely continues to constrain notions of productivity, creativity and the value of the workforce to the traditional arrangements of work" (p. 1427). For HR practitioners, this information will be informative to their policy, procedure and practice development because professional contractors are now a characteristic of a modern workforce. Professional contractors have been known to fall through the cracks at organisations because they are outside the remit of HR policy and advice. Often HR is not involved in the recruitment, selection or contracting of professional contractors so it is no surprise that professional contractors are not considered. The HR literature barely considers professional contractors because they are not employees. However, the reality of a blended workforce is that permanent employees will be working alongside these contractors. Furthermore, professional contractors are doing the work of permanent employees so recognition of the increasingly important role professional contractors play in the functioning of organisations is vital. Professional contractors can no longer be overlooked. 


\subsection{Research Questions}

The research questions for this study were derived from a thorough literature review on professional contractors, a type of non-standard worker. Professional contractors are features of a blended workforce, one that comprises employees and other types of workers (Burke, 2015; McKeown \& Cochrane, 2017; Pichault et al., 2019). An initial literature review revealed that today's professional contractors are not working in peripheral, support positions as was once theorised but are often in central, core, essential functions. This means they are working alongside permanent employees as part of a blended workforce. This reality prompted questions about how they work together, which forms the overarching research question: How do professional contractors and permanent employees work together at organisations in New Zealand?

This literature review had to go beyond the standard HRM literature and examine the literature of organisational behaviour, organisational psychology and management. It emerged that little is known about professional contractors' organisational socialisation or the psychological contracts they develop. Organisational socialisation was chosen because it is about how a newcomer adjusts to a new role, team and organisation. Organisational socialisation is a well-known process that turns an outside into an organisational insider (Feldman, 1981). Like any newcomer, professional contractors have to adjust to the client organisation but without the luxury of time because their tenure is limited. Thus organisational socialisation was identified as concept through which the working relationship between professional contractors and permanent employees could be examined.

Professional contractors are also expected to be productive immediately (Barley \& Kunda, 2004) but what else is expected of them? What are the mutual expectations of professional contractors, permanent employees and managers at organisations? Briefly, the psychological contract is about an unwritten set of expectations operating at all times between every member of an organisation and the various managers and others in that organisation. It involves consideration of promises made and expectations of the parties to the employment relationship (Druker \& Standworth, 2004; Rousseau, 1995; Schein, 1988). The psychological contract has grown from the work of Denise Rousseau, an organisational scholar, and is an example from the field of organisation behaviour. Therefore, the psychological contract was identified as an appropriate concept with which to examine the working relationship between professional contractors and permanent employees. 
Furthermore, it is apparent that though separate concepts they are interrelated although how they are is not yet well understood. Organisational socialisation is considered to be at its strongest just after an individual joins an organisation, a period that coincides with the formation of the psychological contract (De Vos \& Freese, 2011; Woodrow \& Guest, 2017). Therefore, it can be claimed that the organisational socialisation process informs the development of the psychological contract of a newcomer. For professional contractors, their tenure at an organisation is particularly short or limited so both these concepts are particularly relevant. The use of the two key constructs in the way is unique and has the potential to be highly informative.

Therefore, the overarching research question that guides this study is:

How do professional contractors and permanent employees work together at organisations in New Zealand?

The two sub-questions are:

a) How are professional contractors organisationally socialised at client-organisations in New Zealand? What are the implications of their organisational socialisation on the working relationship between professional contractors and the permanent employees they work with?

b) What are the psychological contracts of professional contractors, permanent employees and managers at organisations in New Zealand? What are the implications of these expectations on the working relationship between professional contractors and the permanent employees they work with?

\subsection{Research Design}

This research was designed to explore the various perspectives of the professional contractors, permanent employees and their manager. It involves a variety of industries located in three major cities in New Zealand. Participants were sourced from IT divisions of a total of 10 organisations. Data was collected through one-to-one, face-to-face interviews of 49 participants, which were audio recorded and later transcribed. At each organisation a minimum of three people were interviewed: a professional contractor, a permanent employee and their manager. As is suggested by researchers in this field, "Supplementation with a qualitative methodology such as interviews and intensive case studies would enhance both the richness of the data and increase explanatory value" (McKeown \& Hanley, 2009, p. 313). Therefore, this research has the potential to make several contributions to the growing body of knowledge about professional contractors and contracting. 
This research is qualitative because it is suited to the exploratory nature of the problem being studied (Blaikie, 2000; Grix, 2010). Qualitative research is common within an interpretivist paradigm. A qualitative approach is used as it provides the opportunity to gather 'rich accounts', which further describe the topics on which limited research has been done (Alvesson, 2011). This research is particularly interested in the intensely personal experience of professional contractors, permanent employees and their managers. This research is conducted in order to learn more about the experience of professional contractors and permanent employees working together, rather than to seek to confirm a particular hypothesis. The review of literature on this topic presented in the previous chapter shows that this methodology is in keeping with other research on professional contractors that involves qualitative research methods such as in-depth interviews (Barley \& Kunda, 2004; Osnowitz, 2010). Both organisational socialisation (Morrison, 1993a, 1993b, 2002; Saks \& Ashforth, 1996; Saks et al., 2011; Wanberg \& Kammeyer-Mueller, 2000) and the psychological contract (De Vos et al., 2003; Robinson et al., 1994; Robinson \& Morrison, 2000; Roehling, 2008; Thomas \& Anderson, 1998) are regularly the subject of quantitative research because they are often longitudinal studies. Therefore, using a qualitative method to explore the working relationship will offer a unique perspective and the potential for insight.

This research is qualitative in nature so it has no real quantitative element. A qualitative approach was chosen in order to better explore the actual experiences of interviewees, which is missing from the literature on both organisational socialisation and the psychological contract. A limitation is that this study is not longitudinal but a snapshot in time. Given the small sample size, findings are not easily generalisable but nevertheless they are rich in detail and highly informative. This study involves the exploration of the working relationship through semi-structured interviews, which provide detail on the unique experiences and perspectives of participants.

Initially, a case study research design was seriously considered. Case study design is applicable because this study focuses on an event that the researcher cannot influence or control (Yin, 2003). The literature on the subject of case studies suggests that it the non-representative or a-typical cases that glean the most insight (Yin, 2003). At that time, the relationship between professional contractors and those they work with had not been explored extensively so it was considered more important to focus on the regular or normal examples of the working relationship. Furthermore, the unit of analysis of this study is the individual rather than the organisation. The latter would have been more appropriate for a case study research design. 


\subsection{Methodology}

This qualitative study involves 49 interviews with professional contractors, permanent employees and managers working in IT. This is congruent with an interpretivist approach, particularly because open-ended questions are a feature of data collection (Creswell, 2013). In fact, the use of this method is appropriate for exploratory research. A total of 10 organisations in a variety of industries (public sector, education, finance, transportation and manufacturing) in three major cities in New Zealand agreed to participate by providing access to interviewees. Participants were sourced from IT divisions of those large, well-known organisations. Participation was entirely voluntary so only those who chose to participate were interviewed. At each organisation a minimum of three people were interviewed (a professional contractor, a permanent employee and their manager) to obtain varied perspectives of the working relationship. Interviews were audio recorded and later transcribed. Each anonymised interview transcript was coded according to themes and patterns using NVIVO software. Several of these codes from the literature were reviewed prior to embarking on data collection (deductively). Several of these codes emerged from the data itself during the coding process (inductively). Each code was then carefully analysed in conjunction with the literature reviewed to further interpret the data. This analysis is presented in Chapter 5 (Findings) of this thesis. The conclusions this study draws are based on these findings.

\subsection{Methods}

\subsubsection{Sampling}

The target population for this study is professional contractors in IT. There are several reasons for focussing this study in this way. Firstly, professional contracting in the IT industry is well established and has reached a level of maturity that makes it particularly appropriate for the purposes of this research. In fact, Bidwell (2009) notes that IT workers are frequently considered the archetype of a highly skilled, independent professional. Secondly, due to the project-based nature of the IT sector it is guaranteed to have teams that are comprised of the three parties that this research seeks to explore. Thirdly, previous qualitative research conducted on professional contractors has often involved a sector or industry focus so this is the primary reason for a specific industry or occupation focus. Professional contractors in the IT sector were a focus of both the studies conducted by Barley and Kunda (2004) and Osnowitz (2010).

Sampling for this study involved two steps, which are described next. Step One: organisations willing to participate had to be identified. In order to do this, a type of non-probability sampling 
called purposive sampling method was used (Cavana, Delahaye, \& Sekaran, 2001; Patton, 2002). After an initial Internet search, a list was drawn up of about 40 top employers in New Zealand ranked on the size of their workforce. Organisations that had several thousand employees were at the top of the list. This list was then divided into three respective geographic locations and telephone contact (cold calls) was made with these organisations inviting them to participate in this research. Large organisations were targeted, as the incidence of teams comprising both permanent employees, and professional contractors as well as managers would be high. Initially, the HR departments of the organisation listed were contacted by telephone. However, it became clear that rather than talking to a representative of $\mathrm{HR}$, speaking directly to a representative of the IT division of the organisation produced more immediate results. This was not always the case but certainly seemed to hold true for the majority.

A supplementary list was found online which named the top 100 IT or IT Heads in New Zealand and their organisations so this was used as a starting point (Paredes, 2016). During the initial telephone conversation, the researcher was regularly asked to email the representative with descriptive information about the research and contact details. This information sheet is included in Appendix B: Information Sheet. Depending on the outcome of their internal decision-making discussions the organisation's representative then responded either positively or not. In some instances the researcher was put in touch with other representatives before approval to participate was granted. Once the organisation had given approval in principle, the representative then identified an appropriate team or teams to participate. In some instances this was a team that they themselves were part of. In other instances, the representative simply facilitated the process and made arrangements with another completely separate team.

Step Two: within the organisations that agreed to participate, teams comprising professional contractors, permanent employees and their managers had to be identified. More specifically, a type of purposive sampling called criterion sampling was necessary to identify research participants who were willing and able to deliver the required information (Bryman, 2016; Cavana et al., 2001; Patton, 2002). At each of the participating organisations, a request was made for any team that fulfilled certain criteria to be invited to participate. A team is described as a group of people working toward a collective purpose (Belbin, 1981). For the purposes of this research, a team is a group of people working toward a collective purpose and who all functionally report to the same manager. Certain individuals may have a matrix or dual reporting line but for their function on the team they are accountable to the same manager. 
At each organisation, criterion sampling was used to identify teams that met the basic criteria outlined as follows:

1) Four or more people

2) Permanent employee as a team member

3) Professional contractor as a team member

4) A minimum of one-month's experience.

Teams of four people or larger were considered to be good candidates for participation. It was also considered useful if the team is managed or supervised by a permanent employee but this was not regarded essential to the study. Providing the team comprised at least one permanent employee and one professional contractor as members, it was considered acceptable. Therefore, at each participating organisation a minimum of three individuals were interviewed: manager, professional contractor and permanent employee. In order to have had sufficient experience to talk about his or her working relationships it was important that each professional contractor and permanent employee had been part of the particular team for at least one month. It was felt that this would ensure that they have had the relevant background, knowledge and experience to best answer the questions and make a valuable contribution to this research. No effort was made to seek special cases so each of the participating teams were typical or representative cases rather than critical, rare/unique, revelatory or longitudinal cases (Yin, 2003).

In one city, there was some difficulty in establishing participation from organisations within the required timeframe. The researcher's academic supervisors introduced the researcher (via email) to relevant personal contacts at organisations based in that city. These introductions successfully led to interviews being arranged with appropriate teams at those organisations. No interviewee referred the researcher to other interviewees but in all instances interviewees were aware that other team members and their manager would be participating in an interview. Confidentiality was maintained by not sharing interviewees' responses with other participants.

\subsubsection{Pilot Study}

In preparation for data collection, a pilot study was carried out with the primary aim of testing the interview questions (Burns, 1996). The flow and wording of questions in an interview is considered to be particularly important so testing the interview questions is recommended (Patton, 2002). For the purposes of the pilot study a convenience sample of professional contractors, permanent 
employees and managers was used. Convenience sampling is the easiest method of sampling because it involves collecting data from interviewees who are easily accessible (Miles \& Huberman, 1994). Convenience sampling has the lowest level of credibility so this type of sampling strategy was restricted to the pilot study (Cavana et al., 2001; Patton, 2002). Four interviews were conducted at university meeting rooms. Each interview was conducted as though it was a real part of data collection so interviewees were asked to sign a consent form, provided with an information sheet and the interview was digitally recorded but not transcribed. The data collected during the pilot study were not included in the final data analysis. Each interviewee was aware that they were participating in a pilot study. After the pilot, several changes were made to the order and layout of the questions as well as to some of the words or expressions used in the interview schedule. These changes are described in detail in the next.

The purpose of the pilot study was to test it in order to further refine the questions (Creswell, 2013). During the pilot, it became clear that the terms 'organisational socialisation' or 'socialisation' were not meaningful to interviewees. In fact, they seemed to have the connotations of socialising in the sense of relaxed social activities. Therefore, for all subsequent interviews those words were used sparingly. Instead, socialisation was referred to as integration, which is another way of expressing the process by which newcomers become part of the group they have joined. The word induction was also used, as this resonated with those in the pilot study probably because it is a term used in the workplace to describe the early stages of newcomer adjustment in a new job.

The second part of the research question is about the psychological contract. Similarly, during the pilot it became clear that the term had no intrinsic or intuitive meaning to those being interviewed. In fact, the term psychological contract had to be explained or defined, which proved problematic and potentially biasing. A part of the psychological contract is the mutual perceptions or expectations that are held by each of the parties involved in the employment relationship. Therefore, the term psychological contract was not used during interviews but referred to as expectations. Interviewees were asked about their expectations of those with whom they work. They were also asked to share their perspectives and opinions. 


\subsubsection{Interview Questions}

In this section the development of the interview schedules from this study's research questions is described. There is a strong link between this study's research question and the interview questions. Creswell (2013) suggests that the interview questions are sub-questions of the study's research question phrased in such a way that they make sense to the interviewee. This study's research question has three parts (one overarching question and two sets of sub-questions) so the interview questions stem from each of the research question's sub-questions. The interview questions for this study were developed in a multi-step process culminating in the form of the research schedule, which comprises the questions asked during the interviews.

Once the research questions were established, the researcher conducted an in-depth literature review focussing specifically on the literatures relating to the two key constructs identified as the lenses for this study. In the course of this literature review on organisational socialisation, it became apparent that interviewees needed to be asked directly about their experience of induction, onboarding or orientation. A series of questions were developed to establish how the interviewees, particularly the professional contractors, were organisationally socialised. The information gathered from these questions would contribute to answering the research question sub-question "How are professional contractors organisationally socialised at client-organisations in New Zealand?" Similarly, in order to answer the research question sub-question "What are the psychological contracts of professional contractors, permanent employees and managers at organisations in New Zealand?" a series of questions about the expectations of those they work alongside was developed.

During the literature review of both the organisational socialisation and psychological contract literatures many relevant, pertinent and thought-provoking questions were identified. Some of these were actual questions asked by other interviewers in other studies, some of these questions were ones that emerged from other research studies inductively and others were questions posed by the researcher's academic supervisors. For example, the interview question, “Are contractors included in social functions/activities?" can be traced to Barley and Kunda (2004) who found they were not included. This question relates to the integration of professional contractors so can be linked to the research question sub-question on organisational socialisation. Another example of interview questions that were sourced from a previous study are those related to the Chao et al. (1994) scale. The dimensions in this question are based on the dimensions of performance proficiency, people, politics, language, organisation's goals and values, and history that Chao et al. (1994) identified in their study. The researcher maintained a record of the questions that arose from the literature review 
(See Appendix C). It was from this 7-page table that the actual interview questions were selected and compiled into an interview schedule. The final step in the development of the research instrument was the pilot study, which has been described above.

Three separate interview schedules were developed. Each of these was marginally different for each of the three groups being interviewed. Interviewees were asked different questions depending on whether or not they were professional contractors, permanent employees or a manager. The development of each of the interview schedules is outlined below.

Professional Contractors. The complete interview schedule (Questions for Professional Contractors) is included in Appendix D: Interview Schedules. Professional contractors were asked to discuss their reasons for engaging in this type of work (pushed versus pulled into contracting), their preference for standard or non-standard work, and how they feel about working in contracting (relates directly to research question). They were also asked about the advantages/disadvantages they experienced as contractors (relates directly to research question) as well as their perceptions of the permanent employees they work with (relates directly to research question), for example, "As a professional contractor, what do you expect from your manager at the client-organisation?" Questions about how professional contractors adjust to each new contracting role were also included (relates directly to research question). Examples of questions that were developed to address the workplace socialisation aspect of this research are: What do you need to know in order to effectively perform your role (that is, 'role clarity')? Where does this information come from? When you started here, who 'showed you the ropes?'

Permanent Employees. The complete interview schedule (Permanent Employee) is included in Appendix D: Interview Schedules. Like professional contractors, permanent employees were asked how they feel about working with professional contractors (relates directly to research question), the advantages/disadvantages of working as permanent employees as well as their perceptions of the professional contractors they work with (relates directly to research question), for example, "What are your expectations of a professional contractor on your team?"

Examples of questions directly linked to the research questions are: When a new team member joins this team, what is your role? What do you do? Does this differ if the new member is a permanent employee or a professional contractor? 
Managers. Appendix D: Interview Schedules contains the full interview schedule (Manager). Many of the questions in this schedule are modified versions of those in the other interview schedules. However, the managers in this study are in the position of having both permanent employees and professional contractors (and probably temporary workers or fixed-term employees, too) on the team they are accountable for. This position gives them a unique perspective on the relationship between permanent employees and professional contractors. The questions that were asked of managers were focussed on socialisation, psychological contracts, and the working relationship between professional contractors and permanent employees but particularly in any differences in how professional contractors are socialised, expected to work and interact in the workplace. Examples of such questions are: What does a contractor need to know in order to effectively perform their role ('role clarity')? What do you expect of a professional contractor?

Given the three different types of interviewees (contractors, employees and managers) the wording of the interview schedules was changed slightly for each of the different category of interviewee. Though called an interview schedule, this document is more like an interview guide as it contains questions to be used in a semi-structured fashion rather than a rigid, structured way (Bryman, 2016, p. 469). The interview schedule was further refined to encourage a smooth flow of the interview. Each interview schedule was formatted into four sections. The first section was designed to establish and develop a rapport. The other three sections were directly linked to the research questions. As interview questions were developed, the researcher gave particular thought to sensitive wording so the questions would be easily understood and elicit genuine, candid responses (Creswell, 2013).

Developing a rapport is considered important in order for the interviewee to feel comfortable and able to disclose information both openly and honestly (Bryman, 2016; Cavana et al., 2001). In order to develop a rapport, several steps were taken by the interviewer. At the beginning of each interview, the researcher briefly introduced the research and explained the format of the interview. In addition to this, the first few questions of each interview were designed to encourage an interviewee to engage with the interviewer. These questions were sufficiently simple, broad and open so that every interviewee was able to answer them. In the other sections of the interview schedule, a variety of questions were used with an emphasis on open-ended questions, which would elicit more information (Bryman, 2016). These kinds of questions are aligned with the interpretivist research paradigm discussed at the beginning of this chapter (Grix, 2010). 


\subsection{Data Collection}

The tool for data collection was interviews (Creswell, 2013). After the pilot study and once the interview schedules were finalised, data was collected in three distinct phases corresponding to each of the three main geographic locations: Wellington, Christchurch and Auckland. These are the largest cities in New Zealand. The rationale for collecting data in three distinct locations was that each centre has particular characteristics. For instance, Wellington is predominately government or quasi-government. Christchurch is a mix with public (regional and local government), private (technology, agri-business) and not-for-profit (education and tertiary). Auckland, the largest city in New Zealand, is dominated by private sector organisations. The researcher visited each organisation in each of these main centres to collect data.

\subsubsection{Interviews}

Interviews were conducted because they allow for broad but deep coverage of the topic with a manageable sample of interviewees (Creswell, 2013; Patton, 2002). Like many qualitative studies, data collection involved one-to-one, face-to-face, semi-structured interviews with professional contractors, the permanent employees they work with, as well as their manager at the client organisation. Acknowledged as the most common form of interview, one-to-one interviews involve just one interviewer and one interviewee (Creswell, 2013). One-to-one interviews are particularly conducive to developing a rapport between the interviewer and interviewee (Rubin \& Rubin, 2012). Face-to-face interviews are conducted in person, which allows the researcher to pick up on any nonverbal cues from the interviewee(Bryman, 2016; Cavana et al., 2001; Patton, 2002). Both these types of interview encourage trust to develop, which is an important part of learning life stories and individual perspectives (Rubin \& Rubin, 2012). A semi-structured interview is one where the interviewer has a prescribed series of interview questions as a guide but is able to vary the order of the questions asked to an interviewee (Bryman, 2016). One way of conducting a semi-structured interview is to have a logical, planned approach to focus the interviews (Bryman, 2016). Having a basic structure to an interview is essential so that the same questions are asked of all interviewees, providing consistency across interviews. A semi-structured interview also ensures that the questions asked are related to the literature reviewed and are well connected to the research questions of the study. Although an interview schedule was primarily used, subsequent clarifying or probing questions were also asked during the course of each interview (Cavana et al., 2001; Patton, 2002). The semi-structured format of the interview also allowed the interviewee the space to talk freely and express him or herself. 
At the very beginning of each interview, the interviewee was handed a hard copy of a consent form and invited to agree to participate in the research by signing the agreement (see Appendix A: Consent Form). Each interviewee was also offered a hard copy of the information sheet but many declined because they had received it by email prior to the interview. Obtaining written consent is increasingly common practice among researchers and is required by most ethics committees (Bryman, 2016; Patton, 2002). All interviewees gave their consent in writing, the originals of which are on file and securely stored in the researcher's private office.

Though varied in length, each interview was approximately one hour in duration. The longest interview was 75 minutes long and the shortest was 23 minutes in duration. The majority of the interviews were between 30 and 50 minutes long. The interviews were digitally audio recorded so only minimal notes were made of 'noteworthy' themes or questions that emerged. Patton (2002) suggests that “...notes will consist of primarily key phrases, lists of major points made by the respondent, and key terms or words shown in quotation marks that capture the interviewee's own language" (p. 383). Following this advice note taking was done consistently but kept to a minimum. Each interview schedule containing the handwritten notes made in the course of the interview has been retained on file for later reference, if necessary.

It is recommended that interviews be conducted in a quiet setting in which the interviewee feels comfortable so is able to speak frankly and share information (Bryman, 2016). The majority of interviews were conducted in private meeting rooms at the interviewee's place of work. Such a location was both private and convenient for the interviewees. One organisation was unable to grant access to a meeting room so all participants from that organisation were met at a nearby coffee shop. This alternative location was suggested by several of the interviewees themselves as a reasonable solution to the challenge of identifying a convenient venue. While a public venue was not ideal, the proximity to the interviewees' place of work made it a convenient location if not completely private. All interviewees at that participating organisation were met at that same coffee shop over a period of several days. In two other instances, logistical issues made it impossible to meet face-to-face so these interviews were conducted via Skype. Another interviewee met with the interviewer at a meeting room at the researcher's university. The format and protocol of the interviews remained very similar despite the different venues or medium. 


\subsubsection{Biographical Information}

At the end of each interview, the interviewee was asked several supplementary biographical data questions (age, gender, major income earner, experience and time in role). There are two distinct reasons for collecting biographical information. Firstly, the purpose of gathering this information was to supplement the qualitative data obtained from each individual interviewee. Bryman (2016) suggests recording such information because it is useful for contextualising people's answers. Secondly, the biographical information clearly shows that the sample is indeed diverse and varied. This biographical data is presented in the following section on the sample. These questions could have been asked at the beginning of the interview but a deliberate decision was made to ask these questions at the end when a rapport between the interviewee and interviewer had already been established.

Although this type of quantitative data is not indicative of qualitative research, the biographical data is used to provide some background information to what we know about professional contractors, permanent employees and managers. The quantitative data provides some valuable context for the data collected (Bryman, 2016). It is acknowledged that, given the small sample of participants, the quantitative data gleaned is not representative so is not generalisable to another setting or the wider population (Cavana et al., 2001, p. 153; Creswell, 2013). While the quantitative data does provide some valuable information and patterns it is used to describe the qualitative data.

\subsubsection{Transcription}

After collecting data in each location, the digital file of each interview was transcribed. Transcription involves transforming an audio recording of speech into the written form (Patton, 2002). Each of the 49 interviews was self-transcribed by the researcher. By doing so, the researcher had to listen closely to each interview, thereby gaining a level of familiarity with and understanding of each of the interviews. This intimate knowledge of each interview proved to be a genuine advantage during the coding and analysis process. Self-transcription is useful because it provides the researcher with an early opportunity to engage with the data and create an awareness of emerging themes (Bryman, 2016).

Every attempt was made to remove any identifying features from each of the transcripts to protect the identity of interviewees (Bryman, 2016; Creswell, 2013). All interviewees were given pseudonyms. The protocol for this is described clearly at the end of this chapter where interviewee 
profiles are provided. In some cases, the names referred to by interviewees were replaced with alphanumeric pseudonyms so that the meaning could be accurately maintained. Alternatively, the names of people, companies and clients were replaced with generic terms such as 'the organisation' or 'the manager'. Where interviewees made reference to certain features of their work that would immediately identify the organisation, these were modified to be less specific while being careful to retain the original meaning of the statement.

At each organisation between three (the minimum) and eight people were interviewed, bringing the total to 51 interviews. Once the interviews were transcribed, a copy was sent by email to the particular interviewee for their approval. It is dictated by best practice that transcribed interviews should be returned to the narrator, who may amend, correct or amplify the transcribed interview, in order to obtain a full, accurate account of the interview (Denzin \& Lincoln, 2011). Each interviewee was offered the opportunity to edit the transcription in order to better reflect their opinions and their point of view. A total of five interviewees chose to make changes to their transcripts. The breadth and nature of the changes varied considerably. One permanent employee made several entirely superficial changes to the text. Similarly, two professional contractors made numerous though mainly superficial edits. One professional contractor made significant changes to their transcript by removing, adding and re-wording sentences. One manager thoroughly edited the transcript but many of these changes addressed the fact that transcriptions of the spoken word (often casual, colloquial and rambling) are quite different to the written word particularly in a business environment. These changes made no substantial difference to the meaning of what was said so the researcher does not believe that any bias was introduced.

Of the five interviewees who elected to edit the transcription, final approval was not received from two interviewees. Therefore, these two transcripts - both professional contractors - were excluded from data analysis. In one instance the interviewee chose to withdraw from participation so did not give approval for the transcript to be analysed. In the other instance, the interviewee requested the right to make changes to the interview transcript. However, after many reminders a reviewed transcript was never received so this interview was also excluded from data analysis. In other words, despite receiving written consent at the outset, explicit approval of the transcribed interview was withheld. All other participants responded by email to give their approval for the transcript to be analysed as it was. Later each transcript underwent content analysis using NVivo software as the coding tool. The coding framework that was developed, the coding process and the data analysis process are discussed in detail in the next section. 


\subsection{Data Analysis}

\subsubsection{Coding}

Each of the interview transcripts was subjected to content analysis. Content analysis is a way of doing data analysis usually performed on text or written documents (Denzin \& Lincoln, 2011). It involves the consistent categorising and coding of text according to patterns and/or themes. Furthermore, another type of coding was also employed during the data analysis process: simultaneous coding. Simultaneous coding is when the content of data has multiple meanings and it may be both necessary and justifiable to code it to more than one different code (Grbich, 2007). In fact, in many instances data was coded to two if not three different codes because the content related to more than one specific code. For example, the quote "Most of the good information comes from your peers" (Callum) was coded to three nodes: Methods of Socialisation, Employees' role in socialising contractors and Quotable Quotes. In this instance the quote is clearly relevant to each of these nodes so was coded accordingly.

\subsubsection{The NVivo Coding Process}

Once transcribed and approved all the interviews were then analysed using NVivo as the tool for data analysis. NVivo is an example of a software that assists researchers to manage, shape and analyse qualitative data (Creswell, 2013). The data analysis process undertaken will be described in detail here as it is from this process that the themes that underpin this research emerge. It was considered appropriate to use NVivo because the data was qualitative and semi-structured. Within the NVivo software there is much specialised nomenclature. 'Nodes' are containers or categories within which like data is grouped by coding . NVivo Software is described on the QSR website as:

NVivo software supports qualitative research. It's designed to help you organize, analyze and find insights in unstructured, or qualitative data like: interviews, open-ended surveys responses, journal articles, documents, social media and web content. (QSR International, 2017)

As part of the NVivo coding process, numerous broad themes were developed. Under each of these relevant data from each interview transcript was categorised or coded. These nodes were developed in two ways: deductively and inductively. At the beginning of the coding process, the literature review, the research questions and the interview questions were revisited and reviewed. The theoretical lenses of organisational socialisation and the psychological contract were used as a base 
for coding. From this it became very clear that there were several broad categories in which the data would most certainly be clustered. These categories came about deductively as they are based on prior knowledge; that is, the literature and research questions (Cavana et al., 2001). These categories formed the first set of nodes that were created in NVivo. Examples of the deductively created nodes from this research are Methods of socialisation, Employees' role in socialising contractors, and Contractors' expectations. The use of a deductive approach in the initial phase of coding resulted in the identification of themes, which are in line with the findings that emerged from the existing literature.

The nodes that were developed inductively are those nodes that emerged from the data itself during the analysis process (Cavana et al., 2001). Some examples of the inductively created include: Time to productivity, Positives of contracting and Negatives of contracting, Organisational policy and What does a contractor need to know? Several of these inductively created nodes, in particular, were constantly expanding, shifting and morphing throughout the data analysis process. In fact, during data analysis it became apparent some nodes needed to be separated into two because they contained so much coded data. For example, the node Methods of socialisation had to be split in two for professional contractors and permanent employees respectively. Yet other nodes needed to be combined into one or adopted by other nodes, thereby making them effectively parent and child nodes. For example, a node for Other signs of integration had to be added to the node Indicators of adjustment as the data did not fit the three existing indicators under that node.

The coding process involved several iterations and each cycle involved more coding, un-coding and re-coding. When a new code was developed, some of the data had to be un-coded before it could be re-coded to the new code. Coding is said to be a cyclical act so therefore must be repeated several times (Saldana, 2013). Fortunately, with the NVivo software this was relatively easy to do and was done approximately three times. Analysis of the data was not limited to coding in NVivo. Another essential phase in data analysis was examining each of the nodes to identify and further group the shared themes and patterns that were evident within the node. It was only after seeing these emerging themes and patterns that the data could be linked to the literature. 


\subsubsection{Mind Map of Nodes}

In the diagram below (Figure 7) the NVivo nodes are mapped to the broad concepts that underpin the research. Another way of looking at this is as the essential elements upon which this research is based. The table shows how the nodes relate or where they fit in regard to the main research question. This figure was automatically generated by the NVivo software to diagrammatically represent the relationship between the nodes that were created during the coding process and the main concepts at the heart of this research.

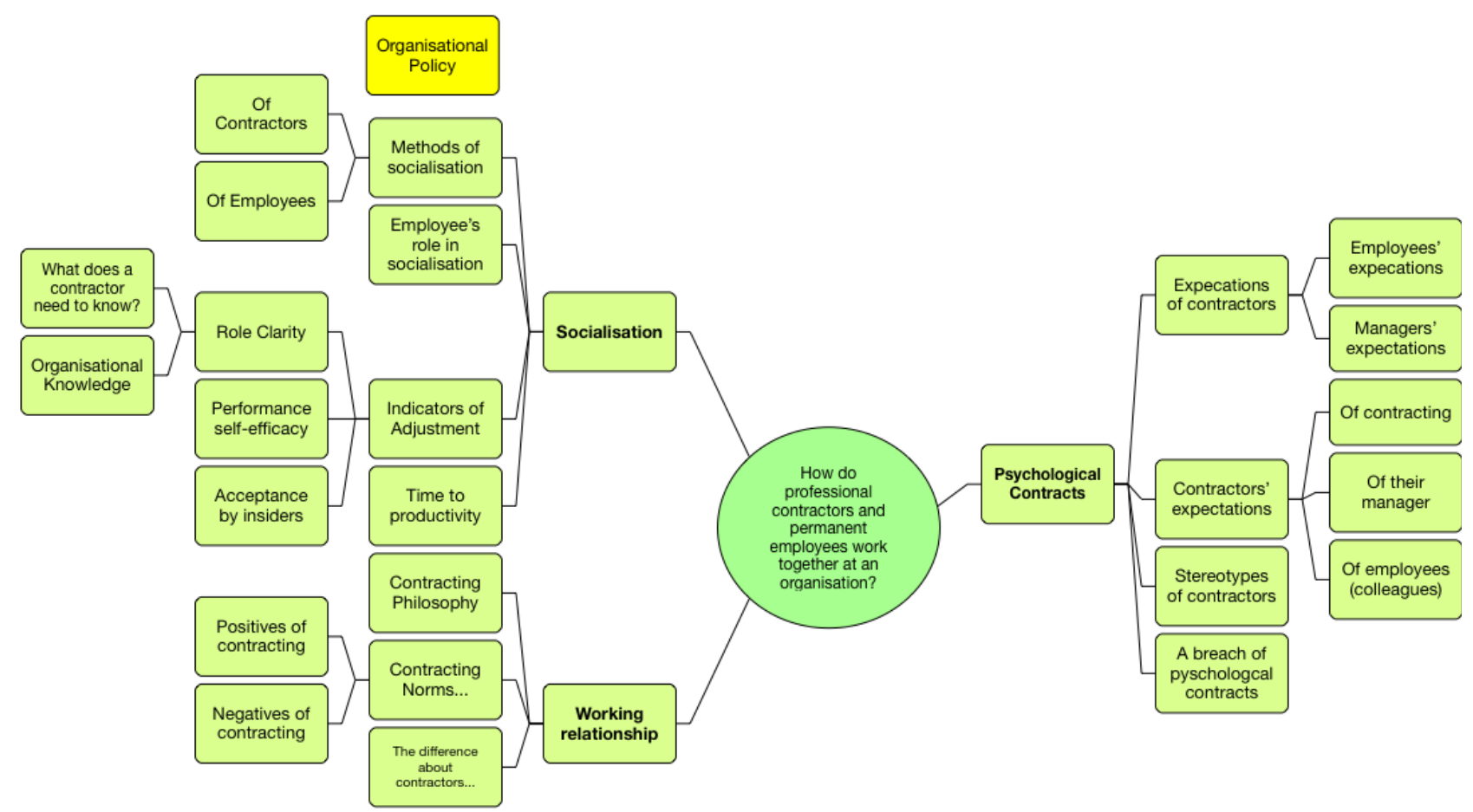

Figure 7. NVivo Nodes mapped to Research Question (and underpinning concepts).

As is clear in Figure 7 the data that is directly related to either organisational socialisation, the psychological contract or the working relationship stems off from the main research question in the centre. The nodes that link to these nodes all contribute/contain data that directly relate to the research question itself.

\subsection{The Sample}

This study investigates the perspectives of professional contractors, the permanent employees and managers who comprise a team. The multiple perspectives that it encompasses are a particularly unique element of this study. The various perspectives provide a much deeper, richer and more 
balanced perspective of the working relationship. Other researchers have called for more research into organisational insiders themselves because little has been done to understand the other side of organisational socialisation (Ashford \& Nurmohamed, 2012; Feldman, 2012). A total of 10 organisations participated in this study, totalling 13 groups of professional contractors, permanent employees and their manager because at several organisations two teams were interviewed. It should be noted that the organisation is not the unit of analysis so the volume of data from one site is not relevant. The unit of analysis is the individual as part of a team.

\subsubsection{Pseudonyms}

By assigning numbers, aliases or pseudonym to participants, the identities of individual interviewees can be protected (Saldana, 2013). Each professional contractor interviewed was given a randomly generated pseudonym beginning with the letter $\mathrm{C}$ for contractor. Pseudonyms beginning with the letter E were used for each permanent employee interviewed. Managers were given pseudonyms beginning with the letter M. This was found to be a way of automatically identifying an individual as a contractor, employee or manager without having to state it repeatedly. The gender of the interviewees was retained: all males have male names and all females have female names. Therefore, when assigning names those that are unisex were avoided. A complete set of interviewees and organisations is presented in Table 4.

Table 4. List of Interviewees by Organisation.

\begin{tabular}{|c|c|c|c|c|c|c|c|c|c|}
\hline \multicolumn{10}{|c|}{ Organisation } \\
\hline A1 & A2 & B 1 & B2 & B3 & B4 & B5 & C1 & $\mathrm{C} 2$ & C3 \\
\hline Cain & Camilla & Carla & Callum & Charles & Carol & Colin & Cliff & Curtis & Cyril \\
\hline Cathy & Elliot & Evan & Eric & Elaine & Chase & Ethan & Ewan & Eli & Emmet \\
\hline Crystal & Mick & Margaret & Michelle & Mitch & Chloe & Maria & Moses & Morris & Edward \\
\hline Earl & & & Caleb & & Cindy & & Murray & Calvin & Ezra \\
\hline Eden & & & Ernest & & Errol & & & Eugene & Murphy \\
\hline Eve & & & Max & & Emily & & & Molly & \\
\hline Emma & & & & & Miles & & & & \\
\hline \multicolumn{10}{|l|}{ Mark } \\
\hline \multicolumn{10}{|l|}{ Matthew } \\
\hline Total: 9 & 3 & 3 & 6 & 3 & 7 & 3 & 4 & 6 & 5 \\
\hline
\end{tabular}




\subsubsection{Organisation Profiles}

A total of 10 organisations agreed to make staff available for participation in this research. Data was collected at organisations located in three of the main cities in New Zealand: Wellington, Christchurch and Auckland. Each city was randomly labelled A, B and C. In addition, each organisation was given a number in order to distinguish that organisation from others in the same location. Table 5 lists all the organisations, provides details on the sector and the number of interviewees at each organisation. The table clearly depicts variety in the type of organisations that participated. The industries that these organisations belong to include finance, transportation, communications and non-profit.

Table 5. Participating Organisations by Sector and Size.

\begin{tabular}{|c|c|c|c|}
\hline Organisation & Sector & $\begin{array}{l}\text { Size of organisation } \\
\text { (approx.) }\end{array}$ & $\begin{array}{l}\text { Number } \\
\text { interviewees }\end{array}$ \\
\hline A1 & Finance & 5000 & 10 \\
\hline $\mathrm{A} 2$ & Transportation & 12,000 & 3 \\
\hline $\mathrm{B} 1$ & Public Sector & 4000 & 3 \\
\hline $\mathrm{B} 2$ & Public Sector & 12,000 & 6 \\
\hline B3 & Public Sector & 3000 & 3 \\
\hline B4 & Public Sector & 1000 & 8 \\
\hline B5 & Public Sector & 2000 & 3 \\
\hline $\mathrm{C} 1$ & Communications & 800 & 4 \\
\hline $\mathrm{C} 2$ & Non-profit & 2000 & 6 \\
\hline $\mathrm{C} 3$ & Non-profit & 600 & 5 \\
\hline Total & 10 & - & 51 \\
\hline Excluded & & & 2 \\
\hline
\end{tabular}

\subsubsection{Interviewee Profiles}

The interviewee profiles provided below are based on the biographical data collected as part of the interview. In each table, interviewees are listed in alphabetical order. Following each table is a short summary or commentary of any patterns or interesting trends that this quantitative data shows.

For the purposes of this thesis, professional contractors are those who have been identified either by themselves or their client as professional contractors. Each of these individuals either considers themselves a contractor and/or their client organisations consider them to be professional contractors. Of the 17 contractors interviewed five are independent contractors, eight are agency contractors and four are what are categorised in this thesis as company contractors because they function like contractors. Among professional contractors interviewed there are several persons 
who are permanent employees of a third party, which contracts them to the client organisation. Interestingly, despite the multi-party employment arrangement that exists, the client organisation regards/considers those individuals to be professional contractors. It goes to follow that those contractors are consequently treated like professional contractors. Therefore, as professional contractors, their organisational socialisation and psychological contract are likely to develop like any other professional contractor.

Table 6 provides some details about the contractors who participated in this study. A clear majority of the professional contractors interviewed are aged between 45-54 years and between 55-64 years. There are only two interviewees who are between 25-34 years. Similarly, there are only two interviewees in the age range 55-64 years. A clear trend among the agency contractors is the fact that majority are not the sole incomer earner. In other words, many of the agency contractors interviewed are part of households where there is more than one income earner. There was no such pattern among either company or independent contractors.

With regard to length of contracting experience, there are three distinct groups: ten years or more, approximately seven years and three years or less. There are four contractors who have been contracting for approximately seven years. One group of contractors is relatively new to contracting so have three years or less contracting experience. The majority of this group have less than one year's experience in contracting. The other groups comprise six contractors who have been contracting (in some cases intermittently) for over 10 years. In fact, several of those interviewed have been contracting for around 20 years. For those interviewees, contracting has been a significant part of their career.

Prior to meeting each interviewee it was possible to establish whether or not they met the criteria for inclusion in this study. All those interviewed were part of a four or more person team comprising permanent employees, professional contractors and their manager. Each interviewee also had been in their role for more than one month. At the beginning of each interview it quickly became clear whether a contractor was truly an independent contractor, an agency contactor or a company contractor. The majority of contractors interviewed are agency contractors, which means they are engaged through an employment or staffing agency. Two of the company contractors interviewed are in the lowest age range of 25-34 years. As company contractors they are permanent employees of a third-party so enjoy that security in the early stages of their career while experiencing the variety of contracting. None of the other contractors were in this young age range. 
Table 6. Professional Contractors.

\begin{tabular}{|c|c|c|c|c|c|c|c|c|}
\hline Interviewee & $\begin{array}{l}\text { Female } \\
\text { /Male }\end{array}$ & $\begin{array}{l}\text { Age } \\
\text { range }\end{array}$ & $\begin{array}{l}\text { Type of } \\
\text { contractor }\end{array}$ & $\begin{array}{l}\text { Time in } \\
\text { current role }\end{array}$ & $\begin{array}{l}\text { Length of } \\
\text { contract }\end{array}$ & $\begin{array}{l}\text { Time in } \\
\text { contracting }\end{array}$ & $\begin{array}{l}\text { Sole income } \\
\text { earner? }\end{array}$ & $\begin{array}{l}\text { Experience in } \\
\text { permanent } \\
\text { employment? }\end{array}$ \\
\hline Cain & $\mathrm{M}$ & $45-54$ & Independent & 2 years & 3 years & 12 years & No & Yes \\
\hline Caleb & $\mathrm{M}$ & $45-54$ & Agency & 5 months & 1 year & 18 years & Yes & Yes \\
\hline Callum & $\mathrm{M}$ & $45-54$ & Agency & 2 years & 3 years & 11 years & No & Yes \\
\hline Calvin & $\mathrm{M}$ & $25-34$ & Company & 1 year & Over 1 year & 7 years & Yes & No \\
\hline Camilla & $\mathrm{F}$ & $35-44$ & Company & 10 months & 1 year & 7 years & Yes & Yes \\
\hline Carla & $\mathrm{F}$ & $45-54$ & Agency & 3 years & 3 years & 3 years & No & Yes \\
\hline Carol & $\mathrm{F}$ & $55-64$ & Agency & 1.5 years & Unspecified & 19 years & No & Yes \\
\hline Cathy & $\mathrm{F}$ & $45-54$ & Independent & 5 months & 1 year & 5 months & Yes & Yes \\
\hline Charles & $\mathrm{M}$ & $55-64$ & Independent & 2 years & 3 years & 3 years & No & Yes \\
\hline Chase & $\mathrm{M}$ & $45-54$ & Agency & 1 year & Unspecified & 12 years & No & Yes \\
\hline Chloe & $\mathrm{F}$ & $45-54$ & Agency & 6 months & 6 months & 6 months & No & Yes \\
\hline Cindy & $\mathrm{F}$ & $35-44$ & Agency & 2 months & 6 months & 2 months & No & Yes \\
\hline Cliff & $\mathrm{M}$ & $45-54$ & Independent & 8 years & 1 year & 20 years & Yes & Yes \\
\hline Colin & $\mathrm{M}$ & $45-54$ & Independent & 4.5 months & 5 months & 1.5 years & No & Yes \\
\hline Crystal & $\mathrm{F}$ & $45-54$ & Agency & 15 months & 2 years & 8.5 years & No & Yes \\
\hline Curtis & $\mathrm{M}$ & $35-44$ & Company & 6 months & 1 year & 6 months & No & Yes \\
\hline Cyril & $\mathrm{M}$ & $25-34$ & Company & 8 months & 1 year & 8 months & Yes & Yes \\
\hline Total: 17 & & & & & & & & \\
\hline
\end{tabular}


The distribution of agency, independent and company contractors in this sample differs geographically somewhat. For instance, most of the contractors interviewed in Wellington are agency contractors while those interviewed in Christchurch were either independent or company contractors. In Auckland, there was a mix of all three types of contractors (independent, agency and company). No dependent contractors were identified in this sample. As is evident in Table 6, one contractor has contracted to the same client for many years (Cliff). This has never been in a fulltime, five days a week capacity because this contractor has several other clients concurrently. Therefore, he is not considered a dependent contractor.

The biographical data gathered on the permanent employees interviewed is presented in Table 7, below. Approximately, half of the employees interviewed have had experience working as professional contractors but are now in permanent employment. This shows how common professional contracting is in the IT sector. Like the contractors interviewed, the most common age range is 45-54 years. The age range 35-44 years is the second most common but only one of the permanent employees interviewed is aged between 25-34 years of age.

Table 7. Permanent Employees.

\begin{tabular}{|l|l|l|}
\hline Interviewee & $\begin{array}{l}\text { Age range } \\
\text { (years) }\end{array}$ & \multicolumn{1}{|l|}{$\begin{array}{l}\text { Worked as a } \\
\text { contractor? }\end{array}$} \\
\hline Earl & $35-44$ & Yes \\
\hline Eden & $45-54$ & No \\
\hline Edward & $45-54$ & Yes \\
\hline Elaine & $45-54$ & Yes \\
\hline Eli & $35-44$ & Yes \\
\hline Elliot & $55-64$ & No \\
\hline Emily & $45-54$ & Yes \\
\hline Emma & $35-44$ & No \\
\hline Emmet & $35-44$ & No \\
\hline Eric & $45-54$ & No \\
\hline Ernest & $45-54$ & No \\
\hline Errol & $55-64$ & Yes \\
\hline Ethan & $45-54$ & Yes \\
\hline Eugene & $45-54$ & Yes \\
\hline Evan & $25-34$ & No \\
\hline Eve & $35-44$ & Yes \\
\hline Ewan & $45-54$ & Yes \\
\hline Ezra & $55-64$ & No \\
\hline Total: 18 & & \\
\hline
\end{tabular}


Table 8 shows the biographical data of the managers interviewed. In order to obtain an indication of just how common experience in contracting is, managers were asked whether or not they have worked as contractor before. Exactly half of these interviewees have had experience as a professional contractor. The other half have only had experience of permanent employment although several have had fixed term employment contracts. The age range of these managers is not a surprise because a certain level of seniority is expected of a manager. This is further validated by the fact that two interviewees are in the 65 years and over age range.

Table 8. Managers.

\begin{tabular}{|l|l|l|l|}
\hline Interviewee & $\begin{array}{l}\text { Age range } \\
\text { (years) }\end{array}$ & $\begin{array}{l}\text { Worked as a } \\
\text { Contractor? }\end{array}$ & \multicolumn{2}{l|}{ Time in role } \\
\hline Margaret & $55-64$ & No & 4 years \\
\hline Maria & $45-54$ & Yes & 2 years \\
\hline Mark & $35-44$ & No & 4 years \\
\hline Matthew & $55-64$ & Yes & 5 years \\
\hline Max & $45-54$ & No & 3 years \\
\hline Michelle & $45-54$ & No & 5 years \\
\hline Mick & $45-54$ & No & 6 years \\
\hline Miles & $45-54$ & Yes & 7 years \\
\hline Mitch & $55-64$ & No & 8 years \\
\hline Molly & $45-54$ & Yes & 1 year \\
\hline Morris & 65 and over & Yes & 22 years \\
\hline Moses & 65 and over & Yes & 4 years \\
\hline Murphy & $45-54$ & Yes & 23 years \\
\hline Murray & $24-34$ & No & 0.5 years \\
\hline Total: 14 & & & \\
\hline
\end{tabular}

\subsection{Ethical Considerations}

\subsubsection{Human Ethics Committee Approval}

As per Victoria University of Wellington guidelines, prior to data collection approval from the Human Ethics Committee (HEC) was received (HEC Approval Number: 0000022108). Evidence of this approval is in Appendix E. All participants were emailed a copy of the consent form as well as an information sheet prior to the interview so the nature of the research was clear to them. Original copies of each of these forms are in Appendices A and B. At the beginning of each interview they were asked to give written consent by signing a consent form. Participants were assured that every attempt would be made to assure the confidentiality of their responses by agreeing to sign the consent form in hard copy immediately before starting the interview. 
In line with HEC guidelines, it was emphasised that participation was entirely voluntary. Organisations agreed in principle to participate, then certain teams or team members were asked if they would be interested in participating. Not all personnel at participating organisations were invited to participate. Only teams that met the criteria were given the option of participation. There was no requirement for an individual person to participate even though the organisation had approved the participation of their team. In several cases the organisation's representative simply sent out an email to a team distribution list inviting those who were interested and willing to participate to contact the researcher directly by email. Therefore, the onus was clearly on the individual team member to make contact, further underscoring the absence of coercion. Interviewees were also reminded of their right to withdraw from participation up until data analysis commenced. One interviewee exercised this right and withdrew participation prior to data analysis but after the interview was transcribed.

Every effort was made to ensure sensitivity to significant social and/or cultural practices of the community to which each individual participant belongs. For example, water or coffee/tea was offered to participants. Given that most interviews were conducted at or conveniently near the participants' workplace, there was no need to reimburse participants for travel or time.

\subsubsection{Data Management}

The management of the data collected in the course of this research is the explicit responsibility of the researcher. Every effort was made to protect the security of the data and the privacy of the individuals interviewed. The researcher ensures that data is secure from unauthorised access, use, modification, disclosure and misuse. Access to the raw data is restricted to the researcher only. No other individual has access to the original, named interview transcripts. These are electronically filed in a separate folder on a password-protected laptop. Hard copies of the signed consent forms and interview notes are filed and kept in a locked cabinet.

The privacy of individual participants is protected by being reported in a non-attributable form. As is stipulated in the information sheet the anonymity of individual participants is ensured by the use of unique descriptors (see Appendix B). Participating organisations were each given alphanumeric descriptors while interviewees are provided with pseudonyms. In additional to this, prior to data analysis any identifying material has been removed from the transcription. This ensures that interviewees cannot be linked to their comments. Personal biographical information is also handled 
in a way, which protects the privacy of interviewees. Again, only the researcher has access to the raw data. It is incumbent on the researcher not to keep the data any longer than necessary. As per the University's policy, the data will be destroyed after peer review, examination and publication. The consent form presented to participants clearly stipulates that the data will be destroyed two years after completion of this research (see Appendix A).

\subsubsection{Conflicts of Interest}

There are no conflicts of interest that need to be acknowledged. No other organisation benefits from the completion of this study in either a financial or reputational sense. Nor do the findings have to be reported to an additional third party other than those who participated in the study. Benefits for the researcher are entirely personal and professional but not commercial. This research has provided the researcher with an opportunity to delve deeply into a subject matter that interests her intensely. It has given the researcher an opportunity to learn a considerable amount. Coincidently, this subject matter is also of professional relevance as it is highly pertinent to work in human resources and/or organisational development. A professional editor, Madeleine Collinge, provided copy-editing and proof-reading services in accordance with the Editorial Advice Policy of Victoria University of Wellington.

\subsection{Chapter Summary}

In this chapter, the research paradigm, philosophical assumptions and the researcher's position in the study are discussed. This research is interpretivist in nature because it involves the subjective perceptions and perspectives of those interviewed (Denzin \& Lincoln, 2011). This research is qualitative as befits exploratory research, which seeks to further understanding (Blaikie, 2000; Grix, 2010). The research problem, research objective and the research questions are presented in some detail as these provide the foundation for this study. The research design and the methodology of the study describe how this research was designed (Creswell, 2013).

The method used in this study is also described in detail. This qualitative study involves 49 face-toface interviews with professional contractors, permanent employees and managers working in the Information Technology divisions of 10 organisations in three major cities in New Zealand.

Purposive sampling was used to identify organisations to participate (Cavana et al., 2001; Patton, 2002). Once an organisation had agreed to participate, criterion sampling was engaged to identify appropriate teams comprising a professional contractor, permanent employee and their manager. 
In line with HEC guidelines, it was emphasised that participation was entirely voluntary. Organisations agreed in principle to participate, then certain teams or team members were asked if they would be interested in participating. Not all personnel at participating organisations were invited to participate. Only teams that met the criteria were given the option of participation. There was no requirement for an individual person to participate even though the organisation had approved the participation of their team. In several cases the organisation's representative simply sent out an email to a team distribution list inviting those who were interested and willing to participate to contact the researcher directly by email. Therefore, the onus was clearly on the individual team member to make contact, further underscoring the absence of coercion. Interviewees were also reminded of their right to withdraw from participation up until data analysis commenced. One interviewee exercised this right and withdrew participation prior to data analysis but after the interview was transcribed.

Every effort was made to ensure sensitivity to significant social and/or cultural practices of the community to which each individual participant belongs. For example, water or coffee/tea was offered to participants. Given that most interviews were conducted at or conveniently near the participants' workplace, there was no need to reimburse participants for travel or time.

\subsubsection{Data Management}

The management of the data collected in the course of this research is the explicit responsibility of the researcher. Every effort was made to protect the security of the data and the privacy of the individuals interviewed. The researcher ensures that data is secure from unauthorised access, use, modification, disclosure and misuse. Access to the raw data is restricted to the researcher only. No other individual has access to the original, named interview transcripts. These are electronically filed in a separate folder on a password-protected laptop. Hard copies of the signed consent forms and interview notes are filed and kept in a locked cabinet.

The privacy of individual participants is protected by being reported in a non-attributable form. As is stipulated in the information sheet the anonymity of individual participants is ensured by the use of unique descriptors (see Appendix B). Participating organisations were each given alphanumeric descriptors while interviewees are provided with pseudonyms. In additional to this, prior to data analysis any identifying material has been removed from the transcription. This ensures that interviewees cannot be linked to their comments. Personal biographical information is also handled 
in a way, which protects the privacy of interviewees. Again, only the researcher has access to the raw data. It is incumbent on the researcher not to keep the data any longer than necessary. As per the University's policy, the data will be destroyed after peer review, examination and publication. The consent form presented to participants clearly stipulates that the data will be destroyed two years after completion of this research (see Appendix A).

\subsubsection{Conflicts of Interest}

There are no conflicts of interest that need to be acknowledged. No other organisation benefits from the completion of this study in either a financial or reputational sense. Nor do the findings have to be reported to an additional third party other than those who participated in the study. Benefits for the researcher are entirely personal and professional but not commercial. This research has provided the researcher with an opportunity to delve deeply into a subject matter that interests her intensely. It has given the researcher an opportunity to learn a considerable amount. Coincidently, this subject matter is also of professional relevance as it is highly pertinent to work in human resources and/or organisational development. A professional editor, Madeleine Collinge, provided copy-editing and proof-reading services in accordance with the Editorial Advice Policy of Victoria University of Wellington.

\subsection{Chapter Summary}

In this chapter, the research paradigm, philosophical assumptions and the researcher's position in the study are discussed. This research is interpretivist in nature because it involves the subjective perceptions and perspectives of those interviewed (Denzin \& Lincoln, 2011). This research is qualitative as befits exploratory research, which seeks to further understanding (Blaikie, 2000; Grix, 2010). The research problem, research objective and the research questions are presented in some detail as these provide the foundation for this study. The research design and the methodology of the study describe how this research was designed (Creswell, 2013).

The method used in this study is also described in detail. This qualitative study involves 49 face-toface interviews with professional contractors, permanent employees and managers working in the Information Technology divisions of 10 organisations in three major cities in New Zealand.

Purposive sampling was used to identify organisations to participate (Cavana et al., 2001; Patton, 2002). Once an organisation had agreed to participate, criterion sampling was engaged to identify appropriate teams comprising a professional contractor, permanent employee and their manager. 
A pilot study was conducted with the primary aim to test the flow and wording of the interview questions (Burns, 1996). The pilot was very useful in determining the wording of several interview questions, resulting in the adoption of the terms 'integration' to describe organisational socialisation and 'expectations' to refer to the psychological contract. It was clear in the pilot study that these academic terms were either ambiguous or lacked meaning for those being interviewed. Particular attention was paid to the wording of the interview schedule in order to create a rapport and establish a comfortable environment for each interviewee (Bryman, 2016; Cavana et al., 2001; Patton, 2002).

The researcher actually conducted a total of 51 interviews in three cities in New Zealand. Each interviewee was given an opportunity to review the transcription so a total of five made changes to the record of their interview (Denzin \& Lincoln, 2011). Subsequently, two interviews had to be excluded from data analysis. At the end of each interview, interviewees were asked several biographical data questions. These supplementary details are presented in order to provide some context about the individuals interviewed and the organisations that participated (Bryman, 2016).

Data was analysed with the assistance of the software NVivo. Each interview was coded according into nodes according to the literature reviewed (deductively). In many instances, data was coded simultaneously or to multiple nodes at one time (Grbich, 2007). Emerging from the data itself were several patterns or themes, which were also coded appropriately (inductively). This study's coding framework is presented as a graphical representation of this research and its elements, and the nodes that were developed in the course of the research process. Finally, ethical considerations such as approval from the university's Human Ethics Committee and data management issues are mentioned.

Each interviewee was provided with a pseudonym that reflects the nature of their work: professional contractor's pseudonyms begin with the letter $\mathrm{C}$, permanent employees begin with the letter $\mathrm{E}$ and manager's names begin with the letter $\mathrm{M}$. This device is apparent in the next chapter (Chapter 5: Findings), in which the findings of this research are presented in detail using the actual words of the professional contractors, permanent employees and managers interviewed. 


\section{Chapter 5: Findings}

\subsection{Introduction}

This research is about exploring the working relationship between professional contractors and permanent employees within an organisation. Key to better understanding the working relationship is discovering the more about the organisational socialisation of professional contractors and the psychological contract of those involved in the working relationship. Despite professional contractors being regular newcomers to the organisations in which they work, surprisingly there is little theorising of contractor socialisation. This thesis contends that the working relationship is specifically influenced by the socialisation of contractors as newcomers to organisations and in the mutual expectations, which form the psychological contract. This chapter reports the findings of this thesis. These findings are the results that emerge after data analysis of the interviews of professional contractors, permanent employees and their manager.

This chapter is divided into two parts. Part A is about the organisational socialisation of the professional contractors in this study. The psychological contract is used as the analytical lens for Part B, in which the findings regarding the mutual expectations of professional contractors, permanent employees and managers are presented. Findings are presented with ample evidence from the interview data, allowing the voices of those interviewed to be clearly perceived.

\subsection{Part A: How are Professional Contractors Organisationally Socialised?}

Organisational socialisation literature defaults to the permanent employee as the norm but, due to the changing nature of work and employment, this is no longer appropriate (Bauer, 2010). In a workplace, the early period of organisational socialisation is often referred to as induction and is a part of the longer organisational socialisation process (Saks \& Gruman, 2012). In the US that same period may also be called orientation or onboarding (Bauer \& Erdogan, 2010). This section aims to address the following sub-question of the research question: How are professional contractors socialised at client organisations in New Zealand?

\subsubsection{Organisational Policy regarding Professional Contractors}

Based on the interview data, organisation policy pertaining to professional contractors emerges as a strong influence on an organisation's approach to professional contractors. An organisation's corporate or HR policy relating to professional contractors sets the tone for how they are inducted, 
included or integrated and managed. Similarly, the lack of a corporate or HR policy regarding professional contractors also sets the tone for how they are treated. In this sub-section the perspectives of the different interviewees will be presented.

\section{Inducting Professional Contractors}

"The extent of [induction] really depends on the organisation and the organisation's approach to contractors. Some organisations do it much better than others" (Camilla).

As the quote above suggests, there is considerable variety in the induction of contractors. Most organisations involved in this study did not have clear corporate or HR policy regarding the induction of contractors. Several of the managers interviewed had developed their own methods based on IT policy. In no instance was there a centrally designed and co-ordinated programme for professional contractors specifically. The majority of these organisations had some form of corporate programme for new permanent employees, however. Van Maanen and Schein (1979) propose polarised pairs of tactics or methods of socialisation: collectively or individually, formal or informal, fixed or variable, sequential or random and serial or disjunctive. Some contractors interviewed experienced very little by way of induction (Cain, Carol). Others reported positively about their induction experienced comparing it favourably to others they had experienced (Cathy, Cyril). Although there was some variety in the data, the common experience of the professional contractors interviewed was that their induction was collective, informal, variable, random and serial. Each of these will be explained further in the paragraphs below.

Of contractors interviewed, it was common for them to be inducted to their role and the organisation collectively. This means that there was no tailor-made induction programme for that individual, which would be an individual tactic. Those contractors who received the collective tactic experienced an induction programme specifically for employees. This is an indication of the unavailability of appropriate resources, support or material for professional contractors. In a few instances, the contractors experienced induction individually in the form of working through an induction checklist. In cases where contractor-specific checklists had been developed, these were simplified versions of those developed for permanent employees, so while not tailored to the specific contractor they were modified for professional contractors in general.

All contractors report that their inductions were generally informal. This means that they were not separated from veterans or employees for that purpose (Van Maanen \& Schein, 1979). In no 
instance was a formal induction process (classroom or workshop based) reported to have occurred. As is quite common among contractors, the majority of interviewees received no handover from a predecessor (a fixed tactic) so almost all contractors experienced a variable tactic because there was no particular timeframe specified. There was one exception to that. In that case, a contractor (Cathy) was engaged to take over a role from an existing permanent employee (Eden). Eden, the predecessor, also remained available to follow up questions after an initial period. In that instance alone was a fixed tactic employed.

For the contractors in this study, their socialisation was largely random as the socialisation procedure was emergent or as required. A few contractors had fixed steps leading to their assumption of the role in the form of some health and safety or documentation management system training. This type of training is required by many large organisations so it is mandatory for all newcomers to participate, regardless of length of contract. In these instances the socialisation is considered sequential. In general, a serial tactic of socialisation was used to socialise new contractors at almost all organisations because in no instance was a contractor secluded or isolated from experienced members of the wider organisation. Current members of the organisation were able to participate in the socialisation of the professional contractor. However, there was some evidence of a disjunctive tactic being used as a few contractors report being put in at the "deep end" (Chloe). Cain admits that his induction could have been better. Similarly, Colin had to "...find all the information, accumulate all the information and then actually start doing something with it." In such cases, the contractor had to take the initiative by finding the information or help.

\section{Managers' Perspective of Induction}

"We don't show [professional contractors] quite so much love. That is the key difference. They come in, they do the job as expected and they are out. We don't spend so much time explaining the culture or how we work" (Mick).

As Mick states in the quote above, the induction of professional contractors is often not given as much time or attention as it would for a permanent employee. However, the managers in this study acknowledge the responsibility of getting a new contractor up to speed. Matthew acknowledges that induction, onboarding and support of newcomers, regardless of whether they are contractors or employees, is a significant part of his role as a manager. They largely recognise that this is part of their people management role. Some managers spend time providing information, resources or social support. Some managers arrange for the contractor to meet with key people to ease their transition. Maria organises briefing sessions with senior, knowledgeable representatives to give the 
newcomer a valuable overview of the business and the organisation. Some managers reactively assist the contractor in response to specific questions or requests from the contractor. Mick feels that because employees are going to be around so much longer than a contractor it is in their best interests to help a contractor understand how things work at the organisation.

Spend Time. Murray feels that onboarding a contractor is an immersion process. The team has documentation but the easiest way is to actually work with the team or "be in the room" to become familiar with how things are done (Murray). Morris only gives them as much information as necessary for the contractor to do their job or, as he puts it, "on an as needed basis." Michelle provides contractors with material, information, tools, processes and a few introductions. Moses notes very little difference between how they onboard permanent employees and contractors because they want to maintain the same high standards. Murphy describes the process as "pretty organic," as team members step in as needed to help induct the contractor. One manager details his involvement in the induction of a newcomer as follows:

We have an induction process but that is for me as a line manager simply getting them to ensure that they've read the code of conduct and [to] sign a piece of paper to say they'll comply with that. And we have an induction booklet that we provide with the individual to read and it is simply what is here [at the workplace] and whom they need to talk to for various things. We used to have an induction session where you'd actually sit down in a room and people would tell you various things. I think we did away with that. We've gone with a booklet and the only other thing as a line manager that I do is that day the person arrives, where I can, I'll take them around the various groups and introduce them to people they need to know and talk to for various things. (Max)

Delegate. Some managers choose to delegate that task either formally or informally. An example of this is through the appointment of a buddy, mentor or peer to support the contractor. Molly delegates onboarding activities to someone else on her team. Molly or her manager assigns them a buddy and they go through some standard documentation before touching on some project specific stuff. "A permanent [employee] will have a buddy but a contractor probably doesn't. They will have team members and they know they can come to talk to me and there's others..." (Margaret). It seems the organisation policy is to assign a buddy to permanent employees but not to contractors so the manager makes it clear that they are to talk to her (Margaret). "So we usually buddy them up with a permanent employee as well when they come on board. How well they relate to that buddy 
and the people around them certainly... Some come onboard and relate a lot better than others. It depends on the type of person" (Mark).

A Process. Some managers refer the contractor to a checklist or other such documentation. Miles created a "slimmed-down" version of the HR induction activities of permanent employees for contractors. Miles felt that not having such information available put contractors at a disadvantage so he developed a system for new contractors. He describes it in detail as follows:

When I first arrived there we didn't have anything really established for onboarding contractors. What I felt was it put them at a disadvantage coming into a strange organisation without the context of the organisation. At least if you come into an organisation as a permanent employee you spend more time researching the organisation as part of the activities involved in your interviews and so on. You already have a touch-base with it. Coming in as a contractor you're expected to hit the ground running. There is a less slow introduction that you might expect for a permanent employee so it seems to me that it was inequitable not to give them the opportunity to get to understand the organisation so we've created an induction guide for contractor staff so it is a summarised version. We don't include all the information about the [organisation] because a lot of it would be irrelevant to them, their focus is what they are doing for us. (Miles)

In one case, the manager had developed an induction document specifically for her large team of both permanent employees and professional contractors. The significance of Margaret's approach is that both the permanent employees and the professional contractors on her team receive the same checklist so there is no differentiation between the two. This finding highlights Margaret's desire to treat all those on her team equitably regardless of whether they are professional contractors or permanent employees. This process is described as follows:

I have a document that I provide them on Day One to permanents and contractors which is the Induction Guide, which is the one I created myself which is something that they can keep and refer to all the time and it tells them how to do things. (Margaret)

However, Mitch feels that induction or on boarding is an administrative "overhead" that requires "time and effort" so it just gets overlooked. He feels that because of time constraints on both managers and employees time only the bare minimum of this is done (Mitch). 


\section{Including or Integrating Professional Contractors}

"What is really important is that you are integrated into the business team, into which you are delivering the project. That is vital because that is where your subject matter expertise comes from and they are the people, it is their expectations, that you need to understand and meet or exceed so that is the really important thing" (Carol).

For Carol, quoted above, being integrated into the business unit that she is working with is key to performance. Being integrated into the organisation or the division she is in is of secondary importance to Carol. Interestingly, the policy approach to contractors varies considerably from organisation to organisation. While managers mentioned policy, many of them are not aware of the organisation's policy or HR policy with regard to contractors but referred to an IT or ICT policy. For example, within the IT division at A1 there is a corporate policy detailing the treatment of contractors and specifies what contractors are permitted to do. At that organisation contractors are generally excluded from organisation-wide meetings, social functions and corporate events, a practice that does not meet with the approval of some interviewees (Crystal and Emma) but other interviewees merely accept it (Cathy and Cain). Some organisations have no explicit policy pertaining to contractors so it is left to the discretion of the manager as to how these workers are treated (B5, C3). It is probable that it is this individual discretion that causes much of the diversity in the treatment and management of contractors in this study.

The level of contractor inclusion in organisational functions such as meetings, briefings, facilities and activities is also a relevant issue for contractors. There is such differing practice regarding the extent to which contractors are included. Some organisations handle contractors very differently by providing them with different security passes or badges and limited access to some company facilities (A1, B4). For example, professional contractors were not able to use the car park, gym and some other recreational facilities at A1. A1 also separates contractor email addresses and have them on different email distribution lists, which means contractors may have limited access to some information. Other organisations have little differentiation, considering contractors to be just like permanent employees (C2). There is evidence that some interviewees did not know which of their colleagues were in fact professional contractors (Emma, Carla and Eve). Some employees also voice opinions on organisational policy in relation to contractors. Emma feels the organisation's policy to exclude contractors has meant that contractors are very "siloed", which has an impact on knowledge sharing. Emma refers to the rules preventing contractors from attending meetings and social events as "silly" and impractical so she refused to adhere to them. 
According to most of those interviewed, professional contractors are generally included in social functions. This is true at a team level where, in some instances, contractors outnumber permanent staff so it is the contractors who are initiating the social activity (Evan). At one organisation, contractors were generally not included in social events but the employee being interviewed did not approve of this practice. For example, "No Christmas gifts, no team lunches. Someone told me something the other day and I went 'Really?' [Contractors] are not meant to go to Friday night drinks. It was something really pathetic and I went 'Really? One beer?’” (Eden).

When it comes to large corporate events or functions there is an understanding that contractors pay their own way. This seems to be common to many of the participating organisations. Margaret says it is the organisation's policy to include contractors in every briefing or meeting for which they are advised on how to charge their time. For social functions contractors are always invited but they must "pay their own way" (Margaret and Michelle). One manager acknowledged a recent change in policy to providing drinks for contractors. Matthew says, "I think that there is a constant attention to trying to build relationships and strengthen team dynamics so it was in the context of that."

Contractors are also not expected to bill the client for their time to attend social functions. For example, Charles refers to an internal policy for contractors outlining that they are welcome to attend functions, such as the Christmas Party, but they must pay their own way and not bill for the time. Like B3, some organisations choose to make this understanding clear and explicit but many do not so it is left to the contractor's manager to enforce. At B5, Ethan says there is no written policy about the inclusion of contractors in social functions so it is left to the discretion of the individual. At organisations where multiple contractors were interviewed, some contractors reported differing induction experiences. This shows that not only is the practice of contractor induction varied across organisations but it is also varied within organisations. In the absence of explicit policy on the treatment of contractors, it is left to the discretion of individual managers, which results in diverse practice.

Professional contractors' references to policy provide some further insight. Crystal talks about a mismatch between what A1's policy is and what team members want to do. Crystal is disappointed with how contractors are excluded at a management and policy level but not by how the staff treat her as a contractor. "Excluding contractors is policy level. It is not these guys that I work with. No. It is embarrassing for them. They hate it" (Crystal). Crystal points out that this policy of exclusion of contractors is not common. Crystal has worked at another organisations where there was no such 
policy. Crystal's experience described here is an example of inclusion at the team level but not the corporate level. There appears to be hierarchy of inclusion evident in the data. Professional contractors are generally included at a team level but this inclusion decreases as the scope widens from team to group, from group to division and from division to organisation. As Osnowitz (2010) reports, "As guests of their clients, [contractors], too, tried to fit in, to integrate themselves as seamlessly as possible into a client organization. Remaining on the margins, however, contractors are never full participants" (p. 118-119). Charles, who claims that contractors are never fully integrated, endorses this sentiment.

\section{Managing Professional Contractors}

"[Contractors are] part of the team and it is an important role and they need to be treated, in that sense, as a valued contributor and managed appropriately" (Matthew).

The quote above captures a shared sentiment among the managers interviewed: contractors are valuable. When it comes to managing contractors versus permanent employees, the sentiment among managers is paradoxically best expressed as "the same but different" (Matthew). As several managers point out, the main differences between employees are that contractors do not have twiceyearly performance reviews, associated bonuses and there is no policy to train a contractor (Margaret, Mick). Such HR procedures and systems are wholly reserved for permanent employees as part of the employer-employee relationship or agreement. However, there is clear evidence that most contractors meet with their manager regularly generally, either weekly or fortnightly. Errol and Evan believe that some managers find contractors easier to manage than permanent employees.

Several managers refer to their organisation's explicit efforts to actively reduce the number of contractors on the books (B2, B5 and C1). According to those interviewed, the reasons for this are the cost of contractors and the loss of intellectual property (IP) or organisational knowledge (Michelle, Max, Maria and Moses). Existing contractors are being converted to permanent employees or transferred onto fixed-term contracts. Ewan is an example of one such contractor, recently employed in a permanent capacity after many years contracting with the same organisation. However, Maria describes unsuccessful efforts to convert contractors to employees. She reports, "Some of them [contractors] won't do it. ... There was a senior business analyst on a project for probably two years or eighteen months maybe. She had no interest in becoming a fixed term and left. [She] wouldn't change over and left at the end of the term that we had her contract for." 
Two of those interviewed described a policy of "enforced stand-downs" in the organisations they work at. Mick describes an organisational policy that requires an "enforced six week stand-down for every contractor for every year that they are here." The rationale for this policy is two-fold. First, it is so that a contractor does not appear like a permanent employee; that is, continuously employed (Mick). The issue with continuously employing a professional contractor is that it may become harder to legally distinguish a contractor from a permanent employee. As with the IBM case in the United States in 1997, in some countries there are legal restrictions placed on professional contractors being treated the same as permanent employees (Barley \& Kunda, 2004).

Therefore, such stand-downs ensure that contractors are not engaged for a long, unbroken period so cannot be considered permanent employees. The second reason is so that management can review the necessity of re-engaging the contractor or not (Mick). Crystal also describes a similar, though shorter, stand-down period over the summer. She believes the rationale for the two-week standdown for professional contractors is that managers feel they are not receiving value for money over this holiday period. Based on the data collected, the latter form of stand-down seems to be more common among organisations in New Zealand but there is no evidence of this in the literature.

Matthew also believes that "...from an HR policy and practice perspective [there is] a tension there that looks to keep the percentage of contractors of the total workforce to a certain level..." At the same organisation, Mark's team is currently 20-25\% contractors but at their peak $35 \%$ of staff were contractors, which Mark feels was a bit harder to manage.

\subsubsection{The Content of Socialisation Messages}

"Different things are important to me being a contractor. [Permanent employees] are worried about wanting the desk by the window. They're worried about the housekeeping and security and comfort that I don't worry about any more. The difference is I have different requirements to a permanent employee. The things that are important to me are not the same as the things that are important to them" (Crystal).

Due to the transient, short-term nature of a contractor's role, it is apparent that they value different aspects of a role than permament employees do. This idea is clearly captured in Crystal's quote above. Crystal acknowledges that she is not concerned with amenties and/or the working environment but more about the work itself. In a similar way, only certain aspects of the socialisation messages given to newcomers will be of relevance and applicable to professional contractors. The review of the literature reveals that organisational socialisation, being a learning activity, involves certain content. What is the content of organisational socialisation messages or 
information? What do professional contractors need to know? Interviewees were asked about that in order to ascertain the opinion or perspective of professional contractors themselves.

Contractors need to know about the client organisation's culture \& values, structure and language. The dimensions used in this question are based on Chao et al.'s (1994) socialisation scale, which was explained in Chapter 3. This scale is one of several that are routinely used to assess or measure the socialisation of individuals at organisations (Haueter et al., 2003; Taormina, 1994). No one measure of socialisation has gained general acceptance or widespread use. Items from this particular scale were selected because of its relevance to professional contractors as well as permanent employees, for whom it is designed. Interviewees were free to answer with simple yes or no as befits a closed question. However, many interviewees chose to elaborate on their answers and explain their opinions. The interviewer also encouraged this with a prompt or two, where appropriate. According to the professional contractors interviewed, they need to know about the client organisation's culture \& values, structure, language and, to an extent, goals and strategy. These findings are summarised in Table 9.

Table 9. Socialisation Content: What a Contractor Needs to Know.

\begin{tabular}{|l|l|}
\hline Dimension & Contractor \\
\hline Culture and Values & Yes \\
\hline Structure & Yes \\
\hline Language & Yes \\
\hline Goals and Strategy & Yes, to an extent. \\
\hline Politics & Inconclusive \\
\hline History & No \\
\hline
\end{tabular}

Culture and Values. Organisational culture surfaces repeatedly in literature reviewed, so interviewees were asked about both culture and values. An organisation's culture needed no explanation or preamble during the interviews because interviewees had an understanding of the term organisational culture. The majority (13) of the contractors interviewed believe that a contractor does have to understand an organisation's culture and values for differing reasons. Cain, Carol and Charles feel that culture and values are very important for a contractor to understand. As Cathy says, "Yes, absolutely or you're never going to fit in." The idea that understanding an organisation's culture helps with a contractor's integration is shared by Colin. He believes that contractors who do not understand an organisation's culture will definitely remain outsiders. For Chloe understanding an organisation's culture is a matter of survival. Charles, Callum, Caleb, Cliff 
and Crystal see culture as the framework, guidelines or lines within which a contractor must operate. If he or she goes beyond or outside these parameters then their tenure may be limited. Charles says, "Yes, it is important because you have to work within that framework so you need to understand what they are." Caleb says, "I learnt then that that rigidity is very hard to ... you've got to understand that rigidity and work through it rather than sometimes try and work around it." Cliff feels that an understanding of culture helps a contractor to "...know, where you can push, where you can't. What you can change, what you can't.” For Carla, understanding an organisation's culture is important to the work, particularly in developing solutions that will be appropriate and acceptable to the organisation. Curtis says, "[Knowledge of culture and values] can be useful. It is good to align as much as possible for credibility."

Camilla, Chase, Cindy and Cyril have alternative views of an organisational culture. Chase distinguishes between espoused values and culture (that which is plastered on an organisation's walls) as opposed to the informal culture and values. According to Chase, it is the latter that is more relevant to a professional contractor. He warns contractors not to be "oil to their water or you will just not last." Camilla states, "Culture and values almost depends on how integrated you are as a contractor. If they're willing to integrate you, you might be more interested in it. It is not that I'm not interested in it..." For Cyril it is not culture and values in general that need to be understood but the work ethic at the client organisation: "Customers may vary but some may be kind of relaxed while others are quite diligent or hard-bent. You have to adapt to them somehow." For Cindy an organisation's culture is nice to know but not all that relevant. Interestingly, Cindy works alongside many other professional contractors. Her exposure to permanent employees is limited, which may hinder her perception of a strong organisation culture.

Structure. Among the contractors interviewed there is general agreement that a contractor needs an understanding the structure of the client organisation. For three contractors understanding the structure is about responsibilities, accountabilities, relationships and networks between teams (Callum, Carla and Carol). For three other contractors, structure is about reporting lines and who the decision-makers are (Cliff, Cyril and Camilla). For three other contractors, it is simply about understanding where they fit in (Colin, Caleb and Chloe). Both Charles and Cliff feel that a contractor does not have to understand the structure of the whole organisation but just the part of it that relates to their work. Three of these contractors point out that it is sometimes quite hard to figure out the structure of the organisation so they have to actively seek out that information on the intranet and from an organisation chart (Caleb, Chloe and Crystal). Two interviewees merely said 
that a contractor does need to understand an organisation's structure but offered little explanation (Cathy and Cain). Curtis says, "Yes, you do or you'll be caught out." None of the contractors interviewed feel that structure does not need to be understood.

Language. The content dimension of language is described as "Knowledge of technical terminology as well as jargon, acronyms and slang that are specific to that organisation" (Chao et al., 1994, p. 732). Every one of the contractors interviewed agrees that a contractor does need to understand the language, jargon or technical terminology used at the client organisation at least to a certain extent. Crystal's comment in relation to jargon epitomises the opinions of many of those interviewed. She says, "It is essential to pick the jargon up or you will always seem on the outside. If you don't know what people are talking about and aren't using the right terminology there is a disconnect." Carol claims to seek out a client's glossary as soon as possible. Colin points out that it is acronyms in particular that everyone uses that are essential to understand. Both Caleb, Cliff and Camilla feel that, though important, jargon is something that a contractor will pick up on the job, over time at the client organisation. Carol, Colin, Chloe and Curtis admit to asking what certain words, acronyms or terms mean.

Goals and Strategy. Chao et al. (1994) combine goals and values in their socialisation scale. Chao et al.'s (1994) description of this dimension is summarised as the link to the larger organisation and includes the unwritten goals and values that are espoused by influential members as well as an understanding of rules and principles of the organisation. However, during the interviews, participants were asked about strategy and goals because both of these are long-term, future orientated and applicable to the wider organisation. Fourteen of the contractors interviewed feel that a client organisation's goals and strategy need to be understood by a professional contractor. Six of those contractors qualify their answers, however. Crystal, Colin, Carla and Cliff all feel that understanding an organisation's goals and strategy may only be essential to a certain extent or for certain tasks, pieces of work or projects. Cain's involvement in a piece of work or project is typically after the need for that work (the business case) has been established with reference to the organisation's goals and strategy, so it is not essential for him to understand those goals or strategies. Carol says, "Yeah, you do need to understand that but to be honest I've been in too many organisations where they have published goals and strategies and plans but they don't follow them. [There are] disconnects all over the place." Three of the contractors interviewed do not feel that contractors need to understand the goals and strategy of the organisation (Charles, Chase and Camilla). Charles points out that some of the work contractors do is only tenuously connected to the 
organisation's strategy. Chase claims to be interested in outcomes rather than the strategies themselves. For Camilla goals and strategies are interesting but those goals and strategies will not have immediate impact on her work and may not for several years.

Politics. Chao et al. (1994) describe politics as “acquiring information about the organisation's formal and informal work relationships and power structures" (p. 732). Organisational politics is something that all three parties - contractors, employees and managers - mentioned in various ways. In general, contractors' opinions about organisational politics are clearly polarised. There are those who think understanding organisation politics is important and those who do not. Seven of the contractors interviewed believe that contractors have to have an understanding of organisational politics (Cain, Caleb, Calvin, Carol, Carla, Curtis and Cliff). This shared opinion is captured well by Carla, who states, "Yes, that can impact [work] as well. You need to have an awareness of this and understand if there could be any roadblocks because of certain politics. This is usually handled by the [manager] who keeps in touch at a higher level..." Like Carla, Cain and Carol also believe that those higher up or more senior will help with the politics.

For the other contractors, understanding organisational politics is not important because it is something that does not relate to their role (Cathy, Cyril, Cindy and Crystal) or it is something that they deliberately avoid (Callum, Camilla, Chloe and Colin). Cyril thinks that organisational politics is not his concern but a manager's. Chase suggests understanding organisational politics but recommends staying out of it. Chase says, "There are lots of ways you can do that. It is very easy to get sucked into it. You don't get into the sort of off-side conversations about people and recognise that there are specific challenges that you have to go through and don't try to circumvent them and don't try to get into the political game." However, Charles is ambiguous with his answer. "Not so much. You need to know the politics in your area and if you need to get things done by using those politics and that comes back to your relationship with the people who are the senior managers. You need support to get things pushed through, which there might be resistance to." Therefore, whether or not professional contractors need to know about organisational politics is inconclusive.

History. Chao et al. (1994) describe history as the knowledge of the background, traditions, customs, myths and rituals of an organisation. Of the contractors interviewed only two responded affirmatively (Camilla and Carol). History is relevant for Camilla's role because the organisation's history may impact on the data she works with. In Carol's experience, history has a particular impact on how those within the organisation think about and approach change. Therefore, an 
understanding of the past may be useful. Nine of the contractors believe that an organisation's history does not have to be understood by a professional contractor (Callum, Calvin, Charles, Cathy, Cliff, Cindy, Chase, Curtis and Crystal). Three of those contractors also added that understanding history "helps" (Callum, Charles and Cliff). In the data, there is a strong sentiment that understanding an organisation's history is helpful but not essential. Five other contractors responded in this way (Cain, Chloe, Caleb, Colin and Cyril). For example, Cain believes history influences the organisation's culture but history is not essential. Similarly, Chloe feels history is helpful but not a necessity. Caleb believes it is important to know the organisation's history in relation to the particular area of work the individual is doing. Colin believes understanding the history is only beneficial if it directly affects the work he is doing. Cyril feels that history is a "nice to have" but it is not really essential. "Sometimes the customers are really proud of their history so if you know that you can engage with them about that it is definitely a pro" (Cyril).

Contractors need to know about processes \& procedures and have strong technical skills.

Newcomer socialisation requires an understanding of certain content or information. Managers were asked what they think contractors need to know in order to perform their role. This question was an open-ended one in order to elicit a broad response from the managers interviewed. Their answers are surprising because they do not conform to the Chao et al. (1994) scale particularly well at all. In fact, those specific dimensions did not surface in the answers that managers supplied. The managers interviewed do not mention an organisation's goals, values and history. Table 10 captures the managers' perspectives of what a contractor needs to know.

Table 10. Managers' Perspective on What a Contractor Needs to Know.

\begin{tabular}{|lllllll|}
\hline $\begin{array}{l}\text { Processes and } \\
\text { procedures. }\end{array}$ & $\begin{array}{l}\text { Strong } \\
\text { technical } \\
\text { skills. }\end{array}$ & $\begin{array}{l}\text { Industry, } \\
\text { sector or } \\
\text { domain } \\
\text { knowledge. }\end{array}$ & $\begin{array}{l}\text { Who is } \\
\text { who? }\end{array}$ & $\begin{array}{l}\text { A social } \\
\text { fit with } \\
\text { the team. }\end{array}$ & $\begin{array}{l}\text { Only } \\
\text { what } \\
\text { they } \\
\text { need to } \\
\text { know. }\end{array}$ & $\begin{array}{l}\text { Scope, } \\
\text { size of } \\
\text { the role. }\end{array}$ \\
\hline Margaret & Mark & Matthew & Margaret & Max & Maria & Maria \\
\hline Murray & Moses & Morris & Michelle & Moses & & \\
\hline Maria & Matthew & Murphy & Mitch & & & \\
\hline Michelle & Molly & & & & & \\
\hline Mark & Max & & & & & \\
\hline Mitch & Mick & & & & & \\
\hline Morris & & & & & & \\
\hline
\end{tabular}


Seven of the managers made reference to an organisation's processes and procedures. Margaret says, "For the context of what we're doing, they need to know our processes and procedures, our software delivery life-cycle, our governance models, who the key people are, who they can go to when they need advice and what that is." Managers refer to professional contractors having strong technical skills in specific tools or technologies. Max says, "Obviously they have to have the right technical skills for the role." Those engaging professional contractors have clear requirements that must be met. Moses says, "Well, apart from being aware of the statement of work which of course is the first thing we do, they've got to have the background that will largely - largely underlined that meets our requirements."

Strong industry, sector or domain knowledge also emerged as a requirement for contractors. This item is second on the list of those that emerge from the interviews with managers. As Matthew points out, “...often there is a technology aspect, sometimes there is a domain aspect to it as with [Cain], he's got a particular background in [a specific field] and his domain knowledge was at the time that was specific expectation with him joining." Three of those interviewed talk about knowing who is who, who to go to for advice, who to engage with and who the stakeholders are. This relates to both the people and politics dimensions of Chao et al. (1994) socialisation scale. Only two managers raise team or social fit although other managers do imply this at other times in their interviews. One manager, Maria, is clear in her opinion that a professional contractor only needs to know what they need to know and/but no more. Maria says, "To do a job [the contractor] only needs to know as much as he needs to know. As long as he has the technical skills."

\subsubsection{Professional Contractors' Indicators of Adjustment}

"I think that is one of the key things you have to be is adaptable. The difference between a permanent and a contractor is the ability to adapt quickly to the environment" (Cliff).

One of the main aims of organisational socialisation is the integration of newcomers so they can be productive in as short a time as possible. Cliff, quoted above, clearly captures this sentiment by highlighting the importance of adaptability for professional contractors. This part of this presentation of findings on organisational socialisation addresses the question: How do you know when a contractor has adjusted/integrated to the new role? Theories of organisational socialisation identify proximal outcomes as those that indicate how well a newcomer is adjusting to his or her new position within the new organisation. There are three well accepted proximal indicators of adjustment: acceptance by insiders, role clarity and performance self-efficacy (Bauer \& Erdogan, 
2012). These indicators of adjustment are used as a way of organising interviewees' responses to the question they were asked. The data collected is presented below according to the category it best exemplifies. After mapping the data gathered from interviewees to these indicators of adjustment, an addition to current theory is proposed regarding the indicators of adjustment that are specific to contractors. These are discussed in detail below.

\section{Acceptance by Insiders}

'Acceptance by insiders' has been positively linked to performance (Bauer \& Erdogan, 2012). Interviewees were asked if they think a contractor is able to function without being accepted by insiders. Based on the data collected, acceptance by insiders is not considered necessary or essential to contractor integration. The general sentiment is that contractors can function without acceptance by insiders but it is much easier for a contractor to deliver if insiders accept the contractor (Cathy, Crystal, Cain, Camilla, Carla, Caleb, Carol, Cliff and Curtis). The professional contractors interviewed report that acceptance by insiders makes the job of a contractor easier to do. According to Carla, “...it would hinder a contractor's work if there is not acceptance by permanent staff as they are usually a wealth of information. So if the contractor is not able to gain acceptance or build relationships with people, it makes the job more difficult." As Cathy points out a contractor who does not have acceptance by insiders would have to be "pretty thick-skinned." Crystal says that without acceptance by insiders contractors will remain on the "periphery." According to Carol a lack of acceptance by insiders would result in "roadblocks all over the place." Chase also says acceptance by insiders is important or a contractor would become "disruptive." Charles holds a contradictory view of acceptance by insiders, rejecting the premise. Charles believes his manager is the only the insider who needs to accept the contractor so acceptance by insiders en masse is not required.

Among permanent employees, there is a much stronger emphasis on the social aspect of acceptance by insiders. Earl, Elliot, Eugene and Emmet all refer to social acceptance or inclusion in social activities as a sign of acceptance by insiders. The implication here is that contractors must earn acceptance by insiders through their relationship with employees. In other words, until there is a relationship established and developed, employees are not likely to accept an outsider. For example, Evan feels that employees regard contractors with a level of "scepticism" (although he does not feel that is quite the right word) so are required to prove themselves before permanent employees will award them with trust. This idea is also captured by Ernest, who says integration has occurred when 
contractors are no longer standoffish but have a rapport, are joking and giving each other a hard time, and then it is apparent that they have integrated sufficiently to be productive. In Emma's experience, employees regard contractors with suspicion because they fear the contractors would take their jobs. In this particular case, acceptance by insiders was not easily given at all.

According to Osnowitz (2010), "Integrated into on-site teams, contractors may function much like employees" (p. 113). For the managers interviewed, acceptance by insiders is something they are conscious of during the recruitment and selection process. Some managers consider team fit at the outset and monitor this (Mark, Mark, Mick and Moses). Other managers are concerned about the relationship the contractor has with the business or a key stakeholder (Michelle, Mitch, Miles and Maria). Murray talks about the social aspect to acceptance by insiders, such as going for drinks with the team. For Murphy, if the contractor works the same hours as an employee that contractor is more likely to be treated like one. It became apparent that acceptance by insiders is indeed a sign that a contractor is adapting to the new role but it is not a prerequisite for adjustment. Many of the professional contractors find it easier to do their job if they are 'accepted by insiders' but this is not necessary or essential.

\section{Role Clarity}

Bauer and Erdogan (2012) relate cost, stress, poor performance, low job satisfaction and commitment to confusion and ambiguity about one's role. Therefore gaining 'role clarity' would be considered a positive sign of adjustment to a role. For those interviewed, gaining role clarity is essentially about questions and there are countless references to professional contractors doing so. It is about the contractor asking questions, questioning, asking the right questions and knowing who to ask questions (Chase, Colin, Cyril, Eden, Evan, Eric, Mitch and Moses). In order to gain role clarity it seems contractors must have "...a clear definition of requirements. What are the deliverables?" (Cain). Role clarity is not only about reading corporate material or documentation but also about having a "conversation" (Camilla) and "having the right people in meetings or workshops" (Carol). The challenge with role clarity is that it is sometimes hard for a contractor to figure out who is involved and where to find the relevant information. For some contractors, asking questions seems to be easier than for others. This finding shows are clear links to proactive socialisation and to proactive behaviours (Crant, 2000). 
According to Eden, Elaine and Max, a sign that a contractor has effectively integrated is that the contractor is no longer asking lots of questions but getting on with the work. For Evan a sign of integration is that the type or nature of a contractor's questions changes. The contractor's questions become ones that even permanent employees cannot answer easily.

\section{Performance Self-efficacy}

The idea is based on Bandura's (1986) work which "predicts that increased confidence in one's ability to do one's job should relate to positive organisational outcomes such as performance" (Bauer \& Erdogan, 2012, p. 100). On one hand, the contractors interviewed appear to be particularly confident in their ability to do their job (Cain, Carla, Charles, Colin and Crystal). This confidence may be about certainty in developing relationships, confidence in their specific skills and abilities, confidence about taking risks or confidence about asking questions.

Several permanent employees interviewed reported that contractors seem to be noticeably confident (Eden, Elliot, Evan and Errol). This confirms an observation by Osnowitz (2010) who writes about contractors exuding confidence in order to engender trust. This confidence is a source of admiration for some employees. For example, Emma reflects, "I'll see contractors come in and within a week they are forging on ahead. They don't seem to have any concerns at all." The confidence professional contractors demonstrate is described as follows:

Possibly the biggest asset they can have is confidence in their own ability to go and ask the questions instead of sitting and waiting for someone to provide it because that is often not going to happen. As a contractor you have to have the confidence to go out and seek the answers to your questions. (Eden)

On the other hand, for some employees the confidence contractors display actually causes dismay. "There are [contractors] who arrive and think that they can just bulldoze through and that doesn't work" (Errol). Emmet feels that some contractors “...think that they are God's gift to anything but usually they are so narrowly focussed on what they are doing." The managers interviewed also feel that contractors often seem confident in their abilities (Michelle, Molly and Murphy). For Morris this confidence manifests itself in the contractor working "semi-autonomously," which is a good sign that the contractor is integrating. The idea of being autonomous is quite important to managers who simply do not have the time to spend with individual contractors. 


\section{An Additional Indicator of Adjustment of a Professional Contractor: Output}

One of the challenges of applying the standard organisational socialisation literature to professional contractors is that they are not permanent employees. There is a lack of knowledge about professional contractors in the existing literature. Therefore, it is possible that models like Bauer and Erdogan's (2012) Socialisation Over Time will not be completely appropriate for professional contractors. In this study the proximal outcomes have been focussed on because of the short-term nature of a professional contractor's role. According to Bauer et al. (2007) proximal outcomes are the early indicators of adjustment. It seems that the three indicators of adjustment to the role are not entirely sufficient. Emerging from interviews of several employees, managers and one contractor were other signs of integration that do not quite fit the model. For example, Elaine, Edward, Ewan, Mitch, Maria, Murphy and Cyril all mention indicators or signs of adjustment that are mostly physical, tangible or measurable in some way. This includes reports (such as regular financial reports) or documents (such as a budget or a plan). However, valuable contribution to meetings or workshops is also cited as an example of an indicator of adjustment (Murphy). Could there be an additional indicator of adjustment?

After careful analysis of the data collected, it became apparent that the other signs of integration mentioned by interviewees are all forms of output. Professional contractors are likely to produce many of these artefacts as a matter of course, particularly in a project capacity, so it is a realistic indicator of adjustment. The definition of the additional indicator of adjustment, output, would be: the completion of several crucial tasks, actions or milestones during the process of performing the role. Given the short or limited timeframe contractors are engaged for at a client organisation, a specific indicator explicitly linked to actual delivery or job performance would be highly useful. Adding output as an indicator of adjustment to Bauer and Erdogan's (2012) model would effectively create a modified model of newcomer adjustment specific to professional contractors.

According to those interviewed, the quality of these outputs is also important. If the contractor is well integrated the documents or reports the contactor produces will be accurate, of the standard expected and follow the organisation's templates or guidelines (Mitch and Elaine). The output referred to may be a valuable contribution to the team in the form of a highlighting an issue, a risk or process fault (Maria and Ewan). If the contractor is doing this and also offering a solution then that is a strong sign that he or she has been integrated effectively and adjusting to the role (Edward). A contractor who is producing quality outputs has integrated sufficiently, if not fully, and has adjusted well enough to be doing the job. The fact that various professional contractors, managers, 
as well as a permanent employee all make reference to an output as an indication that a contractor has integrated is significant. All three parties refer to this additional sign of integration, which serves to substantiate it. Such corroboration is valuable as each of these three parties has quite a different perspective.

\subsubsection{A Professional Contractor's 'Time to Productivity'}

"Time is the critical thing for a contractor. If you are seen as a person who doesn't use time [the way] that you are supposed to use [it] that can be very bad for you. That's why we're very cautious..." (Chloe).

'Time to Productivity' emerged from the litetature review as a particularly important notion for professional contractors. While relevant to permanent employees it is especially important to those who have no expectation of long-term employment such as professional contractors. The quote from Chloe, a first time contractor, show just how relevant time and accoutablity for time is to a professional contractor. Interviewees were asked directly about contractors' 'time to productivity' and what affects or influences this.

\section{Trends in 'Time to Productivity'}

Interestingly, several interviewees responded positively to the phrase and to the very idea of time to productivity. Many interviewees had an intrinsic understanding and appreciation of the term even though they had never encountered it before. Mick referred to the same idea but phrased it "time to value." The quote below epitomises some of the comments made in response to the question on time to productivity.

Time to productivity? Dead right. It probably comes back to the previous question about what they need. Their ability to figure stuff out themselves, some are better than others. Some are technically very good but, you know, they know their product and that is all they are really interested in. (Edward)

The responses other interviewees provided to these questions showed some interesting trends. Generally, it seems that employees' view of contractors' time to productivity is longer than contractors think it is. For example, according to the contractors at A1, a contractor's time to productivity is about two weeks. Employees, however, said that contractor's time to productivity is about a month or more. At least one of the manager's views was aligned with the contractor's opinion. Mark expects to see evidence of productivity by the second week. At A2, the Camilla believes she is productive from her very first day, particularly if the organisation is ready for the 
contractor. Elliot thinks it is three days before a contractor is productive. Again, the employee thinks it is longer than the contractor does. Mick is not specific about time to productivity but implies that a contractor's time to productivity is generally shorter than an employee's because a contractor does not have as many demands on their time as an employee does.

At B1, Evan thinks time to productivity is four to six weeks but the contractor's knowledge is restricted to that specific sphere. Carla only says her time to productivity was not long but does not specify days or weeks. At B2 there is a large difference in perception. The contractor thinks it took him way longer than the employees interviewed say, which is an interesting reversal of the apparent trend. Callum says it was six to nine months, but both Caleb and Eric think it was two or three months. The latter believes it depends on how much help the contractor receives. At B3 the employee thinks time to productivity is only one week, which is similar to Charles's experience because he was already well connected and had some background knowledge about the organisation. Two contractors at B4 say their time to productivity is mere days although Carol adds the caveat that it could be weeks depending on the readiness of the organisation. Cindy claims a month as her time to productivity. Interestingly, the two employees on the team have very different takes on how long it is before a contractor is productive. Errol thinks it is two or three months while Emily thinks it is two weeks. The manager's experience is between the two: three or four weeks. Colin's experience of time to productivity varies from immediately (within the first half and hour) and a week but could be as much as a month. Colin thinks that within a week a contractor should be being productive.

At $\mathrm{C} 1$ there is agreement that a contractor's time to productivity depends on the scope of the piece of work. According to Cliff, it would take two or three months to be productive if the contractor had to understand it all (culture, product and the work). Ewan shares a similar opinion. Cliff reports that for a discrete piece of work a contractor could be productive on Day One. At C2, there is an expectation that contractors will "start being productive within weeks if not days" (Eugene). Calvin says it was only a week or two before he was productive. The employees as C3 have had experience of contractors who are immediately productive and those who are dependent on an employee to get them going (Edward, Emmet and Ezra). Cyril seems to be one of the former, as he believes he and those he worked with were productive on Day One. Murphy agrees with the contractor's estimation of his time to productivity. 


\section{Three Factors Affecting Contractors' 'Time to Productivity'}

The information presented above provides some valuable insights into a contractor's time to productivity. Underlying time to productivity is the importance of minimising it, in order for the organisation to gain the maximum benefit from the professional contractor. Interviewees were also asked what influences a contractor's time to productivity. The data that emerged was analysed and the findings are presented next. Based on interviewees' responses, it was found that the main factors that affect a contractor's time to productivity are organisation readiness, role complexity and contractor capability. It is incumbent on the organisation to maximise the benefit of engaging a contractor by reducing their time to productivity. It is also the responsibility of the contractor to do his or her best based on their professional knowledge, skills, ability and experience that comprise their capability.

Organisation readiness. The 'readiness' of the organisation is mentioned as having a major effect on a contractor's time to productivity (Cathy, Camilla, Charles, Carol, Colin and Calvin). This readiness or preparedness is not straightforward because it includes both physical aspects and other elements as well. The organisation must have access cards, computer logons and a physical workspace, station or desk ready for the contractor. The organisation should also have relevant paperwork, documentation, publications, plans (clear goals) and reports ready for the contractor to access. Chloe, a brand new contractor on her first contract, shared a relevant perspective about a contractor's time to productivity as follows:

...if the project manager is not ready when you come on board and he or she is not ready with the tasks they want us to do then that will take time. If the system is not working, if the PC is not working, then there is no place for you to work in the first place. If the stakeholders you work with are not available then that'll be a blockage. All these three things were ready when I came [to work here]. (Chloe)

The process of accumulating all the information could serve to extend the contractor's time to productivity from days to a week. The example above illustrates the point that if an organisation is ready for contractor, then the contractor is better able to get on with the task they have been engaged to do. Cain, Camilla, Charles and Calvin include access to people and/or managers in their descriptions of what affects their time to productivity. This demonstrates the point that it is not just physical readiness that affects the contractor's time to productivity but also the organisation's readiness to provide support to a contractor. The support an organisation can provide may simply be 
ready access to key stakeholders or representatives from the business to provide valuable information to the contractor.

Most contractors interviewed had a workstation, computer access and security access cards ready for them on arrival. Several contractors pointed out that the high cost of contractors means that managers want them to be able to start the task as soon as possible to ensure that things are up and running (Camilla, Chloe and Colin). However, there were several anecdotes shared by the interviewees of organisations not being ready for the contractor. One contractor did not receive a working laptop for several weeks even though he was entitled to one (Callum). Another contractor reported to work as agreed only to find the floor completely empty. The client organisation had moved over the weekend and had neglected to inform him (Charles).

Role complexity. Complexity refers to the breadth or size of the role. The role that the contractor is required to do seems to have direct bearing on a contractor's time to productivity (Colin, Ethan, Ewan and Ezra). As Colin puts it, if the contractor has to deal with a broad range of internal people, then their time to productivity is longer. Colin's colleague makes this same point. According to Ethan, there is a difference between "vanilla IT" and the infrastructure side with which contractors can come up to speed relatively quickly, and more complicated pieces of work. According to Ewan, tasks with a very narrow, succinct scope require a very short time to productivity but broad, systemwide projects would take a much longer time to reach productivity. Similarly, Ezra thinks that contractors are paid to be up and running in a day but the complexity of their task may moderate that.

Contractor capability. This is about the contractor him or herself. It is about the contractor's KSAs as well as the depth of their professional experience with the type of work they are required to do. It is also about their experience as a contractor. Both highly experienced and less experienced professional contractors participated in this study. Table 11 presents the age range and experience (in years) of the contractors interviewed. 
Table 11. Professional Contractors' Age and Experience.

\begin{tabular}{|llll|}
\hline Contractor & Age range & $\begin{array}{l}\text { Experience } \\
\text { contracting (years) }\end{array}$ & $\begin{array}{l}\text { Work experience } \\
\text { (Approximate years) }\end{array}$ \\
\hline Cain & $45-54$ & 12 & 15.5 \\
\hline Cathy & $45-54$ & 0.4 & 20 \\
\hline Caleb & $45-54$ & 17 (intermittently) & 20 \\
\hline Callum & $45-54$ & 11 & 20 \\
\hline Calvin & $25-34$ & 7 & 7 \\
\hline Crystal & $45-54$ & 8.5 & 20 \\
\hline Camilla & $35-44$ & 7 & 10 \\
\hline Carla & $45-54$ & 3 & 20 \\
\hline Carol & $55-64$ & 19 & 30 \\
\hline Charles & $55-64$ & 3 & 30 \\
\hline Chase & $45-54$ & 12 & 20 \\
\hline Chloe & $45-54$ & 0.5 & 18 \\
\hline Cindy & $35-44$ & 0.2 & 10 \\
\hline Cliff & $45-54$ & 20 & Over 20 years \\
\hline Colin & $45-54$ & 1.5 & 14 years \\
\hline Curtis & $35-44$ & 0.3 & 8 (relevant experience) \\
\hline Cyril & $25-34$ & 0.7 & Over 5 years \\
\hline
\end{tabular}

Table 11 clearly shows that many of the contractors interviewed have had significant experience as contractors. The participants in the current study had an average of approximately seven years of contracting experience. For example, Cliff has been a contractor for over 20 years. It is also evident that almost all contractors interviewed have had at least five years' experience of the work they do. Many of the contractors interviewed have also had substantial work experience in general. For example, both Carol and Charles have had careers spanning 30 years. Cathy, Caleb, Callum, Carla, Chase and Cliff have all have approximately 20 years' work experience. This means they are very familiar with their area of work and the industry or sector they are in. The table below depicts how experienced many contractors are, illustrating the point that contractor capability, the knowledge, skills and abilities that a contractor brings with them, is a strong contribution to their time to productivity. Therefore, a contractor's experience has two different dimensions to it: contracting experience and relevant work experience. Callum explains the value of contracting experience by saying, "I think as a general rule, contractors by virtue of being used to coming into new environments and understanding that most environments have similar or same tool for a different job or same job for a different tool. You ask the right questions sooner than permanents who move around less." 
Calvin is the sole exception among these interviewees because he is the only contractor whose experience in contracting equals his work experience. There is a reason for this anomaly. Firstly, Calvin is a company contractor who was recruited straight from university into a highly technical, very specialised role. This role involves him being contracted to client organisations to do the exactly the same role at each of these sites. As a company contractor Calvin is both a permanent employee and a contractor but he has had no prior work experience. This lack of work experience is unusual among the professional contractors interviewed.

Chloe is able to have such clarity about the experience necessary for her as a professional contractor because she has held a very similar role as this one but as permanent employee. In fact, Chloe has had 12 years in that role and as many as 18 years in the industry. Despite being a novice with regard to contracting, Chloe is very experienced in the field. The experience that a contractor brings to the role is critical to their time to productivity. Mark endorses this claim by expressing the opinion that the more experienced contractors look after themselves and have less need for a buddy. Mick views contractors as being experienced and agile. Mick says, "Internal staff are encumbered by being here a long time. There are lots of people who know what their contact details are and ask them for things. The contractors are usually immune from that until they've been here a long time and then get stuck in the same trap." Emma notes that at times she has seen some contractors who come in with a certain skill set and experience so are "forging ahead within a week." Eli adds that a contractor's time to productivity depends on their experience, skills and knowledge. Edward attributes a contractor's time to productivity to their ability to figure things out for themselves and their technical capability or "nous."

The information presented here is valuable to the developing picture of a contractor's time to productivity and the three factors - organisational readiness, role complexity and contractor capability - that affect it. Figure 8 depicts these three factors diagrammatically. This is the key finding with regard to a professional contractor's time to productivity. It is obvious that two of these factors are within the organisation's sphere of influence. Managers, supervisors or team leaders can impact a professional contractor's time to productivity by being ready and well prepared for that contractor. After all, a contractor's time to productivity is of paramount concern to the organisation, given the short-term tenure of the contractor. 


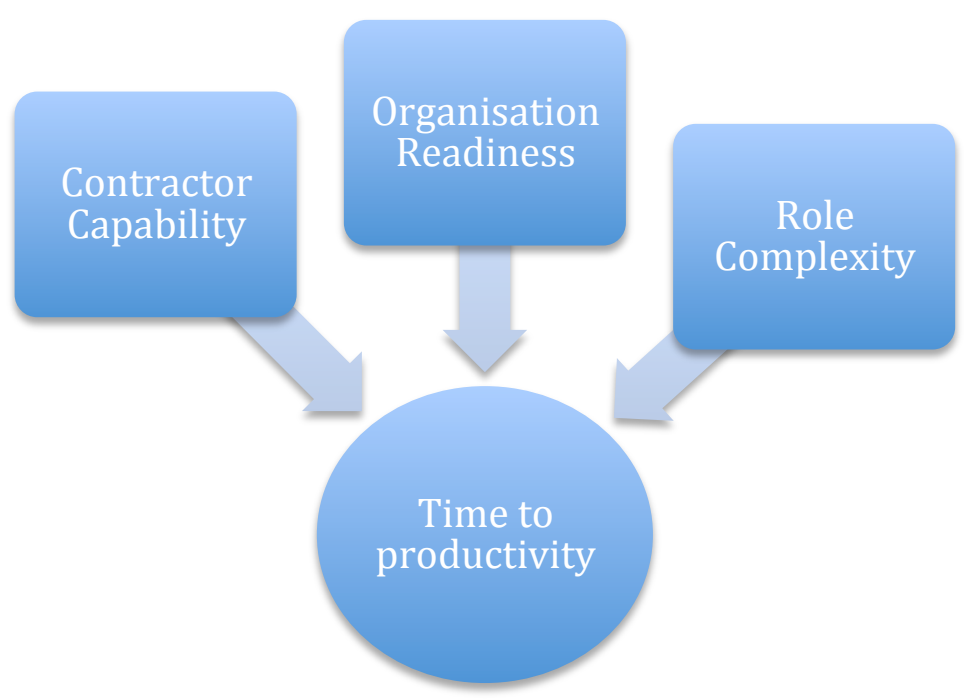

Figure 8. Factors affecting a contractor's Time to Productivity.

\subsubsection{The Role of Socialisation Agents}

"Most of the good information comes from your peers." (Callum)

\section{An Essential Ingredient}

Callum's statement above succinctly indicates the important role co-workers or colleagues play in the organisational socialisation of professional contractors. A key finding of this study is the important role a socialisation agent plays in the organisational socialisation process even for a professional contractor. The vast majority of the contractors interviewed made positive mention of an organisational insider or insiders who either formally or informally assisted the contractor. In fact, an essential ingredient of all good inductions is a good buddy, mentor or peer: the socialisation agent. Some employees may be asked by a manager to help a professional contractor adjust to their new role. At other times an employee assumes the role of socialisation agent. This role may involve the employee voluntarily sharing or imparting relevant contextual and organisation knowledge to the contractor. Emerging strongly from this research is that the role of socialisation agent is important in helping the contractor become productive.

The findings that emerge from this study confirm these points. The majority of contractors talked about being 'showed the ropes' by an organisational insider. For example, Crystal mentions that having a buddy helped her to adjust to the new role. According to Crystal, it took many months for that support to be put into place but when it was she found it very useful. Chase echoes the sentiment that good information comes from a colleague. He was assigned a buddy who gave him a tour, a pass and showed him his desk. Caleb also experienced an informal induction at this 
organisation but also has some personal connections. The implication here is that the personal connections were of assistance in Caleb's socialisation. In Colin's experience, it is other teammates (a combination of permanent employees and contractors) who show a contractor "the ropes." It was a senior manager who showed Calvin around at one client organisation. More recently, however, it was an administrator who gave Calvin an induction. Calvin has found that employees provide information, resources and social support. Cyril said his experience of induction was "fantastic." He was given a brief introduction to the different departments and the structure of the organisation. A particular permanent employee was identified to look after him. This person was familiar with the current systems and the associated rules and regulations.

Charles was shown the ropes by his manager and permanent employees provided support through providing advice, acting as sounding boards and supplying knowledge about particular areas of relevance. Chloe's hiring manager showed her around and informed her of the "dos and don'ts." Being entirely new to contracting, Chloe was coached and helped by her hiring manager quite a bit. Cliff was shown the ropes by the hiring manager who took him to his desk, introduced him to the team he would be working with and explained the role. Curtis received briefings from his predecessor, Chief Information Officer (CIO) and reviewed documents when he started with the organisation. Curtis points out that it does not matter who provides help to a professional contractor. All the examples referred to above refer to the help, support and information that existing workers permanent employees, professional contractors or managers - provided to the contractors interviewed. Common to each of anecdotes is that they involve a socialisation agent.

\section{Socialisation Agents are both permanent employees and professional contractors}

It is evident that in seven instances the individual showing the contractor the ropes was not a permanent employee but another professional contractor (Calvin, Camilla, Carla, Chloe, Cindy, Colin and Curtis). This finding was a surprise, as it was not predicted by the literature, which largely assumes organisational insiders to be permanent employees. Definitions of socialisation agents in the literature specify insiders, employees or veterans as socialisation agents. The reality is that the socialisation agent may be another contractor, fixed-term employee (in Colin's experience) or even a temp (for example the Project Co-ordinator in Calvin's experience). Camilla received help from another contractor (from the same supplier) as well as from the team as a whole. Carla also points out that help came from other contracted staff but permanent employees from the business itself have been able to provide her with information. Cindy found that other contractors who had 
been there a longer period of time helped her with how to do things and where to find things. Cindy was assigned a 'buddy' who also happened to be her manager (although a professional contractor). Cindy admits that she has had very few dealings with permanent employees in the short time she has been contracted to the organisation because in that IT or technology area there seems to be few permanent employees. In each of these cases, the socialisation agent or agents are not typical organisational insiders but, having been with the organisation a while, they were able to act as insiders or assume the role of insiders. The knowledge that other professional contractors may also assume the role of socialisation agent is valuable because it has practical implications for managers and HR professionals.

There are two key findings with regard to socialisation agents and professional contractors. Firstly, it was found that socialisation agents play an important role in the integration process even for professional contractors. The vast majority of the contractors mentioned an organisational insider or insiders who either formally or informally assisted them. An essential ingredient of all positive induction experiences referred to by the professional contractors interviewed was a good buddy, mentor or peer, that is, the socialisation agent. Secondly, it was found that other professional contractors also assume the role of a socialisation agent at client organisations. These workers become buddies or mentors to incoming professional contractors and help them adjust. This finding is surprising as the literature assumes that socialisation agents are permanent employees who take on the role either formally or informally.

\subsubsection{Proactive Socialisation and the Professional Contractor}

\section{Professional Contractors' Perspective}

"You've got to push them into answering your questions, to have some inkling of what you need to do and what you need to ask." (Caleb).

In the data there is ample evidence that the contractors interviewed actively engage in informationseeking to gain an understanding of the job they have been engaged to do. Many of the contractors interviewed were quite clear what information they require and quickly ensure they obtain it either from documents, the intranet or by asking specific questions. In the quote above Caleb asserts that some contractors have to work hard to acquire or collect the information they require to do their job. This observation is particularly interesting as Caleb is clearly talking about being proactive in this instance. A number of contractors talk about 'asking questions' or getting information in order to gain an understanding of the role (Cain, Calvin, Callum, Caleb, Camilla, Chase, Cindy, Colin and 
Crystal). Some of a contractor's questions can be answered by reading relevant documents (a briefing paper, business case or project plan), the intranet (organisation chart) and/or publications (prospectus). Contractors point out that some of the information they require is not yet written down or captured so they have to "start a conservation" (Camilla) or a "discussion" (Cain) with relevant people. Camilla feels that the organisation (or the manager) should get a contractor set up and provide the information he or she needs to start the job. If this is not done Camilla feels it is a "dead end."

As soon as Calvin starts at a new client organisation he establishes whom he can go to with questions. Calvin says, "If there are always people to help me then it will speed up my learning process. If I have a question, there is someone available." This implies that the contractor would like immediate answers, if possible. Both Callum and Chase have found that peers provide good quality information. Chloe starts a new contract by figuring out who does what so she knows who to go to. Crystal claims that some of the information available on the intranet about the organisation is sometimes "disjointed" or "ambiguously worded." Crystal says, “...it is very, very difficult sometimes to piece it all together" and "I think it is good to have permanent staff in there who have been in the organisation for a long time because they are your gospel on how the organisation works." For example, Colin says he has no hesitation in admitting "I don't know. I don't understand." It is clear that information-seeking plays a vital part in helping a contractor to adjust.

\section{Permanent Employees' Perspective}

"There is nothing formally expected of us but it is just the willingness to help and make sure that other people aren't left to sink" (Eric).

It is suggested that organisational socialisation will occur at a quicker pace when managers, employees (insiders) and professional contractors (newcomers) are proactive (Crant, 2000; Reichers, 1987). It is professional contractors who are the particularly proactive players in this sample. There is evidence that some permanent employees do not go out of their way to proactively assist a professional contractor but will assist when asked to. In opening quote, Eric claims that helping a professional contractor adjust is not formally mandated. Whether a permanent employee steps up to assist a professional contractor is a personal choice or decision they make. According to the data, permanent employees provide information to professional contractors in two subtly different ways: reactively and proactively. These are discussed next. 
Reactively. Several of the employees interviewed make reference to being available or nearby to answer contractors' questions, explain context and to share their organisational knowledge. Being in close physical proximity to the contractor is seen as an advantage in being able to engage with him or her. Evan refers to sitting nearby a new contractor so they could ask ad hoc questions. Some employees they share their knowledge but only in response to a contractor asking specific questions or requests for information. Eric says "They are both seen as new and needing help and typically people around them will onboard them and bring them up to speed and it depends on the questions the person asks or the help that they seek out." The latter indicates that it is incumbent on the newcomer to be proactive about seeking out answers so the employee is being reactive. The following quotation shows a clear perspective:

Well, what I tend to do is the first meeting is free so I'm happy to give them an hour and bring them up to speed on any artefacts that we may have had or where they could find them or what it was about back then and maybe a little bit of lessons learnt. If they want any more of my time, they have to go and get approval through the right channels. Yes, so I don't mind it cutting into my day. If I can give them an hour, then that is fine but any more I'll have to sort it out a bit more formally. I don't begrudge them the fact that they - I don't have any problem with that, it is just my time. (Ethan)

Proactively. Sometimes, it is the permanent employee who proactively offers to provide information or assistance to help the professional contractor to adjust. For example, Elaine may spend half a day talking to a newcomer about the work they are meant to do and the processes they are expected to follow. Furthermore, during the first monthly financial reporting cycle Elaine sees that the contractor has additional support to guide them through that process. Elaine enjoys mentoring newcomers because she enjoys teaching so is happy to spend time with a contractor. Eli says the goal is to provide technical information and show a contractor some resources or relevant documentation so that the contractor can subsequently operate without help. Errol suggests that helping a contractor adjust “...is kind of like a once over lightly to get [a contractor] working."

The key finding on proactive socialisation is that proactive socialisation is particularly important to professional contractors whose tenure is limited. The importance of the proactive behaviour information-seeking as a form of proactive socialisation is revealed quite clearly in the data. Those interviewed in this research were very clear that it is incumbent on the professional contractor to be proactive with their organisational socialisation. Organisational socialisation is no longer considered a passive process but an active one (Ashford \& Nurmohamed, 2012). This is supported 
in the literature on proactive socialisation, which suggests that newcomers assume an active role as they become comfortable in their new roles and adjust to the work (Crant, 2000).

\subsection{Part B: Findings about the Psychological Contracts of Professional Contractors, Permanent Employees and Managers}

This section presents the findings with regard to the psychological contract a professional contractor develops. In doing so it deals with the mutual expectations professional contractors, permanent employees and their managers have as members of the same team. At the end of this section, perceived breaches or violations of in the psychological contract and responses to such breaches are presented. This section aims to address the following sub-question of the research question: What are the psychological contracts of professional contractors, permanent employees and managers at organisations in New Zealand?

\subsubsection{The Type of Psychological Contract}

It remains unclear exactly which type of psychological contract professional contractors form but it is clear that it is different to the four types - transactional, transitional, balanced and relational that have been proposed by Rousseau (1995). Two of those interviewed claim that the longer the contractor remains with an organisation the harder it becomes to distinguish that contractor from a permanent employee (Elaine and Elliot). For example, Elaine observes, "What you tend to find is that when contractors stay longer they start to behave a lot more like permanent employees and there can be downsides to that as well." Elliot expresses it somewhat differently saying, "Some [contractors] go native after a period of time. A year? Two years? And that's the real danger they start to just go native. What I mean by native is they get involved in politics and the whole culture and cumbersome decision making and they forget that they are paid very good money - good money because not all contractors are paid great money but most are - to actually stay out of that and just deliver." The implication of both these findings is that over time the psychological contract becomes more relational in nature and less transactional. Transactional contracts are typified by little learning but this is certainly not the case with contractors. In fact, professional contractors trade on their high skill, specialist knowledge and extensive experience. The biographical data collected for this research shows how highly experienced many of the contractors interviewed are. As many as nine of the 17 contractors had approximately 20 years or more work experience. Similarly, about half of the sample of professional contractors (nine of the 17) has had seven years 
or more in contracting. Furthermore, each role a contractor accepts adds to their experience and further builds their reputation.

At three organisations there seem to be many long-term contractors (A2, B3 and C1). These contracts for service start out with a fixed duration but simply get extended, renewed or rolled-over time and time again. In fact, three interviewees (Elliot, Charles and Camilla) referred to contractors who had been around for a long time, as long eight to ten years. As Charles observes, “[They] won't let us increase the headcount but then they give us more work to do so we have to use contractors to get the work done but obviously if someone is doing the role for eight years it is a permanent role, you know." For these professional contractors, it is highly likely that their psychological contracts have converged towards that of a veteran such as a permanent employee (Thomas \& Anderson, 1998).

\subsubsection{What do Employees, Managers and Contractors Expect?}

The findings of what professional contractors, permanent employees and managers expect of each other are illuminating as they contribute some necessary detail to the relationship between professional contractors and permanent employees in organisations in this country. Table 12 summarises the top three expectations, which emerged from the data after careful analysis. In general, the expectations of the parties involved are not in direct opposition to each other but there are some interesting nuances, which will be discussed following the table.

Table 12. Expectations of Permanent Employees, Managers and Professional Contractors.

\begin{tabular}{|l|l|l|}
\hline Employees expect: & Managers expect: & \multicolumn{1}{l|}{ Contractors expect: } \\
\hline Great things & Speed & Respect (from employees) \\
\hline Independence & $\begin{array}{l}\text { Professionalism } \\
\text { (Do the job) }\end{array}$ & Autonomy (from manager) \\
\hline $\begin{array}{l}\text { Professionalism } \\
\text { (Do not...) }\end{array}$ & Value for money & $\begin{array}{l}\text { Support and guidance } \\
\text { (from manager) }\end{array}$ \\
\hline
\end{tabular}

\section{Employees expect great things, independence and professionalism from professional contractors}

Based on the interview data, the expectations employees have of contractors can be summarised as great things, independence and professionalism. In the next section, each of these will be presented with evidence from the interviews. 
Great things. Employees have high expectations of contractors. It seems that permanent employees have generally higher expectations of contractors than of other permanent employees (Eve, Evan, Elaine, Ewan and Eugene). Examples include Eve, who admits to expecting them to perform at a higher level than permanent employees. Evan expects contractors to be "highly competent." Elaine expects contractors to be "quicker on the ground" than a permanent employee and that involves being proactive in finding out the information they need. Ewan notes that because the organisation is paying a contractor more than an employee, expectations are not only specific but high, too. Based on Eugene's 20-year experience of contracting, Eugene thinks the expectations of a contractor are slightly higher. One or two managers express a similar view. Maria wonders if contractors are expected to have a "higher level of intensity of work." Michelle noticed a "definite split between professional contractors and permanent employees so she was able to tell which was which. Michelle admits, "When I first came into [this role] I thought very much so because the permanent employees seemed to be a lot more relaxed and weren't as quick to deliver things. The contractors were there to do a job and they knuckled down and did it and they were a higher calibre of people." Therefore, it was Michelle's "job to try and make sure that the permanent staff came up to speed and that they are delivering." There is a minority opposing view, such as Eric who says that if a contractor and new employee started at the same time he would not have different expectations other than that they perform the role they were brought to do.

Independence. There is also an underlying belief that a contractor is able to be independent and that there will be no handholding or babysitting, particularly after a period of time (Eve, Elliot, Ernest, Edward, Ezra and Errol). For example, Eve expects contractors to get up to speed really quickly, require no handholding and be confident. Elliot expects a contractor to be self-managing and get on with the work without much handholding. Ernest believes that after a period he expects contractors to be self-sufficient and be capable of working things out for themselves. If after four to six weeks they are not able to do so, then Ernest finds that "irritating." Ethan expects little handholding of contractors. Edward describes his role as “...definitely our responsibility to give them an initial overview that is sort of enough that they should be able to figure or find out everything else but you know, it is certainly not up to us to babysit..." Ezra seems quite happy to show a contractor the ropes in the first instance but if that same contractor is engaged again they are expected to remember.

Professionalism (Do not...). Employees expect professionalism from contractor in the form of certain behaviour during working hours. Different employees express professionalism in different 
ways; for some it is about what they do but for others it is about what they do not do. Some employees mentioned what they do not want to see from a contractor. Some employees do not expect contractors to deal with personal or social issues in the workplace (Eden and Elliot). Eden says, "I expect them to be quite focussed on what they are doing. I don't really want to see them having 'chit-chat' coffees with people. You know, we are paying them an hourly rate kind of thing ... I expect them to be the sort of people that people get on with." Elliot has very clear ideas of what he does not expect of a contractor. Elliot expects technical and thought leadership from contractors but they are not to go "off the reservation." He does not expect a contractor to waste time on getting coffees, checking emails, going on Facebook or having long personal calls (Elliot). Evan expects considerable knowledge in their area of expertise and does not expect to "explain business knowledge stuff twice." Elaine does not want to hear complaints or criticism about the organisation from a professional contractor unless the contractor is explicitly asked to do so. Elaine suggests that it is professional to keep these to themselves.

\section{Managers expect speed, professionalism and value for money from professional contractors}

Based on the interview data, the expectations managers have of contractors can be summarised as speed, professionalism and value for money. In the next section, each of these will be presented with evidence from the interviews.

Speed. Time seems to feature significantly in the responses from the managers. Managers expect speed from a contractor. They want everything quickly, which is a sentiment that is absent from the interviews of all the other participants. For example, Mark expects contractors to understand policies and procedures quickly, to build relationships quickly and to familiarise themselves with their project or work quickly. As Mick says, "You expect [a contractor] to be very technically competent. To be able to hit the ground running and the 'time to value' for them to be much, much faster than normal staff." Michelle expects contractors to "hit the ground a lot quicker." This is because when engaging a contractor Michelle is hiring for experience and a specific skill set, which means that the contractor should be able to "walk into the role and pick it up with little mentoring." Moses is quite clear when he says a contractor should "come up to speed as quickly as they can and deliver what they say when they say it at a good quality." Murphy believes the management team expects contractors to "be productive as quickly as possible." Each one of these managers refers to or talks about speed in some form or another, underscoring just how important time is to them. When it comes to contractors, time is money. 
Professionalism (Do the job). Managers also expect professionalism. Managers also want professionalism but in the form of getting the job done or delivering. For them, however, professionalism is about expecting the contractor to deliver what they have been engaged to deliver. Mark also says that his expectations include "...ultimately to be successful with the project that is assigned to them." Contractors need to be able to deliver and that is not just about the outcome but other things such as reports along the way (Michelle). Max believes in empowering his team with the "freedom to get on and do what they need to do their job," but he is available if they encounter difficulties. As Mitch puts it, he expects contractors to "be focussed on the delivery of the project not on understanding administrative things that don't really affect them." Mitch also refers to the statement of work that outlines what is expected of a contractor: the deliverables. A contractor is hired to do a job (Maria). Molly expects commitment to the job.

Value for money. Value for money emerges as an important expectation for managers. As mentioned above, there is evidence that they want everything quickly. Managers expect things to be delivered quickly largely because of the high cost of contractors. Related to the cost of contractors is the notion of value for money. As many as seven managers made reference to expecting value for money from contractors. If contractors are indeed providing the organisation with value for money managers have little issue with the high cost of contractors. Therefore, it seems value for money is a key consideration for managers. There is wide acknowledgment that contractors are well remunerated, so managers expect contractors to provide them with value for money they are paid (Mick, Michelle, Miles, Moses, Murray, Morris and Murphy). Providing a contractor is value for money, a manager is content in the relationship.

Value for money is not only about doing the job but about doing or offering more. That extra value may be in the pace in which a contractor "comes up to speed", their superior technical skills or it may be a contractor's overall productivity. Value for money may also be about providing value that permanent employees do not. Mick expects a contractor to be different to anyone who has been with the organisation for a while. Michelle expects contractors to be experienced enough to handle most challenges. Miles expects a contractor to also have knowledge of industry "best practice" and be willing to share that knowledge with the organisation. Moses and Murray both say they expect good value for money from a contractor. Morris lists value alongside integrity and ongoing support as his expectations for contractors. Murphy expects a contractor to bring their broad experience, not just their technical skills, with them to benefit the whole organisation rather than just the team they join. 


\section{Professional contractors expect respect from permanent employees}

Based on the interview data, contractors' expectations of employees can be summarised as respect. In the next section, this will be presented with evidence from the interviews.

Respect, please. It is challenging to summarise the expectations of the contractors interviewed, as these are all subtly different. Respect is a word that seems to be often used to capture contractors' expectations of those they work with. Examples of this are: Carla expects "good team work and respect" so that everybody can work together effectively in order to meet their goals. Charles expects support, respect, advice, tools and time from his colleagues. Cliff expects acceptance as well as respect from his colleagues at the client organisation. Calvin expects respect from those he works with but from his manager he expects support. At times respect is alluded to, if not explicitly mentioned. For example, Crystal also expects to be treated like an equal or, in her words, like a "normal person." From employees, Cain expects professionalism. Carol expects both team members and suppliers to bring technical skills to the job but to treat others well. Treating others well includes valuing the time of others (Carol). Chase expects "courtesy and professionalism" from colleagues. Cindy has simple expectations of her colleagues: "collaboration" and "understanding." Cindy says with laughter, "I expect that if I require something from them that I will get it when I need it." Of his colleagues, Colin expects courtesy. Even when not explicitly called respect, there seems to be an expectation that many contractors expect it from those they work with.

\section{Professional contractors expect autonomy, support and guidance from their manager}

Based on the interview data, the contractors' expectation of their manager can be summarised as autonomy and, when necessary, support and guidance. In the next section, each of these will be presented with evidence from the interviews.

Autonomy. With regard to contractors' expectations of managers the sentiment is about autonomy. Contractors expect to be given autonomy but be provided with support from their managers. Cain works autonomously but keeps his manager informed of problems. As Cain says, "[The manager] wants to know if there is a problem. And they want to know soon rather than later." Callum expects his manager to say what is required and then be allowed to do it with some guidance. In general, Chase expects a “...hands off, light management approach. I'm a professional who doesn't need to be told how do my daily job, just what they need of me." Cyril expects to be allowed to handle the 
work autonomously but if he encounters problems or issues he expects support or intervention from his manager. Caleb says his expectations of his manager are low. Similarly, being highly experienced and confident in his abilities, Charles's expectations of his manager are minimal because he says he does not need much from the manager.

Support and guidance. Contractors want autonomy but also expect, when necessary, support and guidance from their manager. Cain expects managers to be clear and consistent and to provide "support and guidance." Camilla's expectations of her manager include being able to "manage or mitigate problems." Carla's expectations of her manager include handling any issues or problems caused by organisational politics..." Calvin expects respect from those he works with but from his manager he expects support. The general sentiment is that contractors expect autonomy until they need support or guidance from their manager. This seems particularly necessary with regard to organisational politics.

\subsubsection{A Breach or Violation of the Psychological Contract}

In order to gain a thorough understanding of the psychological contract, the professional contractors interviewed were asked what would constitute a breach or violation of their expectations. They were asked about what would make them leave early or quit a contract. They were also asked what they would do about it. The responses, while differing, do show a clear pattern. Based on the data collected, there are three causes of a breach or violation: organisational problems, social dysfunction or problems with delivery/completion of the work. However, two contractors could not name anything that they would consider as unmet expectations.

\section{The Causes of a Breach or Violation}

Organisational Problems. These include functional, structural, procedural or administrative issues that would cause problems for a contractor. Examples include not being paid, being idle, poor management, poor culture, poor decision-making and uncertainty. Chloe says, "If they didn't pay me. If they said they'd pay me X but paid me Y I wouldn't be happy. I also don't like to waste time for nothing so if there's no work for me to do..." This is the largest category into which most of the breaches of the psychological contract could be grouped. Charles refers to organisations that he would not want to work for again. "They are just so disorganised and indecisive, you know. Resistant to change. It is just dysfunctional, pretty much. Some organisations are just amazingly dysfunctional." 
Social Dysfunction. This is about relationships and people. Examples include being excluded, an intolerable or unpleasant work environment and dysfunctional relationships. This category is linked to the team and working together. Crystal says, "Look if I was completely excluded and made to feel different and placed somewhere where I had to work in isolation or [be] treated as a dogsbody, I'd be out!" In a similar way Cindy refers to an unpleasant working environment by saying, "I guess if I felt maybe the environment itself wasn't very nice. If I felt that the team or the division wasn't very collaborative. [If] they were very conflicting, like bullying. If that was going on I'd consider leaving at that point." Colin makes reference to the work environment by saying, "It would have to be the work environment. Obviously, I've never done it yet. I think if the work environment got intolerable that's when I would imagine I would then try and sort it out within the organisation by talking to the manager, your manager there. If it doesn't improve you'd possibly talk to the agency."

Delivery Problems. These include a variety of issues such as inability to deliver to plan, unrealistic expectations and contractor capability issues. Carol says, "Decisions not sticking so inspite of everything that you do, writing papers ... putting forward recommendations that are well researched and supported, getting a governance body to a point of making a decision and then you find it has been re-litigated again, and again and again. Those organisations are incredibly difficult to work with."

None. Two contractors named nothing that would constitute a breach in the psychological contract (Chase and Curtis). Chase such said he "...would grin and bear it." The other contractor said he would work any problems through to resolve them (Curtis). The fact that these two contractors would not name anything that they would consider a breach in the psychological contract remains telling nonetheless. 


\subsection{Chapter Summary}

In this chapter, this study's numerous especially noteworthy findings about both the organisation socialisation of professional contractors and the mutual expectations of professional contractors, permanent employees and their manager are presented. Each of these numerous findings form the basis of the theoretical contribution that this thesis makes to the body of knowledge. They are summarised and presented in Table 13.

Table 13. Outline of Major Findings.

\begin{tabular}{|c|c|}
\hline $\begin{array}{l}\text { Part A: Organisational socialisation of } \\
\text { professional contractors }\end{array}$ & $\begin{array}{l}\text { Part B: The psychological contracts of } \\
\text { professional contractors, permanent employees } \\
\text { and their managers }\end{array}$ \\
\hline Organisational policy sets the tone. & $\begin{array}{l}\text { Professional contractors have a different type } \\
\text { of psychological contract. }\end{array}$ \\
\hline $\begin{array}{l}\text { Professional contractors induction was collective, } \\
\text { informal, variable, random and serial. ( }\end{array}$ & $\begin{array}{l}\text { Permanent employees expect great things, } \\
\text { independence and professionalism (Do not...) } \\
\text { from professional contractors. }\end{array}$ \\
\hline $\begin{array}{l}\text { Professional contractors need to know about the } \\
\text { organisation's culture \& values, structure, } \\
\text { language. } \\
\text { Managers suggest that contractors need to know } \\
\text { about the organisation's processes \& procedures, } \\
\text { have strong technical skills and industry, sector or } \\
\text { domain knowledge. }\end{array}$ & $\begin{array}{l}\text { Managers expect speed, professionalism (Do } \\
\text { the job) and value for money from professional } \\
\text { contractors. }\end{array}$ \\
\hline $\begin{array}{l}\text { Professional contractors' indicators of adjustment } \\
\text { are acceptance by insiders, role clarity, } \\
\text { performance-self efficacy and output. }\end{array}$ & $\begin{array}{l}\text { Professional contractors expect respect from } \\
\text { permanent employees. }\end{array}$ \\
\hline $\begin{array}{l}\text { A professional contractor's 'time to productivity' } \\
\text { is influenced by the organisation's readiness, the } \\
\text { size of the role/job and the contractor's capability. }\end{array}$ & $\begin{array}{l}\text { Professional contractors expect autonomy, } \\
\text { support and guidance from their manager. }\end{array}$ \\
\hline Socialisation agents play a key role. & $\begin{array}{l}\text { It was found that causes of a breach or } \\
\text { violation of the psychological contract include } \\
\text { organisational, social or delivery problems. } \\
\text { However, for some contractors nothing would } \\
\text { constitute a breach or violation of the } \\
\text { psychological contract. }\end{array}$ \\
\hline $\begin{array}{llll}\begin{array}{l}\text { Proactive socialisation } \\
\text { professional contractors. }\end{array} & \text { is } & \text { important } & \text { for } \\
& & \\
\end{array}$ & \\
\hline
\end{tabular}

It has been found that the organisational socialisation of professional contractors does clearly differ to that of permanent employees. It has been found that an organisation's policy or lack on one sets the tone for the treatment of professional contractors. Four indicators of adjust were identified for professional contractors. This includes and additional indicator of adjustment - output - that is 
particular to professional contractors. This indicator of adjustment is usually a distal or longer-term sign that a contractor is being organisationally socialised. This study reveals that for professional contractors the proximal and distal outcomes are condensed due to a professional contractors short or limited tenure with a client organisation. Specific content dimensions relevant to professional contractors were also identified in this chapter. 'Time to productivity' and three factors that influence it emerge from the findings. The importance of both socialisation agents and proactive socialisation also are revealed by the findings of this study. It is surprising that other professional contractors also act as socialisation agents.

This study explored the psychological contract by asking interviewees about their mutual expectations. The expectations of each of the three parties are subtly different, potentially influencing the psychological contract they develop. The type of psychological contract a professional contractor develops is not clear. However, it is clear that professional contractors have a different type of psychological contract, which changes over time. The change in the psychological contract of professional contractors occurs particularly during the first few months in a new job, a period that coincides with organisational socialisation. In Chapter 6 , the key findings related to organisational socialisation and the psychological contract in relation to the relevant literature are systematically discussed. 


\section{Chapter 6: Discussion}

\subsection{Introduction}

The purpose of this chapter is to discuss the findings presented in the previous chapter and the implications for our understanding of the working relationship between professional contractors and permanent employees at organisations. Specifically, by linking the findings and the theory together this research becomes more meaningful and has the power to explain (Walshaw, 2012). This will be done in order to address the sub-questions that comprise this study's research question. The research question's sub-questions are:

a) How are professional contractors organisationally socialised at client organisations in New Zealand? What are the implications of their organisational socialisation on the working relationship between professional contractors and the permanent employees they work with?

b) What are the psychological contracts of professional contractors, permanent employees and managers at organisations in New Zealand? What are the implications of these expectations on the working relationship between professional contractors and the permanent employees they work with?

This chapter starts with a discussion on the interrelationship between the two key concepts that are used in the thesis. Following that the findings of organisational socialisation and the psychological contract, presented in the previous chapter, will be discussed drawing on the relevant literature.

\subsection{The Interrelationship between Organisational Socialisation and the Psychological Contract}

The interrelationship between organisational socialisation and the psychological contract is apparent in this research. It is clear that there is more of a relationship between these key constructs than there envisaged at the outset of this research. Since the initial literature review, there has been other research about the psychological contract and organisational socialisation. Delobbe, CooperThomas, and De Hoe (2015) examine newcomers' psychological contract during organisational socialisation. These researchers refer to previous studies that have established that the psychological contract is "largely shaped during socialisation" (p. 845). This, too, can be said of the psychological contract of professional contractors. Professional contractors and permanent employees are likely to form working relationships during the organisational socialisation process. This period coincides with the formation and development of the psychological contract (De Vos et al., 2003; Rousseau, 2001). 
Socialisation is considered to be at its strongest just after an individual joins an organisation, a period that coincides with the formation of the psychological contract (Van Maanen \& Schein, 1979). For professional contractors, their tenure at an organisation is short or limited so both these concepts are particularly relevant. This study found that the organisational socialisation process for professional contractors is condensed due to the short-term tenure with a client organisation. This was also indicated by the addition of output as a proximal or short-term outcome of organisational socialisation. The distal or long-term outcome of organisational socialisation process - job performance - is expected considerably sooner than it would be for a permanent employee. Therefore, organisational socialisation for professional contractors needs to be reconceptualised. Due to the aforementioned condensed timeframe, a contractor's time to productivity is all the more relevant. This study's findings regarding the factors three factors that influence it are consequently particularly useful.

This thesis' use of organisational socialisation and the psychological contract as lenses with which the working relationship is explored is both original and meaningful. This is where the relationship between these two concepts becomes apparent. In fact, a crucial phase in the development of a mutually beneficial psychological contract is considered to be the socialisation period (De Vos \& Freese, 2011; Rousseau, 2001). However, for professional contractors the short-term nature of contracting means that their pyscological contract is clearly different to that of an employee. It is also suggested that by having a psychological contract that remains open, dynamic or malleable allows room for it to change, grow and develop as the contractor acquires more information during the organisational socialisation process.

\subsection{Discussion of Organisational Socialisation Findings}

This study has made numerous findings related to the organisational socialisation of professional contractors. In this section, those findings will be discussed and related to the relevant literature on the topic. This study found that an organisation's policy sets the tone for how professional contractors are treated by the client organisation. Professional contractors were asked about the content of the socialisation messages and information that they receive, thereby identifying which of the content dimensions they believe is particularly relevant to professional contractors. According to those interviewed, the indicator of adjustment 'acceptance by insiders' (Bauer \& Erdogan, 2012) may be a sign that the contractor is adjusting to their new role but it is not a prerequisite for adjustment. An additional indicator of adjustment particularly for professional 
contractors clearly emerged: output. The notion of 'time to productivity' emerged as highly relevant to professional contractors. This study identified three factors affecting it, showing that a contractors' time to productivity can be influenced. A socialisation agent was found to be key in every positive induction experience. It was also found that both permanent employees as well as other professional contractors act as as socialisation agents. Finally, it was established that professional contractors play an important role in their own socialisation. Each of these particular findings and their implications on the working relationship will be discussed in the section following the diagram Figure 9, which illustrates these findings within this study's conceptual framework.

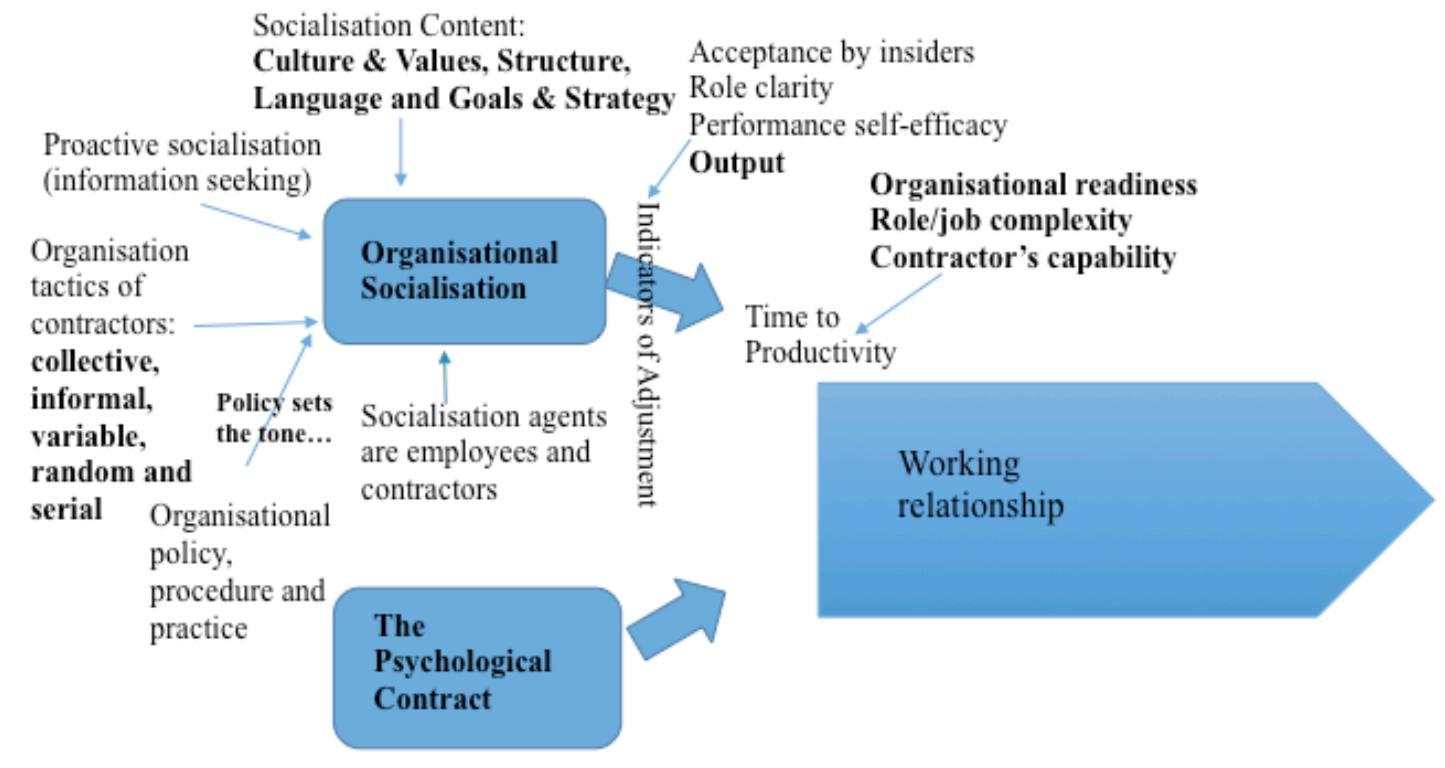

End of contract

Time (weeks or months)

Figure 9. Organisational Socialisation Findings and the Conceptual Framework.

\subsubsection{Organisational Policy Sets the Tone}

This study found that an organisation's policy or lack of one sets the tone for how professional contractors are treated by the client organisation. Many of those interviewed referred to an IT or ICT division policy regarding contractors rather than a corporate or HR policy outlining how professional contractors are to be treated. This confirms the finding that Bidwell (2009) made regarding contingent workers being excluded from the detailed personnel policies that apply to 
regular employees. Not only are they excluded from policy about permanent employees but also there is often no HR policy that relates particularly to professional contractors. Contractors tend to fall between the cracks (Bryant \& McKeown, 2016; Gossett, 2006). It seems that corporate policy regarding professional contractors is generally lacking. Often it is left to the contractors' manager to decide how to treat contractors. The lack of such high-level policy may lead to the diversity of treatment of professional contractors across organisations as well as within them. As McKeown (2003) points out in her study (on contractor commitment) there are some important HR issues about the integration and management of contractors within the larger employee workforce. An organisation's policy sets the tone for how professional contractors inducted, included and managed. Each of these will be discussed next.

Biggs et al. (2006) and Druker and Standworth (2004) found that induction for non-standard workers is non-existent or rudimentary. Though there was some variation in this thesis' data, most of the professional contractors interviewed experienced some form of induction to their role with the client organisation. Overall, it was found that professional contractors in this study experience an induction that is collective, informal, variable, random and serial. In other words, a contractor starts work with a brief tour of the workplace, building and facilities. He or she may be introduced to team members, stakeholders and possibly other key contracts. The contractor is expected to engage in any specific systems training such as OHS or document managements system or similar. Then the contractor may then be left to independently discover what they need to know based on the information they have been given and intranet resources. The contractor is encouraged to get on with the work by finding out answers to his or her questions. Since Biggs et al. (2006) and Druker and Standworth (2004) conducted their studies it seems that the organisational socialisation of professional contractors has developed somewhat.

The lack of explicit organisational policy regarding the induction, inclusion and management of professional contractors means that there is less deliberate use of this opportunity. There is potential for greater strategic use of the organisational socialisation tactics that are available to organisations. Jones (1986) developed a matrix further categorising Van Maanen and Schein's (1979) socialisation tactics, identifying relationships between the socialisation tactic and the outcome. According to his typology the inductions experienced by participating professional contractors were neither institutionalised nor individualised but a mix of the two (Jones, 1986). Collective and serial tactics are considered institutionalised (Jones, 1986). Informal, random and variable tactics are considered to be individualised tactics (Jones, 1986). In this study more of the tactics experienced by the 
contractors fall into the latter category so they lean towards individualised tactics. Individualised tactics are linked to greater role innovation but are also associated with more role conflict and ambiguity (Jones, 1986). Greater role innovation was particularly true for several of the contractors interviewed. These contractors had significant latitude to define their role innovatively and appreciate having innovative reporting structures and communication channels. For example, Cain says, "Whereas if I had a line manager then I'd check with that person, he may then want to check with their GM or whatever. Actually, they'd say I'll handle this conversation, that is probably how it would go. They are paying me to get stuff delivered so I'll get it delivered." Cain talks to whoever he needs to in order to get the job done. However, permanent employees have to follow the chain of command and certain reporting protocols.

If innovative role orientations are desired of a professional contractor then more strategic use of individualised organisational socialisation tactics would be beneficial. Professional contractors could attend one-to-one sessions outlining the role and the deliverables from a several key colleagues or stakeholders. A professional contractor could be assigned a socialisation agent (a buddy or mentor) whose role includes identifying the interventions that the professional contractor may benefit from. These procedures would be informal, one-to-one and would be tailored to the needs of that contractor based on their KSAs and experience. For example, a discussion with an end user, a meeting the CEO or watching a promotional video on the intranet. On the other hand, for roles that require custodial role orientations then more institutionalised tactics would be more effective (Jones, 1986). Institutionalised tactics include collective, formal, sequential, fixed and serial tactics. This was exemplified by Cathy's experience as the only contractor in the sample who received a handover from a predecessor, who also remained available subsequently for advice. Cathy's role requires a typically custodial role orientation so there is very little scope for innovation. The use of a fixed tactic (such as a handover from a predecessor) is entirely appropriate in this case. Even though Cathy did not receive socialisation collectively, the other tactics are generally indicative of an induction that involved institutionalised socialisation tactics.

It was observed that an organisation's policy toward contractors has an influence on their level or extent of inclusion. Organisations like A1 and B1 have an explicit policy about what professional contractors can and cannot do. Organisations like A2 have IT policies that provide guidance on the treatment of contractors. Organisations like B5 and C3 do not have such policies so it is left to the discretion of an individual contractor's manager, which results in quite diverse practice both within organisations and across organisations. It was found that professional contractors are generally 
included at a team level but the extent of inclusion or integration generally decreases from team to group, to division to organisation. Therefore, the team is particularly important for professional contractors. The team is also important to the others who comprise that team. According to the data, interviewees wish to include contractors, where possible, so corporate policies deliberately excluding them are considered inequitable. This is echoed in the literature by Osnowitz (2010) who suggests that, “...managing teams that included both contractors and employees, they seemed acutely conscious of the potential for inequality and for double standards that might undermine team cohesion or productivity. When they oversaw highly productive work groups, they considered even-handed team management an accomplishment" (p. 45).

Continuing with the theme of organisational policy regarding professional contractors, the provision of training and development requires further discussion. In the literature reviewed, organisational socialisation is clearly positioned as fundamentally a learning activity (Ashford \& Nurmohamed, 2012; Bauer \& Greene, 1994; Chao et al., 1994; Cooper-Thomas \& Burke, 2012; Ostroff \& Kozlowski, 1993; Saks \& Ashforth, 1997). Therefore, there is a distinct connection between organisational socialisation and training and development because induction workshops or programmes are often part of a wider training and development structure. There is an anomaly, however. In the data, there is a strong, shared sentiment that contractors are not entitled to organisation funded training or development courses or programmes.

Opinions on the policy regarding training and development for professional contractors are unanimous. Training and development remains a benefit that only permanent employees have the right to receive. Managers, employees and contractors agree that there is no expectation of training unless essential and organisation-specific, such as health and safety, document management system, SAP or a new methodology. This is found to be true among the majority of the organisations participating in this study. Contractors are considered well paid and are technically skilled enough that they should not require it (Mark, Maria, Miles, Mick, Molly and Moses). As Moses says, "We expect them to come trained and developed..." Mark and Murray suggest that contractors should be investing in their own training and development, something that Mark believes their agencies also encourage. In the literature it is acknowledged that training and development is the responsibility of the individual contractor. For example, "Contractors ... receive little or no support for professional development, and most clients expect them to bring all the requisite background to the work they take on" (Osnowitz, 2010, p. 78). 
In special circumstances where contractors do attend client-specific, in-house training they are expected to pay their own way and are not expected to bill the organisation for that time (B1, B2, C3). As pointed out by Margaret, professional contractors are not provided with training unless it is in-house and they pay their own way both for the training course and for their own time. Michelle says, "The contractors often are interested in attending courses as well so we'll do that but it is at their cost. So we'll provide it to them [but] they won't get paid for the day." In these cases it is cost neutral for the organisation to provide the contractor with the opportunity to receive the training and development. The treatment of contractors is particularly clear with regard to training and development. Those interviewed are unequivocal in their opinion that professional contractors are not entitled to receive training and development.

It is clear that an organisation needs to have a corporate or HR policy for professional contractors. Otherwise, it is left to the discretion of manager resulting in diverse practice, which may be inequitable. Explicit, strategic guidance on the induction, inclusion and management of contractors will ensure that they receive the information, resources and social support that they need. The team emerges as particularly important to professional contractors so guidance around how they can be included at this level would be beneficial. While the management of contractors is different, it remains important that all team members are treated equitably. It is widely accepted that professional contractors are not entitled to training and development but this must not preclude them from receiving the organisational socialisation that they require to function in their role. There must be provision for basic induction, onboarding or orientation even for professional contractors to get them up to speed.

\subsubsection{Socialisation Content Needs to be Customised}

The content of the socialisation messages and information that professional contractors receive was analysed, thereby identifying which of the Chao et al. (1994) content dimensions are particularly relevant to professional contractors. According to the professional contractors interviewed, contractors need to know about the client organisation's culture and values, structure and language. However, it was found that professional contractors only need to know about an organisation's goals and strategies to a certain extent. Professional contractors themselves do not believe they need to know an organisation's history but it may help at times. Findings regarding organisation politics were inconclusive, however. 
The results of the finding regarding organisational politics is inconclusive as approximately the same number of professional contractors believe organisation politics is important as those who do not. This is surprising because organisation politics has been cited as one of three main reasons for permanent employees seeking alternative types of employment (Kunda et al., 2002). "Of note, Bidwell (2009) found that highly skilled contractors... are more likely to be employed on projects requiring high levels of interdependence across different organisational groups and less likely to work on tasks that engage directly with organisational politics" (Bidwell, 2009; Bryant \& McKeown, 2016). The fact that professional contractors are neutral or often sit outside organisational politics emerged elsewhere in this research so this inconclusive finding is particularly interesting. It may be a reflection of the scope, nature and type of work the interviewees are engaged in. Many of those interviewed are senior, highly skilled and very experienced contractors so may be required to function in somewhat political realms on occasion.

The perspective of managers on what contractors need to know in order to perform their role is also revealing. The managers interviewed refer to the organisation's processes and procedures, as what they believe is important for a contractor to know. These are a form of organisational knowledge that only organisational insiders are privy to, however. Until a contractor starts work at an organisation he or she cannot be expected to have this knowledge. Based on this feedback from managers it is clear that acquiring knowledge and understanding of an organisation's processes and procedures should be one of the top priorities for a new professional contractor.

The importance of these findings is that they identify specific socialisation content dimensions that are relevant for professional contractors. The significance of this is two-fold. Firstly, this finding confirms that different socialisation content is necessary for professional contractors. Secondly, this finding identifies three dimensions that are relevant, one dimension that is somewhat relevant and one that is not relevant to contractors. Once empirically tested, this information would contribute to developing and customising socialisation messages for professional contractors. There is a clear need for customised socialisation messages for professional contractors.

\subsubsection{Four Indicators of Adjustment for Professional Contractors}

While the traditional models of socialisation over time such as Bauer and Erdogan's (2012) model is particularly useful for permanent employees, the short-term tenure and different desired outcomes for professional contractors causes some interesting implications. The data gathered with regard to 
the integration of professional contractors mapped well to the proximal outcomes of organisational socialisation (Bauer \& Erdogan, 2012). Also referred to as indicators of adjustment, 'acceptance by insiders', 'role clarity' and 'performance self-efficacy' each emerged from the data as signs that a professional contractor is adapting to a role. According to Bauer and Erdogan (2012), failure to succeed is far more likely without 'acceptance by insiders.' However, based on the opinions of those interviewed, 'acceptance by insiders' is not considered essential for a professional contractor but it does make it easier. This is a slight departure from the theorising about permanent employees for whom social acceptance is very important (Bauer et al., 2007; Bauer et al., 1998; Feldman, 1981).

Based on the data, gaining 'role clarity' involves the contractor asking questions, questioning, asking the right questions and knowing to whom to direct questions. 'Performance self-efficacy' was apparent in the data, which is based on Bandura's idea that positive organisational outcomes like performance are related to increased confidence in one's ability to do the job (Bauer \& Erdogan, 2012). There were repeated references made to professional contractor's confidence. Bauer and Erdogan (2012) acknowledge, "Research has already established that one element of self-confidence, self-efficacy, is related to proactive behaviours" (Jones, 1986; Parker, 1998; Speier $\&$ Frese, 1997). Some permanent employees link the confidence contractors have to being proactive. There is an obvious link between both 'role clarity' and 'performance self-efficacy' and the literature on proactive socialisation.

Furthermore, it was found that the three indicators of adjustment identified in the literature do not quite capture all the signs that a contractor is adjusting that emerged from the interview data. An additional indicator of adjustment - output - emerges clearly from the data as one specifically relevant to professional contractors. The fact that output emerges as a proximal or immediate outcome for professional contractors is particularly informative. According to Bauer and Erdogan (2012) Socialisation Over Time model includes an output-type indicator as distal or long-term outcome. This finding clearly shows that for professional contractors specifically output is a proximal outcome because of their short-term tenure. It is likely that for professional contractors, proximal and distal outcomes are condensed. For professional contractors the desired outcomes of the organisational socialisation process are also different. In fact, job performance remains the only outcome that is sought for professional contractors. All other outcomes are relevant to permanent employees, who have indefinite tenure, but not to professional contractors. These findings are also reflected in the diagram in Figure 13 where all but job performance have been removed from Bauer 
and Erdogan's (2012) Socialisation Over Time diagram thereby forming a new model of organisational socialisation for professional contractors. These findings could form the basis of a new model of socialisation for professional contractors as Figure 10 illustrates.

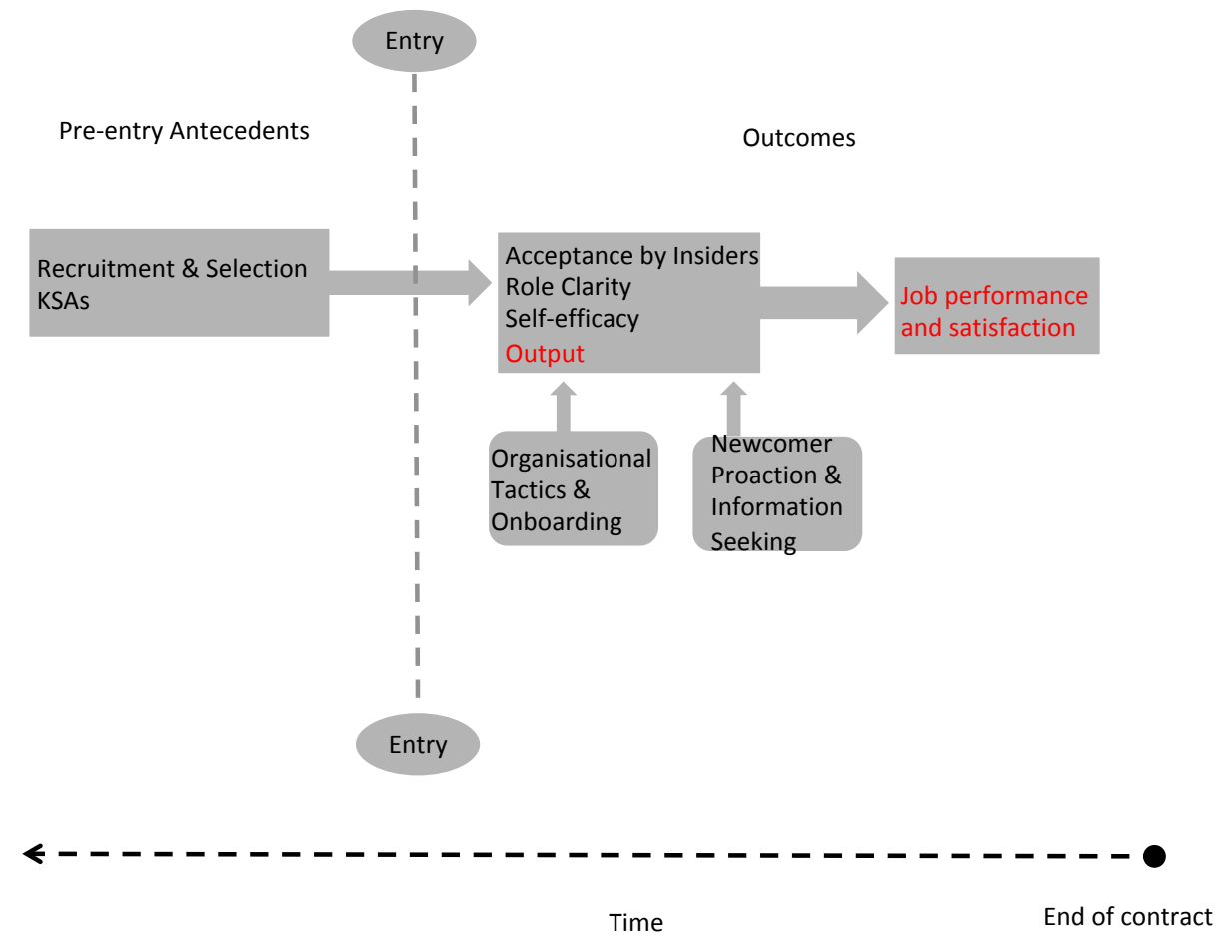

Figure 10. Professional Contractor Socialisation Over Time (based on Bauer and Erdogan, 2012)

\subsection{4 'Time to Productivity' can be influenced}

It is no surprise that the notion of time is very important to a contractor (Ashforth, 2012). The length of time a professional contractor is engaged at a client organisation varies widely but initial contracts (which can be extended/rolled over) are often between three to six months and generally less than a year. Due to the limited time in the role, it is important for both the contractor and their manager that the contractor is productive in the shortest time possible. Time to productivity is the time it takes for a contractor to be performing at a satisfactory level at the client organisation (Tarquinio, 2006). The relevance of time to productivity is clear in the literature but not extensive. There is a clear link between effective organisational socialisation and time to productivity of newcomers. Bauer (2010) claims that, "When surveyed, organizations perceive effective onboarding as improving retention rates (52\%), time to productivity (60\%) and overall customer satisfaction (53\%)" (p. 6). Bauer and Erdogan (2010) suggest that, “...based on these limited 
findings, it is clear that there is a potential to greatly enhance the onboarding of hourly workers if the business case can be made that doing so will result in higher performance, lower turnover and more positive work attitudes" (p. 15).

Krauss and Seitz (2010) qualitative study of hourly workers highlighted differing perceptions of a contractors' time to productivity. Bauer (2010) acknowledges that research into inductions or onboarding have focussed on permanent employees or executives (knowledge workers) but not the “other end of the corporate ladder" (p. 15). In this research Krauss (2010) found that:

New hourly employees reported that they were fully on board after an average of three-and-ahalf weeks, but supervisors reported that new hourly employees were not fully functional until three months after they were hired. Three months is more in line with past research and theories; less than one month is not. (Bauer, 2010, p. 15)

The interview data collected for this thesis indicates differing perceptions of contractors' time to productivity between contractors and those they work with. Like those in this study the hourly workers in Krauss's (2010) study reported a shorter time to productivity than those they worked with (their supervisor) reported. The value of any discussion of time to productivity is not in the actual time to productivity but in understanding what can be done to positively affect or influence a contractor's time to productivity. Emerging clearly from the interview data are three factors that affect time to productivity: organisational readiness, role complexity and contractor capability. Broadly, these are three levers that can be adjusted to influence how long it takes for a contractor to be performing effectively. The latter is about the contractor him or herself. However, the other two factors fall under the organisation's influence or control.

The role complexity depends on the type of work that the contractor is required to do. Discreet pieces of work involving one team will not be complex. Projects that span several divisions or external stakeholders will be significantly more complex. Organisational readiness is not just about physical readiness. The organisations in this study generally proved to have access cards, computers, workstations, phones and so forth ready for the contractor. Organisational readiness also involves whether or not the organisation's members are ready and able to provide help and support to the contractor (as socialisation agents). The very concept of a contractor's time to productivity, though not explicitly discussed in the workplace, resonates with many of those interviewed. It is an idea that almost all interviewees understood without it having to be explained. 


\subsubsection{Socialisation Agents Play a Key Role}

Common to all positive induction experiences of the contractors in this study was a buddy or mentor who supported the professional contractor. The literature refers to organisational insiders who take on the responsibility for socialising a newcomer as a socialisation agent (Feldman, 1984). Socialisation agents are identified as playing an important role in supporting contractors to adjust to their new role. In some instances, the socialisation agent was a formally designated buddy or mentor but in other cases the socialisation agent was merely a supportive colleague or teammate who assumes the role. Socialisation agents are an important resource in the induction of new employees. Bauer and Erdogan (2010) suggest that, "a mentor can teach new employees about the organization, offer advice, help with job instruction, and provide support in social and political terms" (p. 11). Ostroff and Kozlowski (1993) found that newcomers who had mentors were more knowledgeable about organisational issues and practices than those who did not.

It is a significant finding that socialisation agents are not always permanent employees but that another professional contractor may act as the socialisation agent. The literature assumes that a socialisation agent is a permanent employee. If other professional contractors are indeed acting as socialisation agents, then this has implications on the socialisation messages that professional contractors are provided with. Feldman (1981) suggests that socialisation agents do not replace formal orientation but operates in tandem with them. Saks and Gruman (2012) believe that socialisation agents are really helpful in supplementing formal orientation and/or training. However, most of the contractors in this study received informal and random induction to their roles so were not exposed to formal orientation. If their induction is not supplemented by socialisation agents but provided by them, then is their onboarding, therefore, adequate or sufficient?

\section{Who Makes a Good Socialisation Agent?}

Several contractors alluded to the fact that other contractors are in a unique position to identify what the new contractor needs to know because they are or have been in a similar position. The fact that other contractors are sometimes socialisation agents gives rise to the question of whether or not a buddy or mentor with previous contracting experience would be a good socialisation agent? He or she would be able to empathise with the contractor's position. A former contractor would also be well equipped to be able to customise the information they impart to a contractor according to the background of the contractor, the complexity of the role and the timeframes involved. As is pointed out, contractors cannot be assumed to be 'tabula rasa' (a blank slate) but actually a wealth of KSAs and experience gained over many years of work (Feldman, 1994, p. 228). 
The only contractors who did not seem have a positive induction experience are Crystal, Cain and Carol. Crystal was critical of her initial induction but speaks positively about being assigned a buddy after about six months. It is clear that having a socialisation agent helped the Crystal to do her job. Cain reports little such support or guidance other than a tour of the workplace for Health and Safety purposes. Cain has had previous experience at the organisation, albeit many years ago, so he was somewhat familiar with it. This may explain the lack of involvement of a specific socialisation agent. Carol has worked over 20 years as a contractor so has some interesting insights and experiences. Carol reveals, “... some permanent employees are more helpful than others. Some prefer to sit back and watch people fall over. They get some sort of perverse pleasure out of it." This is certainly a striking observation about permanent employees but not a commonly expressed one.

\section{The Benefits for the Socialisation Agent}

The role of socialisation agent is also a two-way communication process where the contractor is provided with support but the socialisation agent also benefits in certain ways as well (Feldman, 1994). Bauer and Erdogan (2010) acknowledge the shared role of both employees and contractors. Employee onboarding is a two-way street so permanent employees should be encouraged to think about their own roles in the process and take some responsibility for making onboarding work (Bauer, 2010). Several employees mentioned enjoying helping newcomers because they are naturally inclined towards teaching or are a people person (Elaine and Eugene). Several employees claim to have learnt a lot from incoming contractors, particularly those who are experts or specialists in their field (Elaine, Evan and Emmet). Other employees mentioned learning from contractors about how other organisations are doing things. There are references to exemplary individual contractors who are quick to learn, share their knowledge or teach and are particularly experienced. For example, an employee talks about one contractor in the following way:

When I've been working with contractors they've been able to teach me things about (the work), guide me along. Yes, one particular contractor I worked for was particularly really good and he didn't have to but he became sort of a mentor to me during that project and he was extremely valuable. (Evan)

Being focussed and getting on with the job is what this kind of contractor is known for. Some of the employees spoke with admiration about the professional contractors they work with: "I can think of some senior consultants, techies who you'd bring in and are just great. And you know this project is going to do much better with them on board. And they just get down and into the work and that's 
what contractors are known for" (Elliot). These contractors are particularly good at what they do. For example, "We've got a couple [of contractors] we've used for certain stuff and they're, you know, fantastic" (Edward). This kind of contractor is highly experienced and capable. As one employee put it, "You can learn a lot from contractors because they have worked in a lot of different environments and I have got one contractor that I work with here at the moment, a project manager, who has been around the traps a few times ... I find that I learn from him" (Elaine).

Some employees see being socialisation agents as part of their role or their responsibility so readily accept the role. Some naturally assume the role of socialisation agent. For example, Ernest says "If you don't provide some integration support [or] some assistance to get them going then that's not helping anybody ... So I think it is actually beholden on me, permanent staff members, to make sure that the contractors are as effective as they can be." Implicit in the comments these interviewees make is the notion that the socialisation agent must be good or that the right socialisation agent does the role. The attributes of an effective socialisation agent that emerged are one who is a natural teacher - knowledgeable, well connected, approachable or friendly, willing and can devote adequate time to the function of helping out a contractor. One of the fundamental reasons for organisations engaging contractors is to alleviate some of the workload on permanent employees so if the socialisation agent then has to spend significant amounts of time helping a contractor it would be counter-productive.

Feldman (1994) explains that socialisation agents can assist contractors by providing social support, information or resources. This research confirmed that contractors were indeed provided with each of the above by organisational insiders. Examples of social support employees provide to a contractor include chatting over coffee before work or beer on a Friday after work (Evan, Eric). Providing information may include giving the contractor relevant documentation or reports to read or an explanation of 'how things work around here.' This information may be task specific or more general. For example, Eugene shares his insights into the unique organisation culture and some of its anomalies with the contractor. Eugene tailors his introduction to the organisation based on the background of the new person. This supports Louis $(1980,1990)$ who “...proposed that co-workers provide information and cues which enable newcomers to cope with surprises, interpret events, and learn the appropriate attitudes, opinions and norms" (Thomas \& Anderson, 1998, p. 751). Employees reported providing resources by pointing the contractor in the right direction. For example, Errol provided a contractor with a copy of a relevant document that the contractor did not have permission to access on the organisation's complex document management system. Many of 
the employees interviewed have been permanent employees at their respective organisations for over 10 years so their level of contextual and organisational knowledge is very high (Errol, Emily, Ethan and Ezra). As Ethan puts it, he is happy and willing to help contractors because as the team's only "lifer" he has a lot of knowledge and information to share.

\section{The Issues with Being a Socialisation Agent}

The positives of being a socialisation agent include opportunities to learn from and be motivated by others (Feldman, 1994). For example, Emmet says that in explaining and justifying a process or design the employee is given an opportunity to reflect, which is positive. Evan admits to having learnt quite a lot from a contractor on the same team. Similarly, Elaine mentions learning a lot from Charles, who is a very experienced contractor. Being motivated or energised by a newcomer was hypothesised by Feldman (1994) but this was not supported in the data collected in this study. Employees made no clear mention of feeling motivated or energised by acting as socialisation agents. There are several possible reasons for employees not to be energised by a new contractor. Firstly, contractors are usually only transitory, so any relationship built between employee, as the socialisation agent, and contractor is likely to be short-term. The exchanges between the two different types of workers are likely to be focussed and needs based because the contractor is not going to be around for long. Secondly, it is possible that employees are generally apathetic towards contractors. There is certainly evidence in the data of an "anti" contractor sentiment. Chloe referred to stakeholders, a group of permanently employed subject matter experts (SMEs), who were very hard to work with because they were "fatigued" and "process weary" though repeated interaction with contractors. Chloe's predecessor left the role suddenly with no notice, leaving no information for a successor, so when Chloe joined the team she had no choice but to redo much of the work the previous contractor had done. This was not received well by the internal stakeholders who did not want to work with yet another contractor. Murphy refers to a "natural antipathy people have for contractors." He feels that some contractors can be "...like the teacher who is one page ahead in the teacher's guide." Murphy also refers to seeing contractors on the same external training courses as his staff members attend so contractors do not always have superior skills or expertise.

At least two employees distinguish between providing information or resources and doing the contractor's job for them. The latter they absolutely resent. Errol voiced frustration over dealings with a current contractor who has produced a document for review that actually requires radical editing and re-drafting. As Errol explains, the contractor was brought on as a specialist but it is Errol who is actually writing a lot of the report. Edward describes his role as "...definitely our 
responsibility to give them an initial overview that is sort of enough that they should be able to figure or find out everything else but you know, it is certainly not up to us to babysit..." Edward refuses to "babysit" a contractor. Several employees echo the idea of not babysitting or handholding a contractor (Eden, Edward Elliot, Errol, Emma and Ezra). It seems there is a honeymoon period, after which a contractor is simply expected to have 'got it'. It is not clear how long this honeymoon period is, as it seems to be arbitrary, but is certainly between a few days and a few months.

As Feldman (1994) notes, the extra time and energy it takes to show a newcomer the ropes may take a toll on the insider in terms of work overload and stress. By the very nature of helping out a contractor the socialisation agent is taken away from their actual job or role. For many of the employees interviewed, time is clearly a major limiting factor when it comes to them helping out contractors. For example, Eden feels that helping a contractor is a question of time and the amount of work she has on. Osnowitz (2010) writes, "Most [contractors], however, depend on designated employees whose jobs include responsibility for providing them with essential information. These employees, then, become their principal points of connection, and these working relationships become especially important" (p. 114).

\subsubsection{Proactive Socialisation is Important}

Organisational socialisation is not just about what the organisation can do, the tactics it can utilise or the programmes it can run. Organisational socialisation is not a passive process but a dynamic one, which involves newcomers themselves to take the initiative to seek out information themselves. Today, more than ever, there is an expectation that newcomers engage in proactive socialisation by engaging in proactive behaviours such as information-seeking, building social networks and negotiating job changes (Crant, 2000, p. 447). Proactive socialisation is where the newcomer is responsible for adapting to the new work environment by taking the initiative (Crant, 2000; Wanberg \& Kammeyer-Mueller, 2000). This initiative involves engaging in certain proactive behaviours such as "information-seeking, building social networks and negotiating job changes" (Crant, 2000, p. 447).

The importance of the proactive behaviour 'information-seeking' as a form of proactive socialisation is revealed quite clearly in the data. For professional contractors, the importance of information-seeking is further enhanced given the short timeframe involved. Proactive socialisation is particularly relevant to contractors because of the short-term tenure of their contracts. According to professional contractors themselves, the permanent employees they work with and their 
managers, it is clear that information-seeking is an important behaviour confirming what has been identified in the literature. Information-seeking or asking the right questions, becomes even more important for a contractor to gain 'role clarity'. As was seen earlier in this chapter, role clarity is just one of the so-called indicators of adjustment. It is apparent that in order for a contractor to gain role clarity, a professional contractor must engage in proactive socialisation. Similarly, 'performance self-efficacy' is related to proactive socialisation. The confidence that the professional contractors in this study exude may be about certainty in developing relationships, confidence in their specific skills and abilities, confidence about taking risks or confidence about asking questions.

However, 'building social networks' emerged less significantly and 'negotiating job changes' did not emerge meaningfully, most likely due to the nature of a contractor's role. A professional contractor's task is particularly focussed so is less likely to require such negotiation. This aspect of proactive socialisation is more applicable to permanent employees who have indefinite tenure and the scope to negotiate job changes. Those interviewed in this research were very clear that it is incumbent on the professional contractor to be proactive with their organisational socialisation. This aligns well with the literature on proactive socialisation, which suggests “...newcomers can take a more active role as they adjust to work and become comfortable with their new roles..." (Crant, 2000, p. 445).

Crant (2000) warns that core activities must not be rejected in favour of initiative, action and change. There is a limit to just how proactive a newcomer should be. Errol describes a relevant experience where a professional contractor had asked him to contribute to a document that she had been tasked to produce. In Errol's opinion the document is riddled with inaccuracies so requires a considerable amount of his input but he feels that he would be doing the contractor's job for her. Errol is absolutely opposed to that. This anecdote is an example of the maladaptive nature of a contractor being too proactive. As Cooper-Thomas and Burke (2012) suggest, more work is caused for a colleague and the productivity levels of an employee are disrupted because of a newcomer's proactive behaviour. A similar sentiment was echoed by several other contractors but was not common to all. 


\subsubsection{Summary}

\section{What are the implications of organisational socialisation on the working relationship between professional contractors and the permanent employees they work with?}

The variety of this study's findings provides a lot of valuable information, insight and detail to the developing picture of the organisational socialisation of professional contractors. For example, organisational socialisation of professional contractors does occur more than the literature acknowledges it does. There is the need to customise content of the socialisation messages that professional contractors receive. Several of this study's findings serve as the basis for developing a model of Socialisation Over Time based specifically for professional contractors. For instance, adding an additional indicator of adjustment output to Bauer's (2010) model of Socialisation Over Time would be the first step in developing such a model. In this model the proximal and distal outcomes could be condensed due to the limited tenure of a professional contractor. The knowledge of the three factors that can influence a professional contractor's time to productivity is valuable for managers. The finding that professional contractors also act as socialisation agents was surprising. This study also emphasises the importance of the role that proactive socialisation plays in the organisational socialisation of workers but particularly professional contractors.

Several of the findings described above have implications for our understanding of working relationship between professional contractors and the permanent employees they work with. The finding that a socialisation agent played a key role in the organisational socialisation of professional contractors has clear implications for permanent employees, who generally fulfil the role of a social agent. However, this research also discovered that other professional contractors were found to act as organisational insiders by being the socialisation agent so the implication for permanent employees is actually shared. The fact that other professional contractors play the role of a socialisation agent has certain implications in terms of socialisation content and messages. As transient members of a team, professional contractors' level of organisational knowledge is likely to be limited so their role may have to be supported or supplemented with other tactics, material, resources and/or information. This would ensure that the new contractor is receiving adequate or sufficient socialisation. Another implication of this finding is that other professional contractors are in a unique position to customise a new contractor's induction, having been in a similar situation. 


\subsection{Discussion of the Psychological Contract Findings}

As Rousseau (1995) describes it, "the psychological contract is individual beliefs, shaped by the organization, regarding terms of an exchange agreement between individuals and their organization" (p. 9). It is suggested that "potential differences in their psychological contracts ... might produce dissonance in the employment relationship" between managers and non-standard workers such as professional contractors (Redpath et al., 2009, p. 74). Figure 11 arranges the findings of this research in the conceptual framework of this study to indicate how these findings will be discussed.

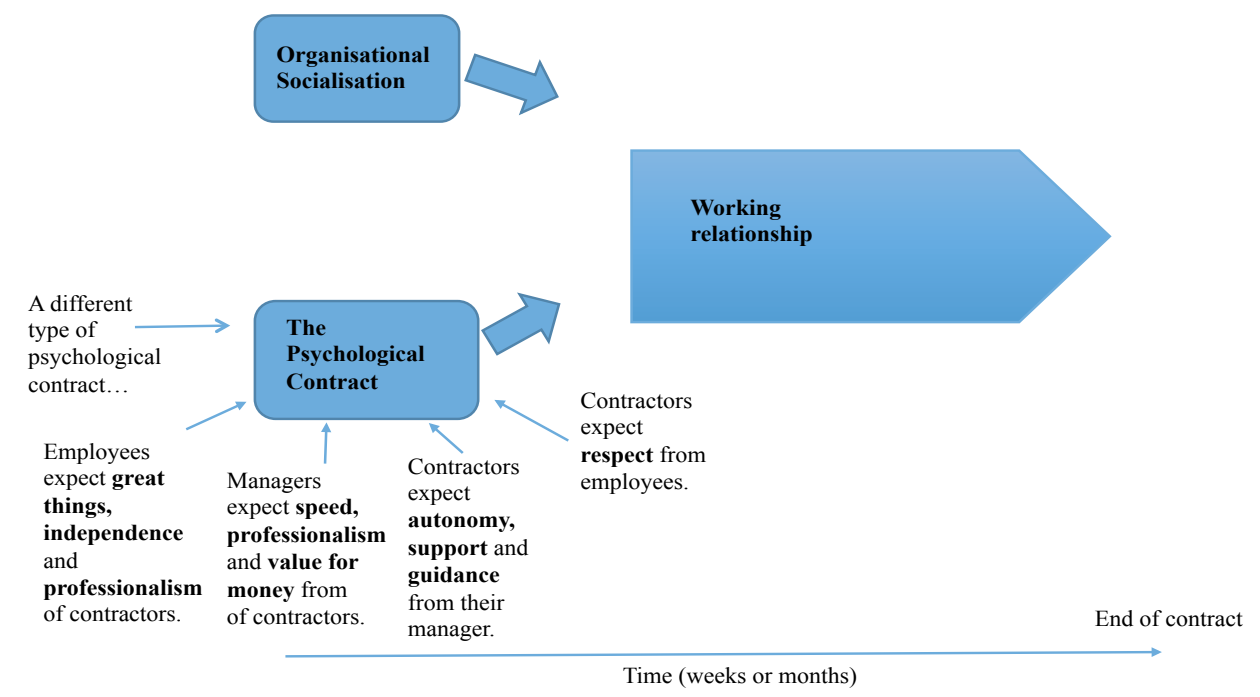

Figure 11. The Psychological Contract Findings and the Conceptual Framework.

\subsubsection{A Different Type of Psychological Contract}

In Chapter 2 Rousseau's Matrix of Types of Psychological Contracts were presented and explained as transactional, transitional, balanced or relational (Rousseau, 1989, 1995). Based on this matrix a professional contractor's psychological contract is generally thought of as a transactional one but does this typology sufficiently capture the nuanced relationship between an organisation, its representatives and the professional contractor? Given the high skill, specialist knowledge and experience of professional contractors a transactional psychological contract seems insufficient. The transactional quadrant describes this type of psychological contract as having low ambiguity, easy exit/high turnover, low member commitment, freedom to enter new contracts, little learning and weak integration/identification (Rousseau, 1995). For many professional contractors only some of these descriptions hold true. 
A professional contractor may have the right to give notice to terminate a contract early. While exit may be relatively easy there are real implications to the reputation of a contractor. In fact, very few of the professional contractors interviewed mentioned leaving a contract early. Those who have had to terminate a contract did so for particularly good reasons. Despite the potential for easy exit, it has been found that contractors have the ability to hold dual commitment to the organisation or the staffing or recruitment agency (McKeown, 2003). Professional contractors, like permanent employees, have been found to identify with the team they are working with so their identification with the organisation is not always weak (Pearce, 1993). Millward and Brewerton (1999) has confirmed the significance the team at the client organisation. "The team may provide a forum in which contractors can derive feelings of being integrated within their place of work to buffer the short-term nature of their contracts" (Millward \& Brewerton, 1999, p. 264). Recently it has been found that "...studies suggest that contractors are committed to their roles or the clients they serve; but may have lower levels of organisational commitment. Often contractors' commitment is higher than standard employees in the same company or industry. These findings appear to hold across countries and industries" (Flinchbaugh et al., 2019, p. 6).

While the type of psychological contract that a professional contractor develops remains unclear, it is clear that they develop a distinctly different psychological contract. As a transient member of the team, the psychological contract of professional contractor is likely to change over the time the professional contractor is at a client organisation (De Vos et al., 2003; Thomas \& Anderson, 1998). Evidence of this phenomenon was clear in Elaine and Elliot experience. Both interviewees observed that the longer a professional contractor is at the client organisation, the more like an employee they become. For example, Thomas and Anderson (1998) found that there is a convergence in the psychological contracts of newcomers and experienced insiders: “...newcomers' psychological contracts are likely to change towards those of experienced insiders as they become accepted as an integral part of the company." While Thomas and Anderson (1998) make this claim about permanent employees, it is likely that a contractor's psychological contract is also malleable enough to change over the duration of the contract. This study's findings indicate that a professional contractor's psychological contract may converge towards that of a permanent employee over time. In fact, the longer a professional contractor remains with a client organisation, the more the psychological contract seems to become relational.

Therefore, it is possible that professional contractors develop a hybrid of these types that is particularly suited to the nature of their work. Millward and Brewerton (1999) found that 
developing a transactional psychological contract did not preclude contractors from forming a relational one later on. Given the dynamic nature of the psychological contract this is entirely feasible. Alternatively, a contractor's psychological contract may move from one type of psychological contract to another during their tenure. It is suggested that the psychological contract may only become relational when the transactional aspects have been fulfilled (Herriot et al., 1997; Millward \& Brewerton, 1999; Svensson \& Wolven, 2009). As Millward and Brewerton (1999) suggest the psychological contract could function similarly to Maslow's Hierarchy of Needs, meaning that transactional considerations must be met first before the psychological contract could become a relational one. Therefore, it is possible that a professional contractor's psychological contract is relational with members of their team but transactional with others in the organisation. It is also possible that a professional contractor's psychological contract is subtly different for different organisational members (Rousseau, 1995). A professional contractor could develop a relational contract with a team member or close colleague. That same professional contractor could develop a transactional psychological contract with a stakeholder or internal client.

\subsubsection{Permanent Employees and Managers have great expectations}

\section{What are the implications of these expectations on the working relationship between professional contractors and the permanent employees they work with?}

In this research interviewees were asked about their expectations of those with whom they work. Expectations are a feature of several definitions of the psychological contract. For example, both Rousseau (1989) and Schein (1988) include expectations in their explanations of the psychological contract. This information was gathered to better understand the expectations that are involved in the psychological contacts of the participants of this research, which will create a deeper picture of the psychological contract each party has developed. Morf et al. (2014) found that fulfilled psychological contracts positively relate to the job attitudes of the temps they studied. In their study about psychological contract fulfilment they used a measure based on (Tekleab \& Taylor, 2003). For instance, they asked participants to answer on a Likert scale the question: "My agency/host did a good job in meeting my expectations." Similarly, the parties involved in this study were asked about their expectations of those they work with in order to further explore the psychological contracts of professional contractors, permanent employees and managers. So what are the implications of these expectations on the working relationship between professional contractors and the permanent employees they work with? 
Permanent employees expect great things, independence and professionalism (Do not...) from professional contractors. Great things are expected because contractors are anticipated to be highly skilled, experienced and knowledgeable. A number of the employees interviewed also expect more of a contractor than they do a permanent employee. Permanent employees expect contractors to be independent because they do not have the time to babysit or handhold contractors. Employees' reluctance to do so is related to the idea that too much proactive behaviour can be maladaptive (Cooper-Thomas \& Burke, 2012). Cooper-Thomas and Burke (2012) refer to the finding that some proactive behaviour actually results in more work for colleagues. This was clearly evident in Errol's experience.

Both managers and permanent employees expect professionalism from the contractors they work with. The fact that both permanent employees and managers expect professionalism from professional contractors, albeit in different forms, is not unpredicted. The very idea of a contractor in IT is linked with being professional, freelance, itinerant and self-employed. Professionalism is being emphasised even more intensely as these independent professionals are cast as IPros (Burke, 2015; McKeown \& Cochrane, 2017). Managers expect a professional to do the job or deliver. To managers it is about getting the job done but to employees it is more about how the contractor does the job. Managers expect professionalism from contractors through doing the job and completing or delivering it (Mark, Michelle, Max, Mitch, Maria, Moses and Molly). Managers expect professional delivery of what was agreed, to the standard that was agreed and in the timeframe that was agreed. Doing the job is of the utmost importance to the managers interviewed. Permanent employees expect a professional to behave like one by refraining from distractions. Permanent employees expect contractors to be professional so they do not want contactors wasting time on personal endeavours, on socialising and/or office politics. This subtly different framing of professionalism suggested by these findings is informative because it showcases multiple perspectives of the one idea.

Managers expect speed, professionalism (Do the job) and value for money from contractors. Managers expect contractors to deliver quickly. Speed is of the utmost importance to most managers interviewed because of the need or pressure to deliver the work as well as the cost of professional contractors. This expectation provides added impetus for the organisational socialisation of professional contractors. Bauer (2010) quotes Tarquinio (2006) in suggesting that $60 \%$ of those surveyed found that an effective onboarding programme increased time to productivity. Put another way, a well designed, effective induction, as part of an organisational 
socialisation programme will help get a contractor up to speed. Managers were also found to expect value for money of a contractor. Value for money is significant because managers have little issue with paying professional contractors high rates if they are indeed delivering value. That value is not just quality work but also work over and above expectations.

\subsubsection{Professional contractors expect to be given respect and autonomy.}

Professional contractors were found to expect respect from the permanent employees they work with. Osnowitz (2010) reports, "Respect...conveys equality and invites reciprocity." (p. 129). It is clear in the data that professional contractors do not seem to expect much from either their permanently employed colleagues or from their manager. Generally, their expectations are pretty low or understated. For example, Cathy actually says, "There is nothing I expect from permanent employees." The answers that professional contractors provide about their expectations of professional contractors are about manner or style. In other words, professional contractors refer to the how (they would like to be treated) rather than what (they would like from them) when referencing their expectations of permanent employees. Contractors want to be treated well. Contractors expect to be treated just like anyone else, certainly not worse than other workers. "Contractors thus seek evidence of respect in social interaction" (Osnowitz, 2010, p. 129). This same author cites studies that show that respect is particularly important to those who might "feel the effects of inherently unequal relationships" (p. 129). In this thesis, the relationship between a professional contractor and permanent employee is an example of such a relationship.

Professional contractors expect autonomy, support and guidance from their manager. De Vos and Freese (2011) suggest that one of the central building blocks in the employment relationship is the interaction between supervisor (or manager) and an employee. It is possible to infer that the relationship between a manager and a professional contractor is equally important but there is an implied distance between the two. As identified by Osnowitz (2010) professional contractors do not like to be closely managed. Osnowitz (2010) writes, "Close supervision, [the informants] explained, was an unwelcome form of micromanagement, which could undermine their self-presentation as expert practitioners" (p. 102). The identification of autonomy as an expectation of a professional contractor echoes this sentiment precisely. The professional contractors interviewed are confident of their abilities and would like to be free to get on with delivering. Contractors want to be given autonomy so they can get on with their job. Many of the contractors interviewed see themselves as professionals who do not need to be closely managed. Contractors value this autonomy, as they 
appreciate not being constrained or restricted by the normal 'chain of command' or hierarchal structures. Autonomy brings the ability to communicate with whomever they need to in order to get their job done. Several contractors interviewed particularly enjoyed that aspect of being a contractor (Cain, Carole and Crystal).

It is interesting to see both autonomy and independence featuring in the expectations of both employees and contractors. Autonomy and independence are very closely linked but are not exactly the same. There is a subtle difference between these two ideas. This difference may, as the literature suggests, cause tension or dissonance at times (Redpath et al., 2009). For example, one employee referred to a contractor "bulldozing" their way through the organisation (Errol). In this example it is possible that the contractor believes he or she is acting autonomously. However, from the perspective of the employee, the contractor is acting totally independently without regard or care of those involved or affected.

Several of this study's findings relating to the psychological contract have been presented from multiple perspectives. As has been noted, it is individuals who form or develop the psychological contract rather than an organisation (Rousseau, 1995). These individuals are the so-called human contract makers, each of whom help shape the psychological contract (Rousseau, 1995). As agents of the organisation permanent employees and managers have a unique role in influencing the development of the psychological contract of professional contractors (De Vos \& Freese, 2011). Permanent employees and managers are agents of the organisation so will play a unique role in influencing the development of the psychological contract of professional contractors (De Vos \& Freese, 2011). Like organisation socialisation, the psychological contract is likely to be different for a professional contractor due to the short-term duration of a contractor's role and different desired outcomes.

\subsubsection{A Malleable or Dynamic Psychological Contract for Professional Contractors}

Violations or breaches of the psychological contract were also explored as a way to further understand this concept in relation to professional contractors. O'Leary-Kelly et al. (2014) state that an awareness that an aspect of the psychological contract has not been met is considered a breach in the psychological contract. There is a different degree of severity between a breach and a violation. The significance of either of a breach or violation is that it potentially damages the psychological contact, undermining trust or leading to an emotional disappointment (Rousseau, 1989, 1990; 
Thomas \& Anderson, 1998). Traditionally, an employer reneging on the expectations of employees was associated with the violation of the psychological contract (Osnowitz, 2010).

The causes of potential breaches identified in this research can be grouped as organisational problems, social dysfunction, delivery problems or none at all. Based on the literature, there are two possible explanations for the latter. It could mean that these contractors' psychological contracts are sufficiently dynamic in order to accommodate changes. Psychological contracts that are able to change, develop and adapt are less susceptible to the perception of a breach or violation (De Vos et al., 2003; Thomas \& Anderson, 1998). As a contractor acquires more understanding about the role, they become better integrated into the team and acquire knowledge about the organisation, and so the psychological contract of the contractor similarly develops (Woodrow \& Guest, 2017). If the psychological contract does not adapt in keeping with the new understanding, information and knowledge gained, then it is possible that a breach in the psychological contract will be perceived. As the review of the literature revealed, during the first few weeks or months the psychological contract should be viewed as a shifting or dynamic set of expectations (De Vos et al., 2003; Thomas \& Anderson, 1998).

An alternative explanation may be that no matter how poorly these contractors are treated they would continue to do their best in order to complete their contract. This shows intense commitment to the role. In the course of this study, it has become apparent that even though contractors are not forming a long-term relationship with the organisation, they do display commitment to the job. Contractors display commitment to the role that they undertake as well as to the team they work with. Again, the importance of the team has been corroborated in the literature (Flinchbaugh et al., 2019; Pearce, 1993). A contractor's level or direction of commitment is likely to be different to that of a permanent employee but it is certainly not nil. A possible reason for this is that a contractor's reputation is closely tied with their performance in their last contract. Both Barley and Kunda (2004) and Osnowitz (2010) refer to a contractor's reputation. Barley and Kunda (2004) refer to a contractor's reputation as attributes of their social capital (along with reach and reciprocity). Osnowitz (2010) identifies the importance of contractors' reputation because it is a contractor's reputation that gets them the next job. "For a contractor, therefore, a track record of quality work and a corresponding reputation can contribute significantly to a stream of referrals" (Osnowitz, 2010, p. 131). As Cindy put it “...it is your reputation on the line and that's how you end up getting your next contract or whether they even extend your current contract." 


\subsubsection{Summary}

\section{What are the implications of these expectations on the working relationship between professional contractors and the permanent employees they work with?}

The different expectations of the multiple parties to the working relationship are certainly illuminating. Although it remains unclear exactly what type of psychological contract professional contractors actually develop it is clear that is a different type of psychological contract to that of permanent employees. Furthermore, it is clear that the longer the contractor is with the client organisation the more like a permanent employee that contractor becomes. This implies that their psychological contract also changes toward that of a permanent employee. The implication here is that their expectations are open, dynamic or malleable, allowing them to change or adjust their expectations as they gather more information through their organisational socialisation process.

The implications on the working relationship between professional contractors and permanent employees are likely to be subtle. Permanent employees actually have high-expectations of contractors so expect them to work independently (which is where a professional contractor's proactive socialisation needs to be engaged) because of their high-skills, extensive experience and superior knowledge. Similarly, permanent employees expect contractors to be highly professional by using their time at the client organisation both effectively and efficiently. For this reason, permanent employees do not want contractors to be wasting time on social events or personal endeavours.

It is apparent that professional contractors have fewer or lower expectations of those they work with. For professional contractors, their expectations of those with whom they work are much lower. In general, contractors simply expect to be treated with respect by employees. This means they are treated like any newcomer and certainly no worse than permanent employees. Professional contractors expect autonomy from their managers so they can get on with performing their role and delivering what the have been contracted to do.

\subsection{Chapter Summary}

In this chapter the findings of this research were discussed drawing on relevant literature to further explore those findings. There are gaps in the literature because much research has been focussed on permanent employees. Professional contracting does not always function like permanent employment because there are several fundamental differences between the two. 
In order to better understand the working relationship between professional contractors and permanent employees this relationship was explored through two relevant lenses: organisational socialisation and the psychological contract. Several of the insights made contribute to the body of knowledge on professional contractors.

This thesis highlights the interrelationship between the two key constructs. It is clear that the two concepts are related and that there is significant overlap between the two. This thesis' use of organisational socialisation and the psychological contract as lenses with which the working relationship is explored is both original and meaningful.

This thesis makes many findings regarding the organisational socialisation of professional contractors, illuminating the relationship between professional contractors and permanent employees. In this discussion of those findings, it is clear that an organisation's policy or lack of one sets the tone for the treatment of professional contractors. This study found that the professional contractors interviewed experienced organisation socialisation or an induction that was collective, informal, variable, random and serial. There was some variety in the data because some professional contractors experienced very little by way of induction while others reported positively about their experience. The content of socialisation messages was discussed with professional contractors themselves. They suggest that professional contractors need to know about an organisation's culture and values, structure, language and goals and strategy, to an extent. On the other hand, managers suggest that professional contractors need to know about the organisation's policy and procedures and have sound technical skills. These different perspectives illustrates the need to further investigate the type of socialisation messages that professional contractors receive in order to design such messages particularly for them.

In this study four indicators of adjustment were found to be relevant to professional contractors. An additional indicator of adjustment output was identified as important for professional contractors because of their limited tenure at a client organisation. This finding clearly indicates the need to reconceptualise organisational socialisation for professional contractors specifically. Therefore, a model of Professional Contractor Socialisation Over Time (based on Bauer and Erdogan's model) has been proposed. It was found that there are three factors - contractor capability, organisational readiness and role complexity - that influence a professional contractor's time to productivity. It was found that a socialisation agent was common to every positive induction experience, underlining the key role that this organisational insider plays in the adjustment of a professional 
contractor. Perhaps the most surprising discovery is the fact that other professional contractors also act as socialisation agents even though they are not permanent employees as the literature suggests. Finally, the importance of proactive socialisation for professional contractors was evident in the findings of this research.

The psychological contract of professional contractors, permanent employees and their manager has been further explored through expectations of that party to this relationship. These expectations were found to be illuminating. While it was not possible to ascertain the exact nature or type of psychological contract that professional contractors develop, it is clear that professional contractors develop a different type of psychological contract to that of permanent employees. There is evidence in the data collected in this study and in the literature that a contractor's psychological contract is likely to converge toward that of a permanent employee the longer they are working at the client organisation. There is also some evidence that a professional contractor's psychological contract may be a hybrid of the types in Rousseau's Matrix. Alternatively, it could move or change between the types of contracts depending on whom the psychological contract is with. It is apparent that an open, dynamic or malleable psychological contract is less likely to be breached or violated so professional contractors are likely to retain one that can bend, change or grow as they acquire more information through the organisational socialisation process.

In the next chapter, Chapter 7: Conclusion, the findings discussed here will be brought together. It is there that will ultimately answer the main research question about the working relationship between professional contractors and permanent employees. The contributions to theory and understanding, practical implications, limitations of this research and opportunities for future research are also presented in the next chapter. 


\section{Chapter 7: Conclusion}

\subsection{Introduction}

This thesis makes a strong case for exploring the working relationship between professional contractors and permanent employees. The investigation involved collecting qualitative data from 49 professional contractors, permanent employees and their managers. The use of one-to-one, faceto-face semi-structured interviews made it possible to collect rich, detailed accounts of the experiences of participants. This method was entirely appropriate because of the exploratory nature of this research. The findings of this thesis contribute significant insight and meaning to the organisational socialisation of professional contractors. It is from these findings that conclusions are drawn about the working relationship between permanent employees and professional contractors.

Professional contractors are one type of non-standard worker, the incidence of which has been steadily increasing in New Zealand and internationally. As part of a blended workforce, professional contractors are now common particularly in some occupational roles such as IT. Therefore, if permanent employees are not already working alongside professional contractors in their current teams, it is increasingly probable that they will in the near future. As they become a larger part of any organisation's workforce, it is interesting to reflect that professional contractors sit outside employment law and HR policies because they are neither permanent nor employees. It is imperative that professional contractors are managed well in order for organisations to realise the benefits of these highly skilled, technically competent and experienced workers (McKeown \& Lindorff, 2011). The conclusions presented by this research support the fact that an effective working relationship between professional contractors and permanent employees will not only benefit organisations but managers, permanent employees and professional contractors, too.

\subsection{Research Objectives}

At the outset, the research objective of this study was to gain a deeper understanding of the working relationship between professional contractors and their permanent employee colleagues. This objective has been achieved through the use of two well-known concepts - organisational socialisation and the psychological contract - as lenses to explore the working relationship between professional contractors and permanent employees. This research sought the experiences and perspective of the professional contractors who do the work, the permanent employees who work beside them and the managers who engage them. This study makes a variety of contributions to 
theory. These findings clearly show that the organisational socialisation of professional contractors requires reconceptualisation. This thesis proposes a model of socialisation for professional contractors, one of the main theoretical contributions of this study. This study also investigated the mutual expectations between professional contractors, permanent employees and their managers. Better understanding of these expectations is both informative and also helps better manage those expectations. This study also reveals more about the interrelationship between the two key concepts. These concepts are clearly related that was envisaged at the outset of this study.

There is also an additional methodological contribution that this study makes by including multiple perspectives rather than those of merely one homogenous group. Interviews were conducted with individuals who comprise a team: professional contractors, permanent employees and their managers. This research also has practical implications for HR practitioners and managers. It is in the interest of both HR professionals as well as people managers to better understand the intricacies of a blended workforce, a characteristic of the modern organisation. For HR practitioners, this information will be informative to their policy, procedure and process development because professional contractors are now a characteristic of a modern workforce.

\subsection{Research Questions}

This following research questions guide this research. The primary research question is:

How do professional contractors and permanent employees work together at organisations in New Zealand?

More specifically, the sub-questions are:

a) How are professional contractors organisationally socialised at client-organisations in New Zealand? What are the implications of their organisational socialisation on the working relationship between professional contractors and the permanent employees they work with?

b) What are the psychological contracts of professional contractors, permanent employees and managers at organisations in New Zealand? What are the implications of these expectations on the working relationship between professional contractors and the permanent employees they work with?

This chapter will now present conclusions supporting the fact that answering these sub-questions, and the main research question, has been achieved. 


\subsection{Key Findings of this Study}

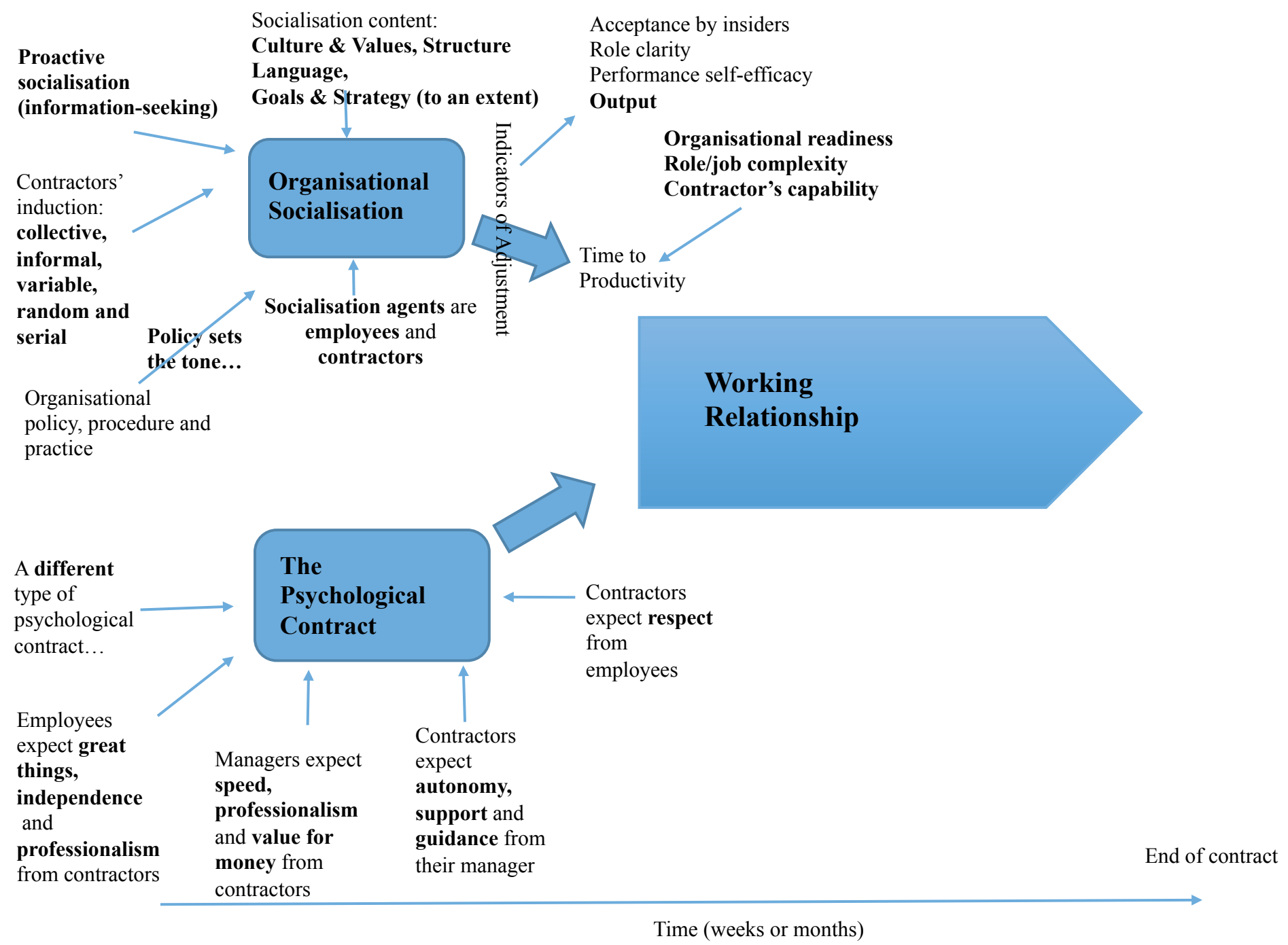

Figure 12. Key Findings and the Conceptual Framework. 


\subsection{Conclusions related to the Organisational Socialisation of Professional Contractors}

In Figure 12 the key findings of this research are illustrated on this study's conceptual framework. In answering the first of the sub-questions, it was found that the majority of the professional contractors in this sample experienced the following organisational socialisation tactics: collective, informal, variable, random and serial. This mix of organisational socialisation tactics is categorised by Jones (1983) to be slightly more individualised, which leads to more innovative role orientations. It was also found that the organisation's policy or lack of policy sets the tone for how professional contractors are treated. Without such guidance, it is left to the discretion of individual managers, resulting in diverse practice both within and across organisations.

In the opinion of the professional contractors interviewed, the socialisation content that is particularly relevant to them is structure, culture and values, language and, to a limited extent, goals and strategy. History was not considered important for professional contractors to know but results were inconclusive about politics. However, the perspective of managers differs somewhat. The managers suggest that contractors need to know about the organisation's processes \& procedures, have strong technical skills and industry, sector or domain knowledge. With regard to the indicators of adjustment, acceptance by insiders was not considered essential for professional contractors but it makes it easier. Output clearly emerged from the data as an additional indicator of adjustment. Output (or job performance) is usually a distal outcome of the organisational socialisation process of a permanent employee. The fact that it emerges in the short-term for professional contractors is significant. This suggests that for professional contractors specifically the proximal and distal outcomes merge because a contractor has limited tenure. Existing models of organisational socialisation are not appropriate because they are for permanent employees. Therefore, a new model of socialisation for professional contractors has been proposed.

The notion of a contractor's time to productivity resonated well with those interviewed. The significant finding with regard to a contractor's time to productivity is the identification of three factors that affect it: contractor's capability, organisation readiness and role complexity. The latter two factors are levers that any organisation can adjust to get their contractors productive as quickly as possible. Organisation readiness is not just about the organisation having a desk or workstation and ready for the contractor. It is also about the team being ready to provide help and support to the contractor. It was discovered that an essential ingredient of all positive organisational socialisation 
experiences was a socialisation agent such as a buddy or mentor. Surprisingly, it was found that other professional contractors also act as an organisational insider, assuming the role of socialisation agent. It was found that proactive socialisation is particularly important for professional contractors. It emerges from the research that many professional contractors are highly proactive and engage in information-seeking in order to gain role clarity. Each of these findings indicates a need to reconceptualise the organisational socialisation of professional contractors.

\subsection{Conclusions related to the Psychological Contracts of Professional Contractors}

In answering the second set of sub-questions, this research has made discoveries relating to elements of psychological contract professional contractors develop. This research highlights that there is not a single, specific type of psychological contract that typifies the professional contractor's psychological contract. It is possible that there could be another hybrid type of psychological contract that is particularly relevant to professional contractors. Contractors may develop relational psychological contracts with members of their team but transactional psychological contracts with others in the organisation. Alternatively, the psychological contract could move between the types developed by Rousseau (1995) over their term with the client organisation as the transactional aspects are fulfilled like Maslow's Hierarchy of Needs (Herriot et al., 1997; Millward \& Brewerton, 1999; Svensson \& Wolven, 2009). This insight into the transitory nature of a professional contractor's psychological contract is valuable. Based on the findings of this study, a malleable psychological contract (one that will shift or adjust as more information is acquired) is less likely to manifest a breach or violation. Therefore, it is better for a professional contractor to develop and maintain a malleable rather than rigid psychological contract.

The mutual expectations of professional contractors, permanent employees and their managers were explored in this thesis. The expectations of each of the three parties are subtly different, potentially influencing the psychological contract they develop. Professional contractors expect to be given autonomy by their managers and support and guidance, should they require it. Professional contractors simply expect to be treated with respect by their colleagues. Permanent employees expect great things, professionalism and independence from professional contractors. Managers expect speed, professionalism and value for money from contractors. These expectations are highly informative and provide new insights to the working relationship from which conclusions can be drawn. In Figure 12 this study's key findings are represented on the conceptual framework in bold. 


\subsection{Conclusions related to the working relationship between Professional}

\section{Contractors and Permanent Employees}

This study reveals that professional contractors and permanent employees work together codependently. There is a co-dependent working relationship because each derives different benefits from the other. It is apparent that contractors and employees rely on each other in different ways and to different extents. The organisation has a role to foster, encourage and/or facilitate this codependent relationship because it is mutually beneficial and ultimately advantageous to the organisation.

\subsubsection{Professional Contractors as Socialisation Agents}

Professional contractors rely on permanent employees for resources, information and social support. Permanent employees provide the organisational knowledge that contractors require in order to do the job they have been engaged for. Socialisation agents (either formally or informally) are those who help a professional contractor adjust to the work, role and team (but not necessarily to the organisation). A valuable finding of this research is the importance of socialisation agents. This is further emphasised by the finding that even other professional contractors will act as organisational insiders to help other professional contractors on the team get up to speed. In the literature, socialisation agents are assumed to be permanent employees so this is a valuable finding.

\subsubsection{Proactive Socialisation is vital for Professional Contractors}

Based on the expectations of the permanent employees interviewed, professional contractors should be independent. This means that the professional contractor has to be proactive in his or her own socialisation at the client organisation. This study found that proactive socialisation was key to professional contractors' organisational socialisation. There was evidence and examples of some contractors being particularly adept at being proactive in seeking information and building relationships. It is this independence that is important to permanent employees. Given the limited tenure of professional contractors, it is in their best interest to adapt to the new role as quickly as possible, so that involves actively seeking information and building relationships. 


\subsubsection{Tensions in the Working Relationship}

Despite the co-dependent relationship, there are several apparent tensions that exist between professional contractors and permanent employees. The use of the lenses of organisational socialisation and the psychological contract has highlighted these tensions in the working relationship between professional contractors and permanent employees. These four tensions can be categorised as: time, team, treatment and training.

Time. The issue of time is a thread that runs though many of the findings of this research. For example, the role of a socialisation agent emerges as important to the induction of a professional contractor. By acting as socialisation agents the individuals are taking time away from their actual day-to-day work. In other words, there is an opportunity cost to the socialisation agent. Socialisation agents have a finite amount of time that they can concede to professional contractors. This tension is exemplified by the expectation that contractors will become independent particularly after a specified period.

Time is an important driver with regard to proactive socialisation. Contractors do not have the luxury of a protracted learning curve, lengthy induction or onboarding but are expected to hit the ground running. It is this imperative that means that actively seeking information and developing relationships is even more important to a professional contractor. There is little time for a contractor to passively absorb the corporate culture, digest corporate publications and chit-chat. It is incumbent on professional contractors to be active in their own socialisation. Most experienced professional contractors also have a good sense of what information or resources they need. They know what questions to ask and who to meet with. It was found that managers expect speed from professional contractors and shows that there is a link to concepts such as swift socialisation (Ashforth, 2012; Bauer et al., 1998) or rapid onboarding (Rollag et al., 2005), which refer to a streamlined organisational socialisation where time is of the essence. In a modern workforce there is a plethora of technological options that are available to assist with orientation, onboarding or induction (Tarquinio, 2006). The findings of this research support the view that given the obvious time constraints involved in a professional contractor's organisational socialisation, there are benefits from such technological tools being explored and evaluated.

Though a simple notion, a contractor's time to productivity clearly resonated with all three parties interviewed. Each party had opinions about it and was able to relate to the concept. In general, contractors and managers believe that a contractor's time to productivity is shorter than the 
permanent employees believe it is. It is not yet clear why there is this apparent difference in the estimation of a professional contractor's time to productivity. It is possible that employees have a different perception of what productivity is, which would explain their different quantification of it. Alternatively, they may genuinely believe it takes a contractor longer to be productive than either the contractor or manager do. Nevertheless, contractor's time to productivity is relevant for all involved. Therefore, several steps or actions can be taken that are likely to positively influence a professional contractor's time to productivity, such as being prepared or ready for the contractor. An organisation's preparedness cannot be underestimated as it involves some key logistics. An organisation's readiness is not simply about a desk, security card, computer and log-on information, although these are essential. It is about whether or not the organisation has the relevant information, documentation and resources available for the contractor. It is about whether team members (either permanent employees or professional contractors acting as socialisation agents) or stakeholders are available to meet with the professional contractor in order to provide information and answer questions. This important conclusion may assist in organisations positively influencing a contractor's time to productivity, providing direct benefits in terms of productivity. Furthermore, this research has found this to be an important metric across all three parties, which will also serve to enhance the quality of the working relationship.

Time is also a factor involved with employees' expectations of professional contractors: great things, independence and professionalism. Employees expect contractors to be independent because they just do not have the time to babysit, handhold or do a contractor's job for them. Professionalism in this instance is about what employees do not expect of contractors. They do not expect contractors to deal with personal issues, attend morning tea (events) or hang around in the kitchen during working (or billable) hours. There is evidence that many contractors are well aware of this tension so are quite conscious of it.

Team. The importance of team is clear in the literature reviewed in this study (Millward \& Brewerton, 1999; Pearce, 1993). In fact, there is recent evidence that contractors are particularly committed to the role and the client they serve but not necessarily to the organisation (Flinchbaugh et al., 2019). The importance of the team a contractor works with emerges from the findings of this study, too. In general, contractors are included at the team level by being invited to team meetings and briefings. They are included in team social events that take place outside of working hours. In fact, depending on the team, they may be the initiators of the social event. However, as the scope widens from team to group, from group to division or department and so on, the likelihood of 
contractors being included decreases. Therefore, the importance of a contractor's team is obvious. In fact, this research has found that, to a professional contractor, the team has more importance than the organisation. The importance of team is particularly relevant to the working relationship for several reasons.

First, emphasising the importance of the team creates a team spirit or 'esprit de corps'. By actively cultivating team camaraderie, the bond and relationships between team members will be strengthened. There is a connection between the team and organisational socialisation, particularly with regard to socialisation agents. Socialisation agents are likely to be members of the contractor's team, whether they are permanent employees or not. It is also possible that by actively developing the team spirit, a professional contractor's time to productivity can also be positively affected.

This study discovered that other professional contractors also act as socialisation agents, a unique finding which is worth examining further. The literature assumes that socialisation agents are organisational insiders but an organisational insider is no longer guaranteed to be a permanent employee. Another professional contractor would be in a unique position to tailor the help, assistance and support he or she provides to the individual needs of the professional contractor because her or she would have an intuitive understanding of what information is important, which documents are relevant and whom the professional contract should meet with. The right socialisation agent is likely to have a profound impact on the working relationship between professional contractors and permanent employees.

Second, with regard to the type of psychological contract, contingent or temporary workers are assumed to have a transactional psychological contract based on Rousseau's Matrix (Rousseau, 1995). However, as has been noted, this research has determined that this belief does not seem to fit professional contractors. There are several aspects of a transactional psychological contract that do not relate to professional contractors. Furthermore, the importance of the team is actually symptomatic of a relational psychological contract. This is another indication that the psychological contract of professional contractors is not merely transactional but has distinct relational aspects to it as well. The knowledge that professional contractors may develop distinctly relational contracts with those on the same team is particularly important for managers who can actively encourage and foster team camaraderie. Strengthening the relational bonds between professional contractors and permanent employees on the same team would serve to even better integrate professional contractors. 
While the team is of particular relevance it is important to remember that contractors are transient so have short-term tenure. In theory, a professional contractor's highly specialised expertise is required for a short time in order to complete a critical task or assignment that cannot be produced economically in-house (Davis-Blake \& Uzzi, 1993; Kalleberg et al., 2003). This study has uncovered the tension here by several interviewees (managers and permanent employees) making mention of long-term contractors, whose contracts are perpetually rolled over. These permanent contractors are an issue for employees, managers and the organisations they are engaged by because they are likely to be dependent contractors, who are reliant on one client for all their work. It is well known that dependent contractors are increasingly likely to be disguised, false or bogus employees (Casale, 2012; IOE, 2019). Disguised employees are a concern in many jurisdictions because they have none of the rights and legal protections that standard employees have (ILO, 2018). This is certainly an area that is worthy of further study in order to fully understand the negative implications.

Treatment. This research has found that organisational policy sets the tone not only for the induction but also the treatment of professional contractors. There was found to be diversity in the organisational socialisation of professional contractors among participating organisations and even within organisations. It is evident that without guidelines the treatment of contactors is delegated to the professional contractor's manager themselves, which results in diverging practice. However, only a minority of organisations had an actual policy that outlined the treatment of contractors. In lieu of explicit policy, it was left to the manager of the team to develop his or her own practice.

The significance of this is that there is a lack of consistency when it comes to socialisation of professional contractors. There is evidence that some organisations socialise their contractors better than others. The socialisation of professional contractors is also the period during which the psychological contract is formed and developed. It is a pivotal time as it lays the foundation for the working relationship. Several of those interviewed took issue with the way contractors are treated at their organisation because they want to see consistency, fairness and equity in the treatment of professional contractors.

There are also varying levels of inclusion of professional contractors. Several organisations include them in every meeting, briefing, event or function. Other organisations restrict contractors' participation to team meetings or events but not gatherings involving the strategic future of the organisation. Given the short-term tenure of a contractor, the assumption is that contractors will not be around for such information to be relevant. Some organisations have clear and explicit policies 
about the inclusion of professional contractors. For example, if they attend an event they pay for it themselves and do not bill the client for the time. Without such clear guidelines inconsistent practice will result. The issue with inconsistency is that a perception of unfairness may result. Kunda et al. (2002) identified inequality as one of three reasons for workers leaving permanent employment in favour professional contracting so fairness and equality is a key concern. Legally professional contractors cannot be treated exactly like employees so the argument is not that professional contractors should be treated the same as permanent employees, but that all contractors should be treated consistently. Furthermore, where feasible, all team members should be treated fairly or equitably.

Professional contractors expectations of either permanent employees or managers are not high. This study found that the indicator of adjustment, acceptance by insiders, is not considered essential for professional contractors but it does make it easier for them. A significant finding of this research however, is that professional contractors do expect to be treated with respect. The majority of the contractors interviewed can command respect because they are highly skilled, technically adept and have extensive experience. In fact, it is because of these particular KSAs that professional contractors expect to be given autonomy by their manager. Most contractors are intimately aware of what they are capable of doing so just want to get on with the job. When the contractor requires their manager's support and guidance, they expect to be provided with it. A contractor's expectation of autonomy actually appears to suit managers very well because managers, too, just do not have the time to micromanage a professional contractor.

Training. This tension is slightly more obscure than the other tensions but nonetheless relevant. Induction, onboarding and orientation need to be considered separately from conventional training, learning and development activities. This study unequivocally confirmed that only permanent employees are entitled to training and development opportunities provided by an organisation. Several interviewees mentioned that because professional contractors are highly skilled, knowledgeable and experienced they do not require training and development. This assumption may lead to a situation where professional contractors are not adequately shown the ropes or inducted to the organisation leading to a delay in organisational socialisation. There is a lot of organisation-specific knowledge and know-how that only organisational insiders are ever privy to. It is this type of information that is so valuable to professional contractors. It is this type of information that they are likely to acquire from a socialisation agent, which explains why a socialisation agent plays an important part in the socialisation process. The lack of training and 
development opportunities for professional contractors may further emphasise the need for effective socialisation agents. Both the literature reviewed (Ashford \& Nurmohamed, 2012) and this study found that the relationships that newcomers have with their peers are vital for their learning. The literature also suggests that socialisation agents supplement other socialisation efforts (Saks \& Gruman, 2012).

Admittedly, not all learning takes place through formal training or development opportunities. Considerable amounts lot of learning takes place informally either on the job or through observation. The findings of this study suggest that organisations are reluctant to invest in the organisational socialisation of professional contractors because they are temporary or short-term. In addition training and development funding is not available to professional contractors. This occurs without recognition of the clear benefits of an effective organisational socialisation programme for a professional contractor (in addition to a permanent employee). It is clear that while this attitude persists, such initiatives will continue to remain ad hoc, underdeveloped or, worse, still non-existent for professional contractors.

\subsection{Contributions and Implications of this Research}

\subsubsection{Contributions to Theory}

The increasing incidence of non-standard work is well documented but these new forms need to be separated and explored in order to better understand them. Given the prevalence of professional contractors in the workforce, it is conceivable that they will remain a feature of a blended workforce for the foreseeable future. Therefore, more information about how professional contractors and permanent employees work together is considered to be highly valuable. This study adds to the growing body of knowledge and understanding about professional contractors and their relationship with permanent employees. This study contributes to that with the use of two well-known concepts - organisational socialisation and the psychological contract - as lenses. These two concepts are not often drawn together in such a manner. The application of organisation socialisation and the psychological contract lenses to the working relationship between professional contractors and permanent employees reveals several insights unique to this research.

Firstly, this study shows that the socialisation content required for professional contractors is different to that for permanent employees. It was clear that some content dimensions such as history and possibly politics are not considered important to professional contractors. Professional 
contractors consider structure, language, culture and values, and goals and strategy, to an extent, are important. However, managers believe that contractors need to know about the organisation's processes and procedures, have strong technical skills and industry, sector or domain knowledge. It is also clear that the proximal outcomes or indicators of adjustment are insufficient for professional contractors. Output was identified as an additional indicator of adjustment for professional contractors. This is significant because output is more typical of actual job performance, which is generally considered a distal outcome. These findings clearly show that the organisational socialisation of professional contractors requires reconceptualisation in order for organisations to fully benefit from professional contractors. Both these findings provide a starting point for the development of a model of socialisation for professional contractors similar to that developed by (Bauer \& Erdogan, 2012). This thesis proposes a model of socialisation for professional contractors, one of the main theoretical contributions of this study.

Secondly, this research further contributes to the body of knowledge about the organisational socialisation of professional contractors. The existing literature on organisational socialisation largely defaults to permanent employees because traditionally the employer-employee relationship was at the heart of such processes (Connelly \& Gallagher, 2012). Professional contractors are neither permanent nor employees. In fact, recently they have been referred to as non-employees (Burke, 2015; McKeown \& Cochrane, 2017). Therefore, the academic literature on organisational socialisation is no longer sufficient. This research makes a contribution to the broader understanding of organisational socialisation by instead choosing to focus on professional contractors. It explores how the professional contractors in this study are inducted and what socialisation tactics are used.

Thirdly, this research makes a contribution to theory about the psychological contract. The psychological contracts of non-standard workers have been investigated by several researchers (Druker \& Standworth, 2004; Millward \& Brewerton, 1999; Morf et al., 2014; Svensson \& Wolven, 2009; Woodrow \& Guest, 2017). This study builds on this research in a different way. The content of the psychological contract in this study is discussed in terms of expectations of each of the parties involved in the working relationship. By exploring the expectations of each of the parties useful insights are gained about the different perspectives, which are not present in previous studies. What managers expect of contractors differs from what permanent employees expect. Similarly, what professional contractors expect from permanent employees and their manager is also highly informative. Furthermore, the notion of a breach of the psychological contract is particularly 
illuminating. It is possible that professional contractors who have malleable psychological contracts, which are able to shift or bend, are less likely to experience a breach or violation of their psychological contract. Therefore, it is in a professional contractor's best interest to maintain a malleable psychological contract for the duration of a contract at a client organisation. These unique insights add depth and detail to the current knowledge about the psychological contract.

The interrelationship between organisational socialisation and the psychological contract is apparent in this research. This is the fourth contribution to theory that this thesis makes. It is clear that there is more of a relationship between these key constructs than there envisaged at the outset of this research. This research shows that organisational socialisation provides an opportunity for a working relationship to be established between professional contractors and permanent employees, during which the psychological contract is driven by the acquisition of knowledge by a professional contractor in order to adjust.

Finally, this study makes a methodological contribution. A unique aspect of this research is the fact that it considered multiple perspectives. This research was deliberately designed to consider multiple perspectives to explore the working relationship between professional contractors and permanent employees. Often such studies are limited to the viewpoint of one group. These differing perspectives provide rich insight into the complexities of the working relationship between professional contractors and permanent employees. Interviews were conducted with individuals who comprise a team: professional contractors, permanent employees and their manager. Ashford and Nurmohamed (2012), echoing Feldman (1994), acknowledge the need to study both the socialisers (managers and colleagues) and socialised (contractors) but few studies do so. Clearly emerging from the findings are distinctly different perspectives, which underscore the necessity to consider various perspectives. This study's findings make the multiple perspective methodological approach highly valuable as a technique to be employed by subsequent researchers.

\subsubsection{Human Resource Practitioner Contribution}

It is in the interest of both human resource professionals as well as people managers to better understand the intricacies of a blended workforce, a characteristic of the modern organisation. Professional contractors are known to fall through the cracks at organisations because they are outside the remit of HR policy and advice. Often HR is not involved in the recruitment, selection or contracting of professional contractors so it is no surprise that professional contractors are 
overlooked. The HR literature barely considers professional contractors because they are neither employees nor permanent. However, the reality of a blended workforce is that permanent employees will be working alongside these contractors. Furthermore, professional contractors are doing the work of permanent employees so recognition of the increasingly important role professional contractors play in the functioning of organisations is vital. It is in the interests of both managers and HR professionals for the working relationship to be good, functional and productive so the findings above provide some valuable insights.

For HR practitioners, it is imperative that the information uncovered by this study inform policy, procedure and process development because professional contractors can no longer be overlooked or dismissed. There is an industry wide need for corporate or HR policy relating specifically to, or at the very least catering for, professional contractors. This research makes a clear case that any such policy should address these three aspects:

1) Managers require guidance and support on how to induct or onboard professional contractors even though they are only transient members of the team. For example, the development of a carefully crafted induction programme specifically for professional contractors could be considered. A variety of induction resources could be developed to assist with the orientation, onboarding or induction of professional contractors. There are now a plethora of online tools that could be very effectively used for this purpose. The literature regarding rapid onboarding (Rollag et al., 2005) and swift socialisation (Ashforth, 2012; Bauer et al., 1998) could be drawn on to develop such programmes.

2) It is also clear that managers also need guidance on the treatment of professional contractors. They need to be clear if they should include contractors in all meetings or briefings. They need advice on whether or not contractors should attend corporate events or social functions. They need to know how to advise contractors whether or not to bill their time for such activities, too.

3) Other professional contractors were found to act as socialisation agents, in most cases providing significant benefits to the organisation in relation to the time to productivity of newly engaged professional contractors. These professional contractors acting as socialisation agents must be privy to the right organisational socialisation content or messages and be appropriately supported in this role by organisation. 


\subsubsection{Practical Implications for Managers}

For people managers, the findings within this research will assist them to more effectively engage, manage and utilise the professional contractors on their teams. There are several practical implications for managers of blended teams, those comprising professional contractors, permanent employees and even other temporary workers.

Firstly, this study strongly confirms that the team is highly important for professional contractors. This was apparent in the literature reviewed and further endorsed by the findings of this study. Managers should be encouraged to create, foster and/or cultivate a team spirit or 'esprit de corps' among their blended team, as it is the team that provides the contractor with much of their identity at the organisation. For example, this means the inclusion of professional contractors in all team meetings, briefings, celebrations and events because they are less likely to be included in broader events particularly organisation-wide functions. In a similar manner, managers are advised to treat the team as a whole rather a collection of individuals. This implies equitable treatment of all of those on the team if equal treatment is not possible. In the words of one highly experienced interviewee, "They are the same but different" (Matthew).

Secondly, time is of the utmost importance for professional contractors. A contractor's time to productivity was found to be highly relevant. For this reason, it is imperative that the organisation is ready or prepared for the contractor. This readiness is not just about having a workstation ready but also about having a plan for the induction of that individual. The findings within this study clearly show that there are benefits if this readiness includes identifying a socialisation agent, arranging a meeting or briefing with key stakeholders or providing the contractor with certain information and resources. It is also important for an accurate understanding of the size or scope of the role as that has a direct impact on the contractor's time to productivity.

\subsubsection{Practical Implications for Professional Contractors and Permanent Employees}

Both professional contractors and permanent employees will benefit from this study's exploration into their working relationship. HR literature is replete with theories, concepts and models that relate directly to permanent employees. The realities of new forms of work such as professional contracting are absent in much of the literature. By linking and framing professional contractors' experiences and perspectives in terms of the academic literature, professional contractors can also gain better insight to the functioning of this form of work, particularly if it is their chosen career. 
This academic grounding is particularly valuable as a sense-making tool for professional contractors, which offers them added insight into the practice. Insight into the expectations of the managers interviewed in this study is also useful to professional contractors who are not always privy to such detailed information. The psychological contract, by its very nature, is a mental model so these expectations are not often shared or voiced (Guest, 1998, 2004). Similarly, the perspectives of permanent employees should be highly enlightening to professional contractors because this is the perspective of those who form a vital part in the working relationship.

Permanent employees will benefit from understanding that they, too, have an important role to play in the socialisation of a new professional contractor as what both Van Maanen (1978) and Feldman (1994) call socialisation agents. The role maybe a formal mentoring role (Chao, 2007) but can also take a more informal form that can positively influence a professional contractor's time to productivity with information, resources or even social support. On the other hand, professional contractors will benefit from an appreciation of the expectations of both managers and permanent employees. Cooper-Thomas and Burke (2012) refer to the finding that some proactive behaviours actually result in more work for colleagues. Permanent employees who already have high workloads often resent this.

\subsection{Limitations of this Research}

There are several limitations of this research. Firstly, this research is fundamentally qualitative because it involves the exploration of the working relationship through semi-structured interviews. It has no real quantitative element, as it does not involve survey of a large sample of participants. Therefore, neither the organisational socialisation nor the content of interviewees' psychological contracts were measured. There are several socialisation scales that could have been administered to measure the socialisation of participants (Chao et al., 1994; Haueter et al., 2003; Taormina, 1994). A choice was made not to use one of these tools because of the quantitative nature of such surveys. The use of one of the socialisation scales, though informative, would have been akin to using an inappropriate tool for a job. For example, measuring a contractor's understanding of a clientorganisation's history would serve little purpose without first establishing if such knowledge is relevant to a professional contractor or not. In a similar way, the content of the psychological contract could have been measured. The psychological contract and/or breach is usually assessed or measured with a questionnaire survey but there is no single agreed upon tool for either (Freese \& Schalk, 2008). It was important to have interviewees share their experiences and perspectives and to 
hear their voices. Therefore, the use of a qualitative method of data collection such as one-to-one, face-to-face interviews was considered highly appropriate for the objective of this research.

Secondly, this study was not longitudinal in nature but offers insight at a snapshot in time. Both organisational socialisation (such as Bauer \& Greene, 1994; Major et al., 1995; Morrison, 1993a) and the psychological contract (such as Robinson et al., 1994; Robinson \& Morrison, 2000) are typically the subject of longitudinal studies. All longitudinal studies risk attrition in the sample over time. This risk was considered particularly high for professional contractors whose work is transient. Similarly, longitudinal studies generally require a very large sample size to be effective. Access to a large pool of appropriate interviewees was not possible at the time this research was designed.

Thirdly, this study was carried out in New Zealand and involves fewer than 50 participants at 10 organisations. This sample size may not be representative enough to allow generalisations across the population. Nor may the scope of this research be broad enough to extrapolate to other international jurisdictions. While the results may not generalisable, the experiences of some of the professional contractors, permanent employees and managers interviewed will be similar to others involved in IT. The experiences of those interviewed are rich, evocative and provide a unique insight into the professional contracting world from the multiple perspectives that comprise a blended workforce. A large number of the experiences, anecdotes and stories shared by those interviewed will resonate strongly with other professional contractors and permanent employees.

\subsection{Future Research}

This research has touched on the issue of organisational socialisation of professional contractors. The findings clearly show that there is a need to reconceptualise organisational socialisation for professional contractors because the socialisation of contractors has to be different. The development of a professional contractor model of socialisation over time similar to that of Bauer and Erdogan (2012) is clearly warranted. While this research identified the socialisation tactics used to induct the contractors in this sample, it did not measure how effective each tactic was. One study has attempted to measure the socialisation of professional contractors or identified the most effective tactics for their socialisation (Benzinger, 2016). Furthermore, the content of the organisational socialisation messages provided to professional contractors has not been tested. This study identified that the dimensions culture and values, structure, language and, to a certain extent, 
goals and strategy of an organisation are important for a contractor to know. These dimensions need to be further investigated and empirically tested in relation to professional contractors organisational socialisation. There is also considerable scope for further research into the role that professional contractors play as socialisation agents within organisations. How effective are these agents while socialising other professional contractors compared to permanently employed socialisation agents? This could be the subject of future work.

The expectations of professional contractors, permanent employees and managers were explored in this study. Expectations are a part of the psychological contract but there are other aspects to the psychological contract that could also be further explored such as beliefs, promises and obligations (Druker \& Standworth, 2004; Roehling, 2008; Svensson \& Wolven, 2009). Due to the unclear definition of the psychological contract, expectations were focussed but there is opportunity for further testing and measuring of the psychological contract of professional contractors, particularly in a longitudinal study. This could potentially answer the questions about the type of psychological contract professional contractors form and develop. It would also be useful to investigate if a professional contractor's psychological contract with a team member is indeed different to the psychological contract they have with other organisational members. How long does it take for the psychological contract of professional contractors to converge towards that of a permanent employee? Such questions merit further investigation given that professional contractors are a ubiquitous part of the modern workforce and are likely to remain so into the future.

Finally, the connection between organisational socialisation and the formation of the psychological contract is not yet well understood. For the purposes of this study it was considered that the psychological contract is driven by the information acquired during the socialisation process (Woodrow \& Guest, 2017). However, is the psychological contract an outcome, intervening variable of the organisational socialisation process or not (De Vos \& Freese, 2011; Woodrow \& Guest, 2017)? This question was out of the scope of this research but begs further research, as it would shed further light on this study and its implications. 


\subsection{Researcher's Reflections}

It has never been my aim to establish a preference between professional contracting and permanent employment. It is apparent that each has an important role to play in a blended workforce and will continue to be a feature of work in the future. I have found this research personally challenging particularly because it has been a long, part-time journey. It has been a professionally stimulating endeavour because it kept me in the HRM discipline (albeit on the periphery). Even during the course of this endeavor, the incidence of contracting has increased and it has become even more relevant against the backdrop of the changing nature of work and employment. I hope that this study will position me as someone who is capable to taking on new, significant and complex pieces of work and getting on with that work. I have further developed my interview skills as I actively worked on these. I have gained a level of proficiency in NVIVO both through trial and error but also availing myself of several webinars, which I found to be excellent. This exposure was entirely new but one I found very valuable. While there is no guarantee that I would need such a tool in the workplace, being able to master such software can only hold me in good stead both personally and professionally. I relished the deep engagement that this research has allowed me. It has kept me intellectually stimulated and provided me with much food thought. I thoroughly appreciated collecting data for this research. I enjoyed interviewing the professional contractors, permanent employees and their managers. I liked visiting their organisations, seeing how they are laid out but most of all I loved hearing the stories, narratives and anecdotes. 


\section{Bibliography}

Addressing zero-hours contracts. (2018). Retrieved from https://www.mbie.govt.nz/infoservices/employment-skills/legislation-reviews/employment-standards-legislationbill/addressing-zero-hour-contracts

Alach, P., \& Inkson, K. (2003). Temping: A study of temporary office workers in Auckland. Auckland, New Zealand: Massey University.

Alvesson, M. (2011). Interpreting interviews. London, UK: SAGE Publications.

Amato, C. J. (2002). The world's easiest guide to using the APA. A user-friendly mannual for formatting research papers according to the American Pyschological Association style guide (3 Ed.). Corona, CA, USA: Stargazer Publishing Company.

Arthur, M. B., \& Rousseau, D. (1996). The Boundaryless Career: A new employement principle for a new organisational era. New York, NY, USA: Oxford University Press.

Ashford, S., \& Nurmohamed, S. (2012). From past and present and into the future: A hitchhiker's guide to the socialisation literature. In Wanberg, C. (Ed.), The Oxford handbook of organisational socialisation (pp. 8-24). Oxford, UK: Oxford University Press.

Ashforth, B. E. (2012). The role of time in socialization dynamics. In Wanberg, C. (Ed.), The Oxford handbook of organisational socialization (pp. 161-186). Oxford, UK: Oxford University Press.

Ashforth, B. E., Sluss, D., \& Harrison, S. (2007). Socialization in organizational contexts. In Hodgkinson, G. P. \& Ford, J. K. (Eds.), International Review of Industrial and Organizational Psychology (Vol. 22). Sussex, UK: John Wiley \& Sons.

Atkinson, J. (1984). Manpower strategies for flexible organizations. Personnel Management(16), 28-31.

Barley, S. R., Bechky, B. A., \& Milliken, F. J. (2017). The changing nature of work: Careers, identities, and work lives in the 21st century. Academy of Management Discoveries, 3(2), 111-115.

Barley, S. R., \& Kunda, G. (2004). Gurus, hired guns, and warm bodies: Itinerant experts in a knowlege economy. Princeton, NJ, USA: Princeton University Press.

Barley, S. R., \& Kunda, G. (2006). Contracting: The new form of professional practice. Academy of Management Perspectives, 20, 45-66.

Bauer, T. N. (2010). Onboarding new employees: Maximising success SHRM Foundations's Effective Practice Guideline Series Retrieved from https://www.shrm.org/foundation/ourwork/initiatives/resources-from-pastinitiatives/Documents/Onboarding New Employees.pdf 
Bauer, T. N., \& Erdogan, B. (2010). Organizational socialization: The effective onboarding of new employees. In Zedeck, S., Aguinis, H., Cascio, W., Gelfand, K., Leung, K., Parker, S., \& Zhou, J. (Eds.), APA Handbook of I/O Pyschology (Vol. III, pp. 51-64). Washington, DC, USA: American Psychological Association.

Bauer, T. N., \& Erdogan, B. (2012). Organizational socialization outcomes: Now and into the future In Wanberg, C. (Ed.), The Oxford handbook of organizational socialization. Oxford, UK: Oxford University Press.

Bauer, T. N., Erdogan, B., Truxillo, D. M., \& Tucker, J. S. (2007). Newcomer adjustment during organizational socialization: A meta-analytic review of antecendents, outcomes, and methods. Journal of Applied Psycology, 92(3), 707-721. doi:10.1037//0021-9010.92.3.707

Bauer, T. N., \& Greene, S. G. (1994). Effect of newcomer involvement in work-related activities: A longitudinal study of socialisation. Journal of Applied Psychology, 79(2), 211-223.

Bauer, T. N., Morrison, E. W., \& Callister, R. R. (1998). Organizational socialization: A review and directions for future research. Research in Personnel and Human Resources Management, $16,149-214$.

Belbin, R. M. (1981). Management teams: Why they succeed and fail. London, UK: Heinemann.

Benzinger, D. (2016). Organisation socialization tactics and newcomer information-skeeing in the contingent workforce. Personnel Review, 45(4), 743-763.

Bidwell, M. (2009). Do peripheral workers do peripheral work? Comparing the use of highly skilled contractors and regular employees. Industrial and Labour Relations Review, 62(2), 200-225.

Biggs, D., Burchell, B., \& Millmore, M. (2006). The changing world of the temporary worker: The potential HR impact of legislation. Personnel Review, 35(2), 191-206. doi: $10.1108 / 00483480610645821$

Blaikie, N. (2000). Designing social research: The logic of anticipation. Malden, MA, USA: Polity Press.

Borg, E., \& Soderlund, J. (2014). Moving in, moving on: Liminality practices in project-based work. Employee Relations, 36(2), 182-197.

Boxall, P., Purcell, J., \& Wright, P. M. (Eds.). (2008). Human Resource Management: Scope, Analysis and Signiciance. Oxford, UK: Oxford University Press.

Bridge, S. (2016). Self-employment: Deviation or the norm? Journal of Management \& Organization, 22(6), 764-778. 
Brosnan, P., \& Walsh, P. (1996). Plus ca change: The Employment Contracts Act and non-standard employment in New Zealand, 1991-1995 Paper presented at the 7th Biennial Labour Employment and Work Conference, Victoria University of Wellington.

Bryant, M., \& McKeown, T. (2016). Experts, outsiders or strangers? The self-positioning of highly skilled workers. Journal of Management \& Organization, 22(3), 388-403.

Bryman, A. (2016). Social research methods (5th ed.). Oxford, UK: Oxford University Press.

Burgess, J., \& Connell, J. (2006). Temporary work and hunman resource management: Issues, challenges and responses. Personnel Review, 35(2), 129-140.

Burke, A. (Ed.) (2015). The handbook of research on freelancing and self-employment. Dublin, Ireland: Senate Hall Ltd.

Burns, R. B. (1996). Introduction to research methods (3rd ed.). Melbourne, VIC, Australia: Addison Wesley Longman.

Bururu, R. (1998). Self-employment in New Zealand. Paper presented at the Laour, Employment and Work in New Zealand 1998, Victoria University of Wellington.

Business.govt.nz. (2019). Finding contract work. Retrieved from https://www.business.govt.nz/getting-started/advice-for-contractors/finding-contractingwork/

Casale, G. (2012). The employment relationship: A comparative overview. Geneva, Switzerland: International Labour Office (ILO).

Cascio, W. F., \& Boudreau, J. W. (2017). Talent management of nonstandard employees. In Collings, D., Mellahi, K., \& Cascio, W. (Eds.), The Oxford Handbook of Talent Management. Oxford, UK: Oxford University Press.

Casey, C., \& Alach, P. (2004). 'Just a temp?': Women, temporary employment and lifestyle. Work Employment and Society, 18(3), 459-480. doi:10.1177/0950017004045546

Cavana, R. Y., Delahaye, B. L., \& Sekaran, U. (2001). Applied business research: Qualitative and quantitative methods. Milton, QLD, Australia: John Wiley.

Cebrian, I., Moreno, G., Smek, M., Semenza, R., \& Toharia, L. (2003). Nonstandard work in Italy and Spain: The quest for flexibility at the margin in two supposedly rigid labor markets. In Houseman, S. \& Osawa, M. (Eds.), Non-standard work in developed economies: Causes and consequences. Kalamazoo, MI, USA: W. E. Upjohn Institute for Employment.

Centre for Research on Work Education and Research. (2004). Report of exploratory case study research into precarious employment. Retrieved from Wellington, New Zealand: 
https://thehub.sia.govt.nz/resources/report-of-exploratory-case-study-research-intoprecarious-employment/

Chao, G. (2007). Mentoring and organizational socialization: Networks for work adjustment. In Ragins, B. R. \& Kram, K. E. (Eds.), The handbook of mentoring at work: Theory, research and practice. Thousand Oaks, CA, USA: SAGE Publications.

Chao, G. (2012). Organizational socialization: Background, basics, and a blueprint for adjustment at work The Oxford handbook of organizational psychology (pp. 579-614). New York, NY: Oxford University Press.

Chao, G., O'Leary-Kelly, A. M., Wolf, S., Klein, H., \& Gardner, P. (1994). Organisational socialisation: Its content and consequences. Journal of Applied Psycology, 79(5), 730-743.

Connell, J., \& Burgess, J. (2006). The influence of precarious employment on career development. The current situation in Australia. Education + Training, 48(7), 493-507. doi:10.1108/00400910610705881

Connelly, C. E., \& Gallagher, D. G. (2004). Emerging trends in contingent work research. Journal of Management, 30(6), 959-983.

Connelly, C. E., \& Gallagher, D. G. (2006). Independent and dependent contracting: Meaning and implications. Human Resource Management Review, 16, 95-106.

Connelly, C. E., \& Gallagher, D. G. (2012). Rethinking the employee-organization relationship: Insights from the experiences of contingent workers. In Shore, L. M., Coyle-Shapiro, J. A., \& Tetrick, L. E. (Eds.), The Employee-Organization Relationship: Applications for the 21st Century. (pp. 255-280). New York City, NY, USA: Routledge.

Cooper-Thomas, H., \& Burke, S. (2012). Newcomer proactive behaviour: Can there be too much of a good thing? In Wanberg, C. (Ed.), The Oxford Handbook of Organizational Socialization. Oxford, UK: Oxford University Press.

Cooper-Thomas, H. D., \& Anderson, N. (2006). Organizational socialization: A new theoretical model and recommendations for future research and HRM practices in organizations. . Journal of Managerial Psychology, 21(5), 492-516.

Crant, J. M. (2000). Proactive behavior in organizations. Journal of Management, 435-462(26).

Creswell, J. W. (2013). Qualitative inquiry \& research design: Choosing among the five approaches (3rd ed.). Thousand Oaks, CA, USA: SAGE Publications.

Dastmalchian, A., \& Blyton, P. (2001). Workplace flexibility and the changing nature of work: An introduction. Canadian Journal of Administrative Sciences, 18(1), 1-4. doi:10.1111/j.19364490.2001.tb00238.x 
David, J. (2008). Standard skilled employees' and job applicants' behaviours in the presence of independent contractors and outsourcing arrangements. Personnel Review, 39(1), 62. doi: $10.1108 / 00483481011007869$

Davis-Blake, A., \& Uzzi, B. (1993). Determinants of employment externalisation: A study of temporary workers and independent contractors. Administrative Science Quarterly, 38(2), 195-223. doi:10.2307/2393411

De Vos, A., Buyens, D., \& Schalk, R. (2003). Psychological contract development during organisational socialization: Adaptation to reality and the role of reciprocity. Journal of Organizational Behavior, 24, 537-559. doi:10.1002/job.205

De Vos, A., \& Freese, C. (2011). Sensemaking during organizational entry: Changes in newcomer information seeking and the relationship with psychological contract fulfilment. Journal of Occupational and Organizational Psychology, 84(2), 288-314. doi:10.1111/j.20448325.2011.02024.x

Delobbe, N., Cooper-Thomas, H., \& De Hoe, R. (2015). A new look at the psychological contract during organizational socialization: The role of newcomers' obligations at entry. Journal of Organizational Behavior, 7(6), 845-867.

Denzin, N., \& Lincoln, Y. (Eds.). (2011). The SAGE handbook of qualitative research (4th ed.). Thousand Oaks, CA, USA: SAGE Publications.

Druker, J., \& Standworth, C. (2004). Mutual expectations: A study of the three-way relationship between employment agencies, their client organisations and white-collar agency 'temps'. Industrial Relations Journal, 35(1), 58-75.

Employment New Zealand. (2018). Types of employee. Retrieved from https://www.employment.govt.nz/starting-employment/who-is-an-employee/types-ofemployee/

Employment New Zealand. (2020). Contractor versus employee. Retrieved from https://www.employment.govt.nz/starting-employment/who-is-an-employee/differencebetween-a-self-employed-contractor-and-an-employee/

Eurofound. (2018). Non-standard forms of employment: Recent trends and future prospects Retrieved from Dublin, Ireland: http://eurofound.link/ef1746

Eurofound. (2020). Non-standard employment2020(31 March 2020). Retrieved from

Farnsworth, E. A. (1982). Contracts. Boston, MA, USA: Little Brown.

Feldman, D. C. (1981). The multiple socialization of organization members. Academy of Management Journal, 6(2), 309-318. 
Feldman, D. C. (1984). The development and enforcement of group norms. Academy of Management Review, 9(1), 50-52.

Feldman, D. C. (1994). Who's socializing whom? The impact of socializing newcomers on insiders, work groups and organizations. Human Resource Management Review, 4(3), 213-233.

Feldman, D. C. (2012). The impact of socialising newcomers on insiders. In Wanberg, C. (Ed.), The Oxford Handbook of Organizational Socialization. Oxford, UK: Oxford University Press.

Feldman, D. C., \& Bolino, M. C. (2000). Career patterns of the self-employed: Motivations and career outcomes. Journal of Small Business Management, 38(3), 53-67.

Field, R., \& Coetzer, A. (2008). The effects of organisational socialisation on individual and organisational outcomes: A review of the literature and directions for future research. Paper presented at the Labour, Employment and Work in New Zealand Conference, Wellington, New Zealand.

Flinchbaugh, C., Zare, M., Chadwick, C., Li, P., \& Essman, S. (2019). The influence of independent contractors on organizational effectiveness: A review. Human Resource Management Review, 30(2). doi:https://doi.org/10.1016/j.hrmr.2019.01.002

Freese, C., \& Schalk, R. (2008). How to measure a psychological contract? A critical criteria-based review of measures. South African Journal of Psychology, 38(2), 269-286.

Fudge, J. (2017). The future of the standard employment relationship: Labour law, new institutional economics and old power resource theory. Journal of Industrial Relations, 59(3), 374-392. doi:10.1177/0022185617693877 journals.sagepub.com/home/jir

Gallagher, D. (2002). Contingent work contracts: Practice and theory. In Cooper, C. \& Burke, R. (Eds.), The New World of Work: Challenges and Opportunities (pp. 115-136). Oxford, UK: Blackwell Publishers.

Gallagher, D. (2008). Contingent work arrangements. In Blyton, P. (Ed.), The SAGE Handbook of Industrial Relations (pp. 670). London, UK: SAGE Publications.

Gibbs, G. R. (2007). Analyzing qualitative data. Los Angeles, CA: SAGE Publications.

Goslin, D. A. (Ed.) (1969). Handbook of socialisation theory and research. Chicago, MA, USA: Rand McNally and Co.

Gossett, L. (2006). Falling between the cracks: Control and communication challenges of a temporary workforce. Management Communication Quarterly, 19(3), 376-415. doi:DOI: $10.1177 / 0893318905280327$

Gowan, D. (2018). The gig economy: You don't have to work 9 to 5(05 September 2018). Retrieved from https:/www.careers.govt.nz/articles/category/how-to-get-a-job 
Grbich, C. (2007). Qualitative data analysis. An introduction. London, UK: SAGE.

Greene, B. (2000). Independent contractors: An attractive option? New Zealand Journal of Industrial Relations, 25(2), 183-204.

Griffin, A. E. C., Colella, A., \& Goparaju, S. (2000). Newcomer and organizational socialization tactics: An interactionist perspective. . Human Resource Management Review, 10(4), 453474.

Grix, J. (2010). The foundations of research (2nd ed.). Basingstoke, UK: Palgrave Macmillan.

Guest, D. E. (1998). Is the psychological contract worth taking seriously? Journal of Organizational Behavior, 19, 649-664.

Guest, D. E. (2004). Flexible employment contracts, the psychological contract and employee outcomes: An analysis and review. International Journal of Managment Reviews, 5/6(1), 19.

Handy, C. (1989). The age of unreason. London, UK: Random Century.

Hannif, Z., \& Lamm, F. (2005). When non-standard work becomes precarious: Insights from the New Zealand call centre industry. Management Revue, 16(3), 324-350.

Haueter, J. A., Macan, T. H., \& Winter, J. (2003). Measurement of newcomer socialisation: Construct validation of a multidimensional scale. Journal of Vocational Behavior, 63, 2039.

Heery, E., \& Noon, M. (2008). A Dictionary of human resource management Retrieved from http://www.oxfordreference.com/view/10.1093/acref/9780199298761.001.0001/acref9780199298761 doi:10.1093/acref/9780199298761.001.0001

Herriot, P., Manning, W., \& Kidd, J. (1997). The content of the psychological contract. British Journal of Management, 8, 151-162.

Herriot, P., \& Pemberton, C. (1996). Contracting careers. Human Relations, 49(6), 757-790.

Houseman, S. (2001). Why employers use fexible staffing arrangements: Evidence from an establishment survey. Industrial and Labor Relations Review, 55(1), 149-170.

ILO. (2018). Non-standard employment around the world. Retrieved from

MIKA LEOTA v PARCEL EXPRESS LIMITED, NZEmpC 61 EMPC 167/2019 C.F.R. (2020).

IOE. (2019). IOE Policy Paper on industrial relations and independent contractors. Retrieved from 
IRD. (2019). Self-employed or an employee? How do you work out your tax status. Retrieved from https://www.ird.govt.nz/roles/employees/self-employed-or-employee

Jones, G. (1983). Psychological orientation and the process of organizational socialization: An interactionist perspective. Academy of Management Journal, 8(3), 464-474.

Jones, G. (1986). Socialisation tactics, self-efficacy and newcomers' adjustments to organisations. Academy of Management Journal, 29(2), 262-279.

Kalleberg, A. L., Reskin, B., \& Hudson, K. (2000). Bad jobs in America: Standard and nonstandard employment relations and job quality in the United States. American Soiological Review, 65(2), 256-278.

Kalleberg, A. L., Reynolds, J., \& Marsden, P. V. (2003). Externalising employment: Flexible staffing arrangements in US organisations. Social Science Research, 32, 525-552. doi:10.1016/S0049-089X(03)00013-9

Kässi, O. (2018). Online labour index - Measuring platform work. Retrieved from http://ilabour.oii.ox.ac.uk

King, R., Xia, W., Campbell, Q. J., \& Sethi, V. (2004). Socialization and organisational outcomes of information technology professions. Career Development International, 10(1), 26-51.

Krauss, A., \& Seitz, R. (2010). A qualitative study investigating the onboarding of the hourly workforce. Paper presented at the Paper presented at the 25th Annual Conference of the Society for Industrial and Organizational Psychology, Atlanta, GA, USA.

Kunda, G., Barley, S. R., \& Evans, J. (2002). Why do contractors contract? The experience of highly skilled technical professionals in a contingent labor market. Industrial and Labor Relations Review, 55(2), 234-261.

Leighton, P., \& McKeown, T. (2015). The rise of independent professionals: Their challenge for management. Small Enterprise Research, 22(2), 119-130. doi:http://dx.doi.org.helicon.vuw.ac.nz/10.1080/13215906.2015.1085627

Louis, M. R., Posner, B. Z., \& Powell, G. N. (1983). The availability and helpfulness of socialization practices. Personnel Psychology, 36, 857-866.

Mackay, S. (2016). The elephant in the room: Contracting or consulting? Retrieved from https://www.ocg.co.nz/blog-article/the-elephant-in-the-room-contracting-or-consulting?i=59

Macky, K., \& Johnson, G. (2003). Managing Human Resources in New Zealand (2nd ed.). North Ryde, NSW, Australia: McGraw Hill.

Macneil, I. R. (1985). Relational contract: What we do and do not know. Wisconsin Law Review, 483-526. 
Major, D., Kozlowski, S., Chao, G., \& Gardner, P. (1995). A longitudinal investigation of newcomer expectations, early socialization outcomes, and the moderating effects of role development factors. Journal of Applied Psycology, 80(3), 418-431.

Mallon, M. (1998). The portfolio career: Pushed or pulled to it? Personnel Review, 27(5), 361-377.

Mangan, J. (2000). Workers without traditional employment: An international study of nonstandard work. Cheltham, UK: Edward Elgar Publishing.

MBIE. (2014). Different kinds of employment. Retrieved from https://www.employment.govt.nz/starting-employment/who-is-an-employee/types-ofemployee/

McKeown, T. (2001). The professional contractor: Worker of the future or opportunist of today? $(\mathrm{PhD})$, Monash University, Melbourne, Australia.

McKeown, T. (2003). Commitment from a contractor workforce. International Journal of Manapower, 24(2), 169-186. doi:10.1108/01437720310475411

McKeown, T. (2005). Non-standard employment: When even the elite are precarious. The Journal of Industrial Relations, 47(3), 276-293. doi:10.1111/j.1472-9296.2005.00174.x

McKeown, T. (2016). A consilience framework: Reveailing hidden features of the independent contractor. Journal of Management \& Organization, 22(6), 779-796.

McKeown, T., \& Cochrane, R. (2011). Professional contractor wellbeing: Mutual benefits of organisational support. International Journal of Manpower, 33(7), 786-803. doi:10.1108/01437721211268320

McKeown, T., \& Cochrane, R. (2017). Independent professionals and the potential for HRM innovation. Personnel Review, 46(7), 1414-1433.

McKeown, T., \& Hanley, G. (2009). Challenges and changes in the contractor workforce. Asia Pacific Journal of Human Resources, 47(3), 295-317. doi:10.1177/1038411109106860

McKeown, T., \& Lindorff, M. (2011). Temporary staff, contractors, and volunteers: The hidden workforce in Victorian local government. The Australian Journal of Public Administration, 70(2), 185-201. doi:10.1111/j.1467-8500.2011.00722x

McLean Parks, J., Kidder, D., \& Gallagher, D. G. (1998). Fitting square pegs into round holes: mapping the domain of contingent work arrangements onto the psychological contract. Journal of Organizational Behavior, 19, 697-730.

Miles, M., \& Huberman, A. (1994). Qualitative data analysis: A sourcebook of new methods. Thousand Oaks, CA, USA: SAGE Publications. 
Miller, V. D., \& Jablin, F. M. (1991). Information seeking during organizational entry: Influences, tactics, and a model of the process. Academy of Management Review, 16(1), 92-120.

Millward, L. J., \& Brewerton, P. M. (1999). Contractors and their psychological contracts. British Journal of Management, 10 253-274.

Moore, W. E. (1969). Occupational socialization. In Goslin, D. A. (Ed.), Handbook of Socialization Theory and Research. Chicago, IL, USA: Rand McNally and Co.

Morf, M., Arnold, A., \& Staffelbach, B. (2014). The double psychological contracts of temporary agency workers. Emloyee Relations, 36(6), 708-726. doi:10.1108/ER-03-2013-0026

Morrison, E. W. (1993a). Longitudinal study of the effects of information seeking on newcomer socialization. Journal of Applied Psychology, 78(2), 173.

Morrison, E. W. (1993b). Newcomer information seeking: Exploring types, modes, sources and outcomes. Academy of Management, 36(3), 557-589.

Morrison, E. W. (2002). Newcomers' relationships: The role of social network ties during socialization. Academy of Management Journal, 45(6), 1149-1160.

Morrison, E. W., \& Phelps, C. (1999). Taking charge at work: Extrarole effort to initiate workplace change. Academy of Management Journal, 42(4), 403.

New Zealand Government. (2019). RealMe. Retrieved from https://www.digital.govt.nz/services/show/RealMe-

O'Leary-Kelly, A. M., Henderson, K. E., Anand, V., \& Ashforth, B. E. (2014). Psychological contracts in a nontraditional industry: Exploring the implications for psychological contract development. Group \& Organization Management, 39(3), 326-360.

OECD. (2014). Changing the conversation on growth. Going inclusive. Retrieved from http://www.oecd.org/inclusive-growth/meetings/Session Notes_IG Workshop 27.02.2014.pdf

OECD. (2016). Be Flexible! Background brief on how workplace flexibility can help European employees to balance work and family. Retrieved from https://www.oecd.org/els/family/BeFlexible-Backgrounder-Workplace-Flexibility.pdf

OECD. (2018a). Glossary of statistical terms. Retrieved from https://stats.oecd.org/glossary/detail.asp?ID=1986

OECD. (2018b). OECD country reviews: Responding to new forms of work. Retrieved from http://www.oecd.org/els/emp/future-of-work/New forms of work Country Reviews.pdf 
Olsen, K. (2006). The role of non-standard workers in client-organisations. Relations Industrielles, 61(Winter 2006).

Osnowitz, D. (2010). Freelancing Professionals: Contract Professionals in the New Economy. Ithaca, NY, USA: Cornell University Press.

Osnowitz, D., \& Henson, K. (2016). Leveraging limits for contract professionals: Boundary work and control of working time. Work and Occupations, 43(3).

doi:10.1177/0730888416642599

Ostroff, C., \& Kozlowski, S. (1993). The role of mentoring in the information gathering process of newcomers during early organisational socialization. Journal of Vocational Behavior, 42, 173-183.

Paredes, D. (2016). The 2016 CIO100 report: Full speed ahead. CIOs from New Zealand's top ICT using organisations talk about driving digital transformation. Retrieved from http://www.CIO.co.nz

Patton, M. Q. (2002). Qualitative research \& evaluation methods. Thousand Oaks, CA, USA: SAGE Publications.

Pearce, J. L. (1993). Toward an organizational behavior of contract laborers: Their psychological involvement and effects on employee co-workers. Academy of Management Journal, 36(5), 1082-1096.

Peel, S., \& Boxall, P. (2005). When is Contracting Preferable to Employment? An Exploration of Management and Worker Perspectives. Journal of Management Studies, 42(8), 1675-1697.

Peel, S., \& Inkson, K. (2004). Contracting careers: Choosing between self and organisational employment. Career Development International, 9(6), 542-558. doi:10.1108/13620430410559142

Pennington, P. (2018). MBIE under reported cost of contractors and consultants by $38 \mathrm{~m}(26$ September 2018). Retrieved from https://www.radionz.co.nz/news/political $/ 360232 / \mathrm{mbie}-$ under-reported-cost-of-contractors-and-consultants-by- $38 \mathrm{~m}$

Peters, S. (2018) Competition for tech jobs predicted to ramp up/Interviewer: Ryan, $K$. Nine to Noon, Radio New Zealand (RNZ), New Zealand.

Pichault, F., McKeown, T., \& (2019). Autonomy at work in the gig economy: Analysing work status, work content and working conditions of independent professionals. New Technology, Work and Employment, 34(1), 59-72.

Pinder, C. C., \& Schroeder, K. G. (1987). Time to proficiency after job transfers. Academy of Management Journal, 30(2), 336-353. 
Pink, D. H. (2001). Free agent nation: How America's new independent workers are transforming the way we live. New York, NY, USA: Warner Business Books, Inc.

Pratt, M. G., Kaplan, S., \& Whittington, R. (2020). The tumult over transparency: Decoupling transparency from replication in establishing trustworthy qualitative research. Administrative Science Quarterly, 65(1), 1-19.

QSR International. (2017). Make better decisions with the \#1 software for qualitative data analysis. Retrieved from https://www.qsrinternational.com/nvivo/enabling-research/qualitativeresearch

Redpath, L., Hurst, D., \& Devine, K. (2009). Knowledge workers, managers, and contingent employment relationships. Personnel Review, 38(1), 74-89. doi:10.1108/00483480910920723

Reichers, A. E. (1987). An interactionist perspective on newcomer socialisation rates. Academy of Management Review, 12(2), 278.

Rizzo, J. R., House, R. J., \& Lirtzman, S. I. (1970). Role conflict and ambiguity in complex organizations. Administrative Science Quarterly, Vol. 15(2), 150-163.

Robert Walters Salary Survey. (2018). Robert Walters Salary Survey 2018, Australia and New Zealand. Retrieved from https://www.robertwalters.co.nz/content/dam/robertwalters/country/new-zealand/files/salary-survey/robert-walters-anz-2018-salary-survey.pdf

Robinson, S. (1996). Trust and breach of the psychological contract. Administrative Science Quarterly, 41(4), 574-599.

Robinson, S., Kraatz, M., \& Rousseau, D. (1994). Changing obligations and the psychological contract: A longitudinal study. Academy of Management Journal, 37(1), 137-152.

Robinson, S., \& Morrison, E. W. (2000). The development of psychological contract breach and violation: A longitudinal study. Journal of Organizational Behavior, 21, 525-546.

Roehling, M. V. (2008). An empirical assessment of alternative conceptualizations of the psychological contract construct: Meaningful differences or "Much to do about nothing"? Employee Responsibilities and Rights Journal, 20(4), 261-290. doi:10.1007/s10672-0089085-z

Rollag, K., Parise, S., \& Cross, R. (2005). Getting new hires up to speed quickly. MIT Sloan Management Review, 46, 35-41.

Rousseau, D. (1989). Psychological and implied contracts in organizations. Employee Responsibilities and Rights Journal, 2(2), 121-139. doi:10.1007/bf01384942 
Rousseau, D. (1990). New hire perceptions of their own and their employer's obligations: A study of psychological contracts. Journal of Organizational Behavior, 11, 389-400.

Rousseau, D. (1995). Psychological contracts in organisations: Understanding written and unwritten agreements. Thousand Oaks, CA, USA: SAGE Publications.

Rousseau, D. (2001). Schema, promise and mutuality: The building blocks of the psychological contract. Journal of Occupational and Organizational Psychology, 74, 511-541.

Rousseau, D., \& Schalk, R. (2000). Psychological contracts in employment: Cross-national perspectives. Thousand Oaks, CA, USA: SAGE Publications.

Rowe, S. (2018). Legislation to address contractors later this year. Retrieved from https://www.hrmonline.co.nz/news/legislation-likely-to-address-contractors-later-this-year248013.aspx

Rubin, H., \& Rubin, I. (2012). Qualitative interviewing: The art of hearing data. Los Angeles, CA, USA: SAGE Publications.

Rubin, J. (1995). Take the money and stay: Industrial location incentives and relational contracting. New York University Law Review, 70(6), 1277-1323.

Rudman, R. S. (2019). New Zealand Employment Law Guide. Auckland, New Zealand: Wolters Kluwer.

Saks, A., \& Ashforth, B. E. (1996). Proactive socialization and behavioral self-management. Journal of Vocational Behavior, 48(3), 301-323. doi:10.1006/jvbe.1996.0026

Saks, A., \& Ashforth, B. E. (1997). Organizational socialization: Making sense of the past and present as a prologue for the future. Journal of Vocational Behavior, 51(2), 234-279.

Saks, A., \& Gruman, J. (2012). Getting newcomers on board: A review of socialization practices and introduction to socialization resources theory. In Wanberg, C. (Ed.), The Oxford hanbook of organizational socialization. Oxford, UK: Oxford University Press.

Saks, A., Gruman, J., \& Cooper-Thomas, H. (2011). The neglected role of proactive behaviour and outcomes in newcomer socialisation. Journal of Vocational Behavior, 79, 36-46.

Saldana, J. (2013). The Coding Mannual for Qualitative Researchers. London, UK: SAGE Publications.

Schein, E. H. (1968). Organizational socialization and the profession of management. Industrial Managment Review, 9, 1-16.

Schein, E. H. (1988). Organizational psychology (3rd ed.). Englewood Cliffs, New Jersey, NY, USA: Prentice-Hall Inc. 
Shore, L. M., \& Tetrick, L. E. (1994). The psychological contract as an explanatory framework in the employment relationship. In Cooper, C. L. \& Rousseau, D. M. (Eds.), Trends in Organizational Behavior (Vol. 1, pp. 91). New York, NY, USA: John Wiley \& Sons Ltd.

Spoonley, P. (2004). Is non-standard work becoming standard? Trends and issues. New Zealand Journal of Employment Relations, 29(3), 3-24.

Spoonley, P., De Bruin, A., \& Firkin, P. (2002). Managing non-standard work arrangements: Choices and constraints. Journal of Sociology, 38(4), 425-441. doi: $10.1177 / 144078302128756769$

Spoonley, P., Dupuis, A., \& De Bruin, A. (Eds.). (2004). Work and working in twenty-first century New Zealand. Palmerston North, New Zealand: Dunmore Press.

Standing, G. (2014). Precariat: A new dangerous class. London, UK: Bloomsbury.

Statistics New Zealand. (2014). Flexibility and security in employment: Findings from the 2012 survey of working life. Retrieved from http://www.stats.govt.nz

Statistics New Zealand. (2016). Employment Status. Retrieved from http://archive.stats.govt.nz/browse_for_stats/income-andwork/employment_and_unemployment/improving-labour-market-statistics/employmentstatus.aspx

Statistics New Zealand. (2019). One in 20 employed New Zealanders are contractors. Retrieved from https://www.stats.govt.nz/news/one-in-20-employed-new-zealanders-are-contractors

Svensson, S., \& Wolven, L.-E. (2009). Temporary agency workers and their psychological contracts. Emloyee Relations, 32(2), 184-199. doi:10.1108/01425451011010122

Taormina, R. J. (1994). The organizational socialization inventory. Organizational Socialization, $2(3)$.

Tarquinio, M. (2006). The onboarding benchmark report, 1-27. Retrieved from https://studylib.net/doc/8092200/onboarding-benchmark-report--aberdeen-group

Tekleab, A. G., \& Taylor, M. S. (2003). Aren't there two parties in an employment relationship? Antecedents and consequences of organization-employee agreement on contract obligations and violations. Journal of Organizational Behavior, 24(5), 585-608.

Thomas, H. D. C., \& Anderson, N. (1998). Changes in newcomers' psychological contracts during organizational socialization: A study of recruits entering the British Army. Journal of Organizational Behavior, 19, 745-767.

Thompson, P., \& McHugh, D. (2009). Work organisations: A critical approach (4th ed.). Basingstoke, UK: Palgrave Mamillan. 
Truss, C., Mankin, D., \& Kelliher, C. (2012). Strategic Human Resource Management. Oxford, UK: Oxford University Press.

Tucker, D. (2002). 'Precarious' non-standard employment - A review of the literature. Wellington, New Zealand: Labour Market Policy Group.

Van Maanen, J. (1978). People processing: Strategies of organisational socialization. Organisational Dynamics, 7(1), 19-36.

Van Maanen, J., \& Schein, E. H. (1979). Toward a theory of organisational socialization. In Staw, B. M. (Ed.), Research in Organizational Behavior (Vol. 1, pp. 209-264). Greenwich, CT, USA: JAI Press.

Walshaw, M. (2012). Getting to Grips with Doctoral Research. Basingstoke, Hampshire, UK: Palgrave Macmillan.

Wanberg, C., \& Kammeyer-Mueller, J. (2000). Predictors of proactivity in the socialization process. Journal of Applied Psycology, 85(3), 373-385. doi:10.1037//0021-9010.85.3.373

Wolcott, H. (2010). Ethnography lessons : A primer. Walnut Creek, CA, USA: Left Coast Press.

Wooden, M. (2001). Are non-standard jobs sub-standard jobs? Australian Social Monitor, 3, 65.

Woodrow, C., \& Guest, D. E. (2017). Knowledge acquisition and effective socialization: The role of the psychological contract. Journal of Occupational and Organizational Psychology, 90, 587-595.

Yin, R. (2003). Case Study Research. Design and Methods (3rd ed.). Thousand Oaks, CA, USA: SAGE Publications.

Zeytinoglu, I. U., \& Muteshi, J. M. (1999). Changing work relationships. Enacting gender, race/ethnicity and economic class. In Zeytinoglu, I. U. (Ed.), Changing Work Relationships in Industrialized Economies (pp. 1-19). Amsterdam, The Netherlands: John Benjamins Publishing Company. 


\section{Appendix A: Consent Form}

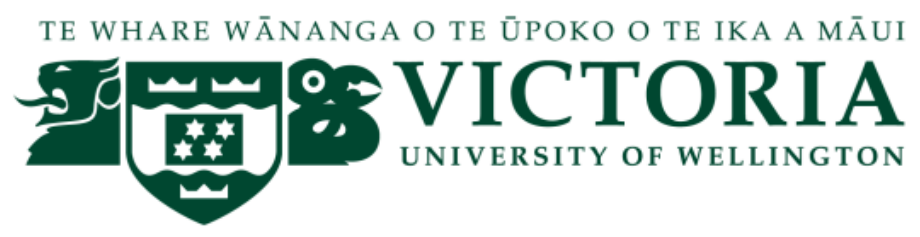

Project Title: A working relationship between professional contractors and the permanent employees they work with at organisations in New Zealand.

This agreement is to ensure that you are sufficiently informed about the purpose of the research, and your right to confidentiality.

Consent to participation:

. I have been given and have understood information about this research project.

. I have had an opportunity to ask any questions and have them answered to my satisfaction.

- I understand the interview will be recorded and a transcript will be made available to me for approval.

- I understand the data collected is confidential and will be reported in a non-attributable form.

- Should I request it, a summary of research results will be provided after all analysis has been completed.

A copy of the thesis will be deposited in the Victoria University of Wellington Library. Findings may be published in academic or professional journals. Any other use will require written consent.

- I understand that I may withdraw myself or any information I have provided from this research during the data collection period without having to supply a reason for doing so. Information collected will be immediately destroyed.

. On completion of this research, information will be destroyed within two years.

- I agree to participate in this research. Additional conditions to be written by the participant:

Participant Name: Organisation:

Would you like a summary of research results? (please tick and provide your email address) Email: 


\section{Appendix B: Information Sheet}

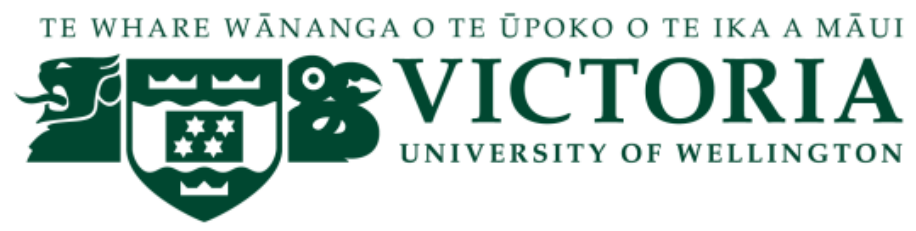

Purpose

This research is about the working relationship between professional contractors and the permanent employees they work alongside. The way in which professional contractors and permanent employees work together at clientorganisations has not been widely explored. How are professional contractors integrated into the workplace (socialised) and how do professional contractors and permanent employees perceive each other (psychological contract)?

Nature of research

Participants are being invited from the broad Information Technology (IT) or Information Communication Technology (ICT) field given the incidence of professional contracting in this area. The IT or ICT departments/divisions of several public, private and non-profit organisations in major cities in New Zealand are invited to participate. The researcher seeks to interview both professional contractors and permanent employees who are members of the same functional team as well as the manager they report to. Participants must be one of three/four or more members of a team and have been part of the particular team for at least one month.

Participation in this research would involve one face-to-face, semi-structured interview of approximately one hour, which would be digitally recorded for later transcription and analysis. This research is entirely voluntary even if the organisation has authorised participation. Participants may choose to withdraw at any time during the data collection process and prior to data analysis. Participants will be provided with a copy of their transcribed interview. Should they request it, summary of the results of the research will also be provided to them.

\section{Use of Material}

Once transcribed, the interview data will be analysed and coded for emerging themes and trends. Any biographical data collected will be collated and summarised before it is reported. Findings will be presented in narrative form combining theory, background information and analysed interview data.

\section{Confidentiality}

The names of each individual participant and their organisations will be kept confidential to the researcher. Transcripts will include a unique descriptor to ensure the anonymity of the participant and their organisation. Any identifying material will be removed from the transcript to ensure that participants cannot be linked to their comments.

All research material and data collected will be stored in a locked filing cabinet at the researcher's university office with restricted access as outlined by the university's Human Ethics Committee (HEC). This research has received ethical approval from Victoria University of Wellington.

Contact information

Should you require further information please contact either of those listed below.

Researcher: Ellen Yarrow

Email: ellen.yarrow@vuw.ac.nz

Phone: $\operatorname{xxxxxx}$
Supervisor: Dr Jane Bryson

Title: Associate Dean, Research, Victoria Business School

Email: jane.bryson@vuw.ac.nz

Phone: $\operatorname{xxxxxx}$ 


\section{Appendix C: Table of Questions}

\begin{tabular}{|c|c|c|}
\hline Question & Sub-question & Explanation, context or source \\
\hline Why did you become a contractor? & $\begin{array}{l}\text { Can you describe, in detail, the steps that led } \\
\text { you to contracting? }\end{array}$ & $\begin{array}{l}\text { Evans, Barley and Kunda }(2004, \text { p. 10). The } \\
\text { intention here is to establish whether it is a } \\
\text { push or a pull that led a person into } \\
\text { contracting. It seems this question teases out } \\
\text { both the pull and the push factors. It is open- } \\
\text { ended enough that it could elicit lots of } \\
\text { interesting, useful information on motivations } \\
\text { and situation/circumstance that would paint a } \\
\text { good picture of the complexity of the issue. }\end{array}$ \\
\hline $\begin{array}{l}\text { Does your human resource management } \\
\text { strategy divide the workforce into permanent } \\
\text { and non-permanent employees? }\end{array}$ & & $\begin{array}{l}\text { Kalleberg }(2003, \text { p. 158) - a survey question } \\
\text { asked by Kalleberg, Marsden, Reynolds, and } \\
\text { Knoke (2002). }\end{array}$ \\
\hline $\begin{array}{l}\text { Describe/define job security? } \\
\text { (May not be so explicit but more elicit.) }\end{array}$ & $\begin{array}{l}\text { What is job security to you as a contractor? } \\
\text { What is job security to you as an employee? }\end{array}$ & $\begin{array}{l}\text { Kunda, Barley, and Evans (2002, p. 251). } \\
\text { Where } 19 \% \text { of those interviewed felt they had } \\
\text { more job security as contractors. }\end{array}$ \\
\hline $\begin{array}{l}\text { How are professional contractors perceived by } \\
\text { those they work with (i.e. hiring managers and } \\
\text { permanent employees)? }\end{array}$ & $\begin{array}{l}\text { How do others perceive professional } \\
\text { contractors? How do professional contractors } \\
\text { perceive themselves? How do professional } \\
\text { contractors perceive and manage their work } \\
\text { status? }\end{array}$ & $\begin{array}{l}\text { Draft/potential Research Questions developed } \\
\text { prior to workshop on the subject. }\end{array}$ \\
\hline $\begin{array}{l}\text { During interviews, will I have contactors talk } \\
\text { about a current, specific contract or their } \\
\text { experience of contracts in general? }\end{array}$ & & $\begin{array}{lllll}\text { Discussion on } & \text { research } & \text { design } & \text { with } \\
\text { Supervisor. } & & & & \end{array}$ \\
\hline $\begin{array}{l}\text { Do contractors actually consider themselves } \\
\text { self-employed? Is contracting synonymous } \\
\text { with self-employment? }\end{array}$ & $\begin{array}{l}\text { Ask something like: What led you to self- } \\
\text { employment? To test if it is indeed considered } \\
\text { so. OR How would you describe the nature of } \\
\text { your employment? OR How did you describe } \\
\text { your employment in the last census? Could }\end{array}$ & $\begin{array}{l}\text { Generated by Peel and Inkson's (2004) article } \\
\text { on 'Contracting and careers: Choosing } \\
\text { between self and organisational employment'. }\end{array}$ \\
\hline
\end{tabular}




\begin{tabular}{|c|c|c|}
\hline & $\begin{array}{l}\text { even ask: Do you consider yourself self- } \\
\text { employed? }\end{array}$ & \\
\hline $\begin{array}{l}\text { When asked to list your occupation, how do } \\
\text { you self-describe? }\end{array}$ & $\begin{array}{l}\text { Which of these categories best describes your } \\
\text { work: Temporary employee or Self- } \\
\text { employed? } \\
\text { If you describe yourself as a temporary } \\
\text { employee which type are you: Casual worker, } \\
\text { Fixed term worker, Seasonal worker, } \\
\text { Temporary agency worker? }\end{array}$ & $\begin{array}{l}\text { As part of context setting (in New Zealand), } \\
\text { wondering if in the stats the 'fixed term } \\
\text { worker' category subsumes some contract } \\
\text { workers. }\end{array}$ \\
\hline $\begin{array}{l}\text { What are the advantages and disadvantages of } \\
\text { being a professional contactor in NZ? }\end{array}$ & $\begin{array}{l}\text { OR What are the issues involved in being a } \\
\text { professional contractor in NZ? }\end{array}$ & Draft/potential research questions. \\
\hline $\begin{array}{l}\text { To a manager: How is managing a contractor } \\
\text { different to managing an employee? }\end{array}$ & $\begin{array}{l}\text { Why? What is different? Is it attitude? Is it } \\
\text { (short) time-span creating an urgency? } \\
\text { What motivates a contractor? }\end{array}$ & $\begin{array}{l}\text { Barley and Kunda (2004) claim that some } \\
\text { Project Managers (in particular) value } \\
\text { contractors because they 'own' them and can } \\
\text { direct them. Anecdotally, some managers feel } \\
\text { that if you want something done give it to a } \\
\text { contractor. }\end{array}$ \\
\hline $\begin{array}{l}\text { In the workplace, do people generally know } \\
\text { who is a contractor and who is not? }\end{array}$ & & $\begin{array}{l}\text { Discussion with supervisor about sampling } \\
\text { and logistics. }\end{array}$ \\
\hline $\begin{array}{l}\text { How can contractors be used to achieve } \\
\text { organisational goals? } \\
\text { (Meeting individual goals, too.) }\end{array}$ & & $\begin{array}{l}\text { Discussion with supervisor. Also speaks to the } \\
\text { unitarist or pluralist perspectives of HR. }\end{array}$ \\
\hline How strategically are contractors engaged? & & $\begin{array}{l}\text { Link to the drive for flexibility }- \text { both } \\
\text { numerical and functional. Which is a firm } \\
\text { trying to achieve and why? }\end{array}$ \\
\hline $\begin{array}{l}\text { How do contractors get their contracts? } \\
\text { How are contractors generally hired? }\end{array}$ & $\begin{array}{l}\text { Directly? Through agencies? } \\
\text { What networks do they belong to? }\end{array}$ & \\
\hline $\begin{array}{l}\text { What (statistics and contextual knowledge) do } \\
\text { we know about contractors? }\end{array}$ & What don't we know about contractors? & \\
\hline $\begin{array}{llll}\text { Are employers being 'exploited' by } \\
\text { contractors? }\end{array}$ & & From a meeting with Supervisors. \\
\hline $\begin{array}{l}\text { Are many contractors engaged but are not } \\
\text { physically present? }\end{array}$ & & From a meeting with Supervisors. \\
\hline
\end{tabular}




\begin{tabular}{|c|c|c|}
\hline $\begin{array}{l}\text { How are professional contractors different to } \\
\text { permanent employees? }\end{array}$ & $\begin{array}{l}\text { How do professional contractors handle and } \\
\text { manage their role? }\end{array}$ & Draft/potential research questions. \\
\hline $\begin{array}{l}\text { In your experience, what is the biggest } \\
\text { difference between being a permanent } \\
\text { employee versus being a contractor? }\end{array}$ & & $\begin{array}{l}\text { To draw interviewee out and get them } \\
\text { thinking. If three major differences could be } \\
\text { identified it would be good but the first one } \\
\text { may be key/main. }\end{array}$ \\
\hline $\begin{array}{l}\text { To a contractor (with no preamble or } \\
\text { coaching): What motivates you? }\end{array}$ & & $\begin{array}{l}\text { In order to get their off-the-cuff answer. Is it } \\
\text { the obvious } \$ \text { or something deeper? }\end{array}$ \\
\hline $\begin{array}{l}\text { In your experience, are contractors ever } \\
\text { formally socialised, i.e. do they attend } \\
\text { induction/onboarding, intro to the } \\
\text { organisation? }\end{array}$ & & Bauer (2010) \\
\hline $\begin{array}{l}\text { IRS' } 20 \text { questions: Ask all interviewees these } \\
\text { or a sub-set of these. }\end{array}$ & & $\begin{array}{l}\text { Distinguishes between dependent contractors, } \\
\text { employees in contractors' guise etc. How } \\
\text { would this be useful or informative? }\end{array}$ \\
\hline $\begin{array}{l}\text { Is being a doctor or nurse an occupation or a } \\
\text { profession? Which is more important to an } \\
\text { individual - occupation or profession? }\end{array}$ & $\begin{array}{l}\text { What is a profession? What is meant by a } \\
\text { professional? What about a professional } \\
\text { contractor? Is being a professional contractor } \\
\text { an occupation, vocation or merely a job? }\end{array}$ & $\begin{array}{l}\text { To establish a definition of the concept of } \\
\text { professional contractor and the importance of } \\
\text { an occupation. }\end{array}$ \\
\hline $\begin{array}{l}\text { How many contractors in NZ are engaged } \\
\text { through intermedaries? } \\
\text { How many are directly hired contractors? }\end{array}$ & $\begin{array}{l}\text { What are the figures for IT department in each } \\
\text { organisation? }\end{array}$ & $\begin{array}{l}\text { A measure of flexible staffing intensity = } \\
\text { intensity by dividing the number of workers in } \\
\text { the establishment who are in that arrangement } \\
\text { by the total number of full- and part-time } \\
\text { employees in the establishment (Kalleberg et }\end{array}$ \\
\hline
\end{tabular}




\begin{tabular}{|c|c|c|}
\hline & & al., 2003, p. 537). \\
\hline $\begin{array}{l}\text { Is professional contracting merely the } \\
\text { commodification of an individual? }\end{array}$ & & $\begin{array}{l}\text { Barley and Kunda (2004, p. 289). Authors } \\
\text { discuss the notion that contracting } \\
\text { commodifies a person. }\end{array}$ \\
\hline $\begin{array}{l}\text { Who do you consider you have more in } \\
\text { common with: other professional contractors } \\
\text { or permanent employees in your field, e.g. IT? }\end{array}$ & & $\begin{array}{l}\text { Barley and Kunda }(2004, \text { p. 299). Identity } \\
\text { with contracting as a profession: } \\
\text { "...contractors believed they had more in } \\
\text { common with each other than they did with } \\
\text { professionals who did similar work under } \\
\text { other models of professionalism. Informants } \\
\text { repeatedly told us that their permanently } \\
\text { employed counterparts had little } \\
\text { understanding of their brand of practice or of } \\
\text { the problems and opportunities they faced." }\end{array}$ \\
\hline $\begin{array}{l}\text { To a professional contractor: Did you receive } \\
\text { any induction or onboarding when you started } \\
\text { in this role? Can you describe this to me? }\end{array}$ & $\begin{array}{l}\text { Was your experience similar at other } \\
\text { organisations you've worked at? }\end{array}$ & $\begin{array}{l}\text { Evidence that induction for non-standard } \\
\text { workers is non-existent or rudimentary. See } \\
\text { Biggs \& Burchell (2006) and Druker and } \\
\text { Stanworth (2004). }\end{array}$ \\
\hline $\begin{array}{l}\text { Under what conditions would you accept a } \\
\text { permanent position? }\end{array}$ & & $\begin{array}{l}\text { To test the appeal of contracting and the } \\
\text { underlying reasons for engaging in it. }\end{array}$ \\
\hline $\begin{array}{l}\text { To employee: Has the use of professional } \\
\text { contractors negatively or positively affected } \\
\text { manager-employee relations in this } \\
\text { workplace? }\end{array}$ & & $\begin{array}{l}\text { Davis-Blake and Broschak (2003, p. 482) } \\
\text { found "... Using both temporary and contract } \\
\text { workers negatively affected manager- } \\
\text { employee relations." }\end{array}$ \\
\hline Are you satisfied with your job? & $\begin{array}{l}\text { Could apply a job satisfaction survey to } \\
\text { interviewees. }\end{array}$ & $\begin{array}{l}\text { For example, Minnesota Satisfaction } \\
\text { Questionnaire (short form) see Hirschfield } \\
\text { (2000). Need to consider what this would add, } \\
\text { reveal, achieve in terms of the relationship? } \\
\text { The question is also ambiguous enough that it } \\
\text { may be revealing. Would contractors answer } \\
\text { about contracting itself or only the role they } \\
\text { are in or a bit of both? Would they attempt to } \\
\text { clarify? }\end{array}$ \\
\hline
\end{tabular}




\begin{tabular}{|c|c|c|}
\hline $\begin{array}{l}\text { alongside given opportunities for training and } \\
\text { development that you are not entitled to? }\end{array}$ & $\begin{array}{l}\text { feel about that? } \\
\text { Have you funded your own training or } \\
\text { development opportunities? }\end{array}$ & $\begin{array}{l}\text { through the organisation. Contractors do not. } \\
\text { Is this an issue for them? } \\
\text { Do contractors actually invest in their own } \\
\text { training? (Hartmann, 2003) }\end{array}$ \\
\hline $\begin{array}{l}\text { What about a contractor in particular gives } \\
\text { them influence? }\end{array}$ & $\begin{array}{l}\text { Is it depth or breadth of experience, is it } \\
\text { reputation, is it educational background? Is it } \\
\text { age? }\end{array}$ & $\begin{array}{l}\text { The more senior, the more "positive mutual } \\
\text { influence" (Feldman, 1994). Is this so for } \\
\text { contractors? }\end{array}$ \\
\hline $\begin{array}{l}\text { To an employee: Describe a good professional } \\
\text { contractor? }\end{array}$ & What makes a good professional contractor? & $\begin{array}{l}\text { See if proaction, information seeking and } \\
\text { relationship building skills are listed. }\end{array}$ \\
\hline $\begin{array}{l}\text { To a professional contractor: Describe a good } \\
\text { professional contractor? }\end{array}$ & What makes a good professional contractor? & $\begin{array}{l}\text { Compare to opinion of an employee to see } \\
\text { where the differences lie. }\end{array}$ \\
\hline $\begin{array}{l}\text { To an employee: How does your involvement } \\
\text { in socialising a contractor affect your learning, } \\
\text { your behaviour or your contributions? }\end{array}$ & Does it change? Has it changed? & $\begin{array}{l}\text { Feldman }(1994, \text { p. 228) suggests that } \\
\text { researcher see how insiders change as a result } \\
\text { of involvement in socialisation activities. }\end{array}$ \\
\hline $\begin{array}{l}\text { To an employee: When a new team member } \\
\text { joins the team, what is your role? What do you } \\
\text { do? }\end{array}$ & $\begin{array}{l}\text { Does this differ if the new member is a } \\
\text { permanent employee or a professional } \\
\text { contractor? How so? Why? }\end{array}$ & $\begin{array}{l}\text { Feldman (1994) says little research has been } \\
\text { done on the socialising agents themselves. }\end{array}$ \\
\hline $\begin{array}{l}\text { To an employee: Are professional contractors } \\
\text { treated just like employees? } \\
\text { To a manager: In your experience, are } \\
\text { professional contractors treated just like } \\
\text { permanent employees? }\end{array}$ & Is this an issue? How so? & $\begin{array}{l}\text { Hannif }(2005, \text { p. } 345) \text {. Does an issue arise } \\
\text { when a part-time worker is treated like a full- } \\
\text { time, permanent worker? Similarly, if a } \\
\text { contractor is treated like a permanent worker, } \\
\text { do issues arise? }\end{array}$ \\
\hline $\begin{array}{l}\text { To the manager: Do you find that the use of } \\
\text { professional contractors affects the behaviour } \\
\text { or attitude of the permanent employees on the } \\
\text { team? Can you describe how? }\end{array}$ & $\begin{array}{l}\text { Do they welcome the professional contractor } \\
\text { as they would another employee? }\end{array}$ & $\begin{array}{l}\text { Gallagher }(2008, \text { p. } 484) \text {. What is the spill- } \\
\text { over effect of the increased use of contingent } \\
\text { workers on standard workers - are their } \\
\text { attitudes and/or behaviours changed? }\end{array}$ \\
\hline To a contractor: Are you self-employed? & $\begin{array}{l}\text { Was this your aim? Did you desire to be self- } \\
\text { employed? Is self-employment considered } \\
\text { attractive? }\end{array}$ & $\begin{array}{l}\text { Greene }(2000, \text { p. 194). Say independent } \\
\text { contracting or being self-employed is } \\
\text { desirable/attractive. }\end{array}$ \\
\hline $\begin{array}{l}\text { To a contractor: Are you an independent, } \\
\text { agency or dependant contractor? }\end{array}$ & $\begin{array}{l}\text { Are independent contractors hired directly or } \\
\text { through a middleman? Are they incorporated } \\
\text { or sole traders? }\end{array}$ & $\begin{array}{l}\text { Information gathering. Maybe have } \\
\text { interviewee do a } 5 \text { min. questionnaire of such } \\
\text { questions. }\end{array}$ \\
\hline Who has control over your work? & & $\begin{array}{l}\text { Control? It has been a distinguishing factor } \\
\text { between being an employee and a professional }\end{array}$ \\
\hline
\end{tabular}


contractor (McKeown, 2001; Rudman, 2013; Greene, 2000). Could ask both employee and professional contractors?

To a contractor: Describe the sequence of Were you ever in permanent employee? events that led you to becoming a professional contractor?

To a contractor: What advice would you give to someone considering contracting?

To a contractor: Do you think there is a difference between the image of contracting yor and the realities of contracting?

Ask interviewees to rate their comfort with being a contractor at different points in time? to how long they've been contractor?

Ask contractors if they are involved in Are these for networking, up-skilling or communities of practice or occupational camaraderie? networks.

Do such groups comprise other contractors or permanent employees, too?

path? Under what circumstances would you recommend contracting?

general, has the reality of contracting met your expectations?

Does this level of comfort change in relation
Kunda, Barley and Evans (2002, p. 240) asked this.

Kunda, Barley and Evans (2002). offered the idea that the longer one is in contracting the less 'scary' it becomes.

Based on a question asked by Kunda and Barley (2004) who wanted to see if informants' opinions had changed. Subquestion address psychological contracts.

Kunda et al. (2002, p. 257). “...Occupation affiliations and proto-occupational communities in the midst of a contract labour market. They served to shield contractors from the isolation, insecurities, and costs of participating as lone individuals in a market for expertise."

To a contractor: Who do you have more in

common with: an HR (other industry)

contractor or someone else in IT?

Do you consider contracting 'precarious'?

Teasing out the differences between
contractors and permanent employees. Identity?

McKeown's idea that even the elite are precarious. Interesting to see if there is a difference in opinions between managers, employees and professional contractors.

Should professional contractors be treated like Why? employees?
McKeown and Cochrane (2017, p. 798). Seem to advocate treating contractors like employees: “...positively influence PC perceptions of organisational support by 


\begin{tabular}{|c|c|c|}
\hline & & $\begin{array}{l}\text { treating PCs the same as, or similar to, other } \\
\text { team members and permanent employees." }\end{array}$ \\
\hline $\begin{array}{l}\text { Are contractors well-managed? } \\
\text { Are contractors strategically engaged, hired, } \\
\text { managed? } \\
\text { Is the use of professional contractors in } \\
\text { keeping with HR strategy? }\end{array}$ & & $\begin{array}{l}\text { McKeown (and others) on the importance of } \\
\text { SHRM. } \\
\text { McKeown and Lindorff (2011) who advocate } \\
\text { for strategic management of contractors and } \\
\text { even extending HR policies to them. }\end{array}$ \\
\hline $\begin{array}{l}\text { What exactly do professional contractors need } \\
\text { to know in order to function? E.g. What do } \\
\text { you need to know about a client-organisation } \\
\text { in order to effectively perform your role? } \\
\text { Where do you obtain that information? }\end{array}$ & $\begin{array}{l}\text { Do they need to know about the industry, the } \\
\text { organisation, the division, the team? } \\
\text { At what level are they (do they have to be) } \\
\text { socialised? } \\
\text { Could the elements on the right be ranked in } \\
\text { order of importance to a contractor? }\end{array}$ & $\begin{array}{l}\text { Bauer and Erdogan (2012). } \\
\text { See Chao et al. Socialization Scale (1994) } \\
\text { Includes performance proficiency, politics, } \\
\text { language, people, organisational goals and } \\
\text { values and history. }\end{array}$ \\
\hline $\begin{array}{l}\text { Is it better to have higher or lower proportions } \\
\text { of a team who are professional contractors? }\end{array}$ & & $\begin{array}{l}\text { Broschak and Davis-Blake (2006, p. 371). } \\
\text { Associated higher proportions of non-standard } \\
\text { workers with less favourable attitudes toward } \\
\text { colleagues and fewer "helping behaviours". }\end{array}$ \\
\hline $\begin{array}{l}\text { Non-standard workers are often considered } \\
\text { lower status. Is this true for contractors? }\end{array}$ & & Broschak and Davis-Blake (2006). \\
\hline $\begin{array}{l}\text { How do unmet psychological contracts } \\
\text { manifest themselves for a contractor? }\end{array}$ & What happens? & $\begin{array}{l}\text { Morf, Arnold, and Staffelbach }(2014, \\
\text { p. 721). Fulfilled psychological contracts } \\
\text { positively relates to temps' job attitudes. }\end{array}$ \\
\hline $\begin{array}{l}\text { What do contractors expect from their } \\
\text { colleagues? } \\
\text { What do contractors expect from their } \\
\text { managers? } \\
\text { What do employees expect from contractors? }\end{array}$ & $\begin{array}{l}\text { My agency/host did a good job in meeting my } \\
\text { expectations? } \\
\text { How much of this is based on industry norms? }\end{array}$ & Morf, Arnold, and Staffelbach (2014). \\
\hline
\end{tabular}




\begin{tabular}{|lll|}
\hline $\begin{array}{l}\text { Do managers explain/communicate/justify the } \\
\text { reasons for bringing in a contractor versus a } \\
\text { permanent hire? }\end{array}$ & From a meeting with Supervisors. \\
\hline $\begin{array}{lll}\text { What are the (IT) industry norms relating to Why or how have these come about? } \\
\text { contractors? }\end{array}$ & $\begin{array}{l}\text { How do they affect the expectations of norms (contracting norms, occupational norms } \\
\text { contractors, managers and permanent or organisational norms) shape the } \\
\text { employees? }\end{array}$ \\
\hline How do these affect their socialisation? & $\begin{array}{l}\text { psychological contract and socialisation of } \\
\text { professional contractors?" }\end{array}$ \\
\hline
\end{tabular}




\section{Appendix D: Interview Schedules}

\section{Questions for Professional Contractors}

\section{Building Rapport}

When asked to list your occupation, how do you self-describe? (If necessary, suggest the following) Are you a causal worker, fixed-term worker, seasonal worker, temporary agency worker or selfemployed? Consultant or contractor?

If you are self-employed: Did you desire to be self-employed? Do you find contractors actually consider themselves self-employed?

Why did you become a professional contractor? Describe the sequence of events that led you to becoming a professional contractor. Were you ever a permanent employee?

Are you comfortable/satisfied with being a contractor? Could you rate your comfort with being a contractor at different points in time?

What are the advantages and disadvantages of being a professional contactor in NZ? What are the issues involved in being a professional contractor?

Are you involved in communities of practice or occupational networks? Are these for networking, up-skilling or camaraderie? Are they made up of contractors or permanent employees, too?

What advice would you give to someone considering contracting? Under what circumstances would you recommend contracting as a career path?

Have you been a permanent employee before? (Should have already answered this earlier.) Under what conditions would you accept a permanent position?

Who has control over your work?

What motivates you at work? (With no preamble or coaching).

\section{Socialisation Process (how contractors are integrated into the workplace)}

In your experience, are contractors formally inducted, i.e. do they attend induction/onboarding, intro to the organisation? Was your experience similar at other organisations you've worked at?

What is your 'time to productivity'? What affects your time to productivity? Do you and the client share the same view of 'productivity'?

Can a contractor be integrated too quickly? Is it possible?

What do you need to know in order to effectively perform your role (i.e. 'role clarity')? Where does this information come from?

When you started here, who 'showed you the ropes'? 
What form does help from permanent employees to professional contractors take? Do they tend to provide information? Or resources? Or social support?

How important is 'acceptance by insiders'? Is acceptance by insiders essential or can a professional contractor function without it?

Do you need to know about the industry, the organisation, the division, the team? At what level do you have to be socialised?

Does a professional contractor need to understand the organisation's history? Culture and values? Organisational politics? Structure? Goals? Strategies? And language?

How do you know when you have been effectively integrated? What does that mean/look like to you?

Did you receive any induction or onboarding when you started in this role? Can you describe this to me? Was the client ready/prepared for you (logins, access cards, workspace, etc.)? How could this have been improved?

Are you encouraged to share your knowledge and expertise with those in the client-organisation? What would encourage you to do so?

\section{Psychological Contracts (how contractors and employees perceive each other)}

In general, has the reality of contracting met your expectations? Do you think there is a difference between the image of contracting and the realities of contracting?

What do you expect from your colleagues? What do you expect from your manager? What do you think they expect from you? Do your expectations change over time?

How are professional contractors perceived by those they work with (i.e. hiring managers and permanent employees)?

Are you different to permanent employees? How are you different to permanent employees? Are professional contractors a different class/breed of worker?

Has your agency (if applicable) done a good job in meeting your expectations?

Has your client-organisation done a good job in meeting your expectations?

Have you discussed your mutual expectations with your current manager?

What do you do if your expectations of the contract are not met? What would make you leave early, quit contract (i.e. what qualifies as a psychological contract breach)? How would unmet expectations manifest themselves?

What causes you stress while you are on a contract?

What does 'getting the job done' (use contractor's words, if possible) mean to you? 


\section{The Working Relationship}

In the workplace, do people generally know who is a contractor and who is not? How would you recognise a contractor?

Are contractors included in social functions/activities?

Are the employees you work alongside given opportunities for training and development that you are not entitled to? How do you feel about that?

Have you funded your own training or development opportunities?

Should professional contractors be treated like employees? Is this an issue? How so?

Who do you consider you have more in common with: other professional contractors (in HR for example) or permanent employees in your field, e.g. IT?

What are the stereotypes of professional contractors that you are aware of? Do you consider contracting 'precarious'? Do you consider contractors 'elite'? Non-standard workers are often considered lower status. Is this true for professional contractors?

Do contractors have influence? What about a professional contractor in particular gives them influence? Is it depth or breadth of experience, is it reputation or is it educational background?

Is it better to have higher or lower proportions of a team who are professional contractors?

How do you think a mixed workforce can be managed effectively?

Describe what makes a good professional contractor?

\section{Biographical Information - Professional Contractor}

\section{Age range:}

18-24 25-34 $\quad 35-44 \quad 45-54 \quad 55-64 \quad 65$ and over

Time in contracting:

Time in current role (contract):

Have you been a permanent employee before?

Are you an independent contractor or an agency contractor?

Do you have dependants?

Yes

No

Are you the sole income earner in your household?

Yes

No 


\section{Questions for Permanent Employees}

\section{Building Rapport}

Tell me about the team you currently work with...

You are a permanent employee now but have you ever been a professional contractor? Under what conditions would you become a professional contractor?

What motivates you at work? (With no preamble or coaching.)

\section{Socialisation Process}

When you joined did you attend induction/onboarding or an introduction to the organisation? Were you formally inducted?

When a new team member joins this team, what is your role? What do you do? Does this differ if the new member is a permanent employee or a professional contractor? How so?

How do you provide help to professional contractor? What form does it take? Do you provide information? Or resources? Or social support?

How do you feel about your involvement helping to integrate a professional contractor? Do you relish or resent the opportunity to help professional contractors adjust? Is the experience positive, negative or other?

How does your involvement in helping to integrate a contractor affect your learning, your behaviour or your contributions to the organisation? Has it changed?

In your experience, are contractors often formally integrated into the organisation? Do they attend induction/onboarding, introduction to the organisation?

Are contractors formally inducted at this organisation?

What does a contractor need to know in order to effectively perform their role (i.e. 'role clarity')? Where does this information come from?

Do they need to know about the industry, the organisation, the division, the team? At what level do you have to be socialised?

How long does it take for a contractor to be performing at a client-organisation? What is a contractor's 'time to productivity'? What affects their time to productivity?

Can a contractor be integrated too quickly? Is it possible?

How do you know when they have been integrated into the organisation? What does that mean/look like to you? (Look for 'acceptance by insiders'.)

How important is 'information seeking' (by the contractor) in the process?

Does a professional contractor need to understand the organisation's history? Culture and values? Organisational politics? Structure? Goals and strategies? And language? 
Are contractors encouraged to share their knowledge and expertise with those in the clientorganisation? Do you learn from contractors? What would encourage them to do so?

\section{Psychological Contracts}

What do you expect from contractors (in general)? How much of what you expect of professional contractors is based on industry norms?

How are professional contractors generally perceived by those they work with (i.e. hiring managers and permanent employees)?

Are contractors different to permanent employees? How are they different? Are professional contractors a different type of worker?

What does 'getting the job done' (use interviewee's words, if possible) mean to each to you?

What do you expect from the professional contractors you work with here?

\section{The Working Relationship}

In the workplace, do people generally know who is a contractor and who is not? How would you recognise a contractor?

Are contractors included in social functions/activities?

Should professional contractors be treated like employees? Is this an issue? How so?

What are the stereotypes of professional contractors that you are aware of? Which ones are applicable to, indicative of the contractors you've worked with? Do you consider contracting 'precarious'? Do you consider contractors 'elite'? Non-standard workers are often considered lower status. Is this true for professional contractors?

Do contractors have influence? What about a professional contractor in particular gives them influence? Is it depth or breadth of experience, is it reputation or is it educational background?

Is it better to have higher or lower proportions of a team who are professional contractors?

How do you feel about contractors? Do you respect or resent contractors?

Has the use of professional contractors negatively or positively affected manager-employee relations in this workplace?

Describe what makes a good professional contractor?

\section{Biographical Information - Permanent Employee}

Age range:

$18-24$

25-34

35-44

45-54

55-64

65 and over

Time in permanent employment:

Time in current role/position: 
Have you been a professional contractor before?

Do you have dependants?

Yes

No

Are you the sole income earner in your household?

Yes

No 


\section{Questions for Managers}

\section{Building Rapport}

Tell me about the team you currently work with...

How long have you been in this role?

\section{Socialisation Process}

When a new team member joins the team, what is your role? What do you do?

Does role differ if the new member is a permanent employee or a professional contractor? How so? Why?

In your experience, are contractors often formally inducted, i.e. do they attend induction/onboarding, introduction to the organisation?

What does a contractor need to know in order to effectively perform their role ('role clarity')?

Do they need to know about the industry, the organisation, the division, the team? Where do they obtain this information from?

How do you know when a contractor has been effectively integrated into the team? What does that mean/look like to you?

Can a contractor be integrated too quickly? Is it possible?

Do employees relish or resent the opportunity to help a contractor be integrated? Is it positive, negative or other?

\section{Psychological Contracts}

How are professional contractors perceived by those they work with (i.e. hiring managers and permanent employees)? How do others perceive professional contractors?

Are professional contractors different to permanent employees? How are professional contractors different to permanent employees? Are professional contractors a different class/breed?

Are there (IT) industry norms associated with contracting? How do these affect the expectations of those involved? Do these industry norms affect the psychological contract and/or socialisation of the professional contractor?

What do you expect from a contractor? What do contractors expect from their managers? How much of this is based on industry norms discussed earlier?

Have you discussed your mutual expectations with the contractors on the team? Have you discussed your mutual expectations with the employees on the team?

What does 'getting the job done' (use interviewee's own words, if possible) mean to each of the parties? 


\section{Organisational Policy}

Is the use of professional contractors in keeping with this organisation's HR strategy?

Does your human resource management strategy divide the workforce into permanent and nonpermanent employees?

Are contractors strategically engaged, hired, managed? How could this be done?

How do you think a mixed-workforce can be managed effectively?

What are the 'consequences' of non-standard work at client-organisations?

On your team, do you generally explain/communicate/justify the reasons for bringing in a contractor versus a permanent hire?

On your team, who has control over a contractor's work?

\section{The Working Relationship}

Do you find that the use of professional contractors affects the behaviour or attitude of the permanent employees on the team? Can you describe how?

Has the use of professional contractors negatively or positively affected manager-employee relations in this workplace?

How is managing a contractor different to managing an employee? What is different? Is it attitude? Is it (short) time-span creating urgency?

In your experience, are professional contractors treated just like permanent employees? Should professional contractors be treated like employees? Is this an issue? How so?

Are the employees on the team given opportunities for training and development that professional contractors are not entitled to? What is your response to this?

What are the stereotypes of professional contractors that you are aware of? Do you consider contracting 'precarious'? Do you consider contractors 'elite'? Non-standard workers are often considered lower status. Is this true for professional contractors?

Is it better to have higher or lower proportions of a team who are professional contractors?

Do contractors have influence? What about a professional contractor in particular gives them influence? Is it depth or breadth of experience, is it reputation or is it educational background?

What motivates a professional contractor at work?

What motivates a permanent employee at work?

Do professional contractors share their knowledge and expertise with those on the team and others in the organisation?

Are contractors included in social functions/activities here? 
Describe what makes a good professional contractor?

Biographical Information - Manager

Age range:

$18-24$ $25-34$ $35-44$

$45-54$

$55-64$

65 and over

Time in this type of employment:

Time in current role/position:

Have you been a professional contractor/permanent employee before?

If applicable, are you an independent contractor or an agency contractor?

Do you have dependants?

Yes

No

Are you the sole income earner in your household?

Yes

No 


\section{Appendix E: Human Ethics Committee Approval}

\section{Welcome to ResearchMaster Enterprise}

0000022108 : A working relationship between professional contractors and the permanent employees they work with ... $\mathrm{P}$ Application Status: Approved Workflow State: Approved (Pipitea) Other Forms: Human Ethics Form v35

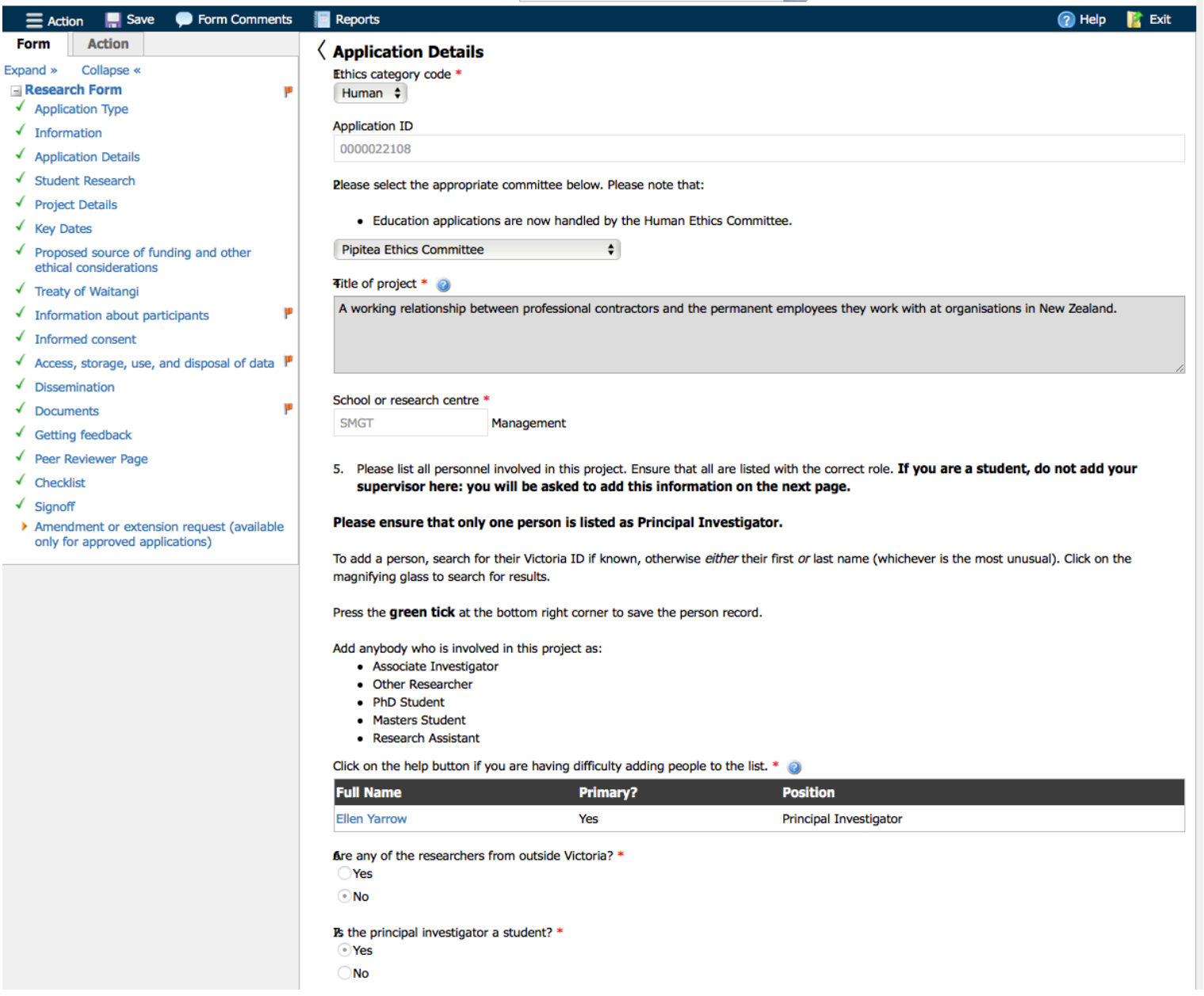

